Universidad Nacional de La Plata

Facultad de Ciencias Exactas

Departamento de Ciencias Biológicas

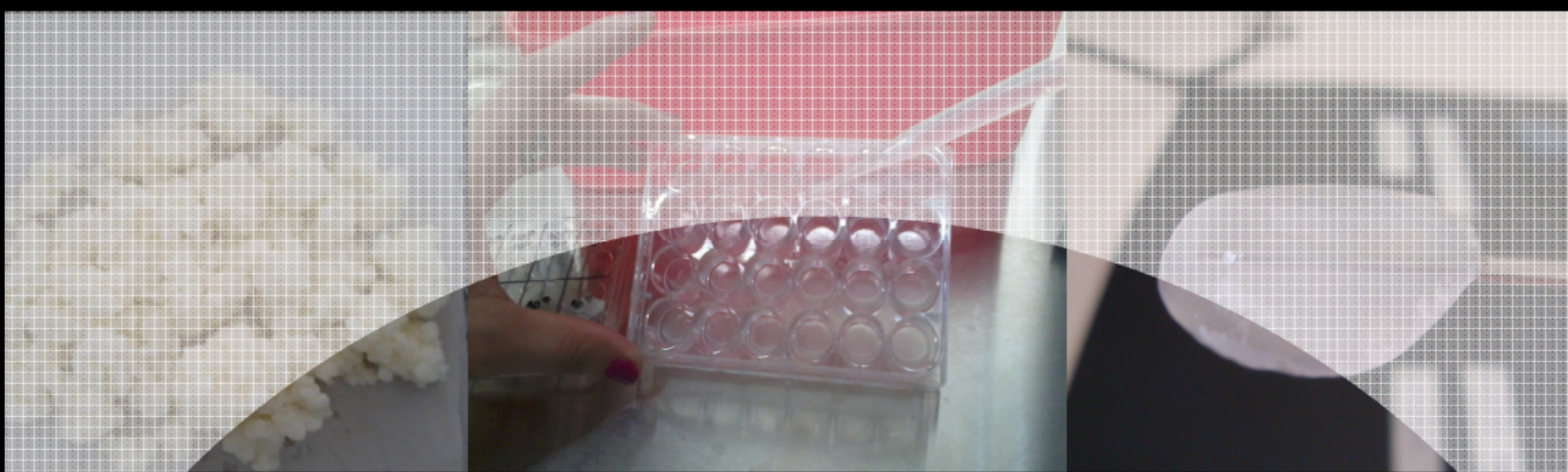

TESIS DOCTORAL

\title{
NUEVAS APLICACIONES DE POLISACÁRIDOS DE BACTERIAS LÁCTICAS: GELES DE KEFIRAN Y SU APLICACIÓN COMO VEHÍCULO DE MICROORGANISMOS PROBIÓTICOS.
}

\author{
Lic. Lucia Zavala \\ Dirección: Dra. Analia Graciela Abraham
}

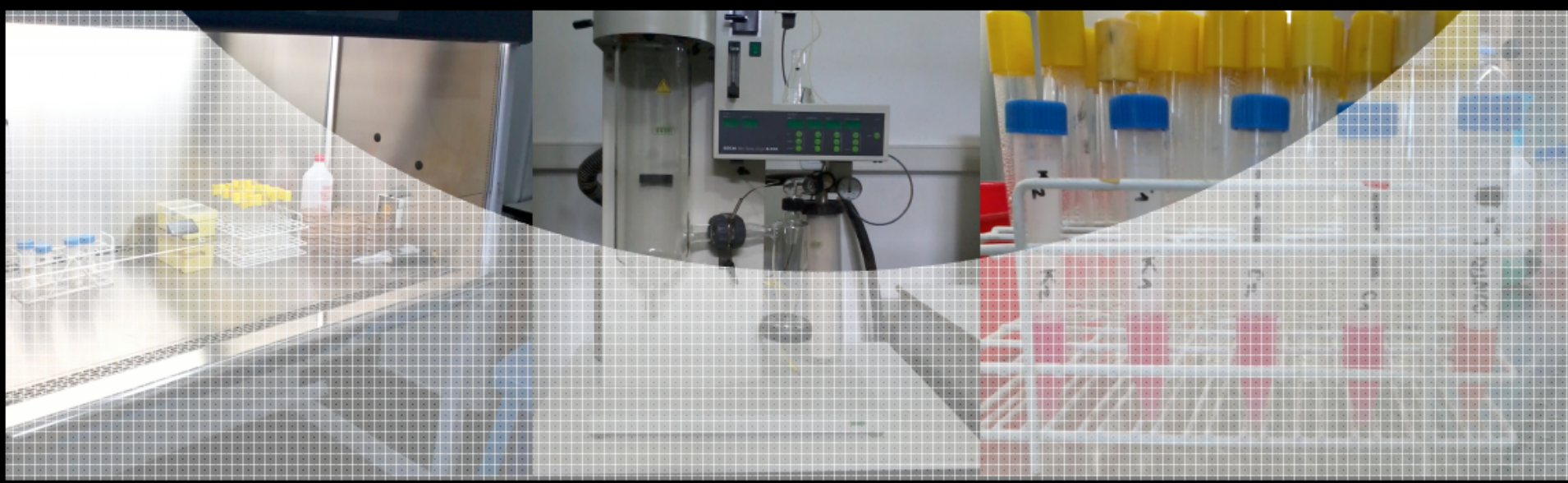




\title{
Universidad Nacional de La Plata
}

Facultad de Ciencias Exactas

Departamento de Ciencias Biológicas

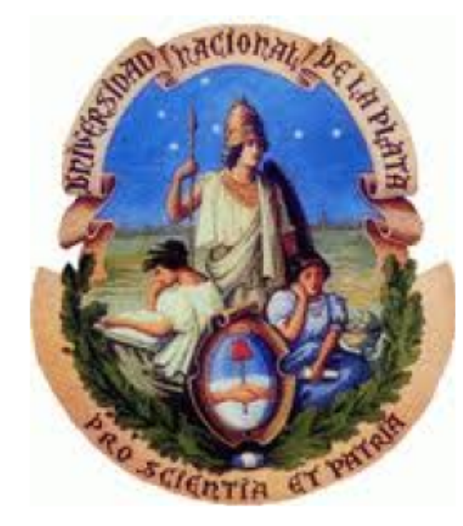

TRABAJO DE TESIS DOCTORAL

Nuevas aplicaciones de polisacáridos de bacterias lácticas: Geles de kefiran y su aplicación como vehículo de microorganismos probióticos.

\author{
Lic. Lucía Zavala \\ Dirección: Dra. Analía Graciela Abraham \\ 2015
}

Centro de Investigación y Desarrollo en Criotecnología de Alimentos

(CIDCA)

Facultad de Ciencias Exactas

Universidad Nacional de La Plata 
El presente trabajo de Tesis, para optar por el título de Doctor de la Facultad de Ciencias Exactas, fue realizado en el Centro de Investigación y Desarrollo en Criotecnología de Alimentos (CIDCA), UNLP-CONICET.
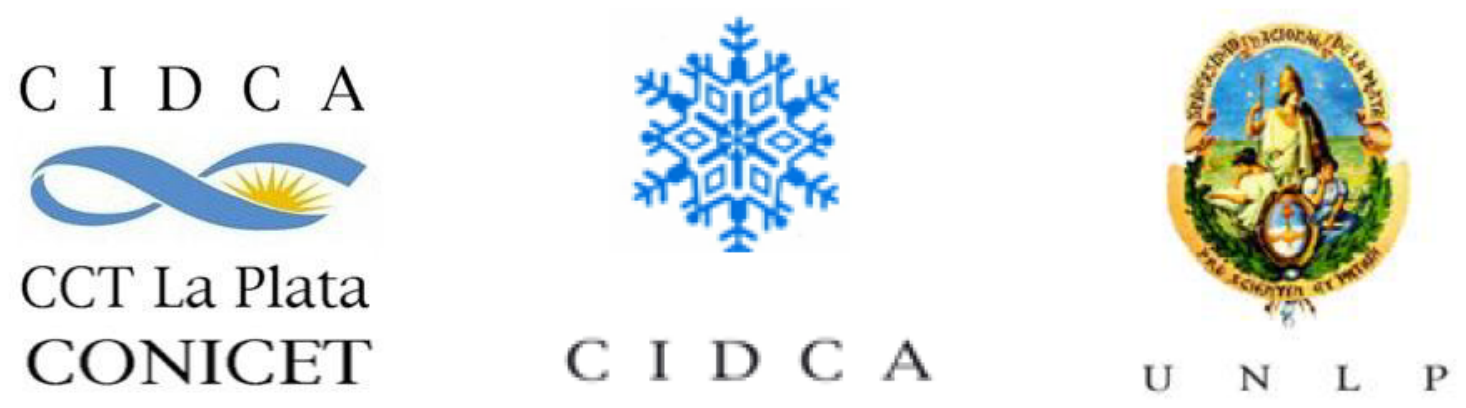

Lucía Zavala - 2015 


\section{AGRADECIMIENTOS,}

A la Facultad de Ciencias Exactas de la Universidad Nacional de La Plata, por la formación profesional otorgada y en especial al Departamento de Ciencias Biológicas por su apoyo para la realización de este trabajo de tesis.

Al Consejo Nacional de Investigaciones Científicas y Técnicas (CONICET), por haberme otorgado las correspondientes becas para el desarrollo de este trabajo de tesis.

A la Dra. Noemí Zaritzky, por abrirme las puertas del Centro de Investigación y Desarrollo en Criotecnología de Alimentos (CIDCA) y permitirme trabajar allí.

A la Dra. Analía Abraham, mi directora, por la confianza depositada, por todos los conocimientos brindados, y por la dedicación y el compromiso durante estos años de trabajo, por la enorme paciencia, cariño y apoyo en todo momento.

A mis compañeros del CIDCA y de la Cátedra, Fernando, Mica, Aye, Ale, Fer, Marina, Judith, Gaby, Caro, Mica, Agus, Pablo, Analía, Grace, Patricio, Angela, Raúl, Robert, Paula, Esteban, Eli, Mauri, Ceci, Ivanna, Jessi, María y Pato por su especial ayuda en la realización de la práctica, por transmitirme sus conocimientos y estar dispuestos cuando los he necesitado. Gracias a todos y cada uno de ustedes por los buenos momentos compartidos.

A Marina, por haber compartido conmigo gran parte de ese trabajo, por su ayuda incondicional y conocimientos brindados.

A Caro y Ale, gracias por su compañerismo y lograr que sean más amenas las largas jornadas de laboratorio.

A Judith, por haberme acompañado en gran parte de este trabajo. Gracias por estar en cada momento que lo necesité durante estos años. 
A Coni, gracias por esa alegría constante. Porque compartimos poco, y mucho al mismo tiempo.

A Paula, por haber recorrido este último tramo juntas, por su paciencia y por haberme enseñado tanto.

A Yani, porque cursamos juntas, y luego terminamos trabajando juntas, gracias por estar dispuesta en cada situación y querer compartir conmigo cada momento.

A Rochi, Ari, Sil, Lour, gracias por estar y permitirme desconectarme cuando era necesario, por escucharme y aconsejarme. Porque estuvieron siempre, de una u otra forma, en cada momento y en cada etapa transcurrida, Gracias!!!

A mi familia, a mi tía y a mi abuela, por su apoyo incondicional, paciencia, cariño y aliento frente a las dificultades. Por comprender mis extraños horarios de laboratorio, por haberme acompañado en esta etapa que termina...

¡ii Muchas Gracias...!!! 
Los resultados del presente trabajo de tesis han sido publicados parcialmente en las siguientes instancias:

Revistas periódicas:

GELLING ABILITY OF KEFIRAN IN THE PRESENCE OF SUCROSE AND FRUCTOSE AND PHYSICOCHEMICAL CHARACTERIZATION OF THE RESULTING CRYOGELS. 2014. Zavala, L.; Roberti, P.; Piermaría, J. A.; Abraham, A. G. Journal of Food Science and Technology. 9 p. Article in Press. DOI 10.1007/s13197-014-1577-2.

INCREASED ADHESION OF LACTOBACILLUS PARACASEI POST-INCUBATION IN SIMULATED GASTROINTESTINAL CONDITIONS. Zavala, L.; Carasi, P.; Serradel, M.; Abraham, A. En redacción.

LACTOBACILLUS PARACASEI ISOLATED FROM KEFIR GRAIN AND SUGARY KEFIR GRAIN: INTERACTION WITH INTESTINAL EPITHELIAL CELLS AND EFFECT ON SALMONELLA INFECTION. Zavala L.; Golowczyc, M.A.; Van Hoorde, K.; Medrano M.; Vercammen, E.; Huys, G.; Vandamme, P., Abraham A. G. En redacción.

Presentación oral:

XI Congreso Latinoamericano de Microbiología e Higiene de Alimentos. IV Congreso Argentino de Microbiología de Alimentos. III Simposio Argentino de Conservación de Alimentos. MICROAL 2012. LACTOBACILOS PRODUCTORES DE POLISACÁRIDOS Y CAPA-S DE AISLADOS DE KEFIR: INTERACCIÓN CON SALMONELLA. Zavala, L.; Golowczyc, M. A.; Abraham, A. G. Buenos Aires, 26 al 29 de noviembre de 2012.

IV Simposio Internacional de Bacterias Lácticas (SIBAL). Alimentos, Salud y Aplicaciones. SIBAL 2013. LACTOBACILLUS PARACASEI ISOLATED FROM KEFIR: PROBIOTIC AND TECHNOLOgYCAL PROPERTIES. L. Zavala, P. Carasi, M. Golowczyc, M. de los A. Serradell, A G. Abraham. San Miguel de Tucumán, 16 al 18 de octubre de 2013. 
JORNADAS DE INVESTIGACIÓN Y TRANSFERENCIA CIDCA 2014. Lactobacillus paracasei aislados del kefir: propiedades probióticas y tecnológicas. L. Zavala, P. Carasi, M. Golowczyc, M.A. Serradell, A.G. Abraham. La Plata, 9 al 12 de diciembre de 2014.

Trabajo completo:

XIII Congreso CYTAL - AATA Congreso Argentino de Ciencia y Tecnología de Alimentos. CARACTERIZACIÓN FISICOQUÍMICA DE GELES DE KEFIRÁN CON AZÚCARES. Zavala, L.; Roberti, P.; Piermaria, J. A. y Abraham, A. G. Buenos Aires - 19 Al 21 De Octubre de 2011.

Posters:

XIII Congreso CYTAL - AATA Congreso Argentino de Ciencia y Tecnología de Alimentos. INHIBICIÓN DE Salmonella sp. Y Escherichia COLI POR SUERO FERMENTADO CON CEPAS AISLADAS DE KEFIR. Londero, A.; Iraporda, C.; Zavala, L.; Garrote, G. L; Abraham, A. G. Buenos Aires - 19 Al 21 De Octubre de 2011.

XIII Congreso CYTAL - AATA Congreso Argentino de Ciencia y Tecnología de Alimentos. TERMOTOLERANCIA DE Lactobacillus EN PRESENCIA DE KEFIRÁN. Zavala, L.; Golowczyc, M. A.; Abraham, A. G. Buenos Aires - 19 Al 21 De Octubre de 2011.

XIII Congreso CYTAL - AATA Congreso Argentino de Ciencia y Tecnología de Alimentos. CARACTERIZACIÓN FISICOQUÍMICA DE GELES DE KEFIRÁN CON AZÚCARES. Zavala, L.; Roberti, P.; Piermaría, J. A. y Abraham, A. G. Buenos Aires - 19 Al 21 De Octubre de 2011.

XI Congreso Latinoamericano de Microbiología e Higiene de Alimentos. IV Congreso Argentino de Microbiología de Alimentos. III Simposio Argentino de Conservación de Alimentos. LACTOBACILOS PRODUCTORES DE POLISACÁRIDOS Y CAPA-S DE AISLADOS DE KEFIR: INTERACCIÓN CON Salmonella. Zavala, L.; Golowczyc, M. A.; Abraham, A. G. Buenos Aires, 26 al 29 de noviembre de 2012. 
Simposio Argentino de Lactología. CARACTERIZACIÓN FISICOQUÍMICA DE GELES DE KEFIRAN, UN POLISACÁRIDO PRODUCIDO POR BACTERIAS LÁCTICAS. Zavala, L.; Piermaría, J. A. y Abraham, A. G. Santa Fé, agosto 2012.

IV Simposio Internacional de Bacterias Lácticas (SIBAL). Alimentos, Salud y Aplicaciones. SIBAL 2013. Lactobacillus paracasei ISOLATED FROM KEFIR: PROBIOTIC AND TECHNOLOgYCAL PROPERTIES. L. Zavala, P. Carasi, M. Golowczyc, M. de los A. Serradell, A G. Abraham. San Miguel de Tucumán, 16 al 18 de octubre de 2013.

XIV Congreso CYTAL - AATA Congreso Argentino de Ciencia y Tecnología de Alimentos. SELECCIÓN DE MICROORGANISMOS POTENCIALMENTE PROBIÓTICOS Y EL ESTUDIO DE SU RESISTENCIA AL SECADO SPRAY Y ALMACENAMIENTO. Zavala, L.; Golowczyc, M. A.; Abraham, A. G. Buenos Aires, 23 al 25 de octubre de 2013.

IX Congreso Argentino de Microbiología General. Sociedad Argentina de Microbiología. LACTOBACILLI ISOLATED FROM KEFIR INCREASE THEIR ADHESION CAPACITY TO INTESTINAL MUCOSA IN VITRO AFTER SIMULATED DIGESTION. Zavala, L.; Carasi, P.; Serradel, M.; Abraham, A.G. Rosario, 5 al 7 de agosto de 2013.

I Jornadas de Investigación y Transferencia CIDCA 2014. Lactobacillus paracasei: PROPIEDADES PROBIÓTICAS Y PROPIEDADES TECNOLÓGICAS. L. Zavala, P. Carasi, M. Golowczyc, M. de los A. Serradell, A G. Abraham. La Plata, Argentina, 8 al 10 de diciembre de 2014. 


\begin{tabular}{|lr|}
\hline INTRODUCCIÓN GENERAL & \\
\hline Alimentos funcionales & 1 \\
\hline Regulación de los alimentos funcionales. & 2 \\
Probióticos, prebióticos y simbióticos como componentes de alimentos & 5 \\
funcionales & \\
\hline Probióticos. & 5 \\
\hline Prebióticos. & 7 \\
\hline Simbiótico. & 10 \\
\hline Interés industrial & 11 \\
\hline El kefir como alimento funcional natural & 13 \\
\hline Gránulo de kefir. & 15 \\
\hline Kefirán, exopolisacárido producido por lactobacilos del kefir & 17 \\
\hline Funcionalidad biológica del kefiran. & 19 \\
\hline Propiedades tecnológicas del kefiran. & 23 \\
\hline Matrices alimentarias utilizadas para la incorporación de microorganismos & 21 \\
\hline probióticos & 20 \\
\hline & \\
\hline
\end{tabular}

\begin{tabular}{|lr|}
\hline CAPÍTULO 1. Selección de microorganismos probióticos. \\
\hline INTRODUCCIÓN & 25 \\
\hline Microorganismos del kefir & 25 \\
Propiedades benéficas atribuidas al consumo de kefir y sus microorganismos & 27 \\
Adhesión bacteriana & 31 \\
\hline \multicolumn{1}{|c|}{ Modelos para el estudio de adhesión bacteriana. } & 32 \\
\hline
\end{tabular}


Microorganismos patógenos: Salmonella entérica serovar Enteritidis

Salmonella como agente causal de enfermedades. 35

Probióticos frente a la acción de Salmonella Enteritidis. 37

$\begin{array}{ll}\text { OBJETIVOS PARCIALES } & 41\end{array}$

MATERIALES Y MÉTODOS

$\begin{array}{ll}\text { Microorganismos y condiciones de cultivo } & 43\end{array}$

Resistencia a la bilis por método ecométrico 43

$\begin{array}{ll}\text { Hidrofobicidad superficial } & 45\end{array}$

Autoagregación $\quad 45$

Resistencia al pasaje gastrointestinal in vitro $\quad 46$

Adhesión bacteriana a epitelio intestinal in vitro 46

Adhesión a células Caco-2/TC-7. $\quad 47$

Adhesión a mucina in vitro. $\quad 47$

Digestión proteolítica de las proteínas de y obtención del mapa peptídico 48 mediante Espectrometría de Masa (MS) MALDI-TOF

Electroforesis Bidimensional (2D). $\quad 48$

Digestión de las proteínas. $\quad 49$

Espectrometría de Masa (MALDI-TOF). 50

Parámetros de búsqueda en bases de datos. $\quad 50$

Interacción con Salmonella entérica serovar Enteritidis 51

Condiciones de cultivo de Salmonella entérica serovar Enteritidis. 51

Ensayo de asociación e invasión de Salmonella a células Caco-2/TC-7. 51

Obtención de sobrenadantes libres de células y las suspensiones de 52 lactobacilos.

Determinación de la concentración de ácidos orgánicos. 52

Determinación de la concentración de ácido láctico no disociado. 53

Coagregación de Lactobacilos con Salmonella entérica serovar Enteritidis. $\quad 54$

Asociación e invasión de Salmonella Enteritidis a células Caco-2/TC-7 previa $\quad 54$ incubación de Salmonella con lactobacilos. 
Asociación e invasión de Salmonella Enteritidis a células Caco-2/TC-7 previa incubación de la monocapa con lactobacilos.

Marcación fluorescente del citoesqueleto con faloidina.

Cinética de muerte de Salmonella Enteritidis en sobrenadantes de cultivo de lactobacilos aislados de kefir.

Efecto de los sobrenadantes de lactobacilos aislados de kefir sobre la asociación e invasión de Salmonella Enteritidis a células Caco-2/TC-7.

Análisis estadístico

RESULTADOS Y DISCUSIÓN

Resistencia a la bilis

Adhesión bacteriana in vitro a células intestinales Caco-2/TC-7

Adhesión a mucina

Adhesión a epitelio y pasaje por el tracto gastrointestinal in vitro

Viabilidad bacteriana luego del pasaje.

Adhesión a línea celular Caco-2/TC-7 y mucina después del pasaje por el tracto gastrointestinal simulado.

Expresión de proteínas después del pasaje por el tracto gastrointestinal (TGI)

Efecto antagónico contra Salmonella enterica serovar Enteritidis

Asociación e invasión de Salmonella a células Caco-2/TC-7.

Interacción de los lactobacilos con Salmonella Enteritidis y efecto en la invasión a células Caco-2/TC-7.

Coagregación de lactobacilos con Salmonella entérica serovar Enteritidis.

Preincubación de Salmonella Enteritidis con lactobacilos aislados de kefir.

Efecto en la invasión a células Caco-2/TC-7.

Efecto barrera de los lactobacilos sobre la asociación e invasión de Salmonella

Enteritidis. Preincubación de la monocapa de enterocitos con lactobacilos.

Efecto de los lactobacilos en la desorganización del citoesqueleto causado por Salmonella Enteritidis.

Efecto de los sobrenadantes libres de células de lactobacilos aislados de kefir sobre Salmonella Enteritidis. 
Acción bactericida de los sobrenadantes libres de células de lactobacilos aislados de kefir sobre Salmonella. Curvas de muerte.

Efecto de los sobrenadantes libres de células de lactobacilos aislados de kefir sobre la asociación e invasión de Salmonella a células Caco-2/TC-7.

\section{CAPÍTULO 2. Geles de kefiran como vehículo de microorganismos probióticos}

INTRODUCCIÓN

Geles en los alimentos

Geles alimentarios de naturaleza glucídica.

Geles de proteínas.

Geles mixtos.

Inclusión de microorganismos probióticos en los geles

OBJETIVOS PARCIALES

MATERIALES Y MÉTODOS

Obtención de kefiran

Preparación de geles de kefiran con azúcares y/o proteínas

Geles mixtos de kefiran y azúcares.

Geles de proteínas.

Geles mixtos de kefiran y proteínas.

Caracterización de las soluciones

Caracterización de los geles

Actividad Acuosa.

Capacidad de retención de agua (WHC).

Reometría oscilatoria de baja amplitud de deformación.

Calorimetría Diferencial de Barrido (DSC).

Análisis de perfil de textura.
105

105

106

108

109

110

113

115

115

115

115

116

116

117

117

117

118

118

119

119 
Microscopía electrónica (SEM).

Inclusión de microorganismos en geles mixtos

Obtención de Lactobacillus paracasei 8339 y Lactobacillus kefiri 83102.

Obtención de geles de kefiran, proteínas y azúcares con microorganismos.

Resistencia al pasaje gastrointestinal in vitro de los microorganismos incluidos en el gel.

Capacidad de adhesión de los microorganismos incluidos en el gel.

\section{RESULTADOS Y DISCUSIÓN \\ Geles de kefiran con azúcares \\ Comportamiento reológico de soluciones de kefiran con sacarosa y fructosa. \\ Obtención de los geles y caracterización fisicoquímica.}

\section{Formación de geles de kefiran y proteínas de suero de leche}

Geles de aislado de proteína de suero: Selección de las concentraciones de WPI capaces de formar geles.

Efecto del tratamiento a $-20{ }^{\circ} \mathrm{C}$ en la formación de geles de proteína de suero de leche.

Geles mixtos de proteína de suero de leche y kefiran.

Inclusión de microorganismos en geles

Resistencia de Lactobacillus paracasei 8339 y Lactobacillus kefiri 83102 al proceso de formación del gel.

Resistencia al pasaje por el tracto gastrointestinal in viitro de Lactobacillus paracasei 8339 y Lactobacillus kefiri 83102 incluidos en los geles mixtos.

Adhesión a células Caco-2/TC-7 de Lactobacillus paracasei 8339 y Lactobacillus kefiri 83102 incluidos en la matriz alimentaria (gel).

\section{CONCLUSIÓN GENERAL}


CAPÍTULO 2. Geles de kefiran como vehículo de microorganismos probióticos

MEDIOS DE CULTIVO

COLORACIONES

175

MEDIOS DE CULTIVO PARA CÉLULAS EUCARIOTAS

175

CULTIVO DE CÉLULAS INTESTINALES Y PREPARACIÓN DE PLACAS

176

BIBLIOGRAFÍA 
INTRODUCCIÓN GENERAL 


\section{INTRODUCCIÓN GENERAL}

\section{Alimentos funcionales}

La visión de la ciencia de la nutrición como aquella que prevenía la aparición de deficiencias nutricionales ha evolucionado hacia un concepto más amplio que incluye la óptima función de órganos y sistemas, la promoción de la calidad de vida y la disminución del riesgo de padecer enfermedades.

Los consumidores están cada vez más conscientes y buscan en el mercado aquellos productos que contribuyan a su salud y bienestar. Estos alimentos, que promueven la salud, han sido denominados genéricamente alimentos funcionales (Sloan 1999).

Los alimentos funcionales son alimentos con la característica particular de que algunos de sus componentes afectan funciones del organismo de manera específica y positiva, promoviendo un efecto fisiológico o psicológico más allá de su valor nutritivo tradicional. Su efecto adicional puede ser su contribución a la mantención de la salud y bienestar o a la disminución del riesgo de contraer enfermedades (Diplock et al. 1996).

El concepto de desarrollar alimentos no sólo para disminuir las deficiencias nutricionales, sino más bien para proteger la salud de la población surgió a principios de los años 80 en Japón (Arai 1996). Allí, se comenzó a dar importancia a esta función de los alimentos que está implicada en la modulación de los sistemas fisiológicos de los organismos vivos, como el sistema inmune, endocrino, nervioso, circulatorio y digestivo, y a partir de entonces, se introdujo en Occidente el término "alimentos funcionales", haciendo referencia a los productos alimenticios fortificados con constituyentes especiales que poseen efectos fisiológicamente ventajosos. En 1991, el Ministerio de Salud de Japón introdujo las reglas para la aprobación de una categoría específica de alimentos relacionados a la salud Ilamada FOSHU (Food for Specified Health Uses, o Alimento para Uso Específico de la Salud), y luego de su aprobación, un alimento podía portar el símbolo "FOSHU" en su etiqueta. De esta manera, el primer alimento FOSHU 
INTRODUCCIÓN GENERAL

correspondió a una especie de arroz de consumo masivo en el que se eliminó por hidrólisis enzimática una proteína causante de alergia cutánea, obteniéndose un nuevo producto inmunológicamente seguro y saludable. El concepto migró a los Estados Unidos y Europa, en donde se identificó su potencial comercial para la industria alimentaria (Cóccaro 2010).

Según la Administración Nacional de Medicamentos, Alimentos y Tecnología Médica (ANMAT), para que un alimento pueda ser considerado funcional, debe demostrar que posee un efecto benéfico sobre una o varias funciones específicas del organismo, más allá de los efectos nutricionales habituales, que mejora el estado de salud y bienestar, o bien que reduce el riesgo de una enfermedad. Esto significa que estos alimentos deben contener, necesariamente, alguno de los llamados componentes o ingredientes funcionales.

Entre los productos que podrían considerarse como funcionales, por contener éstos u otros componentes, pueden mencionarse los lácteos enriquecidos con vitaminas, minerales, fitoesteroles u omega $3, y$ las barras de cereales con vitaminas y/o fibras. También, los yogurths con probióticos, es decir, con microorganismos vivos que, al ser ingeridos en cantidades suficientes, ejercen un efecto positivo en la salud del consumidor, y los llamados alimentos ricos en fibras o prebióticos (sustancias no digeribles que pueden ser fermentadas por la flora bacteriana intestinal, y provocan un efecto favorable sobre ella).

Regulación de los alimentos funcionales.

Muchos académicos, científicos y organismos reguladores están trabajando para encontrar maneras de establecer una base científica que apoye las alegaciones beneficiosas que se asocian a los componentes funcionales o los alimentos que los contienen. Los consumidores tienen que comprender bien y confiar en los criterios científicos utilizados para documentar los efectos de los alimentos funcionales y las atribuciones beneficiosas específicas. Japón está por delante del resto del mundo en este aspecto ya que en 1991, se estableció el concepto de "Alimentos para Uso Específico en la Salud" (FOSHU). Los alimentos que se incluyan dentro de la categoría de FOSHU deben ser autorizados por el Ministerio de Salud, tras la presentación de pruebas 
exhaustivas con fundamento científico, que apoyen la alegación relativa a las propiedades de dichos alimentos, cuando son consumidos como parte de una dieta ordinaria. Cuando se solicita una licencia FOSHU al Ministerio se debe aportar la siguiente información: 1) ingredientes y composición del alimento, 2) efectos beneficiosos para la salud atribuidos al alimento, y 3 ) datos sobre su seguridad. Una vez aprobado el alimento, se puede indicar en la etiqueta del producto sus efectos beneficiosos para la salud, pero no de forma exagerada ni engañosa. Los fabricantes no pueden fomentar el consumo excesivo del alimento, ni incitar de forma alguna al consumidor a que no reciba tratamiento médico, ni difamar a los productos de la competencia. Japón es el único país que cuenta con una legislación específica para la comercialización y rotulado de este tipo de alimentos (Shimizu 2014).

En la Unión Europea (UE) no existe una legislación armonizada sobre las alegaciones de salud, y por lo tanto las cuestiones relativas a dichas alegaciones se resuelven a nivel nacional. El reto en los Estados Miembros de la UE es conseguir, bajo el marco regulador existente, que los mensajes que se comunican no hagan ninguna referencia a que dichos alimentos puedan reducir el riesgo de padecer enfermedades, incluso aunque existan pruebas científicas que avalen dichas afirmaciones. La legislación europea relativa al etiquetado prohíbe atribuir a los alimentos propiedades preventivas, terapéuticas o curativas, y la referencia a dichas propiedades (Roberfroid 2002; Palou et al. 2003, European Food Safety Authority).

En Estados Unidos se permite desde 1993 que se aleguen propiedades "que reducen el riesgo de padecer enfermedades" en ciertos alimentos. Las "alegaciones de salud" están autorizadas por la Administración de Alimentos y Medicamentos (Food and Drug Administration, FDA), siempre que existan "evidencias científicas públicamente disponibles y haya suficiente consenso científico entre los expertos de que dichas alegaciones están respaldadas por pruebas". Aunque los fabricantes pueden utilizar alegaciones de salud para comercializar sus productos, la intención de la FDA es que el fin de dichas alegaciones sea el beneficio de los consumidores, y que se facilite información sobre hábitos alimenticios saludables, que pueden ayudar a reducir el riesgo de contraer enfermedades, como las afecciones cardíacas y el cáncer. Según la FDA, las alegaciones pueden basarse también en "declaraciones autorizadas" de Organismos Científicos Federales, como los Institutos Nacionales de la Salud (National 
INTRODUCCIÓN GENERAL

Institutes of Health) y los Centros para la Prevención y el Control de Enfermedades (Centres for Disease Control and Prevention), así como de la Academia Nacional de Ciencias (National Academy of Sciences). Una gran ayuda para la comercialización de los alimentos y componentes funcionales en los Estados Unidos, ha sido la aprobación del Acta de Suplementos Dietéticos para la Salud y Educación (Dietary Supplement Health and Education ActDSHEA) de 1994. Esta legislación permite el uso de "declaraciones de estructura-función" para los suplementos dietarios sin previa autorización por la FDA. Dichas declaraciones colocadas en el envase de un alimento describen cómo un componente o un ingrediente alimentario afecta alguna estructura y/o función determinada en un organismo (por ejemplo, "el alto contenido de fibra favorece la regularidad intestinal", o "el calcio favorece la formación de huesos fuertes") sin relacionarlo con una enfermedad específica. Debido a que estas declaraciones pueden hacerse sin previa aprobación de la FDA, muchas empresas están escogiendo comercializar los alimentos funcionales como suplementos dietéticos, lo cual es un vacío legal permisible durante el tiempo que la empresa notifica a la FDA 30 días después de la primera comercialización del producto que lleva la declaración (Siró et al. 2008).

En América Latina, el conocimiento de los alimentos funcionales es relativamente reciente, en algunas ciudades las autoridades sanitarias reconocen legalmente las propiedades saludables de determinados alimentos. Brasil posee una regulación en la que se define como funcional un componente alimenticio nutritivo o no, que puede producir efectos benéficos para la salud, diferentes de la nutrición básica cuando forman parte de una dieta normal sin ser un medicamento. La Agencia Nacional de Vigilancia Sanitaria Brasilera exige demostrar la seguridad y eficacia de dichos componentes alimenticios para legalizar su publicidad, comercialización y consumo (Lajolo 2002).

En Argentina, el Instituto Nacional de Alimentos ha organizado un grupo de trabajo orientado a proponer normativa respecto a esta cuestión. De esta manera, la Comisión Nacional de Alimentos (CONAL) conformada por representantes de la SAGPyA, de la Universidad de Buenos Aires, del Centro de Industria Lechera y la Cámara de Fabricantes de Alimentos Dietéticos y Afines (CAFADyA), entre otros, ha establecido normas para su funcionamiento y ha trabajado en la definición para los probióticos y prebióticos, sobre la base de la normativa internacional. En cuanto al rotulado de estos alimentos, solo se permiten declaraciones nutricionales. Es decir, en el producto se debe 
indicar la presencia del compuesto bioactivo pero no se puede decir para qué sirve o cuáles son sus beneficios, dado que de esa forma se estaría induciendo su consumo en forma tendenciosa (Grupo de trabajo Alimentos Funcionales INAL - ANMAT 2003; Olagnero et al. 2007).

\section{Probióticos, prebióticos y simbióticos como componentes de alimentos funcionales}

Los alimentos funcionales más estudiados son los alimentos probióticos, en los últimos años ha aumentado el interés por los prebióticos. La asociación de un prebiótico y un probiótico se denomina simbiótico. A continuación nos centraremos detalladamente en cada uno de ellos.

\section{Probióticos.}

Los probióticos son microorganismos vivos que al ser administrados en cantidades adecuadas confieren beneficios a la salud del hospedador. Los principales géneros de microorganismos considerados probióticos son Lactobacillus y Bifidobacterium.

A medida que los consumidores entienden el papel de los probióticos en la salud, también crece la popularidad de los alimentos que los contienen. El resultado de este fenómeno es un incremento en el número de alimentos probióticos disponibles para el consumo público, que incluye una variedad de bebidas lácteas y no lácteas que contienen probióticos, que proporcionan una manera conveniente para mejorar y mantener la salud. De todas maneras, la composición de bebidas no lácteas probióticas puede plantear problemas específicos para la sobrevida de los microorganismos. Para superar estos retos, la selección de la cepa y las técnicas de protección juegan un papel fundamental en la formulación de un producto estable (Gawkowski \& Chikindas, 2013).

Actualmente se buscan diferentes alternativas de incluir probióticos en otros alimentos, tales como vegetales y productos cárnicos fermentados (Furtado Martins et al. 2013). 
INTRODUCCIÓN GENERAL

Es esencial que los probióticos permanezcan vivos durante su tránsito por el tracto gastrointestinal. Entre las propiedades asociadas al consumo de probióticos se pueden destacar la modulación de la respuesta inmune, mejora del equilibrio de la microflora colónica, incremento de la biodisponibilidad de ciertos nutrientes, mejora del tránsito y la motilidad intestinal, regulación del nivel de colesterol sérico entre otras propiedades. Además disminuyen la intolerancia a la lactosa (Marteau et al. 1997) y la incidencia y duración de las diarreas por rotavirus en lactantes (Saavedra et al. 1994). Estos efectos son cepa dependiente, por ejemplo, Lactobacillus casei GG es capaz de prevenir y acortar las diarreas por rotavirus del lactante, así como incrementar las concentraciones de IgA en tracto intestinal (Isoulari et al. 1991). Sin embargo, no todas las cepas de bacterias ejercen efectos probióticos, por ello es necesario estudiar las diferentes propiedades de cada microorganismo.

Según el Artículo $1^{\circ}$ de la Resolución Conj. 261/2011 SPRel y 22/2011 SAGyP el 27 de diciembre de 2011 se llevó a cabo la inclusión del término "Probióticos" en el Código Alimentario Argentino (CAA) (artículo 1389), donde se define el término probiótico como los microorganismos vivos que, administrados en cantidades adecuadas, confieren beneficios para la salud del consumidor. Los requisitos mínimos que deberá seguir/cumplir una cepa para considerarse probiótico son:

1. Identificación de la cepa (Género/especie/subespecie):

Los análisis para la identificación de la cepa deberán ser llevados a cabo por laboratorios reconocidos por la Autoridad Sanitaria Nacional o internacionalmente mediante metodología validada. El método recomendado para la identificación de las cepas de probióticos por técnicas moleculares es el de la secuenciación del rDNA 16S obtenido a partir del rRNA 16S, de acuerdo con Sambrook \& Russell (2001).

2. Caracterización "in vitro" e "in vivo":

- Resistencia gástrica: ensayo realizado como indicador de que la cepa podrá atravesar la barrera biológica estomacal, arribando viable al intestino. Deberá observarse supervivencia de la cepa en una solución gástrica simulada, a $37{ }^{\circ} \mathrm{C}$ y en condiciones estandarizadas (tiempo y $\mathrm{pH}$ ). 
- Resistencia a bilis: ensayo realizado como indicador de resistencia de la cepa a esta barrera biológica del organismo, presente a nivel de duodeno. Deberá presentar capacidad de desarrollo en un medio de cultivo adicionado de bilis bovina al 0,3\% (entendida como la concentración fisiológica), a $37{ }^{\circ} \mathrm{C}$ y en condiciones estandarizadas (medio de cultivo y tiempo).

- Resistencia a lisozima (opcional): ensayo realizado como indicador de que la cepa podrá sortear esta barrera biológica presente en la boca (saliva) e intestino delgado. Deberá presentar capacidad de desarrollo en un medio de cultivo adicionado de lisozima, a $37^{\circ} \mathrm{C}$ y en condiciones estandarizadas (concentración de lisozima, medio de cultivo y tiempo).

3. Ensayos "in vivo" e "in vitro" que demuestren el(los) efecto(s) probiótico(s) adjudicado(s) debidamente documentados y respaldados en estudios efectuados por organismos nacionales y/o internacionalmente reconocidos.

\section{Seguridad.}

La cepa probiótica no debe ser riesgosa para la salud. La bacteria no deberá presentar o promover la translocación bacteriana (pasaje de bacterias del intestino más allá de los nódulos mesentéricos) en las concentraciones en que se encuentra en el alimento. Puede ser medida sembrando en placas con agar muestras de sangre y de homogenizados de tejidos de nódulos linfáticos mesentéricos, bazo e hígado de animales de experimentación."

\section{Prebióticos.}

Los prebióticos son compuestos de naturaleza glucídica no digeribles por el hombre que benefician al que los consume estimulando de forma selectiva el crecimiento y/o actividad de una o un número limitado de bacterias intestinales (Gibson et al. 1995). Actualmente los compuestos más utilizados como prebióticos son los fructanos tipo inulina (oligosacáridos no digeribles: inulina, hidrolizados enzimáticos de la inulina, oligofructosacáridos $\left(\mathrm{C}_{2}-\mathrm{C}_{10}\right)$, fructosacáridos sintéticos de cadena larga). La 
INTRODUCCIÓN GENERAL

mayoría de la producción industrial procede de la achicoria. De forma natural están presentes en el trigo, la cebolla, los plátanos, el ajo y los puerros.

Las principales acciones de los prebióticos ocurren a nivel gastrointestinal. Llegan al colon sin ser digeridos por las enzimas presentes en el intestino delgado del hombre y allí son fermentados por las bacterias colónicas, lo que condiciona la selección de la microbiota (Roberfroid 2000; Gibson et al. 1995). En estudios in vitro se ha comprobado que la presencia de inulina y otros fructooligosacacáridos en colon produce, como resultado final de la fermentación bacteriana, cantidades importantes de AGCC (ácidos grasos de cadena corta), hidrógeno, metano, dióxido de carbono, lactato e incremento de la biomasa bacteriana. El aumento de la concentración de lactato y acetato disminuye el pH intraluminal, inhibiendo el crecimiento de Escherichia coli, Clostridium y otras bacterias patógenas pertenecientes a los géneros Listeria, Shigella, o Salmonella; pero a su vez incrementa el recuento de Lactobacillus y Bifidobacterium. La presencia de grandes cantidades de AGCC (acético, propiónico y butírico) incrementa la absorción del calcio y magnesio a través del aumento de la solubilización de sales de calcio y por medio de la activación del mecanismo de transporte para la absorción de este mineral (Abrams et al. 2005; Suzuki \& Hara 2004). También, se señalan acciones favorables de los prebióticos con respecto al estreñimiento (Van Loo et al. 1999), las diarreas por infección, la osteoporosis (al incrementar la biodisponibilidad del calcio) (Reddy 1999), aterosclerosis y enfermedad cardiovascular (al corregir la dislipemia) (Davidson et al. 1998) y la resistencia insulínica (Takase et al. 1994), obesidad, diabetes mellitus tipo 2 (Takase et al. 1994; Jacson et al. 1999; Delzenne et al. 2011), e incluso contra el cáncer (Reddy 1999).

Bajo el enfoque tradicional, la fibra dificulta la absorción de minerales al ser secuestrados por ésta. Sin embargo, la evidencia científica actual indica que los minerales unidos a la fibra llegan al colon y allí son liberados, lo que permite entonces su absorción. Más aún, los hidratos de carbono de cadena corta aumentan la absorción colónica de zinc, calcio y magnesio al provocar la atracción de agua por ósmosis, en la que se disuelven dichos minerales (Coudray et al. 1997).

En noviembre de 2011 se incluyó el término "Prebióticos" en el Código Alimentario Argentino (artículo 1390), Resolución Conj. 229 SPRel 731 SAGyP, en el cual se lo define como ingrediente alimentario o parte de él (no digerible) que posee un 
efecto benéfico para el organismo receptor, estimulando el crecimiento selectivo y/o actividad de una o de un número limitado de bacterias en el colon y que confiere beneficios para su salud. Además se enumeran los requisitos mínimos para que un alimento sea considerado como tal, entre ellos:

1. Identificación del compuesto.

- Nombres químicos

- Caracterización fisicoquímica

- Descripción

- Fuente / Origen

- Pureza

- Contaminantes

\section{Caracterización del prebiótico}

- Resistencia a la acidez gástrica: ensayo realizado como indicador de que el prebiótico no es modificado por la acidez estomacal.

- Resistencia a la hidrólisis por enzimas de mamíferos: ensayo realizado como indicador de que el prebiótico no es afectado por enzimas presentes en la saliva, así como por enzimas pancreáticas e intestinales.

- Resistencia a la absorción gastrointestinal: ensayo realizado como indicador de que el prebiótico no se absorbe a nivel del epitelio intestinal.

- Fermentación por la microflora intestinal.

- Estimulación selectiva del crecimiento y/o actividad de bacterias intestinales benéficas que contribuyen a la salud y bienestar: ensayo realizado como indicador de que el prebiótico es utilizado como nutriente selectivamente por la microflora intestinal considerada benéfica.

3. Ensayos "in vivo" e "in vitro" que demuestren el(los) efecto(s) fisiológico(s) adjudicado(s) al prebiótico debidamente documentados y respaldados en estudios efectuados por organismos nacionales $\mathrm{y} / \mathrm{o}$ internacionalmente reconocidos. 


\section{Seguridad.}

El compuesto prebiótico no debe ser riesgoso para la salud. Deberá demostrarse mediante ensayos de toxicidad aguda, subaguda y crónica debidamente documentados y respaldados en estudios efectuados por organismos nacionales y/o internacionalmente reconocidos.

\section{Simbiótico.}

El término simbiótico se refiere a un producto alimenticio que contiene, en forma combinada, probióticos y prebióticos, los cuales pueden actuar en forma sinérgica para modular la microbiota (flora) intestinal del consumidor e impactar positivamente sobre su salud. Un factor importante en el momento de desarrollar un simbiótico es determinar la compatibilidad entre la cepa probiótica y el tipo de prebiótico utilizado. Hay que tener en cuenta que el prebiótico pueda favorecer selectivamente el crecimiento del probiótico en el tubo digestivo a condición que dicho probiótico pueda utilizarlo como substrato, es decir, que tenga las enzimas necesarias para metabolizarlo.

Para la elaboración de un simbiótico, también es importante tener en cuenta que el componente prebiótico pueda ser incorporado con facilidad a un gran número de matrices alimenticias mientras que el componente probiótico, por ser un microorganismo que debe mantenerse viable, es un factor limitante en dichas matrices. En la actualidad, los principales alimentos con simbióticos son productos lácteos, debido al hecho que la leche es la matriz alimenticia más adecuada y fácil de usar para los probióticos que, en su mayoría, son bacterias lácticas. Existen pocos trabajos de estudios de asociación simbiótica en alimentos, entre ellos Alves et al. (2013) estudiaron un queso crema adicionado con inulina como matriz alimentaria de distintos probióticos y su conservación por 45 días en heladera, mientras que Araújo et al. (2010) desarrollaron un alimento simbiótico a base de queso de campo con inulina y Lactobacillus delbrueckii. 


\section{Interés industrial}

La demanda del mercado nacional e internacional ha impulsado en los últimos años una nueva línea de alimentos funcionales probióticos. Conocer y difundir los mecanismos por los cuales las bacterias probióticas ejercen su efecto benéfico permite un uso adecuado por parte de los profesionales de la salud y una mayor confianza en el consumo de alimentos funcionales por parte de la comunidad.

Cabe mencionar que uno de los requisitos principales de este tipo de alimentos es que los microorganismos probióticos permanezcan viables y activos en el alimento y durante el pasaje gastrointestinal, para garantizar así su potencial efecto benéfico en el huésped (Saarela et al. 2000).

En la actualidad, existen alimentos con probióticos y simbióticos que se comercializan en nuestro país. Algunos de ellos, se muestran en la Figura 1.

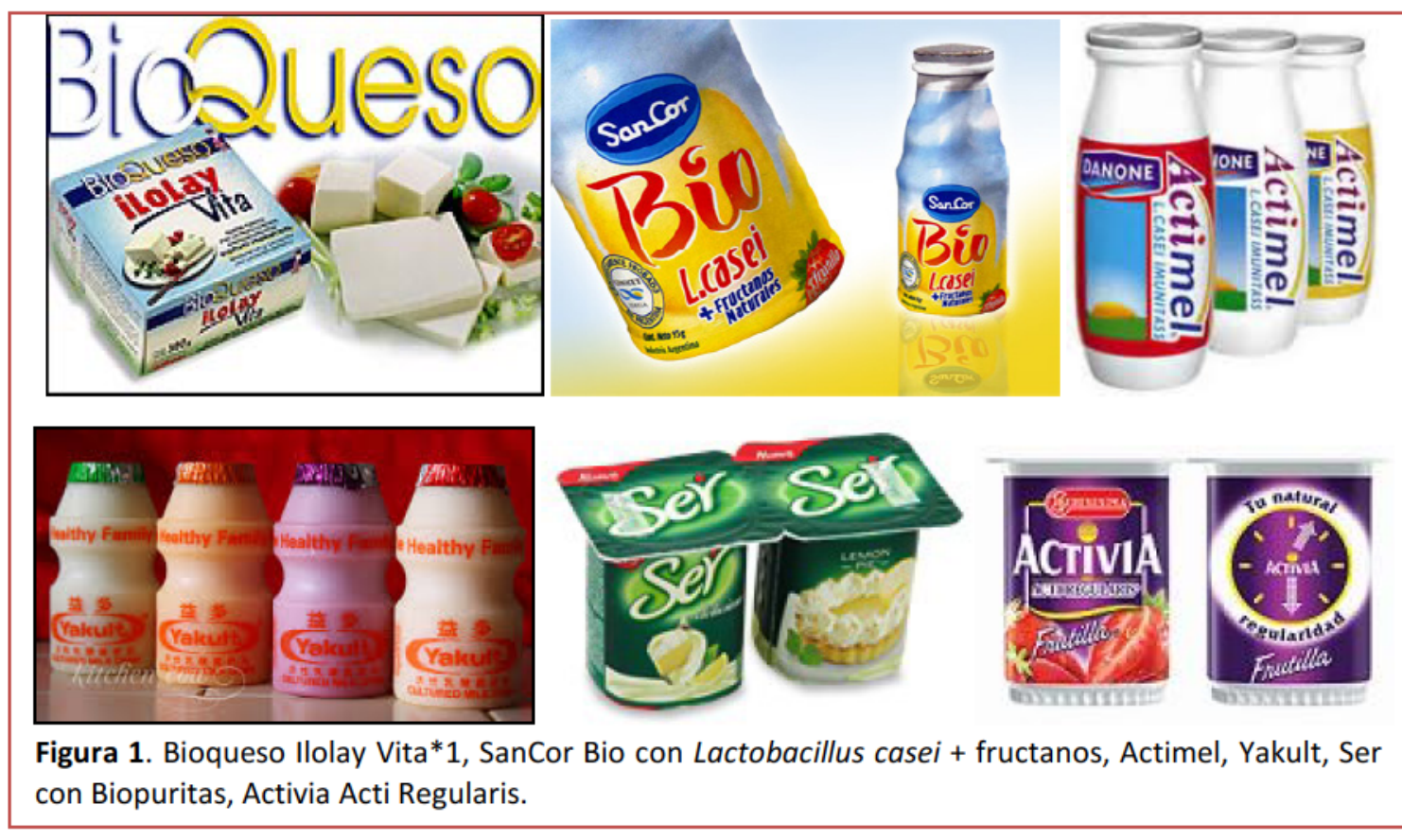

En la siguiente tabla, se presentan las características y funciones de los mismos (Olagnero et al. 2007). 
Tabla 1. Alimentos Funcionales Probióticos y Simbióticos: características y funciones.

\begin{tabular}{|c|c|c|}
\hline $\begin{array}{c}\text { Producto } \\
\text { Alimenticio }\end{array}$ & Probiótico/Simbiótico & Investigación científica \\
\hline ACTIMEL & $\begin{array}{l}\text { Lactobacillus casei defensis } \\
\qquad \text { DN114001 } \\
\text { Concentración: } 10^{8} \mathrm{UFC} / \mathrm{ml}\end{array}$ & $\begin{array}{l}\text { - Ayuda a mejorar la respuesta inmunitaria (Marcos et al. } \\
\text { 2004; Turchet et al. 2003; Cobo Sanz et al. 2006; Pujol et al. } \\
\text { 2000; Parra et al. 2004a; Parra et al. 2004b) } \\
\text { - Disminuye el tiempo de duración de diarreas (Pedone et } \\
\text { al. 1999; Pedone et al. 2000; Agarwal et al. 2002; Agarwal } \\
\text { et al. 2001; Pereg et al. 2005) } \\
\text { - Ayuda al equilibrio de la flora intestinal y favorece la } \\
\text { absorción de nutrientes (Guerin-Danan et al. 1998) }\end{array}$ \\
\hline YAKULT & $\begin{array}{l}\text { Lactobacillus casei Shirota } \\
\qquad \text { YIT9018 } \\
\text { Concentración: } 10^{8} \mathrm{UFC} / \mathrm{ml}\end{array}$ & $\begin{array}{l}\text { - Modulación de la flora intestinal (Macfarlane \& } \\
\text { Cummings, 1999) } \\
\text { - Favorece la digestión de la lactosa (Marteau et al. 1993) } \\
\text { - Previene y trata constipación y diarrea (Marteau et al. } \\
\text { 1993; Tanaka 1997) } \\
\text { - Controla la reproducción de las bacterias nocivas dentro } \\
\text { del intestino (Tanaka 1997) } \\
\text { - Ayuda a modular el sistema de defensa natural del } \\
\text { organismo, fortalece la resistencia a las infecciones (Higashi } \\
\text { \& Micato-Ku, 2006) }\end{array}$ \\
\hline SANCOR BIO & $\begin{array}{l}\text { Lactobacillus casei Sancor } \\
\qquad \text { CRL 431+ } \\
\text { Lactobacillus acidophilus } \\
\text { Sancor } \\
\text { CRL } 730 \text { (johnsonii) + } \\
\text { Fructanos naturales } \\
\text { (InulinaFOS) }\end{array}$ & $\begin{array}{l}\text { - Disminuye tiempo de duración de diarreas persistentes } \\
\text { (Río et al. 2004; Gonzalez et al. 1990; Gaon et al. 2002; } \\
\text { Gaon et al. 2003) } \\
\text { - Prevención de enfermedades respiratorias (Río et al. } \\
\text { 2002) } \\
\text { - Ayuda a prevenir la osteoporosis (Chaila et al. 2005) } \\
\text { - Modula balance de linfocitos Th1 y Th2 (Laiho et al. 2002; } \\
\text { Fontenla et al. 2002) } \\
\text { - L. casei SanCor CRL431 puede proteger contra la infección } \\
\text { por Salmonella (Chateau et al. 1993) } \\
\text { - Disminuye síntomas de intolerancia a la lactosa (Gaon et } \\
\text { al. 1995) } \\
\text { - Estimulación del sistema inmune (Vitiñi et al. 2000; } \\
\text { Maldonado \& Perdigón, 2004; Perdigón et al. 2001) }\end{array}$ \\
\hline $\begin{array}{l}\text { ACTIVIA ACTI } \\
\text { REGULARIS }\end{array}$ & $\begin{array}{l}\text { Bifidobacterium Animalis DN } \\
173010 \text { + Prebiótico FOS } \\
\text { Concentración: } 10^{8} \text { UFC/ml }\end{array}$ & $\begin{array}{l}\text { - Ayuda al equilibrio de la flora, reduciendo el tiempo de } \\
\text { tránsito intestinal (Cats et al. 2003; Antonie et al. 2000) }\end{array}$ \\
\hline $\begin{array}{l}\text { YOGURISIMO } \\
\text { CON } \\
\text { PROVITALIS }\end{array}$ & $\begin{array}{l}\text { Lactobacillus casei } \\
\text { +Bifidobacterium } \\
\text { Concentración: } 10^{7} \mathrm{UFC} / \mathrm{ml}\end{array}$ & $\begin{array}{l}\text { - Favorece un mejor aprovechamiento de los nutrientes } \\
\text { (Guerin-Danan et al. 1998) } \\
\text { - Modulación de la flora intestinal (Guerin-Danan et al. } \\
\text { 1998) }\end{array}$ \\
\hline $\begin{array}{l}\text { SER CON } \\
\text { BIOPURITAS }\end{array}$ & $\begin{array}{l}\text { Bifidobacterium Animalis DN } \\
\qquad 173010 \\
\text { Concentración: } 10^{8} \mathrm{UFC} / \mathrm{ml}\end{array}$ & $\begin{array}{l}\text { - Contribuye al equilibrio de la flora intestinal, } \\
\text { regularizando el tránsito intestinal (Marteau et al. 2002; } \\
\text { Meance et al. 2001; Meance et al. 2003; Antonie et al. } \\
\text { 2000) }\end{array}$ \\
\hline
\end{tabular}




\begin{tabular}{|c|cl|}
\hline & & - Colonización de los intestinos y normalización del tránsito \\
BIOQUESO & Bifidobacterium sp.+ & intestinal. (Medici et al. 2004) \\
ILOLAY & Lactobacillus casei & Protección contra gérmenes patógenos (Vinderola et al. \\
VITA*1 & (paracasei) + Lactobacillus & - Estimulación del sistema inmunológico (Vinderola et al. \\
& acidophilus & 2003) \\
& & - Disminución de la intolerancia a la lactosa (Medici et al. \\
& $2004)$ \\
\hline
\end{tabular}

\section{El kefir como alimento funcional natural}

El kefir es una leche fermentada originada hace miles de años en las montañas caucásicas. Aunque es muy popular en países del este europeo, en nuestro país es elaborado artesanalmente por algunas comunidades de inmigrantes. Es una leche fermentada ácida, viscosa y ligeramente carbonatada, que se prepara a partir de un fermento inmovilizado natural, el "gránulo de kefir" (Thompson et al. 1990; Angulo et al. 1993; Garrote et al. 2001). No se conocen los mecanismos por los cuales se originaron los gránulos de kefir (Koroleva 1988). Cuando éstos son adicionados a la leche, parte de los microorganismos pasan a ella donde se multiplican y producen metabolitos que otorgarán a la leche fermentada sus características químicas y físicas particulares. La composición del kefir, así como sus características organolépticas están sujetas a variaciones regionales (Garrote et al. 1998; Londero et al. 2012). Estas variaciones pueden deberse a factores tales como el origen y almacenamiento de los gránulos de kefir, el tipo de leche utilizada, así como a las condiciones de elaboración del producto, siendo relevantes la relación gránulo-leche y la temperatura de fermentación (Witthuhn et al. 2005; Latorre García et al. 2007; Garrote et al. 1998).

El Código Alimentario Argentino lo describe en el capítulo VIII, art. 576, como "el producto obtenido de la fermentación con cultivos ácidolácticos elaborados con granos de kefir, Lactobacillus kefir, especies de los géneros Leuconostoc, Lactococcus y Acetobacter, con producción de ácido láctico, etanol y dióxido de carbono. Los granos de kefir están constituidos por levaduras fermentadoras de la lactosa (Kluyveromyces marxianus) y levaduras no fermentadoras de la lactosa (Saccharomyces omnisporus, 
INTRODUCCIÓN GENERAL

Saccharomyces cerevisiae y Saccharomyces exiguus), Lactobacillus casei, Bifidobacterium spp y Streptococcus thermophilus".

Actualmente su consumo es popular en distintos países del este europeo. En algunos de estos países, así como en Estados Unidos y en Canadá, su producción alcanza escala industrial y se comercializa en el mercado. En Argentina se elabora artesanalmente (Garrote et al. 2010).

En la Figura 2 se muestran algunas de las presentaciones comerciales del kefir disponibles en otros países.

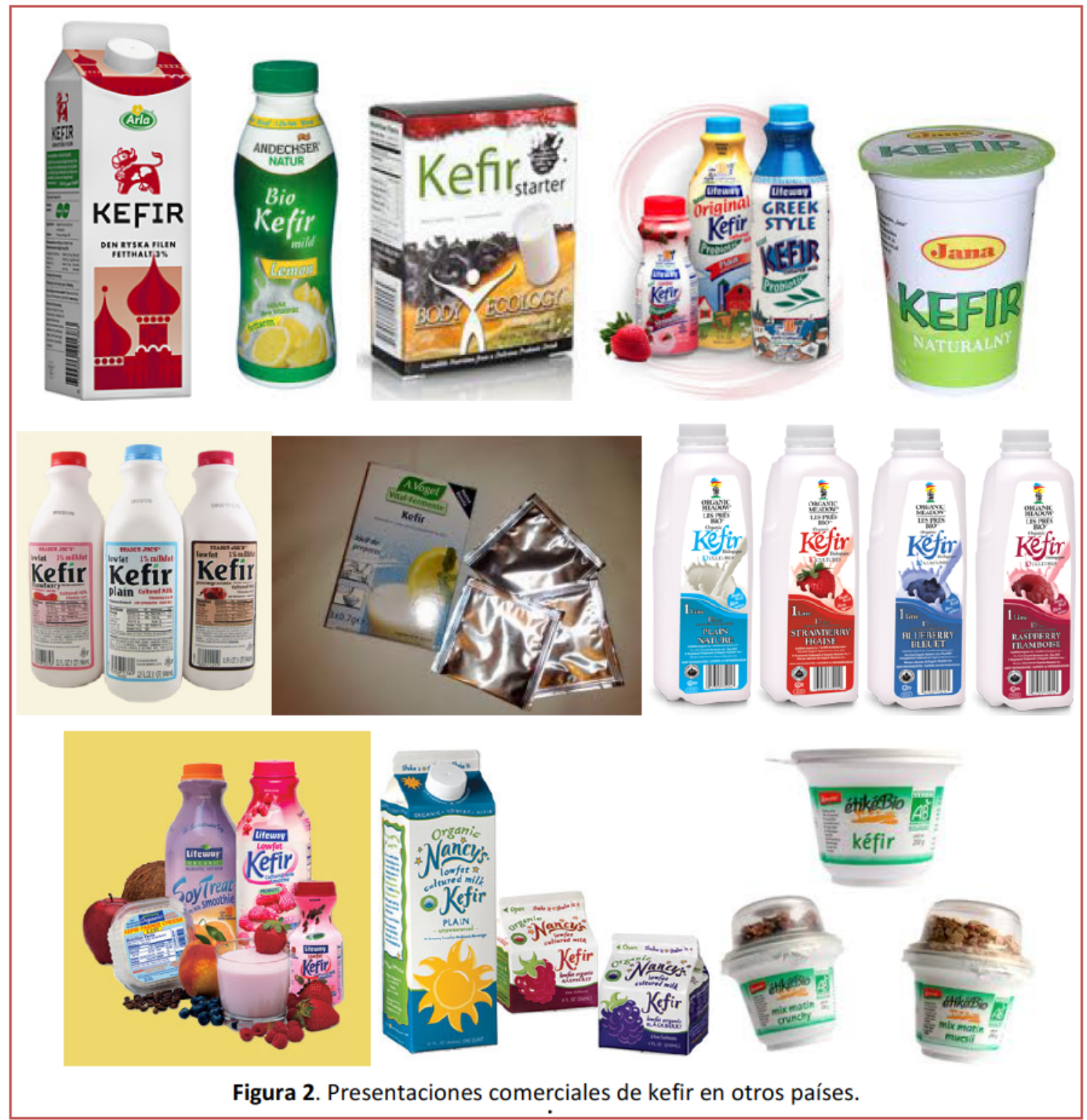


El consumo de kefir ha sido asociado a la longevidad de los pueblos caucásicos y se ha observado que causa beneficios para la salud (Halle et al. 1994; Farnworth 2005). Ha sido administrado en forma empírica para el tratamiento de personas con desórdenes metabólicos, con arterioesclerosis, enfermedades alérgicas y tuberculosis (Lopitz-Otsoa et al. 2006). Se ha estudiado su acción antitumoral, la participación en la estimulación del sistema inmune y la actividad antifúngica. Además, numerosos estudios documentan la acción benéfica del kefir para la salud. Se ha demostrado acción preventiva en el tratamiento de gastritis, diarreas, males intestinales y problemas de digestión (Koroleva 1988). Asimismo, Garrote et al. (2000), han descripto la capacidad inhibitoria de sobrenadantes de kefir sobre el desarrollo de microorganismos Gram negativos (-), aislados de muestras clínicas y Gram positivos (+), aislados del medio ambiente. Estas propiedades se atribuyen a la presencia de una microbiota compleja así como a sus productos metabólicos. Dentro de estos productos se pueden mencionar: ácidos orgánicos, vitaminas (fundamentalmente del grupo B), proteínas de superficie de algunos microorganismos que se liberan al medio (capa-S), y un exopolisacárido llamado kefiran.

Gránulo de kefir.

Los gránulos de kefir son estructuras globulares, gelatinosas, de color blanco amarillento, de consistencia elástica y forma irregular (Figura 3). Están compuestos por una matriz de polisacárido denominado kefiran y proteínas (Abraham \& De Antoni, 1999), donde se encuentran adheridas bacterias lácticas homofermentativas y heterofermentativas $\left(10^{8}-10^{9} \mathrm{UFC} / \mathrm{g}\right.$ de gránulo), bacterias acéticas $\left(10^{5}-10^{6} \mathrm{UFC} / \mathrm{g}\right.$ de gránulo) y levaduras fermentadoras y no fermentadoras de lactosa $\left(10^{7}-10^{8} \mathrm{UFC} / \mathrm{g}\right.$ de gránulo) (Garrote et al. 1997, 2001; Koroleva 1991). Estos microorganismos establecen entre sí una íntima relación simbiótica, producto de la cual se obtiene esta bebida de características organolépticas propias. 


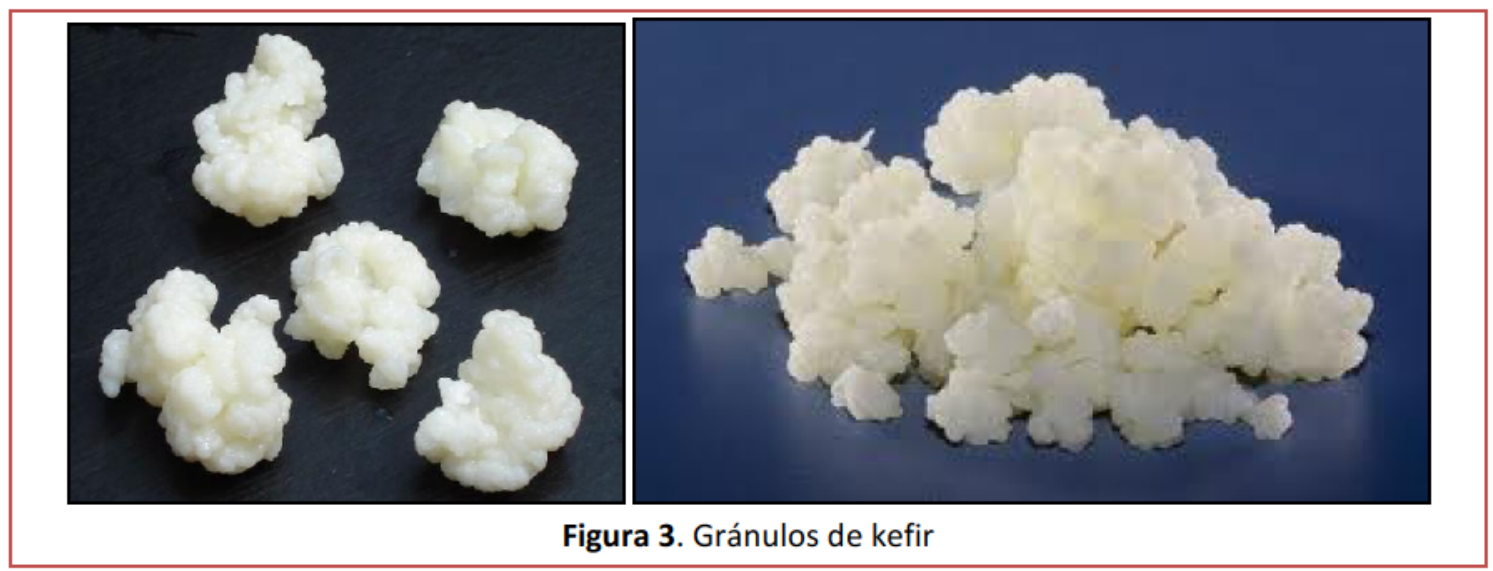

El gránulo de kefir, contiene aproximadamente $83 \%$ de agua, $6 \%$ de proteínas y $11 \%$ de un polisacárido denominado kefiran (Abraham \& De Antoni, 1999) y constituyen un ecosistema natural que se ha mantenido en el tiempo. Durante la fermentación de la leche con gránulos de kefir se produce un incremento de biomasa de gránulo. Esto se debe a que las poblaciones presentes en el gránulo, interaccionando de manera simbiótica (Vedamuthu 1982; Witthuhn et al. 2005), sintetizan las proteínas y el polisacárido que componen la matriz (Garrote et al. 2010). El aumento de la temperatura de fermentación produce alteraciones en el aspecto y en la composición microbiológica de los gránulos así como también se detecta una disolución parcial de los mismos a una temperatura de fermentación superior a $37{ }^{\circ} \mathrm{C}$ (Rimada \& Abraham, 2001; Londero et al. 2012).

El gránulo de kefir es una comunidad compleja (Margulis 1996), siendo este hecho lo que dificulta su empleo como starter (Farnworth 2005). Diferentes autores indican que no existe una única combinación de microorganismos que conforman el gránulo, sino que la microbiota que presentan depende del origen, condiciones de cultivo, procesos de elaboración y condiciones de almacenamiento (Molska et al. 1983; Zourari \& Anifantakis, 1988; Farnworth 2005; Magra et al. 2012). Algunas bacterias y levaduras de gránulo de kefir, al ser aisladas en cultivos puros, no crecen en leche o disminuyen su actividad bioquímica lo cual complica aún más el estudio de la población microbiana del gránulo de kefir (Koroleva 1991).

Los gránulos de kefir se forman solamente a partir de otros gránulos preexistentes y en el laboratorio no ha sido posible formar un nuevo gránulo partiendo de la asociación de cepas aisladas de los mismos (Bottazzi et al. 1994). Sin embargo, 
Wang et al. (2012a) propusieron que la formación de gránulo comienza con la autoagregación de Lactobacillus kefiranofaciens y Saccharomyces turicensis para formar pequeños gránulos. Luego, Lactobacillus kefiri comienza a producir biofilms y empieza a unirse a la superficie de los pequeños gránulos y coagregar con otros microorganismos y componentes de la leche para formar los gránulos. Aquí es cuando comienza el crecimiento de los mismos. Del análisis del gránulo mediante microscopía electrónica de barrido, Wang et al. (2012b) pudieron concluir que los lactobacilos de cadena corta tales como L. kefiri se ubican en la superficie del gránulo, mientras que lactobacilos de cadena larga tales como L. kefiranofaciens forman agregados hacia el centro de los gránulos de kefir.

El exopolisacárido producido por los microorganismos presentes en los gránulos de kefir se denomina kefiran (Kooiman 1968). La responsabilidad sobre la producción de dicho polisacárido fue adjudicada inicialmente a Lactobacillus brevis (La Riviére et al. 1967), "atypical Streptobacterium" (Rosi \& Rossi, 1978) y finalmente a L. kefiranofaciens sp. Nov (WT-2B, ATCC 43761) (Fujisawa et al. 1988). Recientemente las especies Lactobacillus kefiranofaciens (Fujisawa et al. 1988) y Lactobacillus kefirgranum, lactobacilos homofermentativos aislados de gránulos de kefir fueron reclasificados en dos subespecies: L. kefiranofaciens subespecie kefiranofaciens y $L$. kefiranofaciens subespecie kefirgranum (Vancanneyt et al. 2004) siendo la subespecie kefiranofaciens la considerada responsable de la producción del kefiran (Fujisawa et al. 1988; Michelli et al. 1999).

\section{Kefirán, exopolisacárido producido por lactobacilos del kefir}

El kefiran es un polisacárido producido por los lactobacilos presentes en el gránulo de kefir. El kefiran es un glucogalactano ramificado, soluble en agua, que contiene aproximadamente la misma cantidad de residuos de D-glucosa y D-galactosa (Figura 4). Está presente en gránulos de kefir, formando parte de la matriz de los mismos, y también en la leche o suero fermentado por dichos gránulos (Rimada \& Abraham, 2001, 2003). La enzima $\beta, D$ (1-6) glucanasa, es capaz de fragmentarlo generando pentasacáridos y glucosas (La Rivière et al. 1967). La unidad repetitiva del 
INTRODUCCIÓN GENERAL

kefiran está compuesta por hexa o heptasacáridos ramificados formados por un pentasacárido lineal y uno o dos residuos de azúcares unidos aleatoriamente al pentasacárido (Kooiman 1968; Micheli et al. 1999). Otros autores mediante estudios de hidrólisis y metilación demostraron que el kefiran presenta una estructura más compleja que la que se describe, indicando la coexistencia de moléculas con microheterogeneidades en su estructura (Mukai et al. 1988).

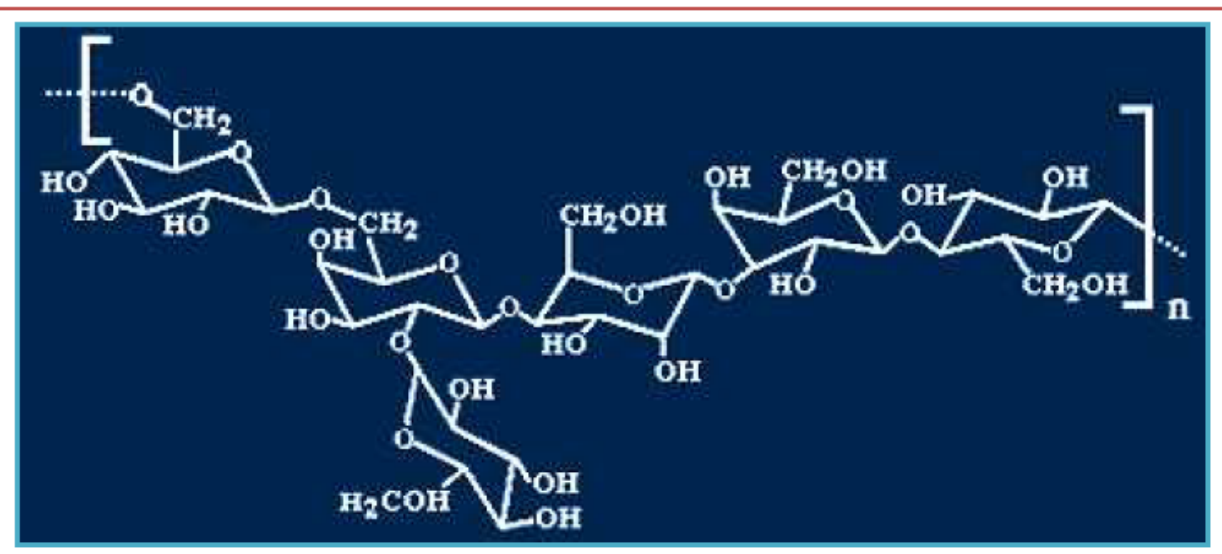

Figura 4. Estructura propuesta para la unidad repetitiva del kefiran en el año 1968 por P. Kooiman. (Carbohydrate Research, 7: 200-211).

Este polisacárido está presente en la leche fermentada en concentraciones de $250 \mathrm{mg} / \mathrm{l}$ y en los gránulos en concentración de 8 a 11 \% (p/v). La extracción de este polisacárido a partir de los gránulos de kefir es un método simple con buen rendimiento (Rimada \& Abraham, 2001). Los gránulos se pueden obtener durante la producción de kefir ya que aumentan su biomasa con los sucesivos repiques y los mismos son capaces de aumentar su biomasa durante la obtención de suero fermentado (Piermaría et al. 2008, Londero et al. 2012), siendo éste un medio más económico que la leche y que se genera en grandes cantidades como subproducto de la industria láctea. Por lo tanto, el kefiran sería un polisacárido que podría utilizarse como aditivo alimentario.

Se han estudiado algunos polisacáridos aislados de cepas provenientes de gránulos de kefir con el objetivo de determinar la similitud con el kefiran. Mediante ensayos de 13C-NMR y análisis de metilación se encontró que Lactobacillus sp. KPB-167B produce un polisacárido cuya estructura es similar al kefiran (Yokoi et al. 1990). El polímero procedente de L. kefiranofaciens ZW3 fue estudiado mediante espectroscopia 
FT-IR resultando ser un glucogalactano que posee grupo carboxilo, hidroxilo y amida en su estructura. Maeda et al. (2004a) estudiaron el polisacárido producido por L. kefiranofaciens WT-2BT crecido en medio líquido a base de hidrolizado de arroz y encontraron que el polisacárido producido posee un peso molecular del orden de $7,6 \cdot 10^{5} \mathrm{~g} / \mathrm{mol}$ y está compuesto por glucosa y galactosa en una relación molar 1,00:1,05.

Funcionalidad biológica del kefiran.

El tipo de uniones que presenta el kefiran hace que no sea digerible por el hombre por lo cual constituiría un aporte de fibras. El kefiran es parcialmente hidrolizado por celulasas provenientes de Trichoderma reesei, pero no puede ser hidrolizado por $\beta$-galactosidasa de Escherichia coli ni por $\alpha$-galactosidasa de Mortierella vinacea (Mukai et al. 1988). Como consecuencia de la estructura que presenta, el kefiran puede llegar intacto al intestino delgado, donde podría ejercer efectos biológicos. Se ha documentado mediante estudios en ratas hipertensas alimentadas con dietas de alto contenido lipídico que el kefiran posee actividad anticolesterolémica; observándose que aquellas que recibieron kefiran disminuyeron significativamente la presión sanguínea y los niveles de colesterol-LDL, colesterol total y triglicéridos en relación a aquellas que no lo recibieron (Maeda et al. 2004a). Al utilizar un modelo de ratas constipadas inducido por una dieta baja en fibras se observó que la administración de kefiran mejora los niveles de humedad y el peso de las heces (Maeda et al. 2004b).

La actividad inmunomoduladora fue estudiada en modelos murinos in vivo y se demostró que la administración oral del kefiran induce una respuesta a nivel de la mucosa intestinal, incrementando la producción de IgA y modificando los patrones de citoquinas liberados a la circulación sanguínea (Vinderola et al. 2006a; Medrano et al. 2011).

Estudios sobre la acción antitumoral del kefiran mostraron una disminución del crecimiento de tumores en ratones tratados oral o intraperitonealmente con este polisacárido (Shiomi et al. 1982). Murofushi et al. (1983) demostraron que la ingesta de kefiran en altas dosis antes del establecimiento del carcinoma produce la remisión de 
INTRODUCCIÓN GENERAL

tumores inducidos y concluyeron que el kefiran es capaz de inducir una respuesta inmune mediada por células.

Otro efecto benéfico que ha sido documentado para el kefiran es la capacidad para antagonizar factores de virulencia de Bacillus cereus in vitro. Los estudios realizados en enterocitos humanos en cultivo (línea celular Caco-2) demostraron que la presencia de kefiran $(800 \mathrm{mg} / \mathrm{l})$ fue capaz de disminuir los efectos citopáticos provocados por factores extracelulares presentes en los sobrenadantes de cultivo de B. cereus B10502 (Medrano et al. 2008), así como también el daño celular causado por las células vegetativas (Medrano et al. 2009). En este estudio, el kefiran fue capaz de disminuir la asociación de $B$. cereus a enterocitos, evitando alteraciones morfológicas, antagonizando la inducción de eventos de muerte celular y previniendo el desprendimiento celular. La capacidad del kefiran de interactuar tanto con la superficie de bacterias como de enterocitos podría ser la responsable del efecto protector observado.

Rodrígues et al. (2005) probaron la actividad antimicrobiana in vitro del kefiran contra varias especies de bacterias y observaron que Streptococcus pyogenes fue el microorganismo más sensible a kefiran, seguido por Staphylococcus aureus y Streptococcus salivarius. Otros ensayos mostraron que la administración tópica de kefiran a ratas Wistar, con lesiones de piel inducidas e infectadas con S. aureus, protege el tejido conectivo.

Propiedades tecnológicas del kefiran.

El kefiran posee propiedades fisicoquímicas y funcionales que permitirían su aplicación como aditivo alimentario (Rimada \& Abraham, 2006). Se puede destacar que al ser utilizado como aditivo en leches fermentadas produce el aumento de la viscosidad aparente (caracterizada por viscosimetría rotacional), y de los módulos elástico (G') y viscoso (G") (realizado por reometría oscilatoria de pequeña amplitud de deformación) (Rimada \& Abraham, 2006).

El kefiran en soluciones acuosas es capaz de formar geles al ser sometido a un proceso de congelación-descongelación, denominanados "criogeles" (del griego kryos, que significa escarcha o hielo) (Lozinsky et al. 2003). Los geles formados resultan 
translúcidos con una alta capacidad de retención de agua $(90,43 \% \pm 1,51)$ y son suficientemente cohesivos como para soportar su propio peso. Los espectros mecánicos de las muestras después de ser sometidas al proceso de congelación - descongelación muestran que el módulo elástico (G') es mayor que el módulo viscoso (G") y ambos módulos resultan independientes de la frecuencia, evidenciando un comportamiento tipo gel. El comportamiento de los geles de kefiran a $37{ }^{\circ} \mathrm{C}$ determina su habilidad para fundirse a la temperatura de la boca; esta propiedad resulta relevante para su aplicación en alimentos (Piermaría et al. 2008). Pintado et al. (1996) demostraron que el kefiran forma geles en solución acuosa conteniendo etanol. La fuerza de los geles preparados con $3 \%$ de kefiran en $8 \%$ de etanol es equivalente a la obtenida en los geles formados con $3 \%$ de gelatina (Mukai et al. 1990).

Finalmente, este polisacárido es capaz de producir películas comestibles extremadamente finas, transparentes, flexibles y homogéneas (Piermaría et al. 2009). Las películas de kefiran observadas por microscopía electrónica de barrido (SEM) muestran superficies lisas y estructuras compactas y homogéneas. La incorporación de glicerol como plastificante disminuye la resistencia a la tracción y aumenta la elongación (Piermaría et al. 2009). Por lo tanto, el agregado de glicerol en concentraciones superiores a $25 \mathrm{~g}$ de glicerol cada $100 \mathrm{~g}$ de kefiran resulta en películas con buenas características mecánicas y baja permeabilidad al vapor de agua (Piermaría et al. 2009, 2011).

\section{Matrices alimentarias utilizadas para la incorporación de microorganismos probióticos}

El mercado mundial de bebidas y alimentos funcionales representa un segmento dinámico y creciente de la industria de los alimentos debido a sus efectos beneficiosos sobre la salud humana (Global Industry Analysts, Inc., 2012), estimándose que llegará a US\$ 130 millones para el 2015. Los alimentos funcionales probióticos, una parte significativa de este mercado, tenían un valor aproximado de US\$15,9 mil millones en 2008 (Marco Trade News, 2012) y se espera que alcance un valor de US\$ 28,8 mil millones en el presente año. 
INTRODUCCIÓN GENERAL

Uno de los criterios más importantes para determinar la eficacia y el éxito del producto que contiene probióticos es la aceptación del producto por los consumidores y la supervivencia de los microorganismos probióticos durante su producción (Heenan et al. 2004). En general, la industria alimentaria ha aplicado el nivel recomendado de $10^{6} \mathrm{UFC} / \mathrm{g}$ en el momento de consumo de Lactobacillus acidophilus, Bifidobacterium y otros microorganismos probióticos (Boylston et al. 2004).

Sin embargo, los productos y suplementos probióticos comercialmente disponibles a menudo proporcionan poblaciones de células insuficientes debido a la pérdida de viabilidad durante la fabricación del producto (Doherty et al. 2011). Además, la sobrevida de probióticos durante el paso a través del tracto gastrointestinal humano (TGI) sigue siendo un reto importante (Anal \& Singh, 2007).

Se han evaluado diferentes alimentos para la incorporación de microorganismos probióticos. Aragon-Alegro et al. (2007) estudiaron la aplicación de mousse de chocolate como vehículo para microorganismos probióticos, incorporando inulina como componente prebiótico. Asimismo, la inclusión en chocolate de Lactobacillus helveticus CNCM I-1722 y Bifidobacterium longum CNCM I-3470 microencapsulado mejoró la supervivencia frente a las condiciones gastrointestinales in vitro (Possemiers et al. 2010). Por otro lado, los procesos de microencapsulación, particularmente mediante secado spray, podrían permitir el uso de probióticos (y por ende de simbióticos) en matrices alimentarias con baja actividad de agua, como es el pan o productos similares.

Dado que, los microorganismos probióticos deben resistir el proceso de elaboración y almacenamiento con el fin de permanecer viables en el producto comercial a una concentración mayor de $10^{6} \mathrm{UFC} / \mathrm{g}$ (Kurmann \& Rasic, 1991), y deben resistir las condiciones adversas del tracto gastrointestinal, como ácidos y secreciones biliares y competir con la microbiota fecal (Fooks \& Gibson, 2002), se han buscado alternativas para mejorar la supervivencia de los mismos.

Actualmente los geles alimentarios se plantean como alternativa para vehiculizar microorganismos probióticos ya que demás, poseen aplicaciones en la industria farmacéutica (Lozinsky et al. 2003). 
Teniendo en cuenta la capacidad del polisacárido kefiran de formar geles, se pretende profundizar el conocimiento del comportamiento de este polisacárido en sistemas complejos y utilizar los mismos como vehículo de sustancias bioactivas o microorganismos.

Se han propuesto los siguientes objetivos específicos:

A. Seleccionar microorganismos aislados de kefir con potencialidad probiótica.

B. Utilizar los geles de kefiran como vehículos para la inclusión de componentes activos y/o microorganismos probióticos para el desarrollo de alimentos funcionales. Para ello, se propone explorar la capacidad del kefiran de formar geles mixtos con proteínas de suero de leche y azúcares, y evaluar el comportamiento de los microorganismos probióticos en dicha matriz. 
INTRODUCCIÓN GENERAL 


\section{CAPÍTULO 1}

SELECCIÓN DE MICROORGANISMOS PROBIÓTICOS 


\section{Microorganismos del kefir}

En el año 2001, Food and Agriculture Organization (FAO) definió al kefir desde el punto de vista microbiológico y destacó que "los microorganismos que lo componen son Lactobacillus kefiri, especies de los géneros Leuconostoc, Lactococcus y Acetobacter y levaduras fermentadoras y no fermentadoras de lactosa creciendo en una íntima relación". No obstante, estudios realizados describen además, la presencia de otros microorganismos que se detallan en la siguiente lista, adaptada de Garrote et al. 2010.

- Lactobacilos

-Lactobacillus kefir (Koroleva, 1991; Pintado et al. 1996; Kandler \& Kunath, 1983; Takizawa et al. 1994; Garrote et al. 2001; Santos et al. 2003; Angulo et al. 1993; Chen et al. 2008; Jianzhong et al. 2009).

-Lactobacillus kefiranofaciens (Fujisawa et al. 1988; Takizawa et al. 1994; Santos et al. 2003; Chen et al. 2008; Jianzhong et al. 2009; Magalhães et al. 2010).

-Lactobacillus kefirgranum (Takizawa et al. 1994).

-Lactobacillus parakefir (Takizawa et al. 1994; Garrote et al. 2001).

-Lactobacillus brevis (Ottogalli et al. 1973; Simova et al. 2002; Santos et al. 2003; Angulo et al. 1993).

-Lactobacillus plantarum (Garrote et al. 2001; Santos et al. 2003).

-Lactobacillus helveticus (Koroleva, 1991, Simova et al. 2002; Jianzhong et al. 2009; Lactobacillus acidophilus (Ottogalli et al. 1973; Santos et al. 2003; Angulo et al. 1993).

-Lactobacillus gasseri (Angulo et al. 1993).

-Lactobacillus delbrueckii (Koroleva, 1991, Simova et al. 2002; Santos et al. 2003).

-Lactobacillus rhamnosus (Koroleva, 1991; Angulo et al. 1993).

-Lactobacillus casei (Simova et al. 2002; Jianzhong et al. 2009).

-Lactobacillus paracasei (Santos et al. 2003). 
Selección de microorganismos probióticos.

-Lactobacillus fructivorans (Yoshida \& Toyoshima 1994).

-Lactobacillus hilgardii (Yoshida \& Toyoshima 1994).

-Lactobacillus fermentum (Angulo et al. 1993).

-Lactobacillus viridescens (Angulo et al. 1993).

-Lactobacillus crispatus (Garbers et al. 2004).

- Bacterias ácido acéticas

-Acetobacter sp. (Garrote et al. 2001).

-Acetobacter pasteurianus (Ottogalli et al. 1973).

-Acetobacter aceti (Koroleva, 1991; Rosi \& Rossi, 1978).

- Lactococos

-Lactococcus lactis subsp. lactis (Koroleva, 1991; Pintado et al. 1996; Yüksekdag et al. 2004); Dousset \& Caillet, 1993; Ottogalli et al. 1973; Simova et al. 2002; Yoshida \& Toyoshima, 1994; Garrote et al. 2001; Angulo et al. 1993).

-Lactococcus lactis subsp. cremoris (Koroleva, 1991; Yüksekdag et al. 2004; Dousset \& Caillet, 1993).

- Enterococos

-Enterococcus durans (Rosi \& Rossi, 1978; Yüksekdag et al. 2004); descripta como Streptobacterium durans (Rosi \& Rossi, 1978); descripta como Streptococcus durans en Yüksekdag et al. 2004).

- Estreptococos

-Streptococcus thermophilus (Yüksekdag et al. 2004; Simova et al. 2002).

-Streptococcus durans (Yuksekdag et al. 2004).

- Leuconostoc

-Leuconostoc sp. (Angulo et al. 1993). 
-Leuconostoc mesenteroides (Koroleva, 1991; Ottogalli et al. 1973; Garrote et al. 2001; Garbers et al. 2004; Chen et al. 2008; Jianzhong et al. 2009; descripta como Leuconostoc kefir en Ottogalli et al. 1973).

- Otras bacterias

-Bacillus sp. (Angulo et al. 1993).

-Bacillus subtilis (Ottogalli et al. 1973).

-Pseudomonas spp. (Chen et al. 2008; Jianzhong et al. 2009).

-Escherichia coli (Angulo et al. 1993; Chen et al. 2008).

-Micrococcus sp. (Angulo et al. 1993).

\section{Propiedades benéficas atribuidas al consumo de kefir y sus microorganismos}

Algunas de las propiedades observadas de los microorganismos del kefir se describen a continuación:

\section{- Actividad antimicrobiana}

La actividad antimicrobiana del kefir ha sido asociada fundamentalmente a su contenido de ácidos orgánicos (Garrote et al. 2000), aunque se ha sugerido que podrían estar involucradas otras moléculas como peróxido de hidrógeno, acetaldehído, dióxido de carbono y péptidos (bacteriocinas) por parte de las bacterias presentes en el ecosistema del kefir (Powell et al. 2007). Garrote et al. (2001) mostraron que el kefir obtenido a partir de diferentes gránulos, alcanza un $\mathrm{pH}$ entre 3,5 y 4,0 (las concentraciones de ácido láctico varían entre 1,30 - 2,30 g/100 ml y las de ácido acético entre $0,13-0,29 \mathrm{~g} / 100 \mathrm{ml}$ ) e inhibe el crecimiento de Escherichia coli. Gulmez \& Guven (2003) compararon la seguridad microbiológica de yogurt y kefir utilizando como indicador E. coli 0157:H7, Listeria monocytogenes y Yersinia enterocolitica y concluyeron que una combinación de microorganismos iniciadores de yogurt y kefir pueden mejorar la seguridad del producto final. Silva et al. (2009) demostraron la actividad antimicrobiana de kefir contra Candida albicans, E. coli, Staphylococcus aureus, 
Selección de microorganismos probióticos.

Salmonella typhimurium y Shigella sonnei. Kakisu et al. (2007) probaron que el kefir disminuye la viabilidad y la germinación de esporas de Bacillus cereus. Otros autores han estudiado la actividad antimicrobiana de los sobrenadantes de productos fermentados con kefir o con microorganismos aislados a partir de ellos (Brialy et al. 1995; Santos et al. 2003; Yüksekdag et al. 2004; Rodrígues et al. 2005, Londero et al. 2012). Golowczyc et al. (2008) demostraron que los sobrenadantes de 11 cepas de Lactobacillus plantarum, aisladas de gránulos de kefir, producen una fuerte inhibición del crecimiento de Salmonella enterica serovar Thipymurium y E. coli y que alguno de ellos también inhibe el crecimiento de Salmonella gallinarum, Salmonella enterica y Sigella sonnei. En cuanto a la producción de bacteriocinas por cepas aisladas de kefir, se encontró una cepa de Lactococcus que produce una bacteriocina, a la que se denomina lacticina 3147, que tiene efecto inhibitorio contra muchos patógenos de alimentos y microorganismos esporulados (Ryan et al. 1996; Dobson et al. 2011). L. plantarum ST8K aislado de kefir produce una bacteriocina de 3,5 kDa (bacST8KF) que es activa contra Lactobacillus casei, Lactobacillus salivarius, Lactobacillus curvatus y Listeria innocua (Powell et al. 2007). También se demostró su actividad antifúngica (Cevikbas et al. 1994; Ismaiel et al. 2011). Carasi et al. (2012) mostraron la capacidad de las proteínas de la capa-S de lactobacilos kefir para antagonizar los efectos biológicos de toxinas de origen bacteriano, en especial de Clostridium difficile. Así también, fue demostrado que la capa-S de L. kefiri antagoniza la adhesión y/o invasión de Salmonella Enteritidis in vitro (Golowczyc et al. 2007).

\section{- Adhesión a superficie intestinal}

Otra propiedad que está documentada para algunos microorganismos aislados de kefir y se suele tener en cuenta a la hora de seleccionar microorganismos probióticos es su capacidad para adherirse a la mucosa gastrointestinal y colonizarla (Ouwehand et al. 1999a). La habilidad de adherirse a células epiteliales in vitro es común en Lactobacillus y es dependiente de la cepa. L. plantarum y L. kefiri aislados de gránulos de kefir son capaces de adherirse a células Caco-2 con diferentes porcentajes de asociación $(0,97$ a $10 \%$ de adherencia). Esta capacidad no se relaciona con la hidrofobicidad, ya que tanto cepas de L. kefiri altamente hidrofóbicas (Golowczyc et al. 2007) como cepas de L. plantarum altamente hidrófilicas (Golowczyc et al. 2008), poseen la capacidad de 
adherirse a células en cultivo Caco-2 (0,97 a 5,30 \% de adhesión). Santos et al. (2003) describieron también la capacidad de lactobacilos aislados de kefir de asociarse a enterocitos. Hugo et al. (2008) estudiaron in vitro el efecto de lactobacilos aislados de kefir sobre la actividad biológica de E. coli enterohemorrágica (ECEH) y encontraron que L. plantarum CIDCA 83114, viable o no, protege las células epiteliales (Hep-2) en cultivo del daño inducido por los factores de virulencia de E. coli. En este trabajo los autores concluyeron que estos lactobacilos podrían antagonizar los mecanismos de virulencia de ECEH, ya sea por la modificación del microambiente o interfiriendo con las cascadas de señalización activadas por el patógeno. Los microorganismos de kefir disminuyen significativamente el número de Clostridium en intestino delgado y grueso respecto a grupos controles (Marquina et al. 2002). Zacconi et al. (2003) estudiaron la exclusión competitiva de Campylobacter jejuni provocada por el kefir en pollos mediante estudios de colonización de la microbiota colónica y encontraron que el kefir, fresco o congelado, podría tener aplicaciones interesantes en el control de la difusión de microorganismos patógenos en hemorragias de aves de corral.

- Actividad antitumoral

La actividad antitumoral también ha sido relacionada al consumo de kefir. De Moreno de LeBlanc et al. (2007) estudiaron el efecto antitumoral del kefir y de una fracción libre de células del kefir en un modelo de ratones con tumores mamarios y destacaron el efecto de los componentes no microbianos. Liu et al. (2002) encontraron que el kefir indujo un proceso de apoptosis en células tumorales que permitieron una disminución significativa en el crecimiento de tumores en ratones. Al mismo tiempo, observaron un incremento significativo en los niveles de IgA en el intestino delgado, proponiendo que este incremento podría originarse por una estimulación del sistema inmune a nivel de las placas de Peyer. Estos autores concluyeron que los microorganismos o el polisacárido producido por ellos podrían ser responsables del efecto observado. Los primeros en documentar un efecto antitumoral relacionado al polisacárido aislado de kefir fueron Shiomi et al. (1982). Este polisacárido, administrado a ratones en forma oral o intraperitonealmente, es capaz de inhibir el crecimiento de 
Selección de microorganismos probióticos.

carcinoma de Erlich o sarcoma 180 comparado con ratones que no recibieron el polisacárido (Shiomi et al. 1982; Murofushi et al. 1983).

- Actividad modulatoria de la respuesta inmune

Se ha propuesto que la modulación del sistema inmune sería uno de los mecanismos por los cuales las bacterias probióticas podrían ejercer sus efectos benéficos para la salud del hospedador (Gill \& Rutherfurd, 2001; De Simone, 2005). Thoreux \& Schmucker (2001) concluyeron que el kefir ejerce un efecto adyuvante en el sistema inmune de mucosas al demostrar un aumento de inmunoglobulina IgA específica y un aumento significativo en los niveles séricos de IgG no específica en ratones tratados con kefir frente al desafío con toxina colérica comparado con ratones control. Otros autores demostraron actividad antiinflamatoria y antialérgica del kefir en un modelo murino de asma (Lee et al. 2007). Además, de acuerdo a la evidencia presentada en los últimos años, los polisacáridos presentes en el producto fermentado podrían tener implicancia en la modulación de la respuesta inmune, habiéndose demostrado este efecto para el kefiran (Furukawa et al. 1992; Vinderola et al. 2006a; Medrano et al. 2011).

- Tratamiento para el colesterol

La fermentación de la leche con gránulos de kefir de distintos orígenes durante 24 horas a $20^{\circ} \mathrm{C}$ es capaz de reducir los niveles de colesterol presentes en leche hasta 62 \% (Vujicic et al. 1992). Además, Lactobacillus acidophilus CU 673 aislado de kefir presenta capacidad de asimilar colesterol in vitro (Yoon et al. 1999) y Kluyveromyces marxianus es capaz de capturarlo en su pared celular (Yoshida et al. 2005). Sin embargo, estudios in vivo arrojan resultados contradictorios respecto al efecto anticolesterolémico del kefir. Liu et al. (2006) demostraron que el kefir, producido en leche de vaca y de soja, disminuye la concentración de colesterol y de triglicéridos en suero en hámster. Urdaneta et al. (2007), en contraposición con los resultados descriptos por Liu et al. (2006), hallaron un pequeño incremento en los niveles de colesterol y triglicéridos en ratas que consumieron kefir. St-Onge et al. (2002) describieron que el consumo de kefir en sujetos con hipercolesterolemia no produjo efecto alguno sobre los niveles de 
colesterol total, y tampoco sobre la concentración de colesterol LDL, colesterol HDL y triglicéridos. En consecuencia, el efecto hipocolesterolémico del kefir está en discusión. Por otro lado, L. plantarum LP09 y LP45 aisladas de kefir redujeron el colesterol, triglicéridos y colesterol-LDL y podrían utilizarse como agentes probióticos para el tratamiento de la hipercolesterolemia (Huang et al. 2013a, 2013b).

\section{- Efecto hipertensivo}

Quirós et al. (2005) revelaron que el kefir elaborado a partir de leche de cabra inhibe a la enzima transformadora de la angiotensina (ACE) in vitro por la presencia de péptidos de bajo peso molecular producidos por la proteólisis durante la fermentación. También se ha descripto que la administración oral de kefiran a ratones reduce la actividad ACE en suero (Maeda et al. 2004a).

\section{- Trastornos intestinales}

El kefir mejora la digestibilidad y absorción de la lactosa debido a la presencia de la enzima $\beta$-galactosidasa cuya actividad en el kefir es $60 \%$ mayor que en el yogurt (De Vrese et al. 1992; Hertzler \& Clancy, 2003). Chen et al. 2013, observaron tanto in vivo como in vitro, un efecto anticolitis atribuido a L. kefiranofaciens M1 aislado de kefir, teniendo el potencial de ser aplicado en productos lácteos fermentados como una terapia alternativa para los trastornos intestinales. Además, Bolla et al. (2013) demostraron que un tratamiento oral con una mezcla de bacterias y levaduras aisladas del kefir, entre ellas Lactococcus lactis sub lactis CIDCA 8221, L. plantarum CIDCA 83114, L. kefiri CIDCA 8348, Kluyveromyces marxianus CIDCA 8154 y Saccharomyces cerevisiae CIDCA 8112, fueron capaces de prevenir la diarrea y enterocolitis en un modelo animal de hamsters Syrian provocada por $C$. difficile.

\section{Adhesión bacteriana}

Uno de los principales criterios para la selección de cepas de probióticos es su capacidad de adherirse al epitelio intestinal, ya que esto determina sus interacciones con el huésped y los microorganismos presentes en el sistema anfitrión (Alander et al. 
Selección de microorganismos probióticos.

1999). Sin embargo el concepto que las bacterias probióticas tienen que ser capaces de colonizar el segmento gastrointestinal está muy discutido. El término colonización describe la habilidad de una cepa particular de establecerse en el hospedador por un período prolongado de tiempo sin necesidad de que la misma sea introducida constantemente (Guarner et al. 2005). Se sabe que a nivel de género, la microbiota de una persona adulta sana es estable, mientras que a nivel de especie, se producen variaciones menores (Zoetendal et al. 1998). Sin embargo, la administración de antibióticos puede cambiar bruscamente la composición microbiana intestinal y en este caso, la administración de bacterias probióticas puede modular el balance microbiano positivamente, causando un incremento de las mismas y cambios en el nivel de otras bacterias. De todas formas, no hay pruebas que las bacterias probióticas tengan que colonizar el intestino para ejercer efectos benéficos para la salud (Isolauri et al. 2004).

Aunque generalmente la adhesión al intestino es considerada como un factor importante para lograr la colonización y pre-requisito esencial para ejercer una actividad probiótica, también hay que considerar que la adhesión no es esencial dado que un rápido crecimiento puede lograr el mismo fin si los microorganismos son consumidos en forma constante (Fuller 1997; Ehrmann et al. 2002; Servin \& Coconnier, 2003). Algunos trabajos demuestran que la adhesión al epitelio intestinal no garantiza la colonización (Lee et al. 2000). Otro punto importante para tener en cuenta es que algunos investigadores sugieren que la adhesión de las bacterias al intestino puede causar la traslocación y posterior infección de órganos en personas con predisposición a la bacteriemia, aunque consideran que existen otros factores que podrían estar involucrados (Apostolou et al. 2001; Rinkinen et al. 2003).

Modelos para el estudio de adhesión bacteriana.

La capacidad de adhesión de los probióticos está estrechamente relacionada con sus propiedades de la superficie. La pared celular de las bacterias Gram positivas se compone de una capa gruesa de peptidoglicano, que está "decorado" con varios componentes, entre ellos ácido lipoteicoicos, polisacáridos, proteínas, y entre ellas, las proteínas de la capa-S (Schar-Zammaretti et al. 2005; Deepika et al. 2010). 
Una aproximación simple para obtener información acerca de la capacidad de adhesión en el ecosistema intestinal es estudiar las propiedades superficiales de las cepas seleccionadas. Esto se puede lograr utilizando una combinación de metodologías tales como partición en hidrocarburos, interacción con otros microorganismos, adhesión a monocapas celulares en cultivo, etc. Hasta ahora no ha sido desarrollada una técnica que por sí misma pueda caracterizar adecuadamente todos los aspectos de la interacción microorganismo-sustrato.

Existen diferentes modelos para estudiar las características de la superficie bacteriana y la capacidad de adhesión de microorganismos. Estos modelos van desde los estudios de hidrofobicidad superficial hasta los estudios de adhesión in vivo. La hidrofobicidad como una característica de la superficie bacteriana ha sido estudiada ampliamente. Cuando un componente no polar está en un medio acuoso tiende a agregarse para disminuir el área de la interface hidrocarburo-agua. En este fenómeno están involucradas las proteínas, entre otras moléculas, que contienen aminoácidos con residuos hidrofóbicos que podrían intervenir en las reacciones de adhesión entre microorganismos entre sí y con algún sustrato. Un microorganismo se va a adherir a una superficie a través de un efecto hidrofóbico si posee una alta densidad de sitios no polares sobre su superficie. Para muchos microorganismos, la partición en hexadecano parece ser proporcional a la adherencia a determinadas superficies. Sin embargo, varios autores (Ouwehand et al. 1999a; Schillinger et al. 2005; Golowzcyc et al. 2008) han demostrado que no existe correlación entre la hidrofobicidad de la superficie celular y la adherencia a las células epiteliales. Por lo tanto, la hidrofobicidad podría contribuir a la adhesión, pero no es indispensable.

La adhesión de las bacterias probióticas en el tracto gastrointestinal comúnmente se prueba in vitro utilizando líneas celulares modelo, tales como las células Caco-2 (Tuomola \& Salminen, 1998), células productoras de mucus (HT-29 MTX) o mucus en sí mismo (Ouwehand et al. 1999) y componentes de la matriz extracelular, tales como los colágenos, fibronectina y laminina (De Leeuw et al. 2006). Estos sistemas permiten y facilitan la selección preliminar de cepas potencialmente adherentes (Collado et al. 2005). Las células Caco-2 son células de carcinoma de colon humano y se diferencian en enterocitos maduros luego de la confluencia, son células polarizadas con 
Selección de microorganismos probióticos.

desarrollo del borde apical "en cepillo" característico de las células intestinales (Blum et al. 1999). El tiempo de incubación y la composición del medio de crecimiento son factores que influyen en la adhesión bacteriana a las células Caco-2. (Deepika et al. 2009; Ojeda et al. 2008). Esta línea es una de las más utilizadas para estudiar y seleccionar bacterias lácticas en base a su capacidad de adhesión (Pinto et al. 1983; Tuomola \& Salminen, 1998), sin embargo existen otras líneas celulares, también derivadas de carcinoma de colon humano, ampliamente utilizadas, tales como HT29, HT29-MTX (productora de mucus) y Caco-2/TC-7 que son un clon de las células Caco-2 (Blum et al. 1999; Servin 2004). Haeri et al. 2012 compararon el nivel de adherencia de bacterias probióticas en tres líneas celulares de diferente origen tales como Caco-2, células HEp-2 y líneas de células T84 (Tabla 2). El porcentaje de adhesión de 14 de los 16 microorganismos estudiados fue similar en células HEp-2 y Caco-2. La similitud observada entre T84 y Caco-2 fue de 10 sobre 16. Estos sistemas ofrecen la ventaja de que las células presentan una uniformidad celular, hay mayor reproducibilidad entre ensayos que en los ensayos in vivo y los experimentos son más simples. Por otro lado, tienen la desventaja que pueden presentar una superficie diferente a la original, especialmente en términos de distribución y accesibilidad de receptores.

Tabla 2. Líneas celulares más usadas y origen correspondiente.

\begin{tabular}{|c|c|}
\hline Línea Celular & Origen \\
\hline Caco-2 & Células epiteliales de intestino - Origen humano \\
\hline Caco-2/TC-7 & Clon de la línea Caco-2 \\
\hline HEp-2 & Células epiteliales de laringe - Origen humano \\
\hline T84 & Células epiteliales de intestino - Origen humano \\
\hline HT29 & Células epiteliales de intestino - Origen humano \\
\hline Raw & Monocitos macrófagos de ratón \\
\hline Vero & Fibroblastos de riñón de mono \\
\hline
\end{tabular}

Los estudios de adhesión a tejidos vivos son la mejor aproximación. Ciertos estudios sugieren una correlación entre los resultados in vitro e in vivo, lo que indica que la adhesión in vitro podría ser utilizada para predecir el tiempo de residencia de los 
probióticos en el tracto gastrointestinal humano (Jacobsen et al 1999; Dunne et al. 2001).

La inoculación de animales o voluntarios humanos es el sistema más natural y adecuado (Gardiner et al. 2004; Valeur et al. 2004). Los ensayos con animales son un modelo que presenta buena correlación con los ensayos en humanos. Hay que tener en cuenta que para el relevamiento de un número elevado de bacterias los ensayos pueden ser complicados ya que para los experimentos se necesita contar con una población suficientemente grande de animales para obtener resultados estadísticamente representativos.

\section{Microorganismos patógenos: Salmonella entérica serovar Enteritidis}

Salmonella como agente causal de enfermedades.

Salmonella pertenece a la familia enterobacteriaceae, es un bacilo Gram negativo (-), no esporulado. Es uno de los microorganismos patógenos más estudiados debido a que es el agente etiológico causante de muchas enfermedades definidas como Salmonelosis. La enfermedad comúnmente se manifiesta por enterocolitis aguda, con aparición repentina de cefalea, dolor abdominal, diarrea, nauseas y a veces vómitos; y puede evolucionar a septicemia o infección focal. Rara vez es mortal, excepto en niños de corta edad, personas de avanzada edad e inmunodeprimidos. Las estrategias convencionales para el tratamiento de esta enfermedad como la terapia con antibióticos y la vacunación tienen no sólo demostrado que son de eficacia sub-óptima sino que también conducen al desarrollo de cepas resistentes a múltiples fármacos contra Salmonella. Los cuadros clínicos de Salmonella entérica serovar Enteritidis están asociadas principalmente al consumo de huevos crudos o mal cocidos y productos derivados contaminados, tales como mayonesas y merengues entre otros (Vaquero et al. 2011). A pesar de las mejoras en sanidad e higiene, la salmonelosis continúa siendo un grave problema económico y para la salud (Patrick et al. 2004; Velge et al. 2005). 
Selección de microorganismos probióticos.

En la Unión Europea se estima que se producen cerca de 160.000 casos anuales de gastroenteritis causada principalmente por Salmonella entérica serovar Typhimurium y serovar Enteritidis. En el período 1995-1999, Salmonella fue el segundo agente causal más importante (35,3\%) de brotes de ETA (Enfermedades Trasmitidas por Alimentos) en América Latina y el Caribe. Durante el periodo 1993-2002 se han registrado en Latinoamérica 1256 brotes de salmonelosis, que afectaron a 48334 personas y produjeron 15 muertes. El 29,2 \% de los casos fue consecuencia del consumo de huevos o productos derivados y el 9,4\%, fue debido a la ingesta de carne de aves. El 9,8 \% de los brotes fue causado por Salmonella enterica serovar Enteritidis y en el $85 \%$ de los casos no se pudo determinar la serovariedad implicada (Fuente: Sistema de Información Regional para la Vigilancia Epidemiológica de las Enfermedades Transmitidas por Alimentos [SIRVETA]).

En Argentina durante el período 1993-2002 ocurrieron 60 brotes de salmonelosis que produjeron 889 enfermos y 4 muertos. Según un informe del Boletín epidemiológico Nacional publicado en 2006 las 5 serovariedades prevalentes en muestras de origen humano en Argentina en el período 2004-2005 fueron: S. Enteritidis (36,0 \%), S. Typhimurium (20,5\%), S. Infantis (8,7 \%), S. Newport (5,3\%) y S. Agona $(4,9 \%)$; siguiendo la misma tendencia que en años anteriores. La mortalidad por salmonelosis en países desarrollados es poco frecuente $(<5 \%)$ sin embargo en países en desarrollo con mayor frecuencia de enfermedades invasivas la mortalidad se encuentra entre 18 y $24 \%$ (Chimalizeni et al. 2010).

Para llevar a cabo el proceso patogénico, Salmonella presenta varios mecanismos de virulencia. Los genes de virulencia más importantes son los que se encuentran dentro de las denominadas islas de patogenicidad de Salmonella (SPI). Hasta el momento, se ha descripto que cinco SPI tienen una importante contribución a la patogénesis (Frábega \& Vila, 2013). En la primera etapa de la infección, la bacteria debe encontrar y adherirse a uno o más tipos de células del tejido intestinal. Algunos mecanismos de adhesión pueden involucrar varios tipos de fimbrias o pili (Salyers \& Whit, 2002). El ribete en cepillo del epitelio intestinal permanece intacto hasta el momento en que Salmonella llega al intestino y se acerca a la superficie epitelial. A partir de ese momento, las microvellosidades circundantes empiezan a degenerarse con elongación, edema y 
crecimiento en un proceso llamado ruffling (rizado). Aquí, los efectores interactúan con las proteínas de la célula hospedadora para arreglar el citoesqueleto de actina e inducir cambios morfológicos que causan que estas células, normalmente no fagocíticas, internalicen la bacteria en un proceso llamado invasión (Darwin \& Miller, 1999).

Maciel et al. (2012) mostraron que la administración oral de Salmonella entérica serovar Enteritidis a ratones provoca alteraciones en las microvellosidades del intestino delgado de distintos grados de degeneración, y crecimiento bacteriano en el ciego luego de 2-3 semanas de la administración de Salmonella.

Probióticos frente a la acción de Salmonella Enteritidis.

Las bacterias probióticas, principalmente bacterias lácticas y bifidobacterias, producen un efecto positivo sobre la inmunomodulación y actúan eficazmente en la prevención de diversos desórdenes gastrointestinales (Fooks \& Gibson, 2002; Perdigon et al. 2002; Servin \& Cocconier, 2003). Las bacterias de género Lactobacillus spp. tienen la capacidad de interferir en la adhesión de Salmonella y otros patógenos intestinales a las células de epitelio intestinal. Existen numerosos trabajos, donde se demuestra este papel protector, tanto sobre células en cultivo como in vivo. Lactobacillus acidophilus LB y Lactobacillus johnsonii La1 junto con su sobrenadante de cultivo demostraron inhibir la adhesión de E. coli enterotoxigenica, S. enterica serovar Typhimurium, Yersinia pseudotuberculosis y Listeria monocytogenes (ETEC) a células Caco-2, de manera dosisdependiente (Coconnier et al. 1993; Bernet-Camard et al. 1997; Hudault et al. 1997). Lee et al. (2002) demostraron que L. casei rhamnosus GG y L. casei Shirota fueron capaces de competir con E. coli y Salmonella spp por la unión a células Caco-2 a través de un impedimento estérico, y el grado de inhibición estuvo relacionado con la distribución de los receptores a los que se unen los lactobacilos sobre las células Caco-2. Dos lactobacilos aislados de intestino de pollo, L. acidophilus y L. fermentum, fueron capaces de excluir por competición a S. pullorum y S. enterica serovar Typhimurium en cultivo de células intestinales, aunque no ocurrió lo mismo cuando las células fueron infectadas con S. enterica serovar Enteritidis (Jin et al. 1996). En estudios sobre células HT-29, Casey et al. (2004) observaron que las cepas aisladas de intestino de porcinos 
Selección de microorganismos probióticos.

pertenecientes a las especies Lactobacillus salivarius subsp. salivarius DPC6005 y L. murinus DPC6002 y DPC6003, redujeron un 78 \% la invasión de Salmonella. Santos et al. (2003) demostraron que dos cepas aisladas de kefir, L. acidophilus CYC 10051 y L. kefiranofaciens CYC 10058, fueron capaces de adherir a células Caco-2, presentaron resistencia a $\mathrm{pH}$ ácidos y ácidos biliares y fueron capaces de inhibir la adhesión de $S$. enterica serovar Typhimurium a células Caco-2.

Reid \& Burton (2002) señalan que mas allá de que los estudios de actividad antagónica de lactobacilos y bifididobacterias probióticas sobre células intestinales en cultivo son un buen modelo y sirven para simular las condiciones in vivo, es difícil extrapolar los resultados in vitro al proceso que se produce en el sistema digestivo in vivo. Además, la flora residente, la presencia de mucus y el continuo movimiento peristáltico podrían modificar la adhesión de las bacterias exógenas.

Los modelos animales podrían reflejar más acertadamente el comportamiento de las bacterias probióticas. El modelo in vivo más comúnmente usado para estudiar la protección de bacterias probióticas contra la infección por Salmonella es el ratón. L. johnsonii La1 (Bernet-Camard et al. 1997) y Lactobacillus GG (Hudault et al. 1997) administrado a ratones gnotobióticos (con flora microbiana conocida), demostraron tener actividad antibacteriana contra la infección con S. enterica serovar Typhimurium C5, aumentando la supervivencia de los ratones. L. rhamnosus HNO01 ha demostrado aumentar la respuesta inmune y proteger a ratones BALB/C frente a la infección con $S$. entérica serovar Typhimurium 1772 (Gill et al. 2001). También el sobrenadante de cultivo de la cepa L. acidophilus LB administrado diariamente a ratones infectados con Salmonella demostró reducir los niveles de Salmonella viable en las heces (Coconnier et al. 1997). Das et al. (2013) evaluaron la eficacia de L. plantarum KSBT 56, (aislado a partir de un producto alimenticio tradicional de la India), en la prevención de Salmonella entérica serovar Enteritidis y su patogenicidad in vitro. Observaron que inhibe el crecimiento, la invasión y la capacidad de formación de biofilm de Salmonella Enteritidis sin inhibir el crecimiento de otras cepas de Lactobacillus. En los estudios realizados en ratones hay que considerar que la patología que provoca Salmonella difiere marcadamente de lo que ocurre en el humano por lo que algunos trabajos han 
propuesto algunas modificaciones, por ejemplo, tratamiento con estreptomicina previo a la infección, para favorecer que se desencadene la enfermedad (Barthel et al. 2003). 
Selección de microorganismos probióticos. 
El objetivo del siguiente capítulo es la selección de microorganismos aislados de kefir con potencialidad probiótica.

Para cumplir dicho objetivo se plantearon los siguientes objetivos específicos:

- Caracterizar la superficie de microorganismos aislados de kefir mediante diferentes aproximaciones experimentales que van desde hidrofobicidad superficial hasta adhesión a células intestinales in vitro.

- Evaluar la resistencia al pasaje por el tracto gastrointestinal (TGI).

- Estudiar el efecto de los sobrenadantes de lactobacilos aislados de kefir sobre la viabilidad de Salmonella entérica serovar Enteritidis y en el proceso de asociación e invasión del patógeno.

- Estudiar la interacción patógeno-lactobacilo y su efecto en el proceso de adhesión e invasión en células Caco-2/TC-7. 
Selección de microorganismos probióticos. 


\section{Microorganismos y condiciones de cultivo}

Se estudiaron 13 lactobacilos aislados de gránulos de kefir pertenecientes a la colección del CIDCA (Hamet et al. 2013) y una cepa de colección:

-L. sp.: CIDCA 8383, CIDCA 8384.

-L. kefiri: CIDCA 8381, CIDCA 83101, CIDCA 83102.

-L. paracasei: CIDCA 8339, CIDCA 83120, CIDCA 83121, CIDCA 83123, CIDCA 83124.

-L. kefiranofaciens: CIDCA 8371, CIDCA 83118, CIDCA 83119, JCM 6985 (JCM Japan Collection of Microorganisms, Institute of Physical and Chemical Research, Japan).

En todos los experimentos, se procedió a realizar un primer repique de cada microorganismo a partir del cepario a $-80{ }^{\circ} \mathrm{C}$ en caldo De Man-Rogosa-Sharpe (MRS) (Biokar Diagnostics, Beauvais, France) y a partir de ese primer repique se realizó un segundo repique de trabajo. La pureza de los cultivos se verificó por coloración de Gram y características de las colonias en agar MRS.

Los cultivos de Lactobacillus paracasei y Lactobacillus kefiri CIDCA 83102 se realizaron en caldo MRS a $30{ }^{\circ} \mathrm{C}$ en aerobiosis durante 48 horas y 72 horas, respectivamente. Para la obtención de las suspensiones, los microorganismos se centrifugaron a $10.000 \mathrm{~g}$ durante 10 minutos, se lavaron 2 veces en buffer fosfato $\mathrm{pH} 7$ (Apéndice), y se resuspendieron en el mismo buffer.

\section{Resistencia a la bilis por método ecométrico}

Para estudiar el desarrollo de los lactobacilos en presencia de bilis se utilizó el método ecométrico (Kociubinski et al. 1999). De un cultivo abundante de microorganismos en caldo MRS se tomó una ansada y se realizaron cinco estrías en forma consecutiva (Figura 5) sin cargar nuevamente el ansa de manera tal de depositar 
Selección de microorganismos probióticos.

la totalidad del inóculo, quedando en la última estría una pequeña cantidad de bacterias. Este procedimiento es equivalente a la siembra en tubos con diferentes diluciones, de modo que el desarrollo bacteriano en la dilución más grande evidencia la tolerancia real del microorganismo a la presencia de bilis.

La siembra se realizó sobre una placa de Petri conteniendo $9 \mathrm{ml}$ de agar MRS adicionado de $1 \mathrm{ml}$ de solución de bilis de buey al $5 \%(\mathrm{p} / \mathrm{v})$ esterilizada por filtración. En forma paralela, se realizó un control de crecimiento de la cepa en placas con agar MRS. Se incubó a $30{ }^{\circ} \mathrm{C}$ durante $48-72$ horas.

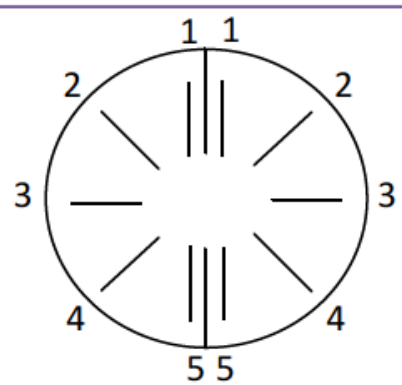

Figura 5. Método ecométrico, modo de siembra.

Para el análisis de los resultados se comparó el crecimiento en el medio sin bilis (control) y el crecimiento en presencia de bilis. Se asignó un valor de 1 al crecimiento en la primera estría, de 2 en la segunda, 3 en la tercera, 4 en la cuarta, y 5 en la quinta estría. Luego se sumaron los valores obtenidos, siendo 15 el valor máximo que indica un alto grado de resistencia a la bilis. En caso que exista en una estría con menos crecimiento que en el control sin bilis, se le asigna un valor igual a la mitad del valor correspondiente para un buen crecimiento en dicha estría. En forma paralela, como control del experimento, se ensayaron cepas de microorganismos cuya resistencia a la bilis de buey es conocida. Aquellas cepas cuyo valor fue de 0 - 5 se les asignó (+), de $5-10(++)$ y de $10-15(+++)$.

\section{Hidrofobicidad superficial}


A los efectos de caracterizar los microorganismos de kefir en cuanto a sus propiedades superficiales se comenzó a evaluar su hidrofobicidad superficial. El método seleccionado en este trabajo es el denominado MATH (Microbial Adhesion to Hexadecan) y está basado en la tendencia de ciertos microorganismos de interactuar con hidrocarburos líquidos, luego de un breve período de contacto (Ofek \& Doyle, 1994). Se utilizó n-hexadecano (J. T. Baker, Mallinckrofdt Inc.). Para las determinaciones se utilizaron tubos de vidrio lavados con solución sulfocrómica para eliminar cualquier sustancia que pudiera interferir con el resultado.

Una suspensión de lactobacilos en fase estacionaria se ajustó a $\mathrm{DO}_{600}=1$ en un espectrofotómetro Spectronic 20D+ (Spectronic Instruments, U.S.). Se tomaron $2 \mathrm{ml}$ de la suspensión $\left(\mathrm{DO}_{600}=1\right)$ y se le agregaron $0,5 \mathrm{ml}$ de $\mathrm{n}$-hexadecano. Se procedió a la medición de la densidad óptica inicial de la fase acuosa $\left(\mathrm{DO}_{\mathrm{i}}\right)$ y luego se agitó en vortex por 120 segundos a máxima velocidad. Se esperó 10 - 15 minutos para permitir la separación de las fases y se midió nuevamente la densidad óptica $\left(\mathrm{DO}_{\mathrm{f}}\right)$ de la fase acuosa a $600 \mathrm{~nm}$. Se utilizó como blanco $2 \mathrm{ml}$ de buffer fosfato con $0,5 \mathrm{ml}$ de $\mathrm{n}$-hexadecano. La temperatura durante los ensayos se mantuvo entre los 22 y los $24{ }^{\circ} \mathrm{C}$ y se determinó el porcentaje de hidrofobicidad:

$$
\% H=\left[\left(D O_{i}-D O_{f}\right) / D O_{i}\right] \times 100
$$

donde $\mathrm{DO}_{\mathrm{i}}$ y $\mathrm{DO}_{\mathrm{f}}$ son la densidad óptica inicial y final de la fase acuosa después de la extracción con n-hexadecano, respectivamente.

\section{Autoagregación}

Se prepararon suspensiones de microorganismo de $\mathrm{DO}_{600}=1$ en buffer fosfato $\mathrm{pH}$ 7. Se colocaron $2 \mathrm{ml}$ de la suspensión bacteriana en cubetas de vidrio cilíndricas, se agitó rápidamente y se introdujo la cubeta en el espectrofotómetro Spectronic 20D+ (Spectronic Instruments, U.S.) manteniendo las cubetas dentro del espectrofotómetro sin agitar la suspensión. Las medidas se realizaron a temperatura ambiente entre 22 y $24{ }^{\circ} \mathrm{C}$. Inmediatamente se tomó la densidad óptica inicial y luego se midió la disminución 
Selección de microorganismos probióticos.

de la turbidez de las suspensiones durante 24 horas. Los resultados se expresaron como cinética de coagregación en función del tiempo.

\section{Resistencia al pasaje gastrointestinal in vitro}

Para la evaluación de la resistencia de lactobacilos a las condiciones gastrointestinales, se utilizó el protocolo descripto por Grimoud et al. (2010). Se prepararon suspensiones de $10^{8} \mathrm{UFC} / \mathrm{ml}$ de lactobacilos en una solución gástrica simulada ( $\mathrm{NaCl} 125 \mathrm{mM}, \mathrm{KCl} 7 \mathrm{mM}, \mathrm{NaHCO}_{3} 45 \mathrm{mM}$, pepsina porcina $3 \mathrm{~g} / \mathrm{l}$ (P7125 SigmaAldrich, Inc., St. Louis, MO, USA) ajustando el pH final a 2,5) y se incubaron 90 minutos, a $200 \mathrm{rpm}$ y $37{ }^{\circ} \mathrm{C}$ con agitación. Los microorganismos se lavaron con PBS $\left(\mathrm{KH}_{2} \mathrm{PO}_{4}\right.$ 0,144 $\mathrm{g} / \mathrm{l}, \mathrm{NaCl} 9 \mathrm{~g} / \mathrm{l}, \mathrm{Na}_{2} \mathrm{HPO}_{4}$ 0,795 g/l, pH 7,2), los pellets se resuspendieron en una solución intestinal simulada $\left(\mathrm{NaCl} 22 \mathrm{mM}, \mathrm{KCl} 3,2 \mathrm{mM}, \mathrm{NaHCO}_{3}\right.$ 7,6 mM, pancreatina porcina 0,1 $\%(p / v)$ (P1625 Sigma-Aldrich, Inc., St. Louis, MO, USA), sales biliares 0,15 \% (p/v) (48305 Sigma-Aldrich, Inc., St. Louis, MO, USA) ajustando el pH final a 8 y se incubaron 180 minutos a $37{ }^{\circ} \mathrm{C}$ con agitación (200 rpm). Se realizaron diluciones seriadas en triptona $0,1 \%(p / v)$ y se realizó el recuento de microorganismos viables en agar MRS. Las placas fueron incubadas a $30{ }^{\circ} \mathrm{C}$ en aerobiosis durante 48 horas. Los resultados se presentaron como el número de microorganismos que resistieron el proceso. Los ensayos se realizaron al menos tres veces, con cuadriplicados intra-ensayo.

\section{Adhesión bacteriana a epitelio intestinal in vitro}

Se estudió la adhesión de lactobacilos al epitelio intestinal utilizando dos modelos: adhesión a mucina y adhesión a células Caco-2/TC-7. Se analizó la adhesión a partir de cultivos en fase estacionaria y de los microorganismos luego de la simulación por el pasaje del tracto gastrointestinal.

Adhesión a células Caco-2/TC-7. 
Se estudió la adhesión de lactobacilos aislados de kefir a monocapas de células intestinales in vitro. Se utilizaron células de la línea Caco-2/TC-7 cultivadas como se indica en el Apéndice.

Para los ensayos de adhesión de bacterias lácticas, las monocapas fueron lavadas con PBS a temperatura ambiente. A cada fosa se le agregó $500 \mu \mathrm{l}$ de suspensión bacteriana previamente lavada con PBS llevada $a \mathrm{DO}_{600}=1$ de un cultivo en fase estacionaria (1-5.10 $\mathrm{UFC} / \mathrm{ml}$ ), resuspendida en DMEM de adhesión (Apéndice) a esta concentración no se observa saturación en la curva de adhesión bacteriana (datos no mostrados). Las placas fueron incubadas a $37^{\circ} \mathrm{C}$ durante 1 hora en atmósfera controlada ( $5 \% \mathrm{CO}_{2}-95 \%$ aire) sin agitación. Luego fueron lavadas 3 veces con PBS para remover las bacterias no adheridas. A cada fosa se le colocó $500 \mu \mathrm{l}$ de agua bidestilada estéril y se dejó 1 hora a $37^{\circ} \mathrm{C}$ para permitir la lisis y desprendimiento de la monocapa. Se tomó todo el volumen de la fosa, se realizaron diluciones seriadas en triptona $0,1 \%(p / v)$ y se realizó el recuento de microorganismos viables en agar MRS. Las placas fueron incubadas a $30^{\circ} \mathrm{C}$ en aerobiosis durante 48 horas y las bacterias adheridas se expresaron como UFC/ml. Los resultados son la media de al menos tres ensayos independientes en tres pasajes consecutivos.

\section{Adhesión a mucina in vitro.}

Los ensayos se realizaron según lo descripto por Tallon et al. (2007). Se sensibilizaron placas de 96 fosas (Maxisorp Nunc, Roskilde, Denmark) con una solución de mucina gástrica porcina tipo III parcialmente purificada (Sigma-Aldrich, USA) en PBS a una concentración final de $10 \mathrm{mg} / \mathrm{ml}$, toda la noche a $4{ }^{\circ} \mathrm{C}$. Luego, se adicionó a cada fosa $100 \mu \mathrm{l}$ de suspensión bacteriana en PBS llevada a $\mathrm{DO}_{600}=1$ (1-5.10 $\left.{ }^{8} \mathrm{UFC} / \mathrm{fosa}\right)$, incubándose durante 1 hora a $37^{\circ} \mathrm{C}$. Finalmente, las fosas se lavaron exhaustivamente con PBS para eliminar los microorganismos no adheridos, se removieron las bacterias adheridas con una solución $0,5 \%(v / v)$ de Tritón X-100 y se cuantificaron mediante recuento en placa. Los resultados son la media de al menos tres ensayos independientes, cada uno de los cuales contó con 4 replicados intra-ensayo. 
Digestión proteolítica de las proteínas y obtención del mapa peptídico mediante Espectrometría de Masa (MS) MALDI-TOF

Electroforesis Bidimensional (2D).

L. paracasei CIDCA 83123 antes y después de ser sometida a la soluciones que simulan el pasaje por el tracto gastrointestinal fueron resuspendidas en $400 \mu \mathrm{l}$ de Tris- $\mathrm{HCl} 30 \mathrm{mM}$ a pH 8,0 conteniendo urea $7 \mathrm{M}$, tiourea $2 \mathrm{M}$, 3-[(3-cholamidopropyl)dimethylammonio]-1-propanesulfonate (CHAPS) $4 \%$ (p/v) y amidosulfobetaine-14 (ASB14) $2 \%$ (p/v). Las suspensiones bacterianas fueron sonicadas durante 1 minuto con pulsos cada 0,5 segundos y luego centrifugadas a $16.000 \mathrm{~g}$ por 5 minutos. Los sobrenadantes fueron tratados con 2D Clean-up kit (GE Healthcare, USA), y las proteínas que resultaron precipitadas fueron resuspendidas en $100 \mathrm{ml}$ de Tris- $\mathrm{HCl} 30$ $\mathrm{mM}$ a pH 8,5 con urea 8M, CHAPS 2,5\% (p/v) y ASB14 $2 \%(\mathrm{p} / \mathrm{v})$. La primer dimensión (isoelectroenfoque) fue corrida en el equipo Ettan ${ }^{\mathrm{TM}}$ IPGphor 3, usando una gama de anfolitos de 3-10 (tiempo: 8 hs, voltaje total: 16525 volts). Luego de la primera corrida, fueron tratados con $10 \mathrm{mg} / \mathrm{ml}$ Ditiotreitol (DTT) para reducir los grupos disulfuro, y luego tratados con $25 \mathrm{mg} / \mathrm{ml}$ de iodoacetamida con el fin de alquilar los grupos sulfhidrilos libres. La segunda dimensión (SDS-PAGE) fue realizada en geles de poliacrilamida al 12 \% usando un equipo BioRad Mini-Protean IV (BioRad Laboratories, Richmond, CA, USA) según Laemmli (1970). Como referencia de peso molecular se usó Bench Mark Protein Ladder (GE Healthcare). Los geles se revelaron usando la tinción Colloidal Blue, y luego se seleccionaron los spots que fueron removidos usando un bisturí y se cortaron en piezas de $1 \mathrm{~mm}^{3}$.

Digestión de las proteínas. 
Para obtener la huella peptídica (peptide mass fingerprint) mediante espectrometría de masa MALDI-TOF se realizó una digestión tríptica in situ de los polipéptidos separados mediante SDS-PAGE, siguiendo el protocolo detallado a continuación:

- Las muestras conteniendo los polipéptidos a ser digeridos se sometieron a SDSPAGE y se colorearon con la tinción de Coomasie. Las bandas seleccionadas se separaron con bisturí, se cortaron en cubos de aproximadamente $1 \mathrm{~mm}$ de lado y éstos se transfirieron a un tubo eppendorf.

- Se lavaron durante 5 minutos con 100-150 ml de agua MilliQ, se centrifugaron y se retiró el líquido.

- Se agregó un volumen de acetonitrilo equivalente a 3 o 4 veces el volumen que ocupaban los trozos de gel y se incubó durante 10-15 minutos. Luego se centrifugó, se retiró el líquido y se secó en vacío.

- Para decolorar completamente los trozos de gel se rehidrataron con 100-150 $\mu$ l de $\mathrm{NH}_{4} \mathrm{HCO}_{3} 25 \mathrm{mM} /$ Acetonitrilo (ACN) $5 \%(\mathrm{p} / \mathrm{v})(\mathrm{pH}$ 9), con agitación durante 20 min. Luego se lavó con $100 \mu \mathrm{l}$ de $\mathrm{NH}_{4} \mathrm{HCO}_{3} 25 \mathrm{mM} / \mathrm{ACN} 50$ \% (p/v) (pH 9) y finalmente con $100 \mu \mathrm{l}$ de ACN.

- Las proteínas se trataron con $100 \mu \mathrm{l}$ de ditiotreitol $10 \mathrm{mM}$ en $\mathrm{NH}_{4} \mathrm{HCO}_{3} 25 \mathrm{mM}$ / ACN $5 \%(p / v)$ durante 1 hora a temperatura ambiente, y luego los sulfhidrilos de las cisteínas fueron alquilados mediante el tratamiento con iodoacetamida $50 \mathrm{mM}$ en $\mathrm{NH}_{4} \mathrm{HCO}_{3} 25 \mathrm{mM} / \mathrm{ACN} 5 \%(\mathrm{p} / \mathrm{v})$ durante 1 hora a $37^{\circ} \mathrm{C}$.

- Finalmente se realizó otro lavado y se secó al vacío.

Para la digestión enzimática de las proteínas, a las piezas de gel se les agregó tripsina (Promega Trypsin Gold, TPCK treated) en $\mathrm{NH}_{4} \mathrm{HCO}_{3} 25 \mathrm{mM} / \mathrm{ACN} 5$ \% (p/v), en una relación aproximada de 1:20 tripsina a proteína. La reacción enzimática se mantuvo durante $3 \mathrm{~h}$ a $37^{\circ} \mathrm{C}$, y luego se centrifugó, reservando el sobrenadante en un tubo.

Los péptidos se extrajeron de los trozos de gel mediante tres incubaciones sucesivas con $100 \mu \mathrm{l}$ de ácido trifluoroacético (TFA) $0,2 \%(\mathrm{p} / \mathrm{v})$, y finalmente una incubación con $15 \mu$ l de ACN $50 \%$ (p/v) y TFA 0,1\% (p/v).

Luego de cada incubación se realizó una centrifugación y todos los sobrenadantes se reunieron en un tubo. Los sobrenadantes colectados se secaron en 
Selección de microorganismos probióticos.

SpeedVac y luego los péptidos se resuspendieron en $5 \mu \mathrm{l}$ ACN 50 \% / TFA 0,1 \% para analizarlos por MALDI-TOF MS.

Todos los reactivos utilizados fueron provistos por Sigma-Aldrich.

\section{Espectrometría de Masa (MALDI-TOF).}

Se utilizó MALDI-TOF MS (Matrix-assisted laser desorption ionization time-offlight mass spectrometry) para determinar las identidades de las proteínas. La labor experimental se realizó en colaboración con el Dr. Sebastián Trejo y el Dr. Francesc Xavier Avilés Puigvert, en el laboratorio de Ingeniería de Proteínas y Enzimología del Instituto de Biotecnología y Biomedicina (IBB) de la Universidad Autónoma de Barcelona, España.

El análisis se llevó a cabo en un espectrómetro de masas MALDI-TOF Bruker modelo UltraFlex TOFTOF (Bruker Daltonics, Billerica, MA) equipado con un láser de $\mathrm{N}_{2}$ (337 nm con pulsos de 1-5 ns) y una fuente de aceleración de iones de $25 \mathrm{kV}$. En un tubo se mezcló $0,5 \mu \mathrm{l}$ de cada muestra con $1 \mathrm{ml}$ de solución de matriz (ácido $\alpha$-ciano-4hidroxicinámico $10 \mathrm{mg} / \mathrm{ml}$ en una solución acuosa de acetonitrilo $30 \%$ (p/v) y ácido trifluoroacético $0,1 \%(\mathrm{p} / \mathrm{v}))$. Se depositó 0,5 a $1 \mathrm{ml}$ de la mezcla sobre una placa GroundSteel (Bruker Daltonics) y se dejó cristalizar. Para la calibración externa se utilizó una mezcla de patrones Bruker Daltonik $\mathrm{GmbH}$. Las masas peptídicas fueron adquiridas dentro del rango de $\mathrm{m} / \mathrm{z} 800$ a 4000 .

Parámetros de búsqueda en bases de datos.

Luego de la calibración externa e interna de los espectros se generaron listas de péptidos monoisotópicos con una sola carga que se utilizaron como valores de entrada para la búsqueda en bases de datos usando el programa flexAnalysis (Bruker Daltonics). Las búsquedas se llevaron a cabo en las bases de datos MSDB y NCBInr, usando la herramienta de búsqueda MASCOT PMF (www.matrixscience.com). Se incluyeron como posibles modificaciones la oxidación de metionina y la alquilación de cisteínas, se consideraron hasta dos cortes trípticos no realizados y se fijó en 100 ppm la tolerancia 
para la masa de los péptidos monoisotópicos. Se realizaron asignaciones de picos de manera interactiva utilizando el programa BioTools (Bruker Daltonics).

\section{Interacción con Salmonella entérica serovar Enteritidis}

Condiciones de cultivo de Salmonella entérica serovar Enteritidis.

Salmonella entérica serovar Enteritidis CIDCA 101 aislada de una muestra clínica del Hospital de Pediatría Prof. Juan P. Garrahan, Buenos Aires, Argentina, fue provista por el Dr. H. Lopardo. La cepa se conservó a $-80^{\circ} \mathrm{C}$, se reactivó en caldo nutritivo y luego se sembró en agar nutritivo inclinado (que se mantuvo a $4{ }^{\circ} \mathrm{C}$ ). Para todos los ensayos, se tomó una ansada del agar inclinado y se creció en caldo nutritivo a $37{ }^{\circ} \mathrm{C}$ durante 18 horas.

Ensayo de asociación e invasión de Salmonella a células Caco-2/TC-7.

Para determinar la capacidad de asociación e invasión de la cepa de Salmonella enterica serovar Enteritidis las células de la línea Caco-2/TC-7 se incubaron 7 días en placas de 24 fosas. Las monocapas fueron lavadas 2 veces con PBS a temperatura ambiente. Se centrifugó un cultivo de Salmonella a $5.000 \mathrm{~g}$ durante 5 minutos y se resuspendió en DMEM de adhesión (Apéndice). A cada fosa se le agregó $500 \mu \mathrm{l}$ de suspensión de Salmonella (aproximadamente $1.10^{8} \mathrm{UFC} / \mathrm{ml}$ ). Las placas se incubaron durante 1 hora a $37{ }^{\circ} \mathrm{C}$ en atmósfera controlada $\left(5 \% \mathrm{CO}_{2}-95 \%\right.$ aire) sin agitación y luego se lavaron 3 veces con PBS para eliminar las bacterias no asociadas. Para cuantificar la asociación (bacterias adheridas + internalizadas), a cada fosa se le agregó $500 \mu \mathrm{l}$ de agua bidestilada estéril y se incubó 1 hora a $37^{\circ} \mathrm{C}$. Esto permitió desprender la monocapa. Luego, se tomó todo el volumen de la fosa, se realizaron diluciones en triptona $0,1 \%(p / v)$ y se sembraron en agar nutritivo.

Para diferenciar las bacterias asociadas de las internalizadas se utilizó gentamicina como antibiótico. La gentamicina no difunde a través del dominio apical de 
Selección de microorganismos probióticos.

las células; las bacterias que no internalizan son afectadas por el antibiótico y las que están internalizadas sobreviven. La concentración de gentamicina utilizada fue de $100 \mu \mathrm{g} / \mathrm{ml}$ en PBS, teniendo como stock solución 100 X (100 mg/ml) (Golowzcyc et al. 2007). Para ello se colocó a cada fosa $0,5 \mathrm{ml}$ de gentamicina ( $100 \mu \mathrm{g} / \mathrm{ml}$ PBS) y se incubó durante 1 hora a $37^{\circ} \mathrm{C}$. Luego de la incubación, la monocapa fue lavada 3 veces con PBS para eliminar el antibiótico y se agregaron $500 \mu \mathrm{l}$ de agua bidestilada estéril (1 hora a $37^{\circ} \mathrm{C}$ ) para lisar la monocapa y permitir que las bacterias internalizadas se liberen. Se realizaron diluciones apropiadas en triptona $0,1 \%(p / v)$ y el recuento en placas de agar nutritivo. Los resultados se expresaron como UFC/ml.

Obtención de sobrenadantes libres de células y las suspensiones de lactobacilos.

Los cultivos de L. kefiri y L. paracasei incubados en las condiciones descriptas en el presente capítulo fueron centrifugados a 10.000 g durante 15 minutos. Para obtener los sobrenadantes libres de células, éstos fueron filtrados a través de una membrana de celulosa con un diámetro de poro de 0,45 $\mu \mathrm{m}$ (Millipore Corporation, Milford, MA 01757, USA). El pH de estos sobrenadantes se determinó con un microelectrodo combinado de vidrio (Cole-Parmer).

Los pellet de cada bacteria fueron resuspendidos en PBS y se ajustaron a la concentración requerida en cada ensayo, siendo la misma de $10^{8} \mathrm{UFC} / \mathrm{ml}$.

Determinación de la concentración de ácidos orgánicos.

La concentración de ácidos orgánicos en los sobrenadantes se determinó por cromatografía líquida de alta presión (HPLC) según el método descripto por Lombardi et al. (1994). La separación de los ácidos se llevó a cabo en una columna de intercambio iónico AMINEX HPX- 87H (Biorad Labs) equipado con un detector UV a 214 nm (Waters TM 996, Millipore Corporation, Milford, MA 01757, USA). La identificación se basó en la comparación de los tiempos de retención de los ácidos de las muestras con soluciones standard de ácido láctico y ácido acético (Sigma Chemical Co., St. Louis, MO, USA). Los sobrenadantes se filtraron a través de una membrana de 0,45 $\mu \mathrm{m}$ (Millipore 
Corporation) y se inyectó en el cromatógrafo un volumen de $10 \mu \mathrm{l}$. La determinación se llevó a cabo a una velocidad de flujo de $0,7 \mathrm{ml} /$ minuto a $60{ }^{\circ} \mathrm{C}$ utilizando $\mathrm{H}_{2} \mathrm{SO}_{4} 0,009 \mathrm{~N}$ como fase móvil. Los solventes fueron desgaseados previamente bajo vacío. Se realizaron curvas de calibración con ácido láctico y ácido acético mediante las cuales se calcularon las concentraciones de dichos ácidos en las muestras.

Determinación de la concentración de ácido láctico no disociado.

Para el cálculo de la concentración de ácido láctico no disociado ([LH]) se tuvo en cuenta que la reacción de disociación del ácido es,

$\mathrm{LH}<->\mathrm{L}^{-}+\mathrm{H}^{+}$

Con una constante de equilibrio

$\mathrm{K}_{\mathrm{eq}}=\left[\mathrm{L}^{-}\right]\left[\mathrm{H}^{+}\right] /[\mathrm{LH}]$

La concentración de ácido láctico total está dada por la suma del ácido disociado ([L]]) y el no disociado ([LH])

$\mathrm{C}_{\text {ácido }}=[\mathrm{LH}]+\left[\mathrm{L}^{-}\right]$

A partir de lo anterior se puede expresar la $\mathrm{K}_{\text {eq }}$ como

$\mathrm{K}_{\text {eq }}=\left(\mathrm{C}_{\text {ácido }}-[\mathrm{LH}]\right)\left[\mathrm{H}^{+}\right] /[\mathrm{LH}]$

Considerando que $\mathrm{pH}=-\log \left[\mathrm{H}^{+}\right]$y que el $\mathrm{pK}=-\log \mathrm{K}_{\text {eq }}=3,86$ (para el ácido láctico), el cálculo de la concentración de ácido láctico no disociado se realizó con la siguiente expresión:

$[\mathrm{LH}]=\mathrm{C}_{\text {ácido }} / 1+10^{(\mathrm{pH}-\mathrm{pK})}$

Coagregación de Lactobacilos con Salmonella entérica serovar Enteritidis.

Las suspensiones de bacterias lácticas se ajustaron a $\mathrm{DO}_{600}=1$, se tomó $1 \mathrm{ml}$ y se la mezcló en una cubeta cilíndrica con $1 \mathrm{ml}$ de suspensión de Salmonella enterica 
Selección de microorganismos probióticos.

serovar Enteritidis. Luego de mezclados 10 segundos por vortex, la cubeta con la mezcla se introdujo en el espectrofotómetro, se tomó el valor de $\mathrm{DO}_{\text {inicial }}$ y se midió la $\mathrm{DO}_{\mathrm{t}}$ cada 15 minutos por un total de 8 horas y se graficó la cinética de coagregación.

Asociación e invasión de Salmonella Enteritidis a células Caco-2/TC-7 previa incubación de Salmonella con lactobacilos.

Se prepararon suspensiones de lactobacilos (en una concentración de aproximadamente $1.10^{8} \mathrm{UFC} / \mathrm{ml}$ ) y de Salmonella de $1.10^{6} \mathrm{UFC} / \mathrm{ml}$ aproximadamente. Se preincubó $200 \mu \mathrm{l}$ de la suspensión de lactobacilos con $200 \mu \mathrm{l}$ de la suspensión de Salmonella durante 1 hora a $37^{\circ} \mathrm{C}$ y luego, fueron adicionados a la placa de Caco-2/TC-7 junto con $400 \mu \mathrm{l}$ de DMEM de adhesión. Se incubaron las placas durante 1 hora a $37^{\circ} \mathrm{C}$ en atmósfera controlada ( $5 \% \mathrm{CO}_{2}-95 \%$ aire) sin agitación. Luego de lavar las fosas 3 veces con PBS, se cuantificó Salmonella asociada e internalizada. Como control, $200 \mu \mathrm{l}$ de suspensión de Salmonella se preincubó con $200 \mu \mathrm{l}$ de PBS sin lactobacilos a $37^{\circ} \mathrm{C}$ y se procedió de la misma forma.

Asociación e invasión de Salmonella Enteritidis a células Caco-2/TC-7 previa incubación de la monocapa con lactobacilos.

Se utilizaron placas de 24 fosas con células Caco-2/TC-7. Las fosas se lavaron 3 veces con PBS para eliminar el medio de cultivo. A cada fosa se le agregó $500 \mu \mathrm{l}$ de una suspensión de lactobacilos previamente lavada y resuspendida en DMEM de adhesión (Apéndice). La concentración de lactobacilo agregada a la fosa fue de $1.10^{8} \mathrm{UFC} / \mathrm{ml}$. Las placas se incubaron 1 hora a $37{ }^{\circ} \mathrm{C}$ en atmósfera controlada $\left(5 \% \mathrm{CO}_{2}-95 \%\right.$ aire) sin agitación. Luego, se lavaron 3 veces para eliminar los lactobacilos no adheridos. A las fosas preincubadas con los lactobacilos se agregó $500 \mu \mathrm{l}$ de una suspensión de Salmonella en DMEM de adhesión y se incubó nuevamente durante 1 hora a $37{ }^{\circ} \mathrm{C}$ en atmosfera controlada (5\% $\mathrm{CO}_{2}-95 \%$ aire). La concentración de Salmonella agregada a la fosa fue de $1.10^{6} \mathrm{UFC} / \mathrm{ml}$. Luego de la incubación, se determinó el número de bacterias asociadas e internalizadas y se analizó el citoesqueleto mediante tinción con 
faloidina marcada con isotiocianato de fluoresceína (FITC). Se realizó un control de la asociación e invasión de Salmonella. Para ello, 4 fosas ( 2 para evaluar asociación y 2 para evaluar invasión) fueron preincubadas con DMEM de adhesión sin lactobacilos antes de adicionar la suspensión de Salmonella.

\section{Marcación fluorescente del citoesqueleto con faloidina.}

Las células Caco-2/TC-7 se sembraron en placas de 24 fosas sobre portaobjetos de vidrio (Assistent, Alemania). Estos vidrios fueron previamente lavados con agua y detergente no iónico (Extran MAO2 neutro, Merck, Darmstadt, Alemania) y luego de un enjuague exhaustivo con agua destilada, se colocaron en cajas de Petri y se esterilizaron en autoclave. Se realizaron ensayos de infección con Salmonella Enteritidis CIDCA 101 sin tratar y luego de tratar la célula epitelial con lactobacilos tal como se describió en el ítem anterior.

Las muestras se lavaron 3 veces con PBS y se fijaron durante 2 min con paraformaldehído $3 \%(\mathrm{p} / \mathrm{v})$ en PBS y se trataron durante 10 minutos con $\mathrm{NH}_{4} \mathrm{Cl} 50 \mathrm{mM}$ para bloquear las funciones aldehído libres. Luego fueron permeabilizadas mediante tratamiento durante $4 \mathrm{~min}$ con 0,2 \% (p/v) de Tritón X -100 (Sigma Chemical Co., St. Louis, Mo.), se agregó PBS y se incubó durante $10 \mathrm{~min}$. Las células lavadas dos veces con PBS fueron tratadas durante 10 minutos con $0,2 \%(p / v)$ de gelatina en PBS. Se extrajo completamente el buffer y se agregaron a cada fosa $20 \mu \mathrm{l}$ de faloidina fluorescente (Sigma Chemical, St. Louis, USA) en concentración 0,5 $\mathrm{gg} / \mathrm{ml}$ en PBS-gelatina. Las células se incubaron a temperatura ambiente durante 45 min en cámara húmeda y al abrigo de la luz. Luego fueron lavadas 3 veces con PBS e incubadas durante 10 minutos en PBS-gelatina. Los vidrios fueron retirados de las fosas, escurridos y montados invertidos sobre $7 \mu \mathrm{l}$ de glicerol $50 \%(p / v)$ en PBS con 0,1 \% (p/v) de azida de sodio. Las muestras fueron conservadas en oscuridad hasta su observación en un microscopio invertido de fluorescencia Nikon TI-Eclipse en combinación con un software de procesamiento de imágenes NIS-elements.

Cinética de muerte de Salmonella Enteritidis en sobrenadantes de cultivo de lactobacilos aislados de kefir. 
Un cultivo de Salmonella de 18 horas en caldo nutritivo a $37{ }^{\circ} \mathrm{C}$ se centrifugó durante 4 minutos a $5.000 \mathrm{~g}$. El pellet se resuspendió en el mismo volumen de sobrenadante de cultivo libre de células de lactobacilos y se incubó a $37^{\circ} \mathrm{C}$. A intervalos de tiempo predeterminados se tomaron alícuotas y se realizaron diluciones en triptona $0,1 \%(p / v)$. Las diluciones se sembraron en agar nutritivo y las colonias se contaron después de 24 horas de incubación. Como control se resuspendió el pellet de Salmonella en el mismo volumen de MRS acidificado artificialmente con ácido láctico a los pH correspondientes de los sobrenadantes de cada lactobacilo.

Efecto de los sobrenadantes de lactobacilos aislados de kefir sobre la asociación e invasión de Salmonella Enteritidis a células Caco-2/TC-7.

Para estos ensayos se realizó una preincubación de Salmonella con sobrenadantes de cultivo de diferentes lactobacilos aislados de kefir. Para esto, un cultivo de 18 horas de Salmonella se centrifugó (5.000 g, 4 minutos) y el pellet fue resuspendido en igual volumen de sobrenadante de cultivo de lactobacilos libre de células llevado a pH 4,5. Luego, se incubó a $37^{\circ} \mathrm{C}$ durante 1 hora, condición donde no se ve afectada la viabilidad de Salmonella. Pasado el tiempo de incubación, se centrifugó y se resuspendió en DMEM de adhesión. Se cuantificó la asociación e invasión de Salmonella a las células en cultivo como se indicó anteriormente. Se realizaron los siguientes controles:

-Salmonella sin ningún pretratamiento resuspendida en PBS.

-Salmonella pretratada con MRS acidificado artificialmente con ácido láctico a pH 4,5.

\section{Análisis estadístico}

Los resultados se expresaron como la media \pm desvío standard de al menos tres experimentos independientes. El estudio estadístico se realizó con el programa GRAPHPAD Prism version 5.0 para Windows (San Diego, CA). Se efectuó un análisis de 
varianza simple (ANOVA) para determinar la diferencia entre medias. Las diferencias significativas entre los valores medios de cada experimento fueron determinadas por el test Tukey (intervalo de confianza del $95 \%$ ). 
Selección de microorganismos probióticos. 


\section{Resistencia a la bilis}

La selección de nuevas cepas con propiedades probióticas es un aspecto de interés ya sea desde el punto de vista básico como aplicado. Una cepa para ser considerada probiótica debe llegar viable al intestino para ejercer su efecto promotor de la salud. En consecuencia, debe resistir el pasaje por el tracto gastrointestinal, ser capaz de colonizar el intestino al menos en forma transitoria, ejercer efecto probiótico in vivo o in vitro contra algún microorganismo patógeno, y no producir riesgos para la salud (Código Alimentario Argentino, artículo 1389). Para llegar viable al intestino las bacterias deben tolerar las condiciones adversas a las que son sometidas al atravesar el tubo digestivo. Se estudió como primera propiedad para la selección de microorganismos potencialmente probióticos la capacidad de crecer en presencia de bilis de buey a $0,5 \%(\mathrm{p} / \mathrm{v})$. En este trabajo se utilizaron 13 cepas de Lactobacillus aisladas de gránulos de kefir que fueron identificados como L. paracasei (5 cepas), L. kefiri (3 cepas), L. kefiranofaciens (4 cepas) y dos cepas de Lactobacillus cuya especie no pudo determinarse con las técnicas utilizadas (Hamet et al. 2013). En la Tabla 3 se muestran los resultados del crecimiento de las cepas mencionadas en presencia de bilis.

De las 13 cepas de Lactobacillus estudiadas sólo 3 de ellas, L. kefiri CIDCA 83101 y L. kefiranofaciens CIDCA 8371 y CIDCA 83118, no mostraron crecimiento en medio con bilis. El resto de los lactobacilos fue capaz de desarrollar en presencia de bilis siendo L. paracasei CIDCA 83124 y L. kefiri CIDCA 83102 las cepas que presentaron mayor capacidad de desarrollar en esta condición (Tabla 3). Cabe destacar que lactobacilos de la misma especie presentaron comportamientos diferentes en cuanto a su capacidad de crecer en presencia de bilis de buey $0,5 \%(p / v)$ confirmando que esta propiedad es cepa-dependiente. 
Selección de microorganismos probióticos.

Tabla 3. Crecimiento de lactobacilos en presencia de bilis de buey $0,5 \%(p / v)$.

\begin{tabular}{|c|c|c|}
\hline Cepa (código CIDCA) & Especie & $\begin{array}{c}\text { Crecimiento en bilis } \\
\text { (método ecométrico) }\end{array}$ \\
\hline 8383 & Lactobacillus sp & + \\
\hline 8384 & Lactobacillus sp & ++ \\
\hline 8339 & Lactobacillus paracasei & ++ \\
\hline 83120 & Lactobacillus paracasei & ++ \\
\hline 83121 & Lactobacillus paracasei & +++ \\
\hline 83123 & Lactobacillus paracasei & +++ \\
\hline 83124 & Lactobacillus paracasei & - \\
\hline 83102 & Lactobacillus kefiri & + \\
\hline 83101 & Lactobacillus kefiri & - \\
\hline 8381 & Lactobacillus kefiri & + \\
\hline 8371 & Lactobacillus kefiranofaciens & + \\
\hline 83118 & Lactobacillus kefiranofaciens & + \\
\hline 83119 & Lactobacillus kefiranofaciens & + \\
\hline
\end{tabular}

(*) CIDCA: Centro de Investigación y Desarrollo en Criotecnología de Alimentos.

\section{Adhesión bacteriana in vitro a células intestinales Caco-2/TC-7}

La adhesión a epitelio es un requisito previo para la colonización bacteriana y ha sido considerado como uno de los principales criterios para la caracterización de bacterias probióticas (Castro \& De Robetto, 2006; Tuomola et al. 2000). Al adherirse, las bacterias extienden su tiempo de residencia en el intestino y como consecuencia, pueden influir en la salud del hospedador modificando la microbiota local o modulando la respuesta inmune. Los experimentos de adhesión in vivo son difíciles de llevar a cabo, por ello se han desarrollado varios modelos in vitro para evaluar la capacidad de adhesión de diversas bacterias. Se han utilizado muchas matrices para ensayos de adhesión in vitro que incluyen mucus, proteínas de membrana (colágeno, laminina, fibronectina, etc) y diferentes líneas celulares entre las que se puede mencionar la línea celular Caco-2 que es modelo de epitelio intestinal. En este trabajo se seleccionó la línea Caco-2/TC-7 para realizar los ensayos de adhesión in vitro de las 13 cepas de lactobacilos. En una primera etapa se analizó el efecto de la concentración de bacterias 
iniciales agregadas a la monocapa de células en la adhesión. A modo de ejemplo, en la Figura 6 se muestra la adhesión de L. kefiranofaciens CIDCA 83118 en función del número de microorganismos iniciales. Se observó una relación lineal entre microorganismos adheridos e iniciales cuando el número inicial varió entre $1.10^{6} \mathrm{y}$ $1.10^{9} \mathrm{UFC} / \mathrm{ml}$. A una concentración inicial de $10^{9} \mathrm{UFC} / \mathrm{ml}$, el número de lactobacilos adheridos fue $1.10^{7} \mathrm{UFC} / \mathrm{ml}$. A partir de dicha concentración no se observó aumento en el número de microorganismos adheridos indicando que los sitios probables de adhesión de las células ya estarían cubiertos o saturados. El mismo comportamiento se observó para todos los lactobacilos estudiados, aunque en algunas cepas, la relación lineal se mantuvo hasta mayores concentraciones de lactobacilos iniciales $\left(1.10^{10} \mathrm{UFC} / \mathrm{ml}\right)$.

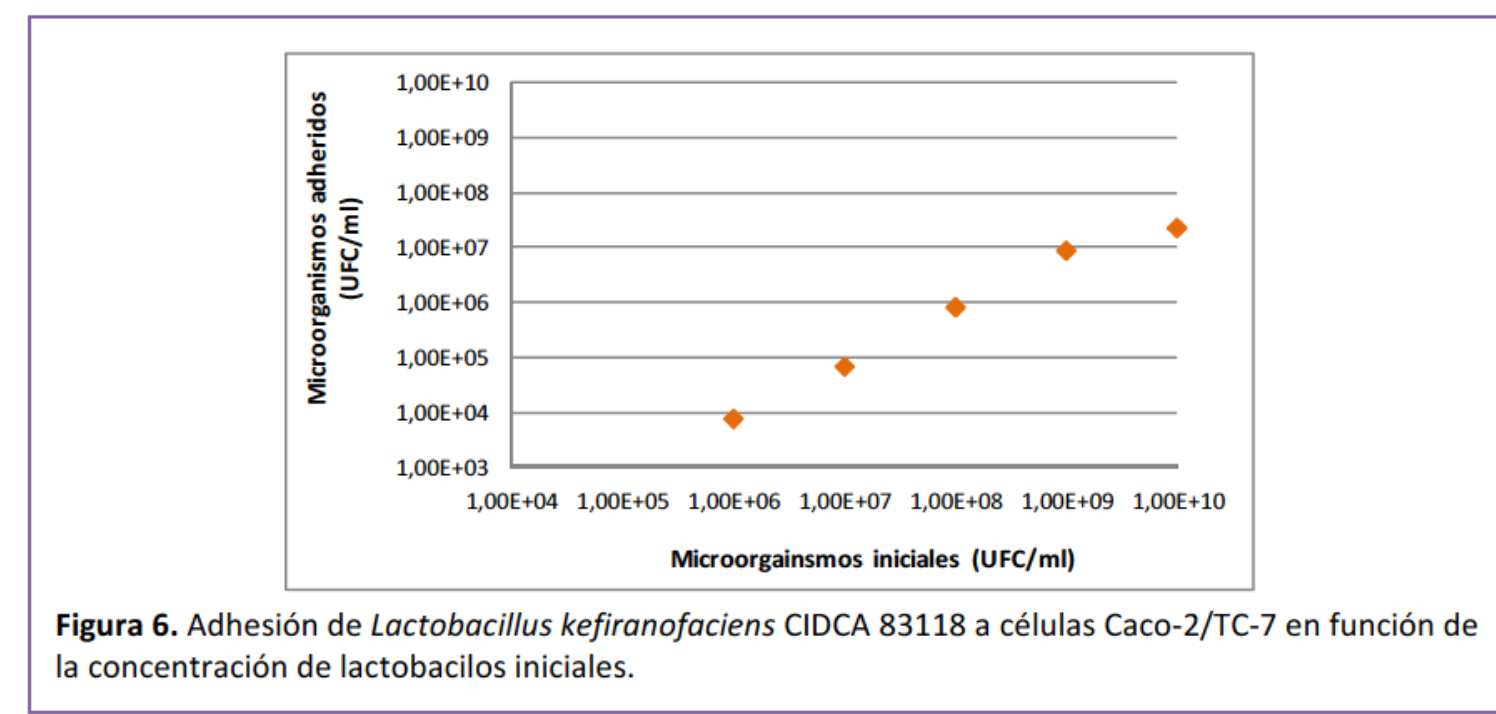

Teniendo en cuenta estos resultados, la concentración de lactobacilos elegida para comparar la capacidad de adhesión de las cepas en estudio a esta línea celular fue $1.10^{8} \mathrm{UFC} / \mathrm{ml}$. Los resultados obtenidos se presentan en la Figura 7.

Se observó que las cinco cepas de L. paracasei presentaron los mayores valores de adhesión (entre $1.10^{6}$ y $1.10^{7} \mathrm{UFC} / \mathrm{ml}$ ). L. kefiranofaciens CIDCA 8371 y CIDCA 83118 presentaron valores de adhesión próximos a $1.10^{6} \mathrm{UFC} / \mathrm{ml}$. L. kefiri CIDCA 83101 y CIDCA 83102 mostraron valores de adhesión del orden de $10^{5}-10^{6} \mathrm{UFC} / \mathrm{ml}$ mientras que L. kefiri CIDCA 8381, Lactobacillus sp. CIDCA 8383 y CIDCA 8384 presentaron los menores valores de adhesión $\left(10^{2}\right.$ y $\left.10^{3} \mathrm{UFC} / \mathrm{ml}\right)$. 


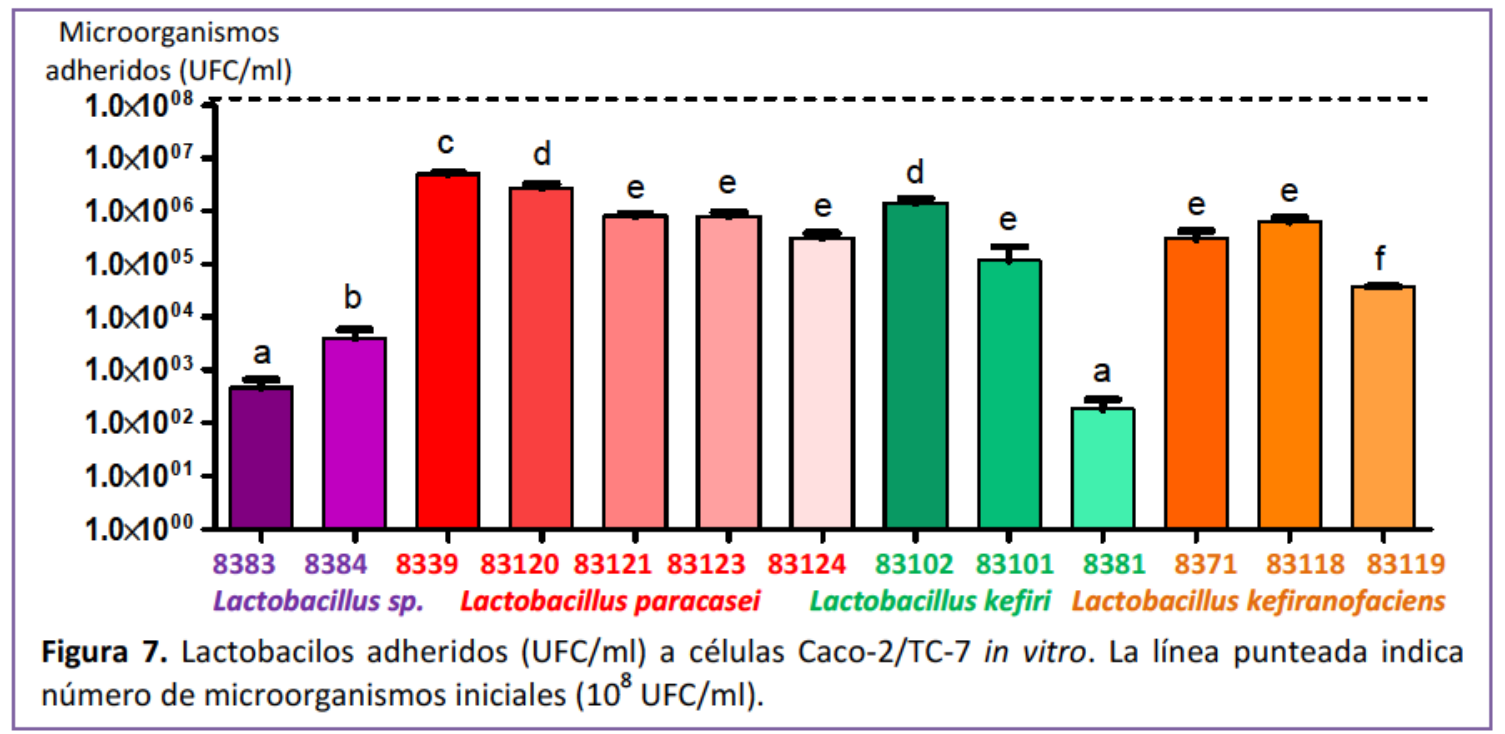

La capacidad de adhesión de lactobacilos es muy variada, inclusive dentro de una misma especie. Los mayores valores de adhesión en las condiciones del presente trabajo se obtuvieron con las 5 cepas de L. paracasei, con L. kefiri CIDCA 83102 y CIDCA 83101 y L. kefiranofaciens CIDCA 8371 y CIDCA 83118. Sin embargo, algunos trabajos describen que cepas de L. paracasei aisladas de otras fuentes presentan una capacidad de adhesión entre 0,08 \% a 0,11 \% (Minelli et al. 2004; Maragkoudakis et al. 2006), menor a la encontrada en el presente trabajo cuyos valores oscilan entre $0,31 \%$ y $5,04 \%$.

En la Figura 8 se presentan los resultados de resistencia a la bilis y adhesión a células Caco-2/TC-7 de las cepas estudiadas.

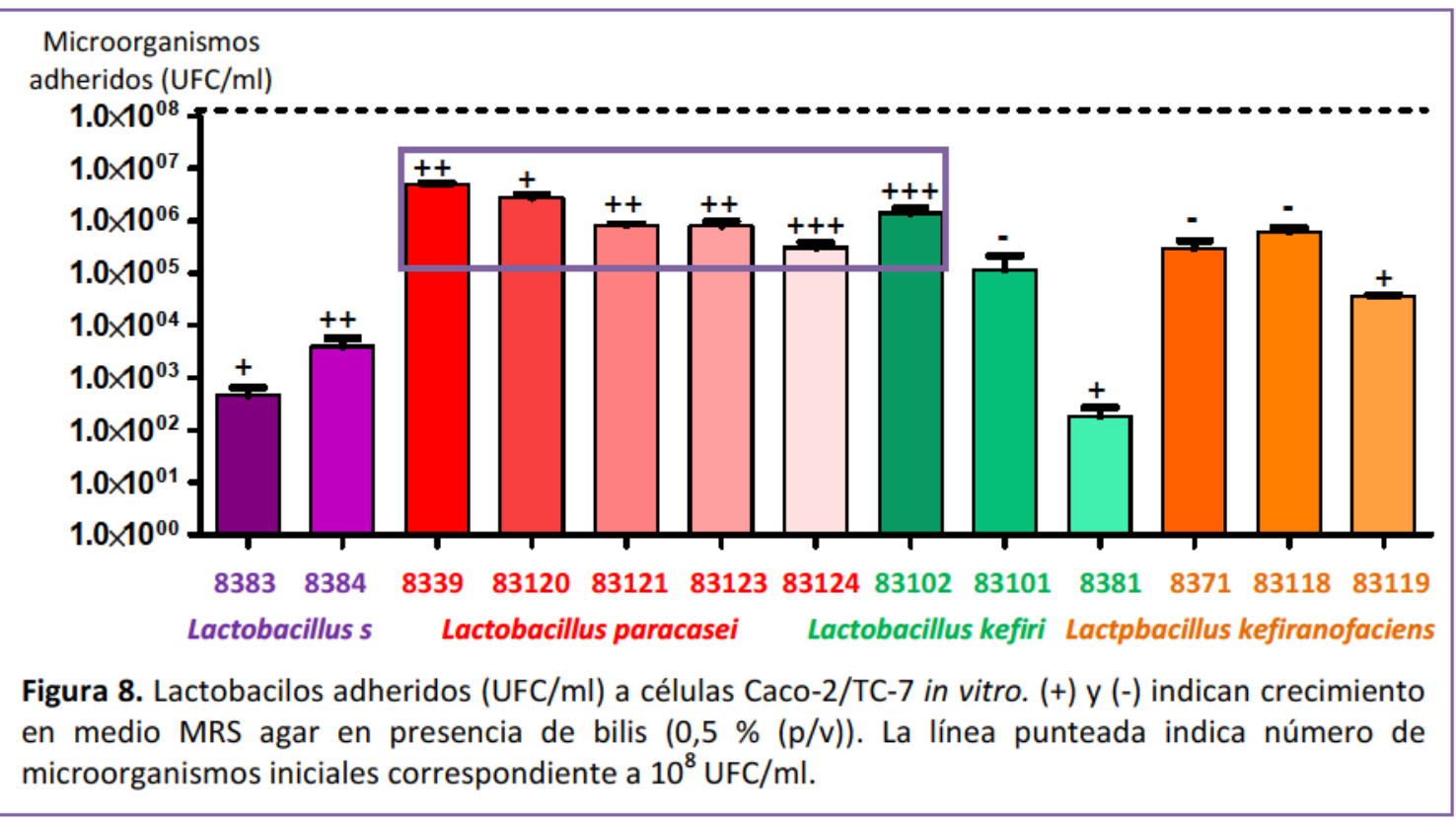


Las 5 cepas de L. paracasei estudiadas en este trabajo presentaron resultados similares entre ellas en la capacidad de adhesión a células Caco-2/TC-7 in vitro y todas fueron capaces de crecer en presencia de bilis de buey $0,5 \%(p / v)$, pero presentaron distinta capacidad de crecimiento. L. paracasei CIDCA 83124 presentó la mayor resistencia al desarrollo en bilis, L. paracasei CIDCA 8339, CIDCA 83121 y CIDCA 83123 presentaron una resistencia intermedia, mientras que L. paracasei CIDCA 83120 presentó una menor resistencia al crecimiento en bilis. La capacidad de adhesión y de crecimiento en presencia de bilis de las distintas cepas de L. kefiri fue variable, y sólo L. kefiri CIDCA 83102 presentó alta capacidad de adhesión a células de epitelio intestinal y resistencia al crecimiento en bilis.

Teniendo en cuenta el crecimiento en bilis y la capacidad de adherirse al epitelio intestinal (Figura 8), se seleccionaron las siguientes cepas para continuar los estudios de propiedades probióticas: L. kefiri CIDCA 83102, L. paracasei CIDCA 8339, CIDCA 83120, CIDCA 83121, CIDCA 83123 y CIDCA 83124.

\section{Adhesión a mucina}

Las células epiteliales del tracto gastrointestinal están cubiertas por una capa de mucus que protege al epitelio de los daños mecánicos, de patógenos, y también proporciona un hábitat y nutrientes para la microflora intestinal (Tuomola et al. 1999). El mucus es la primera barrera en el intestino que enfrentan los microorganismos, por lo tanto, la adhesión a esta matriz se considera requisito previo para la colonización del intestino (Ouwehand et al. 1999). Los componentes principales del mucus son glicoproteínas poliméricas llamadas mucinas que han sido ampliamente utilizadas para los ensayos de adhesión in vitro de probióticos (Tuomola et al. 2000; Matsumoto et al. 2002). Algunos autores estudiaron la adhesión sobre células productoras de mucus tales como HT-29 MTX y se ha informado que muchos lactobacilos y bifidobacterias son capaces de unirse a esta capa protectora que cubre la mucosa intestinal (Collado et al. 2007b; Ruas-Madiedo et al. 2006). 
Selección de microorganismos probióticos.

Se evaluó la capacidad de adhesión de las cepas seleccionadas a mucina gástrica porcina tipo III parcialmente purificada y los resultados se presentan en la Figura 9.

Los 6 lactobacilos estudiados (5 cepas de L. paracasei y una de L. kefiri) fueron capaces de adherirse a mucina en concentraciones entre $1.10^{5}$ y $1.10^{6} \mathrm{UFC} / \mathrm{ml}$ cuando la concentración de microorganismos iniciales fue de $1.10^{8} \mathrm{UFC} / \mathrm{ml}$. L. paracasei CIDCA 8339 y CIDCA 83120 fueron las cepas que presentaron mayor capacidad de adhesión a mucus. El resto de las cepas estudiadas presentaron menor capacidad de adhesión y entre ellas no se observaron diferencias significativas $(p \leq 0,05)$.

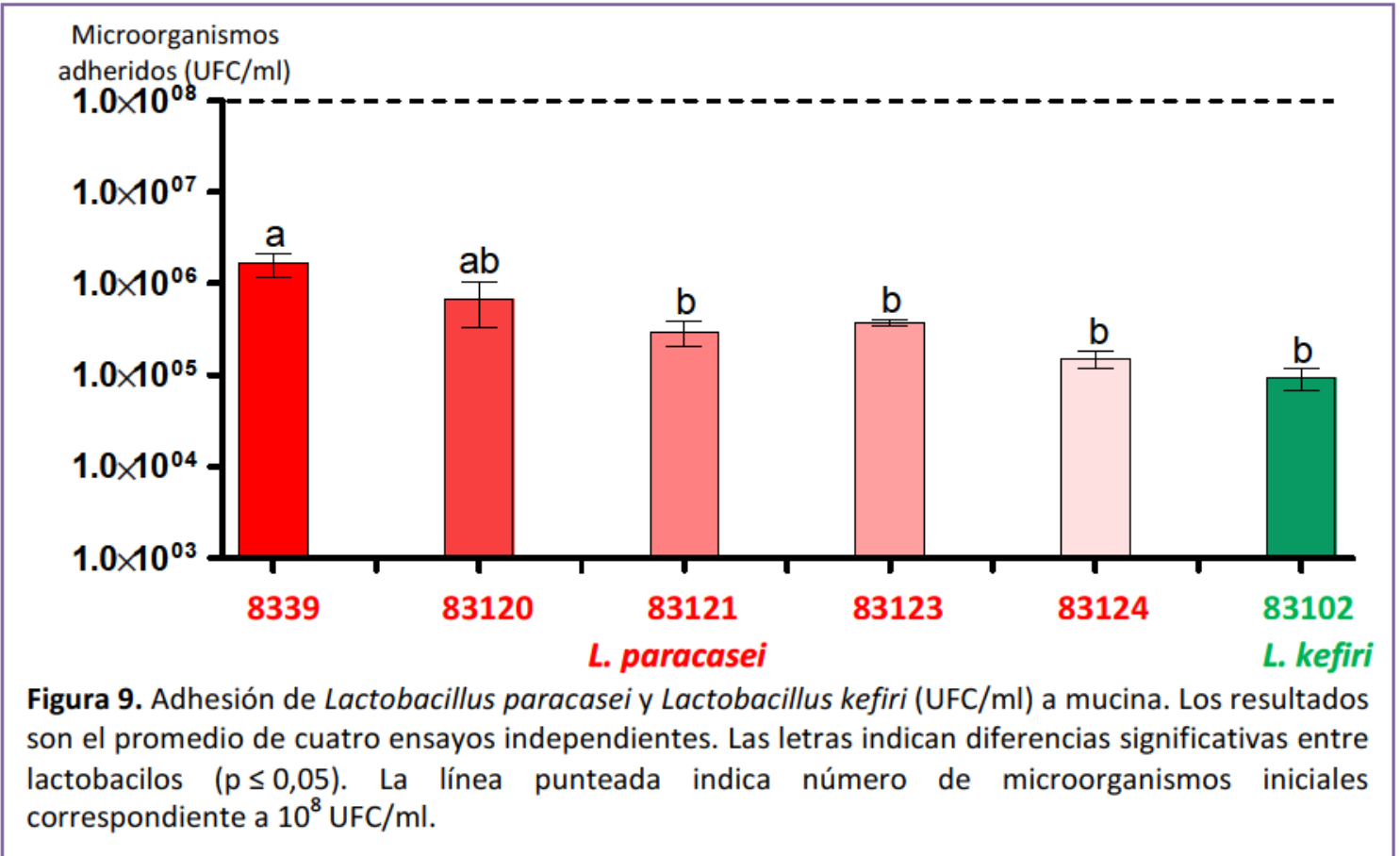

Los mecanismos mediante los cuales se lleva a cabo la adhesión a mucus son poco conocidos pero se ha descripto la participación de proteínas de superficie bacterianas ya que se ha observado una disminución de la adhesión después de tratamientos con proteasas sobre las bacterias (Tuomola et al. 2000; Lorca et al. 2002). Además las proteínas de superficie purificadas son capaces de adherirse a mucus o a células epiteliales (Roos et al. 1996; Sillanpaa et al. 2000). Muchas de ellas presentan componentes glicosídicos en su estructura. Por ejemplo, la cepa L. kefiri 8348 posee capa-S glicosilada (Mobili et al. 2009) y tiene capacidad de adhesión a mucus (Carasi et al. 2013) y a células epiteliales (Golowczyc et al. 2007). Por otro lado, la adhesión de Lactobacillus plantarum a células HT-29 es una propiedad cepa-dependiente y mediada 
por manosa (Adlerberth et al. 1996). Las cepas de L. paracasei estudiadas en este trabajo son productoras de polisacárido (Hamet et al. 2013), en consecuencia sería factible pensar en la intervención de componentes glucídicos en las propiedades de adhesión.

En la Figura 10 se compara la adhesión de los lactobacilos estudiados a células del epitelio intestinal Caco-2/TC-7 y a mucina.

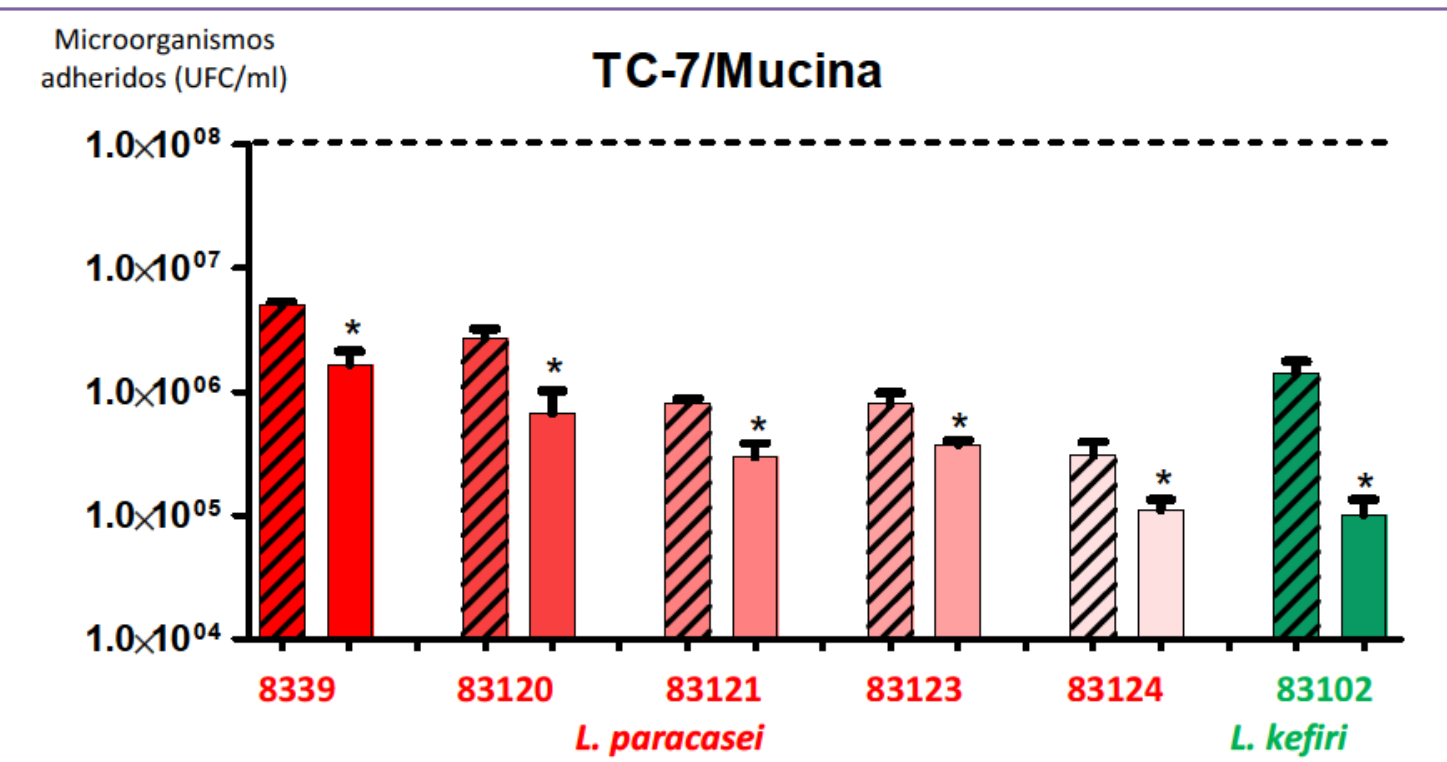

Figura 10. Comparación de valores de adhesión de lactobacilos (UFC/ml) a células Caco-2/TC-7 ( $\boldsymbol{Z}$ y a mucina $\left(\square .{ }^{*}\right)$ indica diferencias significativas entre los valores de adhesión a las dos matrices para cada lactobacilo. Las barras de desvío estándar corresponden al promedio de tres ensayos independientes. La línea punteada indica número de microorganismos iniciales correspondiente a $10^{8} \mathrm{UFC} / \mathrm{ml}$.

Todos los lactobacilos estudiados presentaron valores de adhesión a mucina significativamente diferentes respecto a los obtenidos en la adhesión a células Caco-2/TC-7. La diferencia entre ambas matrices no superó el orden logarítmico excepto para L. kefiri. La adhesión de lactobacilos a distintos modelos ha sido estudiada por otros autores y los porcentajes de adhesión observados resultaron muy variables, incluso entre cepas de una misma especie de microorganismos (Cebrián et al. 2012; Piątek et al. 2012). La capacidad de adhesión a diferentes superficies de cepas de L. plantarum depende de la cepa y la matriz biológica utilizada (Tallon 2007; Jacobsen et al. 1999). Resultados similares se han descripto con diferentes cepas de L. casei (Tuomola \& Salminen, 1998). 
Selección de microorganismos probióticos.

La capacidad de adhesión a diferentes superficies estaría asociada a los componentes presentes en la superficie microbiana. Los componentes presentes en la superficie de los microorganismos afectan el valor de la hidrofobicidad superficial.

El método más común para medir la hidrofobicidad es medir la partición de una suspensión bacteriana en un hidrocarburo, tal como el hexadecano. Este método es popular por su simplicidad, reproducibilidad y por ser no destructivo para las bacterias (Doyle \& Rosenberg, 1990).

En este trabajo se utilizó el denominado MATH (Microbial Adhesion to Hexadecan), una técnica basada en la tendencia de ciertos microorganismos de mantenerse en la fase acuosa (hidrofílico) o migrar a la fase no polar (hidrofóbico) luego de un breve período de contacto (Ofek \& Doyle, 1994). Los resultados de partición en hexadecano se presentan en la Tabla 4. En la tabla también se muestra un lactobacilo hidrofóbico como L. kefiri CIDCA 8348 y un lactobacilo hidrofílico como L. plantarum CIDCA 83114, que fueron utilizadas como controles.

Tabla 4. Porcentajes de hidrofobicidad superficial de los lactobacilos estudiados.

\begin{tabular}{c|c} 
L. plantarum CIDCA 83114 & $5,28 \pm 1,29$ \\
L. kefiri CIDCA 8348 & $37,41 \pm 2,62$ \\
L. kefiri CIDCA 83102 & $5,22 \pm 1,20$ \\
L. paracasei CIDCA 8339 & $7,13 \pm 0,09$ \\
L. paracasei CIDCA 83120 & $9,00 \pm 1,23$ \\
L. paracasei CIDCA 83121 & $3,83 \pm 0,14$ \\
L. paracasei CIDCA 83123 & $5,74 \pm 0,19$ \\
L. paracasei CIDCA 83124 & $5,39 \pm 0,73$
\end{tabular}

Todos los lactobacilos estudiados mostraron ser altamente hidrofílicos, y durante el ensayo no presentaron una tendencia a pasar al solvente orgánico sino que se quedaron en el buffer (fase acuosa) que las contenía (Tabla 4). Este comportamiento hidrofílico podría ser debido a la presencia de componentes de naturaleza glucídica en la superficie bacteriana. 
La hidrofobicidad superficial se ha asociado con la habilidad de un microorganismo de adherirse a un sustrato, aunque la adhesión a superficies generalmente involucra múltiples factores. En bifidobacterias, la hidrofobicidad superficial se ha relacionado con la capacidad de adherirse al epitelio intestinal (Perez et al. 1998), sin embargo en lactobacilos existen resultados contradictorios sobre la relación entre la hidrofobicidad superficial y la adhesión a epitelio (Ouwehand et al. 1999; Vinderola et al. 2004; Schillinger et al. 2005; Golowczyc et al. 2008; Wadstrom et al. 1987; Ehrmann et al. 2002; Van Der Mei et al. 2003). En este trabajo demostramos que cepas altamente hidrofílicas son capaces de adherirse tanto a células epiteliales como a mucina, indicando una posible interacción de componentes de naturaleza glucídica, ya sea asociado a proteínas o la presencia de exopolisacáridos en la superficie.

\section{Adhesión a epitelio y pasaje por el tracto gastrointestinal in vitro}

Si bien la adhesión a epitelio y a mucus es una de las propiedades a estudiar de las bacterias potencialmente probióticas, las mismas antes de llegar al epitelio deben pasar por el tracto gastrointestinal, es así, que la resistencia al ácido y a la bilis es otro de los parámetros a analizar que podrían afectar la capacidad de adhesión (Kalliomaki et al. 2008). La exposición a los fluidos gástricos e intestinales a lo largo del tracto digestivo es el principal estrés que afecta la viabilidad de los probióticos ingeridos (Liong \& Shah, 2005). Si una cepa probiótica está destinada para la administración oral, es requisito esencial sobrevivir a las condiciones adversas del tracto gastrointestinal para llegar viva al sitio de acción de destino, el intestino delgado y grueso. La tolerancia a la acidez, bilis y pancreatina in vitro permiten predecir el comportamiento de las bacterias lácticas en las condiciones encontradas en el tracto gastrointestinal (OMS / FAO, 2006). Sin embargo, hay muy pocos resultados sobre las propiedades de adhesión a epitelio y mucus de los microorganismos después de pasar por el tracto gastrointestinal (TGI). 
Selección de microorganismos probióticos.

Viabilidad bacteriana luego del pasaje.

Para evaluar la capacidad de los microorganismos para sobrevivir a las condiciones de estrés del tracto gastrointestinal humano, principalmente $\mathrm{pH}$ bajo en el estómago y las sales biliares y jugo pancreático en el intestino delgado (Sánchez et al. 2008), se realizaron dos incubaciones seriadas, la primera simulando las condiciones gástricas, a pH ácido y en presencia de pepsina, y la segunda, simulando las condiciones intestinales, a pH alcalino y en presencia de sales biliares y pancreatina. Se realizaron recuentos de microorganismos iniciales, luego del pasaje gástrico simulado, y luego del pasaje intestinal simulado en forma secuencial, según se detalla en el esquema de la Figura 11. El número de microorganismos viables después de las diferentes etapas del tránsito gastrointestinal simulado se muestran en la Figura 12.

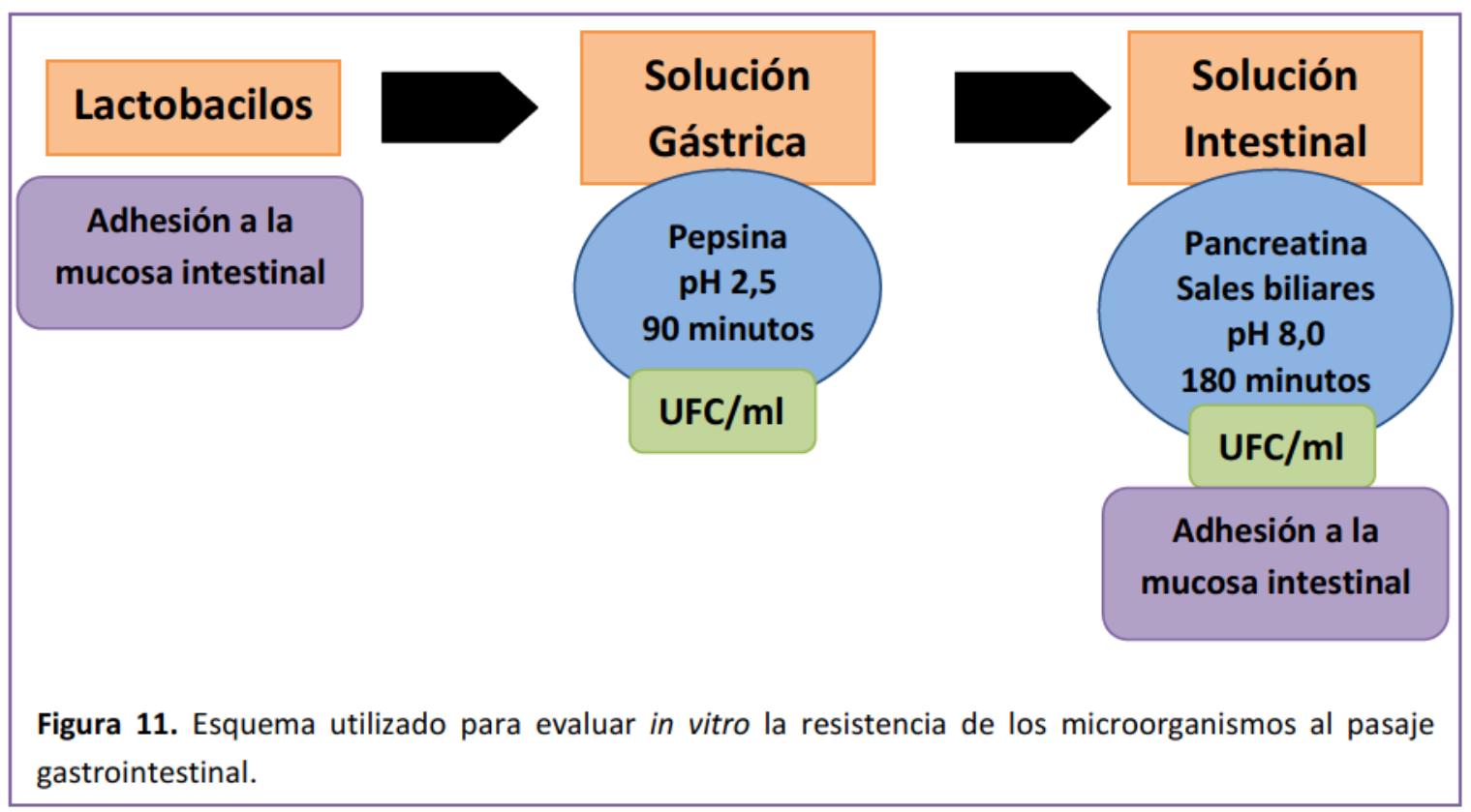




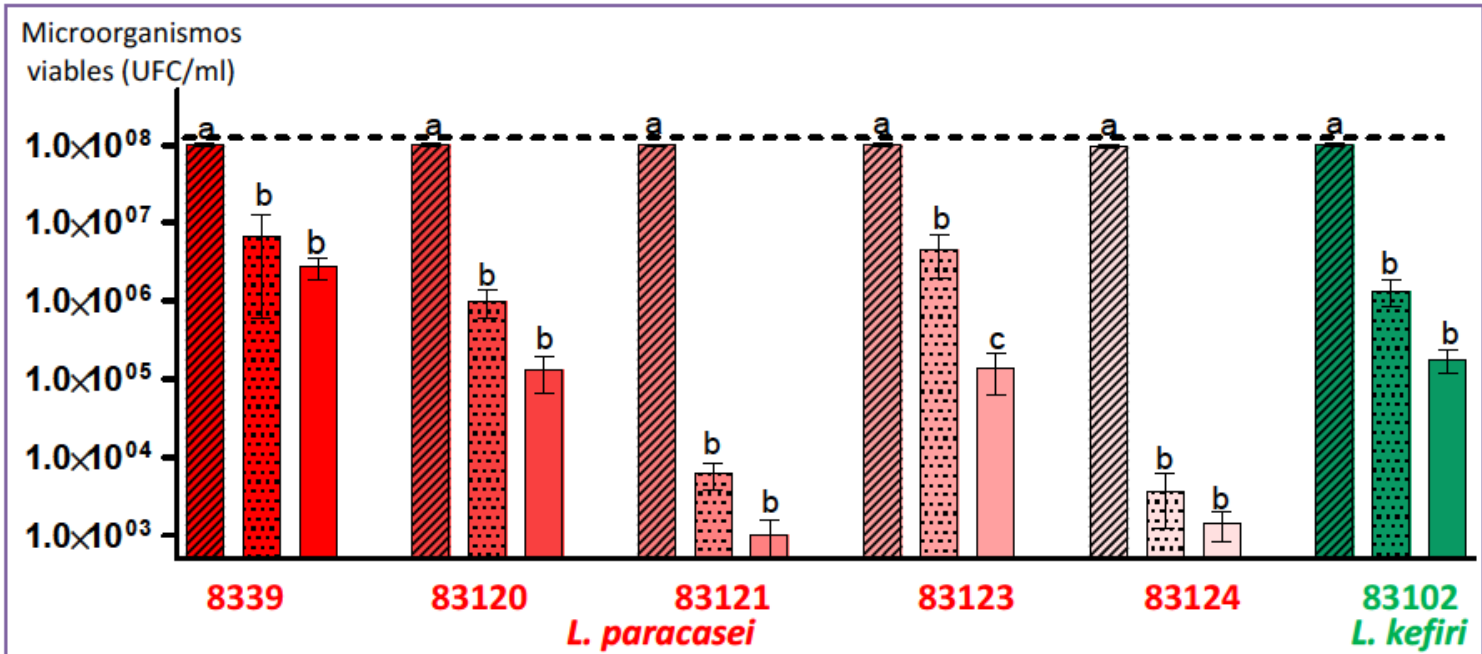

Figura 12. Resistencia al pasaje a través del tracto gastrointestinal. Número de lactobacilos viables (UFC/ml) luego de 90 minutos de incubación en medio ácido con pepsina y 180 minutos en medio con pancreatina y sales biliares, en forma secuencial. Las barras corresponden al número de microorganismos iniciales $(\mathbb{Z})$, después del tratamiento en condiciones gástricas $(\square)$, y después del tratamiento secuencial ( $\square$. Las letras indican diferencias significativas correspondientes al análisis de cada lactobacilo. Las barras de desvío estándar corresponden al promedio de tres ensayos independientes. La línea punteada indica número de microorganismos iniciales correspondiente a $10^{8} \mathrm{UFC} / \mathrm{ml}$.

El estrés al ácido conferido por el jugo gástrico afectó la viabilidad de la mayoría de los lactobacilos. L. paracasei CIDCA 83121 y CIDCA 83124 fueron los más afectados disminuyendo el número de microorganismos viables hasta 4 unidades logarítmicas. Este hecho pone de manifiesto la alta sensibilidad de los mismos al pH bajo. Al someter a L. paracasei CIDCA 8339, CIDCA 83120, CIDCA 83121 y CIDCA 83124 y L. kefiri CIDCA 83102 al tratamiento secuencial no se encontraron diferencias significativas en el número de microorganismos viables comparado con los que se mantuvieron viables después del pasaje por jugo gástrico, mientras que L. paracasei CIDCA 83123 disminuyó su viabilidad en un orden logarítmico. Estos resultados coinciden con los obtenidos por Fumnilola et al. (2011) quienes estudiaron la resistencia al pasaje gástrico de dos L. paracasei en condiciones similares a las del presente trabajo, encontrando que la acidez (solución ácido - pepsina) producía una caída del número de microorganismos viables de hasta 6 ciclos logarítmicos. También demostraron que el jugo intestinal simulado (sales biliares - pancreatina) no afectó la viabilidad de los aislados, concordando con los resultados obtenidos en este trabajo con las cepas L. paracasei CIDCA 8339, CIDCA 83120, CIDCA 83121 y CIDCA 83124 y L. kefiri CIDCA 83102. Se cree que una buena supervivencia a la bilis puede reflejar también una buena resistencia del microorganismo probiótico a las condiciones adversas del tracto gastrointestinal 
Selección de microorganismos probióticos.

humano (Watson et al. 2008). Por esta razón, los lactobacilos seleccionados podrían ser propuestos para su utilización en alimentos potencialmente probióticos.

Las variaciones observadas en la resistencia al pasaje gastrointestinal simulado y secuencial nos proporcionan un importante primer criterio de análisis, seleccionando lactobacilos con diferente capacidad de resistencia tales como L. paracasei CIDCA 8339, CIDCA 83123, CIDCA 83124 y L. kefiri CIDCA 83102 para estudiar su respectiva adhesión a células epiteliales o mucus. Es factible pensar que la capacidad de producir exopolisacáridos esté relacionada a la resistencia a la bilis, correlación que ya fue descripta en otras especies de bacterias como Lactobacillus spp., Lactococcus spp. y Pediococcus spp. aislados del kefir (Sabir et al. 2010). Sin embargo, la resistencia a la bilis también se observó en cepas no productoras de exopolisacáridos tal como lo es L. kefiri CIDCA 83102.

Adhesión a línea celular Caco-2/TC-7 y mucina después del pasaje por el tracto gastrointestinal simulado.

Se evaluó la adhesión de los 4 lactobacilos seleccionados a células epiteliales intestinales de la línea Caco-2/TC-7 luego del pasaje simulado por el tracto gastrointestinal. Los valores de adhesión a las células luego del pasaje por el tracto gastrointestinal se expresaron normalizando los valores obtenidos a un recuento inicial de $1.10^{8} \mathrm{UFC} / \mathrm{ml}$ (Figura 13).

La adhesión de tres de los lactobacilos seleccionados a células Caco-2/TC-7 fue mayor después del tratamiento a las condiciones gastrointestinales. Esto indicaría que el estrés al que fueron sometidos generó cambios en la superficie bacteriana que se vieron reflejados en un aumento significativo de la adhesión. Sólo L. paracasei CIDCA 8339 no presentó diferencias en los valores de adhesión antes y después del tratamiento. 


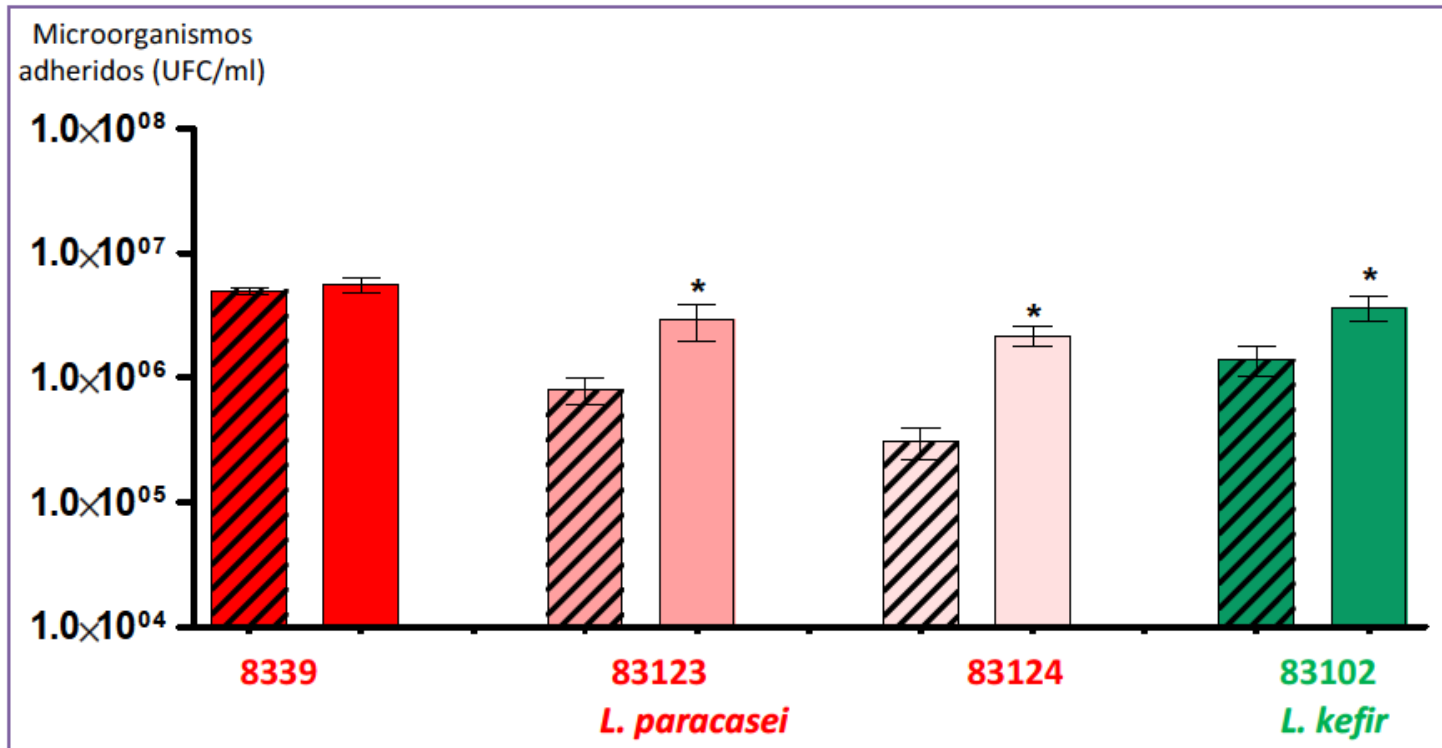

Figura 13. Valores de adhesión de lactobacilos (UFC/ml) a células Caco-2/TC-7 antes (control- $\square$ y después de someterlos a las condiciones que simulan el pasaje a través del tracto gastrointestinal $\square$. Las diferencias significativas corresponden al análisis de cada lactobacilo en forma individual $\left(^{*}\right)$. La línea punteada indica número de microorganismos iniciales correspondiente a $10^{8} \mathrm{UFC} / \mathrm{ml}$. Los valores de adhesión se expresaron como microorganismos adheridos cada $1.10^{8} \mathrm{UFC} / \mathrm{ml}$ microorganismos iniciales.

Posteriormente se evaluó la capacidad de adhesión a mucina de lactobacilos sometidos a las condiciones gastrointestinales simuladas. En la Figura 14 se muestran los valores de adhesión a mucina expresados de la misma forma que para los resultados de adhesión a células Caco-2/TC-7.

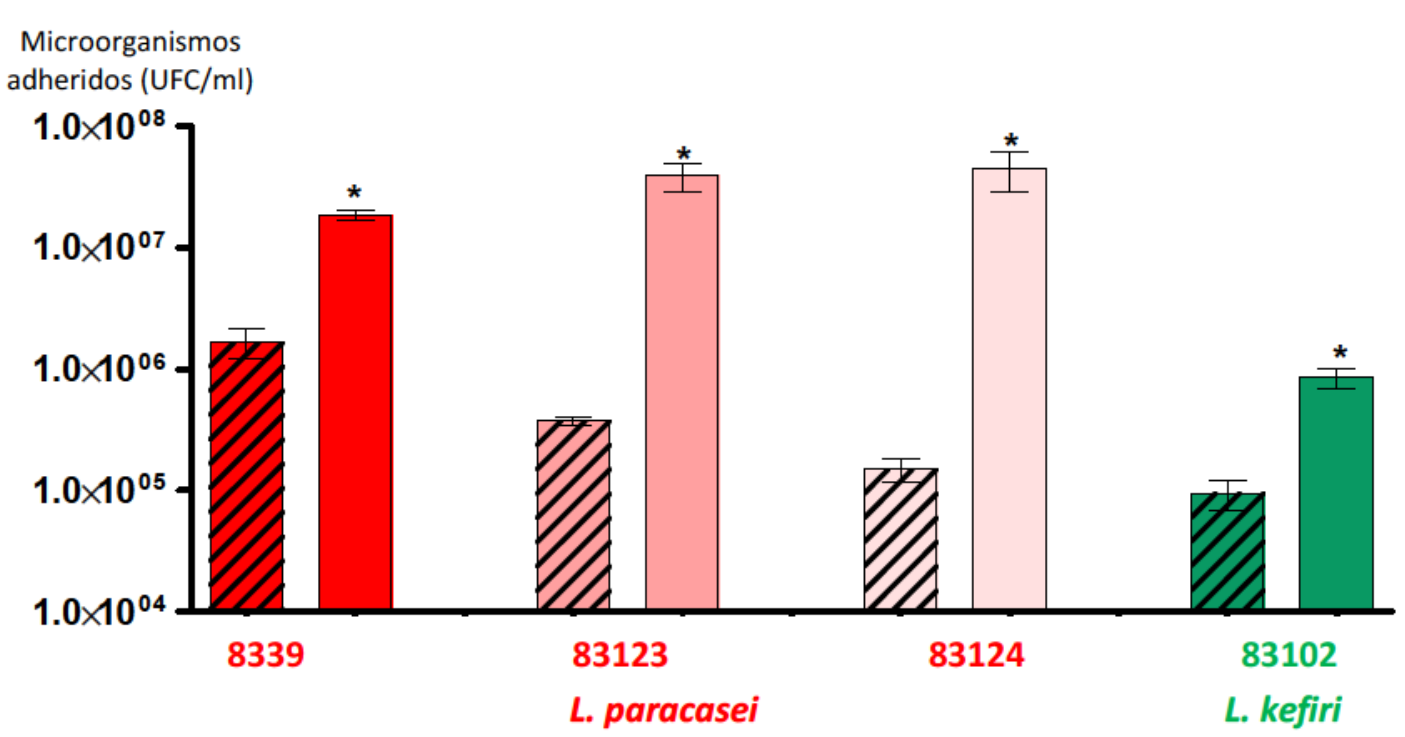

Figura 14. Valores de adhesión de lactobacilos (UFC/ml) a mucina antes (control- $\square$ ) y después de someterlos a las condiciones que simulan el pasaje a través del tracto gastrointestinal ( $\square$ ). Las diferencias significativas corresponden al análisis de cada lactobacilo en forma individual $(*)$. Los valores de adhesión se expresaron como microorganismos adheridos cada $1.10^{8} \mathrm{UFC} / \mathrm{ml}$ microorganismos iniciales. 
Selección de microorganismos probióticos.

En lo que respecta a la adhesión a mucina, se observó que los 4 lactobacilos presentaron un aumento en su capacidad de adhesión luego del tratamiento gastrointestinal, en coincidencia con los resultados obtenidos en el modelo celular Caco-2/TC-7.

Hasta el momento, la mayoría de los trabajos publicados evalúan la sobrevida a la simulación de las condiciones del tracto gastrointestinal y la adhesión a células epiteliales en forma independiente. La evaluación de la capacidad de adhesión luego de someter a los lactobacilos al estrés gastrointestinal permite avanzar hacia un modelo que se acerca a las condiciones fisiológicas. Es interesante destacar que la capacidad de adhesión de los lactobacilos aumentó después del estrés ácido y presencia de bilis. Esto indicaría que este tratamiento modifica la superficie de los microorganismos favoreciendo la interacción con las células epiteliales y la mucina. Estos cambios podrían ser sólo cambios en la conformación de los componentes de la superficie, o debidos a que el estrés podría inducir la expresión de diferentes proteínas a nivel de la superficie bacteriana que contribuyan al proceso de adhesión.

La buena adhesión de los lactobacilos seleccionados al epitelio intestinal luego de ser sometidos a la simulación del pasaje por el tracto gastrointestinal, es un indicador para proponer su uso como potencial probiótico.

\section{Expresión de proteínas después del pasaje por el tracto gastrointestinal (TGI)}

Con la finalidad de indagar los efectos inducidos por el ácido y las sales biliares, e interpretar qué cambios podrían ocurrir en la bacteria que lleven a un aumento en su capacidad de adherirse a epitelio, se seleccionó L. paracasei 83123 porque presentó un aumento significativo en la adhesión a células luego de ser sometida a la simulación de las condiciones del tracto gastrointestinal. Se obtuvieron extractos de las proteínas de las bacterias por lisis de las mismas antes y después de la simulación por el tracto gastrointestinal. Se llevó a cabo una electroforesis de dos dimensiones (2D). Los resultados se muestran en la Figura 15. 


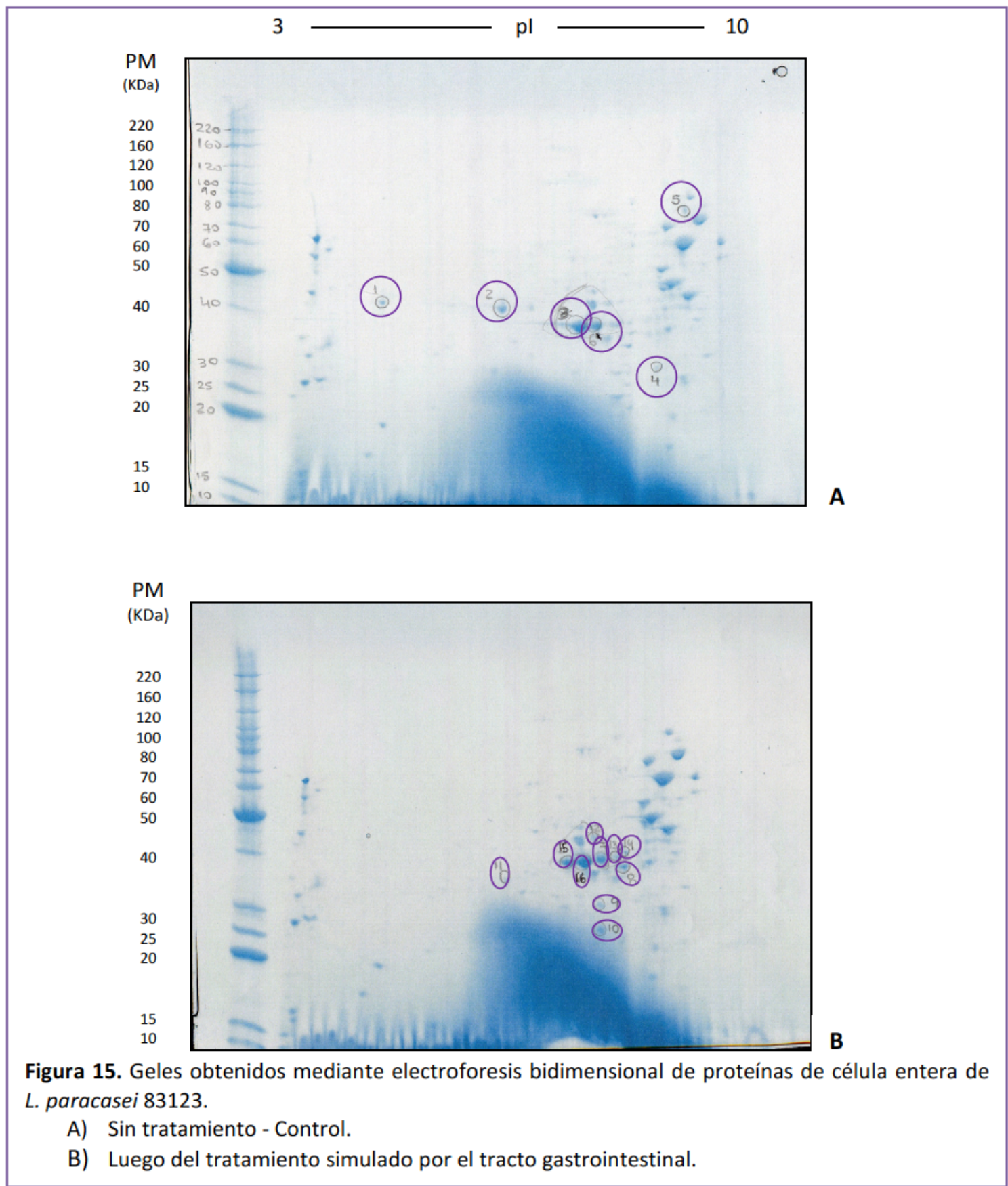

La inspección visual de los spots obtenidos en los geles mostraron algunas diferencias entre los perfiles de las electroforesis bidimensional (2D) de los lactobacilos sometidos al tratamiento de simulación del pasaje gastrointestinal y los lactobacilos no tratados. Se evidenciaron 16 spots que presentaron intensidades diferentes en ambos geles, que corresponden a las proteínas expresadas de manera diferencial antes y después del tratamiento (marcado en la Figura 15). 
Selección de microorganismos probióticos.

Con el fin de averiguar qué proteínas se vieron afectadas por el estrés gastrointestinal que puedan desempeñar un papel en las propiedades de adhesión, se analizaron por espectrometría de masas los 16 spots resultantes cuya intensidad relativa se vio modificada entre los lactobacilos sometidos al estrés ácido y a la presencia de bilis y aquéllos que no lo fueron (Tabla 5). No fue posible la identificación de 3 de los spots seleccionados, por ello no se listan en la tabla.

Tabla 5. Proteínas expresadas de manera diferencial en L. paracasei CIDCA 83123 sometida al estrés ácido y de bilis.

\begin{tabular}{|c|c|c|c|c|}
\hline Spots & $\begin{array}{l}\text { PM } \\
\text { (KDa) }\end{array}$ & pl & $\begin{array}{l}\text { Intensidad relativa } \\
\text { de los spots (TGI/C) }\end{array}$ & Identificación por MALDI-TOF \\
\hline 01 & 41 & 4,34 & 0,08 & $\begin{array}{l}\text {-Hidrolasa de pared celular, de la familia } \\
\text { amilasa (L. paracasei) } \\
\text {-Antígeno de superficie, parcial (L. paracasei) }\end{array}$ \\
\hline 02 & 39 & 5,99 & 0,22 & $\begin{array}{l}\text {-Antígeno de superficie (L. casei ATCC } 334 \text { ) } \\
\text {-Hidrolasa de pared celular, de la familia } \\
\text { amilasa (L. paracasei) }\end{array}$ \\
\hline 03 & 36 & 7,15 & 0,59 & $\begin{array}{l}\text {-Gliceraldehído 3-fosfato deshidrogenasa } \\
\text { (L. casei, L. paracasei) }\end{array}$ \\
\hline 04 & 29 & 8,09 & 0,53 & $\begin{array}{l}\text {-Proteína LacX, plásmido, parcial } \\
\text { (L. paracasei) } \\
\text {-Galactosa mutarotasa, parcial (L. paracasei) }\end{array}$ \\
\hline 05 & 75 & 8,51 & 0,26 & $\begin{array}{l}\text {-Hidrolasa asociada a la pared celular, parcial } \\
\text { (L. paracasei) }\end{array}$ \\
\hline 06 & 36 & 7,25 & 1,69 & $\begin{array}{l}\text {-Gliceraldehído 3-fosfato deshidrogenasa } \\
\text { (L. casei, L. paracasei) }\end{array}$ \\
\hline 07 & 36 & 7,48 & 2,7 & $\begin{array}{l}\text {-Gliceraldehído 3-fosfato deshidrogenasa } \\
\text { (L. casei, L. paracasei) }\end{array}$ \\
\hline 08 & 35 & 7,83 & 4,3 & $\begin{array}{l}\text {-L-lactato deshidrogenasa (L. casei, } \\
\text { L. paracasei) }\end{array}$ \\
\hline 10 & $\sim 25$ & $\sim 7,45$ & ND & -Fosfogliceromutasa (L. casei, L. paracasei) \\
\hline 11 & 34 & 6,14 & 2,6 & $\begin{array}{l}\text { UTP-glucosa-fosfato uridiltransferasa } \\
\text { (L. casei BL23, L. paracasei) }\end{array}$ \\
\hline 12 & 41 & 7,43 & 1,0 & -Fosfoglicerato quinasa OS (L. casei) \\
\hline 13 & 37 & 6,96 & 1,5 & No se pudo identificar. \\
\hline 14 & 37 & 7,88 & 1,8 & No se pudo identificar. \\
\hline
\end{tabular}

Cuando los lactobacilos fueron sometidos a las condiciones gastrointestinales in vitro, 6 spots de los seleccionados fueron más intensos, mientras que 5 disminuyeron su intensidad respecto a los lactobacilos control, no tratados. Un spot que visualmente parecia tener diferente intensidad en los geles después del tratamiento, al ser analizado el densitograma dio una relación 1. 
Se identificaron 3 péptidos que podrían estar asociados a las proteínas de superficie de L. paracasei cuya intensidad relativa disminuyó después del pasaje simulado por el tracto gastrointestinal, mientras que las otras 2 proteínas también reguladas negativamente fueron identificadas como gliceraldehído-3-fosfato deshidrogenasa (vía glicolítica) y galactosa mutarotasa. La mayoría de las células vivas poseen un galactosa mutarotasa (Galm), que cataliza rápidamente la conversión de $\beta$-D-galactosa en $\alpha$-D-galactosa (Beebe \& Frey, 1998). La regulación negativa de esta enzima indicaría una acumulación de $\beta$-D-galactosa que podría ser precursor de exopolisacáridos.

De los 8 spots con mayor intensidad que fueron seleccionados, sólo pudieron identificarse 6 proteínas que se regularon positivamente. Se identificaron 2 isoformas de la enzima de la vía glicolítica gliceraldehído-3-fosfato deshidrogenasa, un péptido fue identificado como fragmento de L-lactato deshidrogenasa, otro como fosfogliceromutasa, otro como UTP glucosa-1-fosfato uridiltransferasa y el último spot fue identificado como fosfoglicerato quinasa. La enzima L-lactato deshidrogenasa participa en la obtención de piruvato a partir de lactato. Las enzimas fosfoglicerato quinasa y fosfogliceromutasa intervienen también en la síntesis de piruvato.

Por lo tanto, se observó que la mayoría de las proteínas que fueron reguladas positivamente corresponden a enzimas de la ruta glicolítica, siendo un efecto general del estrés activar la fuente de energía. Esto mismo fue observado recientemente para Lactobacillus casei lbz-2 luego de ser sometido a una adaptación ácida durante 1 hora a $\mathrm{pH} 4,5$, donde encontraron que fueron reguladas positivamente 5 proteínas (Pgk, LacD, Hpr, y Galm) implicadas en el metabolismo de los carbohidratos y otras 5 proteínas de respuesta al estrés (GroEL, GrpE, DnaK, Hspl y LCAZH_2811). Entre ellas, GrpE en combinación con GroEL interaccionan con las enzimas glicolíticas a pH bajo y aumentan la estabilidad de las proteínas en presencia de ácido, mientras que se cree que Dnak puede servir como un "termómetro celular" que transduce señales a otros factores celulares en respuesta al estrés térmico (Wu et al. 2014).

Bron et al. (2004) investigaron la base genética de la persistencia de Lactobacillus plantarum WCFS1 a través del tracto gastrointestinal en ratón. Identificaron 72 genes cuya expresión se indujo durante el pasaje a través del tracto gastrointestinal. Nueve de 
Selección de microorganismos probióticos.

estos genes codifican para funciones relacionadas al metabolismo de azúcares, incluyendo ribosa, celobiosa, sacarosa y sorbitol. Otros 9 genes codifican para funciones involucradas en la adquisición y la síntesis de aminoácidos, nucleótidos, cofactores y vitaminas. También encontraron cuatro genes que codifican para proteínas extracelulares que podrían estar implicadas en la interacción con factores específicos del huésped.

La enzima UTP glucosa-1-fosfato uridiltransferasa interviene en la activación de azúcares catalizando la siguiente reacción:

glucosa-1-fosfato + UTP $\rightleftharpoons$ UDP-glucosa + pirofosfato

La regulación positiva de las enzimas que puedan estar relacionadas a la activación de azúcares podría indicar que frente al estrés aumentaría la producción de exopolisacáridos. El rol fisiológico que los exopolisacáridos (EPS) juegan en las bacterias que los producen no es claro, pero la gran cantidad de energía que se consume en su producción hace suponer que otorgan importantes ventajas a los microorganismos que los originan. Los EPS no actúan como fuente de energía o de carbono sino que se relacionan con la adaptación y reconocimiento de factores ambientales, mejorando así la adaptación de los microorganismos a diferentes ecosistemas (Ruas-Madiedo et al. 2008).

Muchos trabajos describen el efecto del estrés ácido y de bilis de manera separada. Se ha descripto que la respuesta al tratamiento con bilis implica una variedad de procesos dirigidos tanto al proceso de detoxificación de la bilis (la activación de la salida de bilis o sales biliares o su hidrólisis) y a contrarrestar el efecto del medio en estructuras celulares mediante cambios en la pared o membrana celular. La exposición a la bilis puede dar lugar a cambios en la composición de ácidos grasos y fosfolípidos de las membranas bacterianas y a la distorsión de la superficie celular. Entre ellos la producción de EPS o generación de proteínas de superficie podrían ser mecanismos de respuesta al estrés (Ruiz et al. 2013). En Bifidobacterium se ha demostrado que la producción de EPS es un mecanismo de respuesta al estrés de bilis (Ruas-Madiedo et al. 2009). El ambiente hidrofílico creado por el exopolisacárido alrededor de las estructuras celulares externas podría favorecer la absorción de nutrientes e iones, o bien actuar 
como mecanismo de desintoxicación bloqueando el contacto de compuestos tóxicos con la pared y membrana celular. Así, los EPS constituyen una barrera hidrofílica que puede proteger a la bacteria y contribuir a su adhesión a superficies, por ejemplo, a la mucosa intestinal.

La enzima gliceraldehído-3-fosfato deshidrogenasa (GAPDH) es una enzima citoplasmática que participa en la glicólisis, sin embargo muchas enzimas del metabolismo de carbohidratos a menudo se encuentran asociadas a la pared celular y son capaces de ejercer otras funciones denominandas "Moonlighting functions". Se ha descripto en $L$. plantarum que la GAPDH asociada a superficie es capaz de interactuar con otras matrices como mucina y fibronetectina (Gonzalez-Rodríguez et al. 2012). En consecuencia la regulación positiva de esta enzima no sólo podría asociarse a una activación de las vías que producen energía, en caso de que estas enzimas se encuentren en el citosol, sino también podría pensarse que las isoenzimas de GAPDH que están reguladas positivamente estarían asociadas a pared y jugarían un rol en los procesos de interacción con células epiteliales o mucus del hospedador. 
Selección de microorganismos probióticos.

\section{Efecto antagónico contra Salmonella enterica serovar Enteritidis}

Para estudiar el efecto antagónico contra Salmonella Enteritidis de L. paracasei CIDCA 8339, CIDCA 83120, CIDCA 83121, CIDCA 83123 y CIDCA 83124 y L. kefiri CIDCA 83102 se empleó el modelo de células de epitelio intestinal Caco-2/TC-7. Se analizó la capacidad de asociación e invasión de Salmonella enterica serovar Enteritidis utilizando diferentes diseños experimentales. Se evaluó luego el efecto antagónico de los microorganismos seleccionados como también de sus sobrenadantes.

Asociación e invasión de Salmonella a células Caco-2/TC-7.

En una primera etapa, se estudió la capacidad de asociación e invasión de Salmonella a células Caco-2/TC-7 en cultivo. Salmonella posee un sistema altamente especializado que le permite interactuar con la célula epitelial y causar una infección. El primer paso es la colonización del epitelio intestinal que va a depender de la capacidad de adhesión de las bacterias. Hay numerosos receptores fisiológicos en la superficie de las células intestinales donde la bacteria se puede unir (Lu \& Walker, 2001). Generalmente, adherirse al epitelio intestinal es un paso esencial para poder resistir el flujo de fluidos y los movimientos peristálticos en el intestino. Una vez adherida al epitelio, se producen cambios morfológicos y arreglos en el citoesqueleto que tienen como consecuencia que las células intestinales internalicen la bacteria (Darwin \& Miller, 1999).

Para los estudios de asociación de Salmonella a las células epiteliales in vitro se realiza un recuento del total de bacterias (adheridas + internalizadas), mientras que para determinar el nivel de internalización o invasión es necesario diferenciar las bacterias adheridas de las que se encuentran dentro de las células utilizando un antibiótico. Uno de los más utilizados es la gentamicina. Este antibiótico tiene la particularidad que no difunde a través del dominio apical de las células por lo que las bacterias que no se internalizan se ven afectadas por el antibiótico y las que están internalizadas sobreviven. Se utilizó $100 \mu \mathrm{g} / \mathrm{ml}$ de gentamicina durante 1 hora de incubación, considerándose este tratamiento apropiado para los estudios de invasión (Golowczyc et al. 2007; Mynott et al. 2002). 
Se analizó la asociación e invasión de Salmonella Enteritidis empleando una dosis infectiva de patógeno de $10^{6} \mathrm{UFC} / \mathrm{ml}$, lo que representa una multiplicidad de infección (mdi) de 1 bacteria por cada célula epitelial. Los estudios de asociación e invasión a células Caco-2/TC-7 mostraron que Salmonella enterica serovar Enteritidis se asocia $\left(2,85.10^{5} \mathrm{UFC} / \mathrm{ml}\right)$ un orden menos, e invade $\left(3,34.10^{4} \mathrm{UFC} / \mathrm{ml}\right)$ dos órdenes menos que las bacterias iniciales (Figura 16).

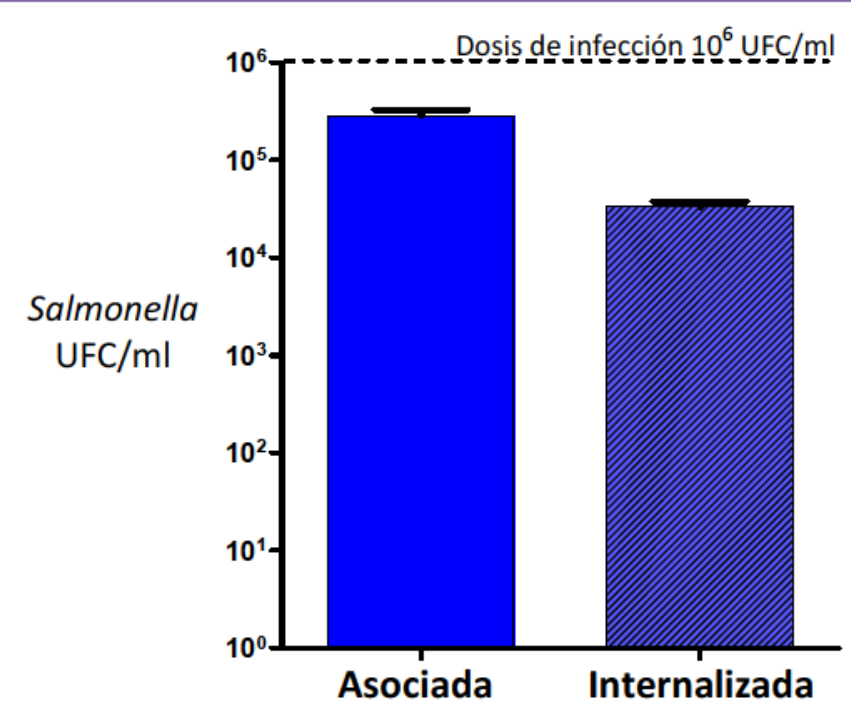

Figura 16. Asociación (adhesión + invasión) e invasión de Salmonella enterica serovar Enteritidis CIDCA 101 a monocapas de células Caco-2/TC-7. Los valores corresponden al promedio de diez ensayos independientes. Las barras indican desvío estándar. La línea punteada indica una dosis de infección $1.10^{6} \mathrm{UFC} / \mathrm{ml}$.

Los resultados también se pueden presentar como el porcentaje de bacterias asociadas e internalizadas con respecto al total de bacterias agregadas por $\mathrm{ml}$. En este caso, se pudo observar que aproximadamente un $28,50 \%$ de las bacterias se asocian y un 3,33\% de las bacterias totales agregadas invaden siendo la relación entre las bacterias que internalizan con respecto a las que se asocian de $12,72 \%$ aproximadamente.

Golowczyc et al. (2007) describieron que la asociación de esta cepa a células Caco-2/TC-7 es 6,5 \% y la invasión de 0,11 \% coincidiendo con los resultados de Londero et al. (2014). Ambos ensayos se realizaron utilizando una dosis inicial de $10^{8} \mathrm{UFC} / \mathrm{ml}$. Sin embargo los ensayos realizados con una dosis de infección de $10^{6} \mathrm{UFC} / \mathrm{ml}$, presentaron valores de asociación e internalización de Salmonella (Londero et al. 2014) similares a los obtenidos en esta tesis. 
Selección de microorganismos probióticos.

Shah et al. (2011) hallaron que la capacidad de invadir células Caco-2 de 55 cepas de Salmonella Enteritidis era variable, encontrando que de las cepas evaluadas, 30 presentaron capacidad invasiva alta ( 0,60\%), 18 intermedia $(\sim 0,10 \%)$, y 7 baja ( 0,05 \%). Considerando la clasificación descripta por estos autores la capacidad invasiva de Salmonella Enteritidis CIDCA 101 evaluada en el presente trabajo fue alta (3,33\%).

La capacidad de asociación de Salmonella varía según la línea celular utilizada debido a los diferentes tipos de receptores superficiales celulares y las estructuras de adhesión del patógeno. Salmonella establece un estrecho contacto con el ribete en cepillo del epitelio intestinal. Cuando la bacteria se acerca a la superficie epitelial, las microvellosidades circundantes empiezan a degenerarse con elongación, edema y crecimiento en un proceso llamado ruffling (rizado). Aquí, los efectores interactúan con las proteínas de la célula hospedadora para arreglar el citoesqueleto de actina e inducir cambios morfológicos que causan que estas células, normalmente no fagocíticas, internalicen la bacteria en un proceso llamado invasión.

Se ha descripto que luego de la entrada de Salmonella a los enterocitos, las bacterias internalizadas en vacuolas membranosas son rodeadas por estructuras densas de 5-10 $\mu$ m conformadas por varios componentes del citoesqueleto. Estas estructuras consisten en agregados de actina polimerizada, alfa-actinina y tropomiosina sobre la bacteria invasora y a los costados de la misma, y son evidentes luego de la adición de la bacteria patógena a células epiteliales en cultivo, siendo detectadas luego de 20 a 60 minutos de incubación dependiendo del modelo de células empleado (Finlay et al. 1991). A fin de estudiar las modificaciones en el citoesqueleto de las células Caco-2/TC-7 luego de su infección con Salmonella, se analizó la red de actina del citoesqueleto mediante la utilización de faloidina que presenta alta afinidad por esta estructura. Se utilizó como marcador fluorescente isotiocianto de fluoresceina unido a faloidina (FITCfaloidina) (Figura 17). 


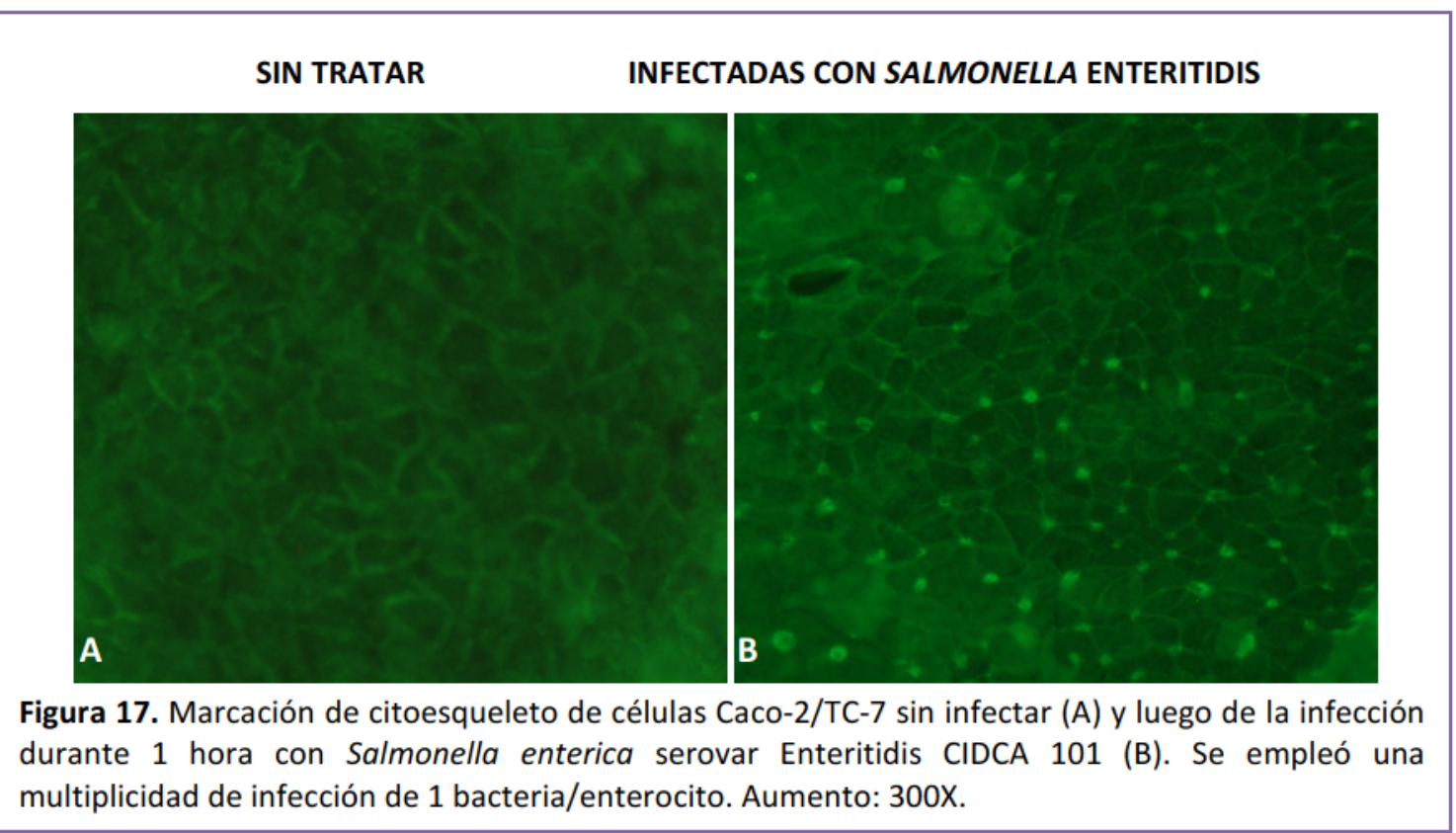

En las células sin infectar, la actina se distribuyó de modo uniforme en los bordes de las células y en las microvellosidades, asimismo se observó un patrón continuo de contacto entre las células (Figura 17 A). Las células infectadas presentaron una alteración de la estructura del citoesqueleto, en algunas zonas de la monocapa se observó una distribución menos homogénea de la actina y mayor concentración de la misma en los contactos entre células (Figura 17 B) coincidiendo con trabajos publicados con diferentes cepas de Salmonella (Londero et al. 2014; Coconnier et al. 1999; Zihler et al. 2011).

Interacción de los lactobacilos con Salmonella Enteritidis y efecto en la invasión a células Caco-2/TC-7.

Coagregación de lactobacilos con Salmonella entérica serovar Enteritidis.

Existen microorganismos probióticos que tienen la capacidad de interaccionar con microorganismos patógenos. Ciertos lactobacilos pueden coagregar con Salmonella y mediante esta coagregación modificar la capacidad de adhesión o invasión de este patógeno. Por este motivo, se estudió primero el potencial de coagregación de estos microorganismos con Salmonella, y luego el efecto de esta interacción respecto a la asociación-internalización de Salmonella a las células epiteliales Caco-2/TC-7. 
Selección de microorganismos probióticos.

Podemos definir como coagregación a la interacción entre diferentes microorganismos a través de moléculas superficiales tales como proteínas, carbohidratos, etc. Durante la coagregación actúan mecanismos físicoquímicos, tales como fuerzas de Van der Waals, electrostáticas, interacción mediada por lectina (Golowczyc et al. 2009), etc. La coagregación es altamente específica y cada microorganismo tiene un conjunto de moléculas y mecanismos de reconocimiento célula-célula que le permite interaccionar sólo con microorganismos que presenten ese mismo patrón (Kolenbrander 1991). La coagregación entre pares microbianos es frecuentemente estudiada mezclando ambos microorganismos en un tubo de ensayo y realizando la evolución de la coagregación mediante diferentes determinaciones. Uno de los métodos más sencillos es el macroscópico, donde se ve a simple vista la formación de agregados. También se puede ver la formación de cúmulos bajo el microscopio (método microscópico). Estas dos formas tienen la ventaja que son simples y rápidas pero no son métodos cuantitativos. Una forma de medir cuantitativamente la coagregación es por el método turbidimétrico donde se mide en un espectrofotómetro la caída de la densidad óptica en el tiempo, producto de la sedimentación de los agregados. Este método no sólo es simple y cuantitativo sino que permite tener una idea de la cinética de coagregación, es decir, cuán rápido se produce la interacción entre los pares coagregantes. En estos ensayos, si ocurre la coagregación, se observa una sedimentación más rápida.

Se realizaron ensayos de coagregación enfrentando los lactobacilos con Salmonella entérica serovar Enteritidis CIDCA 101 en buffer fosfato pH 7. En la Figura 18 se muestran las curvas de descenso de DO $(600 \mathrm{~nm})$ en función del tiempo de L. paracasei 8339, L. paracasei 83123 y L. kefiri 83102, junto con la curva de descenso de DO correspondiente a Salmonella (autoagregación) y la curva correspondiente a la coagregación de cada lactobacilo con Salmonella. Las suspensiones fueron ajustadas a $\mathrm{DO}_{600}=1$ y la concentración de bacterias lácticas fue de $1.10^{8} \mathrm{UFC} / \mathrm{ml}$. 

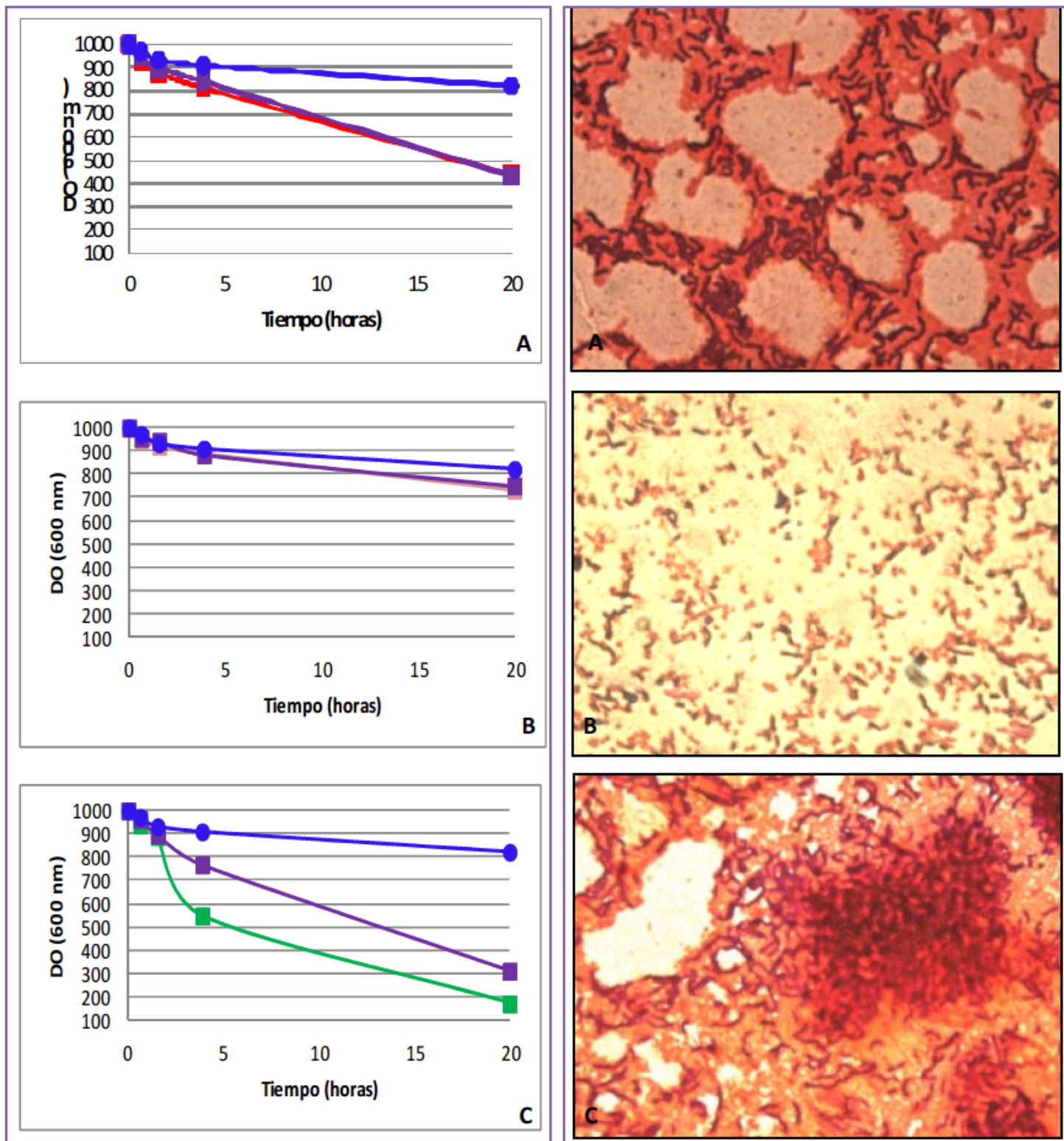

Figura 18. Descenso de DO en función del tiempo de lactobacilos (autoagregacion) o lactobacilos con Salmonella entérica serovar Enteritidis CIDCA 101 (coagregación). Lactobacillus paracasei CIDCA 8339 (A) Lactobacillus paracasei CIDCA 83123 (B) Lactobacillus kefiri CIDCA 83102 (C)

Autoagregación de lactobacilos ( $\square \square \square$ ), coagregación con Salmonella entérica serovar Enteriditis CIDCA 101 (口) y autoagregación de Salmonella entérica serovar Enteriditis CIDCA 101 (O).

Figura 19. Observación microscópica de la coagregación de Salmonella entérica serovar Enteritidis CIDCA 101 (100X) con Lactobacillus paracasei CIDCA 8339 (A) Lactobacillus paracasei CIDCA 83123 (B) Lactobacillus paracasei CIDCA 83102 (C) a las 20 horas de ensayo.

En la Figura 18 se puede observar que Salmonella Enteritidis no mostró autoagregación alguna (curva azul). Las curvas roja, rosa y verde ( $\square \square$ ) representan el descenso de DO (600 nm) en función del tiempo de los lactobacilos indicando que las 
Selección de microorganismos probióticos.

cepas seleccionadas presentan un comportamiento diferente. Se observó que L. kefiri CIDCA 83102 (verde) es capaz de autoagregar, mientras que L. paracasei CIDCA 8339 (roja) presenta un comportamiento parcialmente autoagregante y L. paracasei CIDCA 83123 (rosa) no tiene la capacidad de autoagregar. Las curvas violetas ( $\square$ ) indican la coagregación entre cada lactobacilo y Salmonella. En la Figura 18 A se observó un descenso parcial de DO $(600 \mathrm{~nm})$ indicando autoagregación de L. paracasei CIDCA 8339, no encontrándose diferencias con el descenso de la DO al incubarlo con Salmonella. Al analizar el aspecto del sedimento a las 20 horas de contacto, mediante microscopía óptica (100X), se observó interacción de L. paracasei CIDCA 8339 (Gram +) con Salmonella (Gram -) (Figura 19 A). L. paracasei CIDCA 83123 no mostró descenso de DO en función del tiempo (Figura 18 B), tanto cuando el lactobacilo se ensayó solo como con Salmonella, siendo ambas curvas muy similares a la correspondiente a Salmonella. La observación al microscopio de los sedimentos se presenta en la Figura 19 B, en la cual se observaron los lactobacilos dispersos sin interacción evidente con Salmonella, concluyendo que L. paracasei CIDCA 83123 no autoagrega ni coagrega con Salmonella. Por último, en la Figura $18 \mathrm{C}$ se presentaron las curvas de descenso de DO correspondientes a L. kefiri CIDCA 83102. Se observó que el descenso en la curva de DO en función del tiempo correspondiente al lactobacilo con Salmonella es menor al del lactobacilo solo. En las imágenes al microscopio óptico (Figura $19 \mathrm{C}$ ) se observaron "cúmulos" de diferentes tamaños de lactobacilos (coloración violeta) y Salmonella (coloración roja). Esto indicaría que al cabo de 20 horas, existe interacción entre ambos microorganismos. Los resultados obtenidos con L. paracasei CIDCA 83120, CIDCA 83121 y CIDCA 83124 se asemejan a los obtenidos para L. paracasei CIDCA 83123, no coagregantes con Salmonella (Tabla 6). 
Tabla 6. Valores de DO $(600 \mathrm{~nm})$ obtenidos a partir de las cinéticas de coagregación de lactobacilos con Salmonella entérica serovar Enteritidis CIDCA 101 determinadas a 1 y 20 horas de incubación.

\begin{tabular}{|c|c|c|}
\hline & \multicolumn{2}{|c|}{ Coagregación con Salmonella } \\
\hline & 1 hora & 20 horas \\
\hline L. paracasei CIDCA 8339 & $0,674 \pm 0,023$ & $0,374 \pm 0,082$ \\
\hline L. paracasei CIDCA 83120 & $0,708 \pm 0,006$ & $0,603 \pm 0,066$ \\
\hline L. paracasei CIDCA 83121 & $0,670 \pm 0,014$ & $0,477 \pm 0,033$ \\
\hline L. paracasei CIDCA 83123 & $0,686 \pm 0,006$ & $0,583 \pm 0,059$ \\
\hline L. paracasei CIDCA 83124 & $0,608 \pm 0,002$ & $0,523 \pm 0,075$ \\
\hline L. kefiri CIDCA 83102 & $0,724 \pm 0,037$ & $0,275 \pm 0,049$ \\
\hline
\end{tabular}

Preincubación de Salmonella Enteritidis con lactobacilos aislados de kefir. Efecto en la invasión a células Caco-2/TC-7.

Se estudió la capacidad de Salmonella de asociarse y/o invadir la monocapa de células Caco-2/TC-7 previa incubación de Salmonella Enteritidis con los lactobacilos seleccionados. Para ello, se siguió el protocolo experimental que se detalla en la Figura 20.

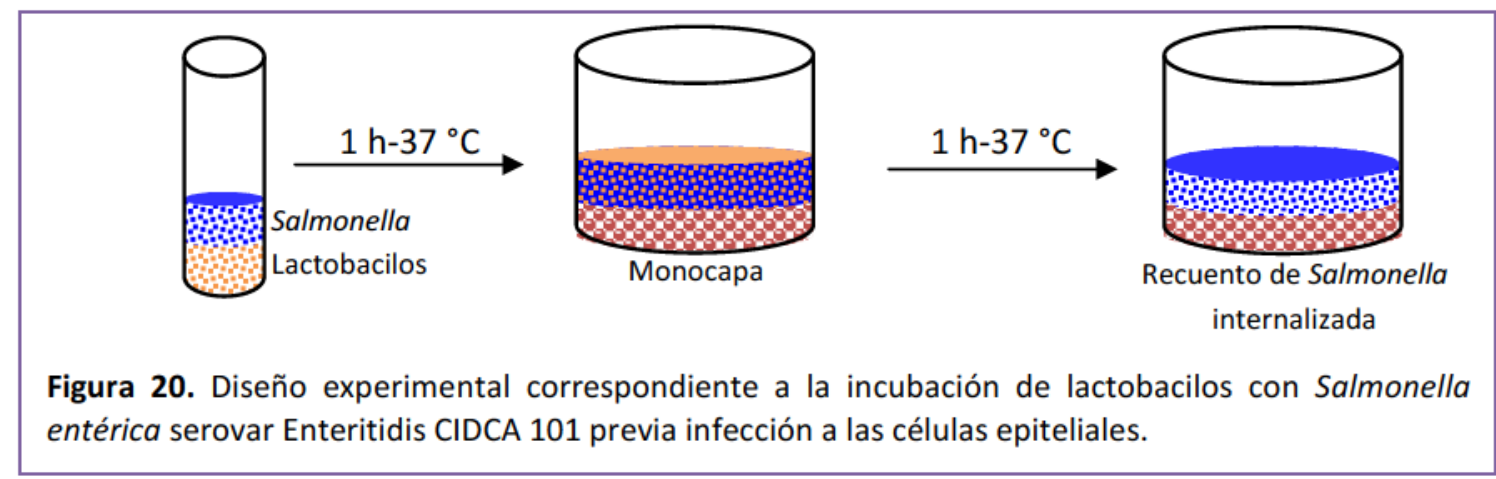

Los resultados se presentan en la Figura 21 donde se muestra el recuento de Salmonella internalizada en las células epiteliales (columna azul) y el recuento de Salmonella internalizada previa incubación de este patógeno con los lactobacilos estudiados. 
Selección de microorganismos probióticos.

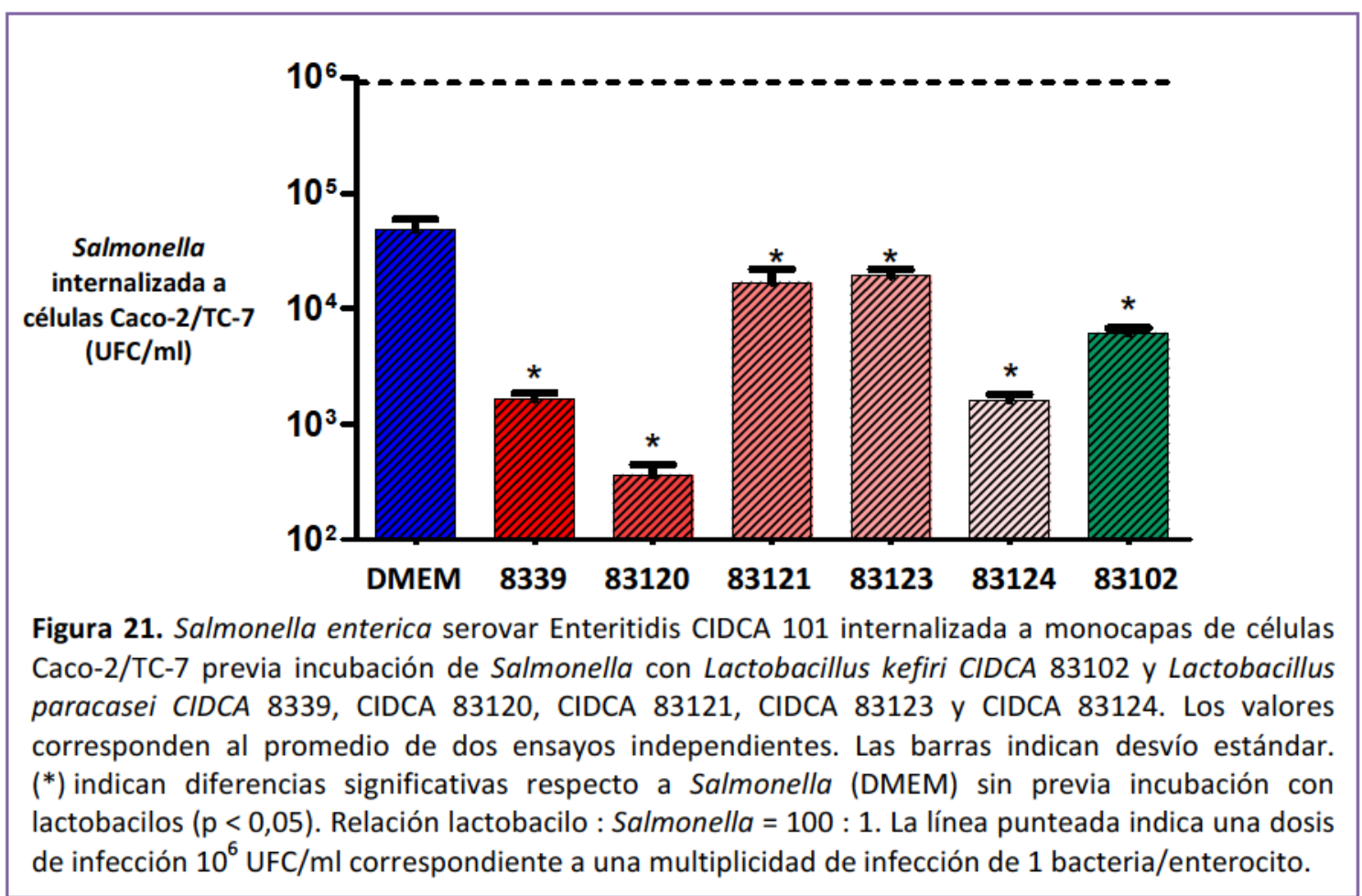

La incubación previa de Salmonella con L. kefiri CIDCA 83102 y L. paracasei CIDCA 8339, CIDCA 83120, CIDCA 83121, CIDCA 83123 y CIDCA 83124 (Figura 21) tuvo como consecuencia una disminución significativa del número de Salmonella internalizada $(p<0,05)$ con respecto al control (Salmonella internalizada sin previa incubación con lactobacilos). Todos los lactobacilos presentaron diferencias significativas respecto al control.

Esto indicaría que la incubación del lactobacilo con el patógeno estaría induciendo algunos cambios en Salmonella que afectan su capacidad de invadir el epitelio, resultando en un menor número del patógeno internalizado. Esta disminución fue más acentuada (dos órdenes logarítmicos) cuando Salmonella fue incubada previamente con L. paracasei CIDCA 8339, CIDCA 83120 y CIDCA 83124, mientras que cuando Salmonella fue incubada previamente con L. kefiri CIDCA 83102 la disminución de Salmonella internalizada fue de sólo un orden. L. paracasei CIDCA 83121 y CIDCA 83123 fueron los lactobacilos que afectaron la internalización de Salmonella en menor medida, siendo la disminución sólo de medio orden logarítmico.

Estos resultados demuestran que la preincubación de los lactobacilos con Salmonella afecta la capacidad que tiene este patógeno de invadir la monocapa. La interacción lactobacilo-patógeno comienza antes de que ambos microorganismos tomen 
contacto con el epitelio intestinal y como resultado de esta interacción, determinados sitios o estructuras necesarias del patógeno para la invasión podrían ser enmascarados o modificados por el diálogo que se establece con el lactobacilo. Otros investigadores demostraron que la coagregación con patógenos previene la colonización del epitelio por estos microorganismos (Reid et al. 1988; Boris et al. 1998; Šušković et al. 1997; Del Re et al. 2000). Golowczyc et al. (2007) usaron 8 cepas de L. kefiri, de las cuales sólo 4 de ellas coagregaron con Salmonella entérica serovar Enteritidis CIDCA 101, siendo las mismas capaces de afectar significativamente la capacidad de Salmonella de invadir las células. Por otro lado, se ha descripto que L. plantarum CIDCA 8327 no coagrega con Salmonella Enteritidis (Golowczyc 2008), y sin embargo Londero et al. (2014) describieron que esta cepa ejerce un efecto antagónico sobre la invasión de Salmonella a células epiteliales, coincidiendo con los resultados obtenidos con L. paracasei CIDCA 83120 y CIDCA 83124, lactobacilos no coagregantes con Salmonella. De acuerdo a los resultados presentados con las cepas en estudio, todas las cepas de L. paracasei estudiadas y L. kefiri CIDCA 83102 tuvieron la capacidad de disminuir significativamente la cantidad de Salmonella internalizada a células de epitelio intestinal in vitro, aunque en diferente medida, siendo las que ejercieron un mayor efecto protector L. paracasei CIDCA 8339, CIDCA 83120 y CIDCA 83124 y L. kefiri CIDCA 83102, no asociándose este efecto con la capacidad de coagregación.

Efecto barrera de los lactobacilos sobre la asociación e invasión de Salmonella Enteritidis. Preincubación de la monocapa de enterocitos con lactobacilos.

Uno de los mecanismos a través del cual los probióticos pueden proteger al hospedador de la acción de patógenos intestinales es mediante el denominado "efecto barrera". Este hace referencia al proceso mediante el cual los microorganismos benéficos asociados a la monocapa impiden el contacto del patógeno con las células epiteliales evitando así su asociación e invasión.

A fin de evaluar si los lactobacilos seleccionados son capaces de ejercer el efecto barrera en la asociación del patógeno, los mismos fueron resuspendidos en PBS e incubados con las células de epitelio intestinal durante 1 hora a $37{ }^{\circ} \mathrm{C}$. Durante este 
Selección de microorganismos probióticos.

tiempo quedaron adheridos a la monocapa bacterias ácido lácticas en el orden de $3.10^{5}$ a $5.10^{6} \mathrm{UFC} / \mathrm{ml}$ (Figura 7). Luego se procedió a la infección con Salmonella Enteritidis CIDCA 101 a una concentración $10^{6} \mathrm{UFC} / \mathrm{ml}$ y se evaluó la asociación e invasión del patógeno (Figura 22).

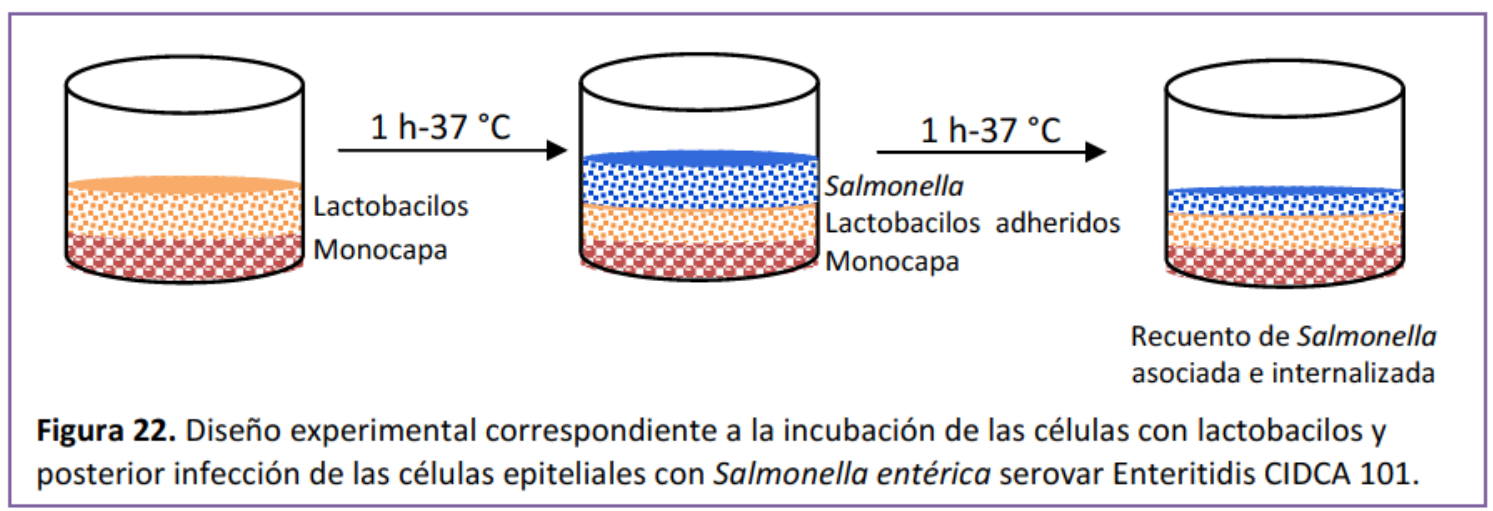

La acción protectora de microorganismos probióticos sobre la asociación de Salmonella Enteritidis a enterocitos en cultivo depende de la relación numérica entre el patógeno y los probióticos (Bernet et al. 1994, Coconnier et al. 1993). Londero et al. (2014) demostraron que era necesario que el número de probióticos supere en dos órdenes logarítmicos al de patógeno para ejercer un efecto protector, por ello, en este trabajo se eligió una relación entre lactobacilo y patógeno 100 : 1.

En la Figura 23 se presentan los resultados correspondientes a los ensayos de Salmonella asociada e internalizada a las células epiteliales en presencia de diferentes cepas de lactobacilos siguiendo el diseño experimental de la Figura 22. 

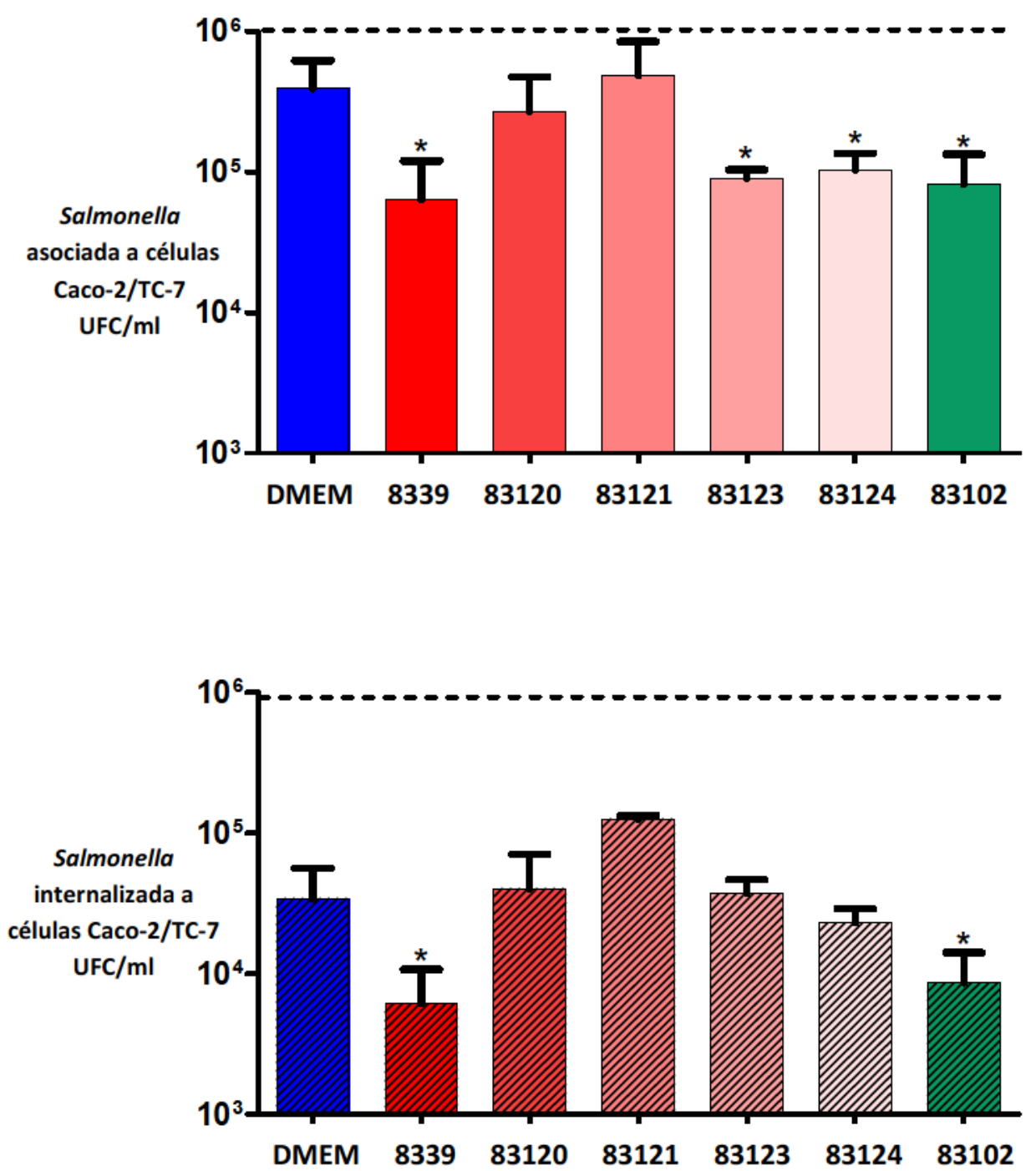

Figura 23. Asociación (arriba) e invasión (abajo) de Salmonella enterica serovar Enteritidis CIDCA 101 preincubada con lactobacilos aislados de kefir a monocapas de células Caco-2/TC-7. Los valores corresponden al promedio de tres ensayos independientes. Las fosas preincubadas con DMEM sin lactobacilos fueron usadas como control. Las barras indican desvío estándar. $\left({ }^{*}\right)$ indican diferencias significativas positivas respecto al control $(p<0,05)$. Relación lactobacilo : Salmonella $=100: 1$. La línea punteada indica una dosis de infección $10^{6} \mathrm{UFC} / \mathrm{ml}$ correspondiente a una multiplicidad de infección de 1 bacteria/enterocito.

La capacidad de las cepas de lactobacilos para inhibir la asociación de bacterias patógenas es una propiedad altamente específica, dependiendo tanto de la cepa probiótica como del patógeno (Lee et al. 2003). La incubación de la monocapa con las cepas L. paracasei CIDCA 8339, CIDCA 83123, CIDCA 83124 y L. kefiri CIDCA 83102 disminuyeron el número de Salmonella asociada a las células epiteliales en cultivo. Sin embargo, sólo las cepas L. paracasei CIDCA 8339 y L. kefiri CIDCA 83102 disminuyeron la capacidad de Salmonella de internalizar en la monocapa. 
Selección de microorganismos probióticos.

Trabajos previos demostraron que la inhibición de la asociación de patógenos a células Caco-2 está directamente relacionada con la capacidad de adhesión de los lactobacilos (Bernet-Camard et al. 1997; Fernandez et al. 2003; Lee et al. 2003; Santos et al. 2003). En este trabajo se encontró que si bien todos los lactobacilos seleccionados presentaron buena capacidad de adhesión a células Caco-2/TC-7, los lactobacilos que se adhirieron en menor medida como L. paracasei CIDCA 83123 y CIDCA 83124 afectaron solamente la capacidad de asociación de Salmonella a las células epiteliales, mientras que los lactobacilos que presentaron los valores de adhesión a células Caco-2/TC-7 más altos como L. paracasei CIDCA 8339 y L. kefiri CIDCA 83102 disminuyeron no sólo la capacidad de Salmonella de asociarse al epitelio sino también su capacidad de internalizar en las células. Por otro lado, L. paracasei CIDCA 83120 y L. paracasei CIDCA 83121 no presentaron efecto alguno sobre la infección con Salmonella.

Teniendo en cuenta el número de lactobacilos adheridos (Figura 7) y el número de células en la monocapa, la misma no está homogéneamente cubierta por los lactobacilos apareciendo zonas descubiertas donde Salmonella podría asociarse e invadir (Golowczyc et al. 2008). Se ha descripto que, cuando los microorganismos adheridos a células epiteliales in vitro no forman una cubierta homogénea, no impiden la asociación del patógeno (Martins et al. 2010). De acuerdo a nuestros resultados este hecho no sería tan relevante ya que lactobacilos con capacidad de adherirse a epitelio muestran diferentes efectos protectores del daño inducido por Salmonella, indicando que este resultado no se debe solamente a un efecto barrera y que podrían existir otros cambios en la célula epitelial que mejoren la resistencia a la infección.

La interacción previa de los lactobacilos con la célula epitelial es esencial para ejercer un efecto protector. Das et al. (2013) observaron una reducción significativa en la asociación de S. Enteritidis a células HCT-116 (línea celular de carcinoma colorrectal humano) cuando se preincubaron las células con L. plantarum KSBT 56. La eficiencia de la invasión se redujo en un 80 \% con la adición de L. plantarum KSBT 561 hora antes de la adición de S. Enteritidis. Sin embargo, algunos autores mostraron que hay un aumento en la adhesión de patógenos a células y mucus en presencia de probióticos (Rinkinen et al. 2003). 
Al analizar el porcentaje de Salmonella que internalizó en las células respecto a las que se asociaron se pudo evidenciar que los ensayos realizados preincubando con L. paracasei CIDCA 8339 y L. kefiri CIDCA 83102 presentaron la misma relación que Salmonella control (10,77 \%) (Figura 24), indicando que la disminución en la capacidad de invasión de Salmonella observada en la Figura 23 se debe principalmente a la disminución en la capacidad de asociación a epitelio.

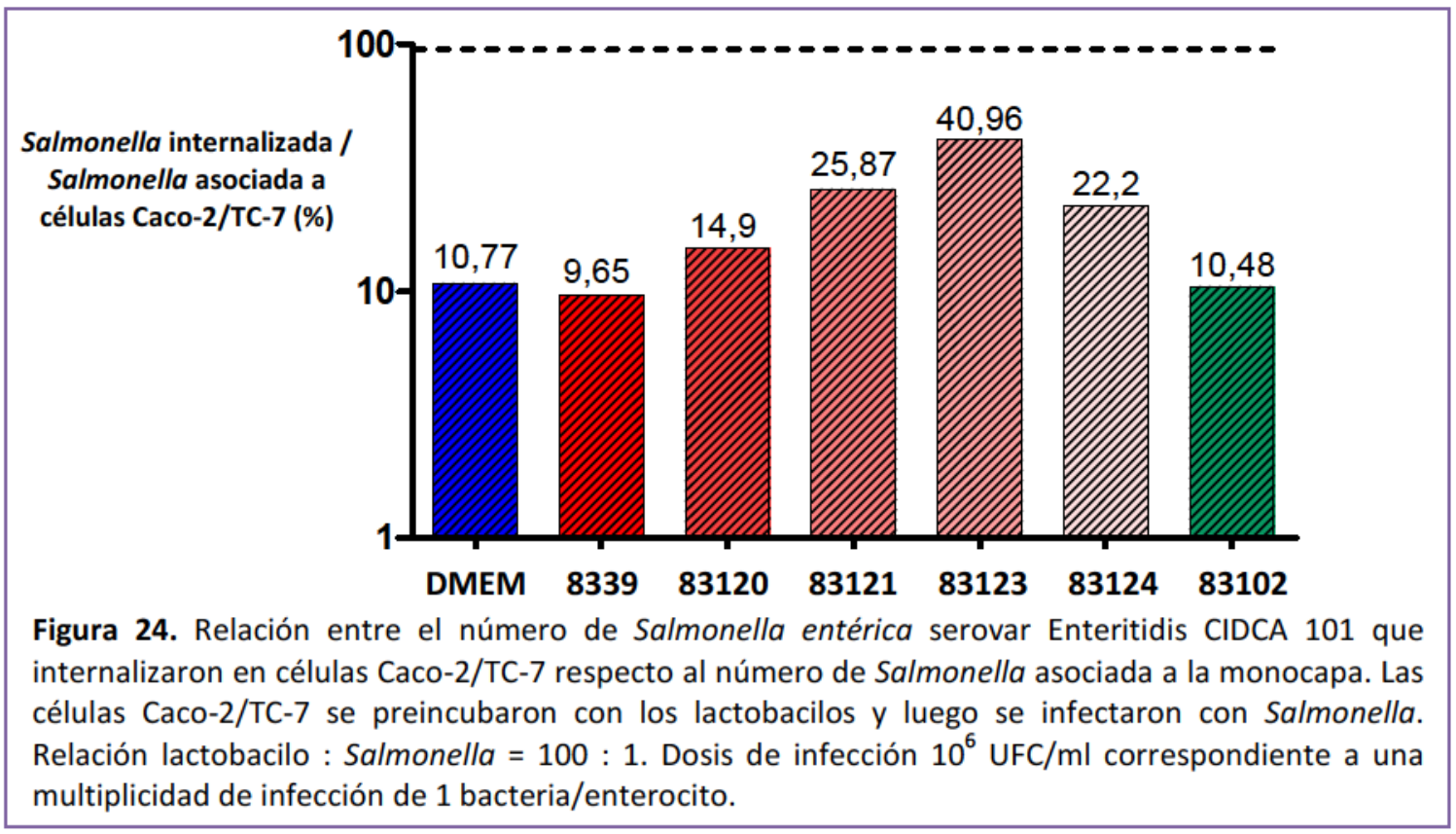

Efecto de los lactobacilos en la desorganización del citoesqueleto causado por Salmonella Enteritidis.

Habiendo demostrado que las cepas L. paracasei CIDCA 8339 y L. kefiri CIDCA 83102 fueron capaces de disminuir la invasión de Salmonella a los enterocitos se estudió la morfología de la red de F-actina de las células Caco-2/TC-7 luego de la preincubación de las células con los lactobacilos e infectadas con Salmonella (Figura 25). 
Selección de microorganismos probióticos.
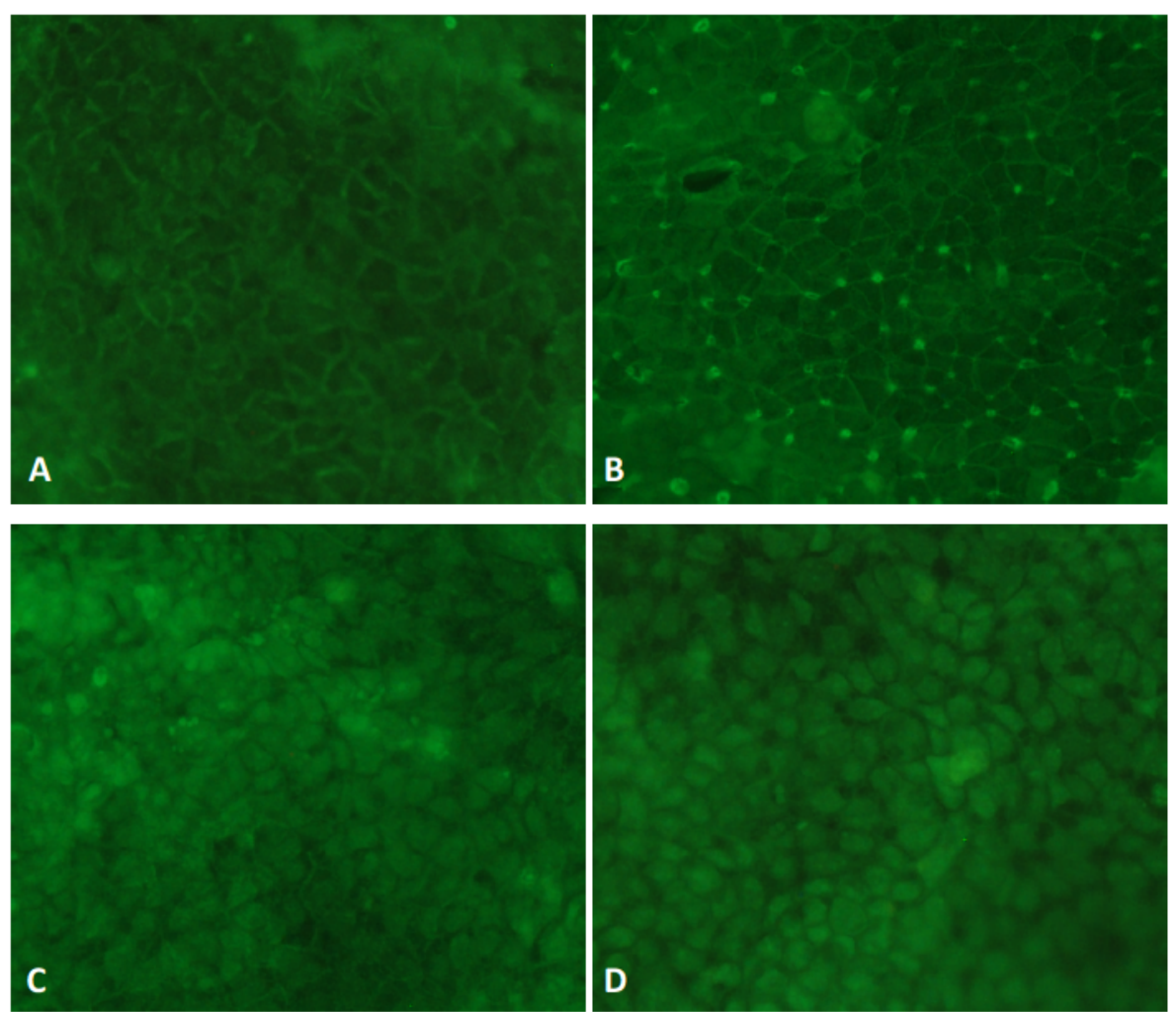

Figura 25. Marcación de citoesqueleto con faloidina FITC de células Caco-2/TC-7 sin tratamiento (A), infectadas con Salmonella entérica serovar Enteritidis CIDCA 101 (B), incubadas con Lactobacillus paracasei CIDCA 8339 (C) y con Lactobacillus kefiri CIDCA 83102 (D) antes de la infección. Se empleó una dosis de infección $10^{6} \mathrm{UFC} / \mathrm{ml}$ correspondiente a una multiplicidad de infección de 1 bacteria/enterocito. Aumento: 300X.

Como se muestra en la Figura 25 B la infección de la monocapa con Salmonella causó una desorganización de la red de actina que se evidenció mediante acumulación de esta proteína en las uniones entre las células sin llegar a redondearlas ni causar su desprendimiento. La observación microscópica de la morfología y del citoesqueleto de los enterocitos demostró que la preincubación de las monocapas con L. paracasei CIDCA 8339 (Figura 25 C) y, L. kefiri CIDCA 83102 (Figura 25 D) fue capaz de antagonizar el efecto del patógeno en las células eucariotas, preservando la monocapa y mostrando un aspecto similar al control sin tratamiento (Figura $25 \mathrm{~A}$ ). 
Efecto de los sobrenadantes libres de células de lactobacilos aislados de kefir sobre Salmonella Enteritidis.

Acción bactericida de los sobrenadantes libres de células de lactobacilos aislados de kefir sobre Salmonella. Curvas de muerte.

En una primera etapa se evaluó el efecto sobre la viabilidad de Salmonella de los sobrenadantes libres de células de los lactobacilos crecidos en caldo MRS. En la Tabla 7 se muestra el pH y la concentración de ácido láctico presente en los sobrenadantes de cultivo de cada lactobacilo. Sólo se consideró el ácido láctico debido a que los valores de ácido acético encontrados en los sobrenadantes de cultivo no fueron significativamente diferentes al encontrado en el medio MRS fresco. El pH de los sobrenadantes de L. kefiri CIDCA 83102 fue cercano a 4,28 mientras que el pH de los sobrenadantes de L. paracasei variaron entre 3,70 y 4,09. Los valores bajos de $\mathrm{pH}$ se correlacionan con un mayor contenido de ácido láctico (Tabla 7). En la misma tabla se presentan los valores de ácido láctico no disociado.

Tabla 7. pH, concentración de ácido láctico total y ácido láctico no disociado de los sobrenadantes de cultivo en MRS de lactobacilos aislados de kefir.

\begin{tabular}{|c|c|c|c|}
\hline Lactobacilo & $\begin{array}{c}\text { pH sobrenadante } \\
\text { (SN) }\end{array}$ & $\begin{array}{c}\text { Concentración de } \\
\text { ácido láctico total } \\
\text { (mM)* }\end{array}$ & $\begin{array}{c}\text { Concentración de } \\
\text { ácido láctico no } \\
\text { disociado (mM) }\end{array}$ \\
\hline L. paracasei CIDCA 8339 & 3,70 & $291,32 \pm 6,78$ & 175,02 \\
L. paracasei CIDCA 83120 & 4,09 & $282,98 \pm 4,21$ & 105,98 \\
L. paracasei CIDCA 83121 - & 3,76 & $281,19 \pm 10,30$ & 160,77 \\
L. paracasei CIDCA 83123 & 3,85 & $282,93 \pm 1,86$ & 143,76 \\
L. paracasei CIDCA 83124 & 3,70 & $287,28 \pm 2,45$ & 168,78 \\
L. kefiri CIDCA 83102 & 4,28 & $144,42 \pm 8,73$ & 39,78 \\
\hline
\end{tabular}

*analizado por HPLC

La Figura 26 A muestra las curvas de muerte de Salmonella en los sobrenadantes de L. paracasei CIDCA 83120 ( $\square$ ) y L. kefiri CIDCA 83102 (๑) cuyos pH son 4,09 y 4,28 respectivamente. Estas curvas están representadas junto al control de Salmonella ( $\boldsymbol{\Delta})$ en caldo MRS acidificado artificialmente con ácido láctico $(\mathrm{pH} 4,25)$. Se observó que al cabo de una hora, el número de Salmonella viable es menor en los sobrenadantes de 
Selección de microorganismos probióticos.

ambos lactobacilos respecto al medio acidificado artificialmente con un $\mathrm{pH}$ similar al de los sobrenadantes de los lactobacilos antes mencionado. Este efecto fue más marcado cuando Salmonella se incubó en el sobrenadante de L. kefiri CIDCA 83102, indicando que en este sobrenadante podrían existir otros factores que conllevan a una pérdida de la viabilidad de hasta 3 órdenes logarítmicos con respecto al valor inicial correspondiente al tiempo cero.

En la Figura 26 B se muestran las curvas de muerte de Salmonella en los sobrenadantes de cultivo de L. paracasei CIDCA 8339 (pH 3,70-ם), CIDCA 83121 (pH 3,76- $\triangle$ ), CIDCA 83123 (pH 3,85- ) y CIDCA 83124 (pH 3,70- ). Estas curvas, al igual que en la figura anterior, fueron representadas junto a una curva control de Salmonella (-) en caldo MRS artificialmente acidificado con ácido láctico $(\mathrm{pH} 3,75)$. En este caso, se observó un mayor poder bactericida de los sobrenadantes de los lactobacilos mencionados anteriormente sobre Salmonella, alcanzando a la hora de incubación una caída del número de microorganismos viables de 6 órdenes logarítmicos, dos órdenes mayor que el obtenido en el control de MRS acidificado artificialmente.
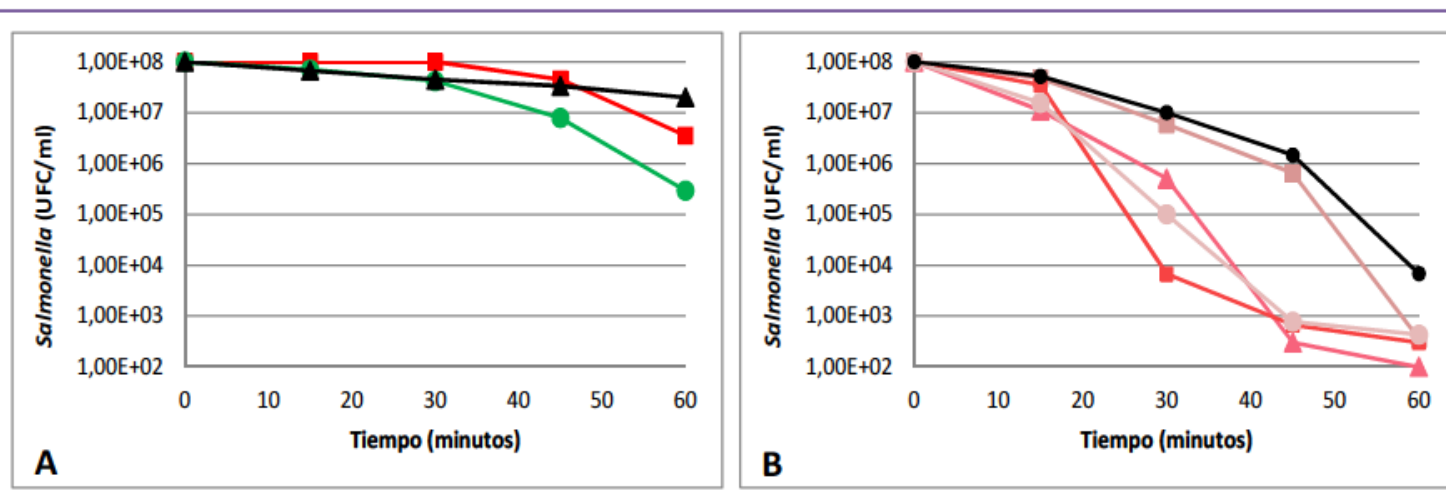

Figura 26. Acción bactericida de los sobrenadantes de cultivo de lactobacilos heterofermentativos aislados de kefir sobre Salmonella entérica serovar Enteritidis CIDCA 101.

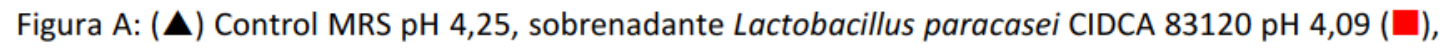
sobrenadante Lactobacillus kefiri CIDCA $83102 \mathrm{pH} \mathrm{4,28(О).}$

Figura B: (-) Control MRS pH 3,75, sobrenadante Lactobacillus paracasei CIDCA 8339 pH 3,70 (口), sobrenadante Lactobacillus paracasei CIDCA $83121 \mathrm{pH} 3,76(\mathbf{A})$, sobrenadante Lactobacillus paracasei CIDCA 83123 pH 3,85 (•), sobrenadante Lactobacillus paracasei CIDCA 83124 pH 3,70 (०).

Los sobrenadantes de los cultivos de L. paracasei CIDCA 8339, CIDCA 83121 y CIDCA 83124, que presentaron los valores más bajos de $\mathrm{pH}$, mostraron un mayor efecto bactericida sobre Salmonella en 1 hora $(\circlearrowleft \Delta \bullet)$, respecto al resto de los 
sobrenadantes de lactobacilos (ㅁ) . De todas formas, ambos grupos de lactobacilos presentaron un efecto inhibitorio más pronunciado que el correspondiente a los controles con MRS acidificados artificialmente. El sobrenadante de L. paracasei CIDCA 83120 es el que provoca menos efecto inhibitorio sobre Salmonella, debido tal vez, a que es uno de los sobrenadantes que posee $\mathrm{pH}$ más alto y en consecuencia menor cantidad de ácido láctico no disociado. El resto de los sobrenadantes tuvieron un mayor efecto bactericida. Al llevar el pH de estos sobrenadantes hasta 4,5, se observó una disminución del efecto inhibitorio como consecuencia de una disminución del ácido láctico no disociado.

Trabajos previos encontraron que Salmonella se muestra más resistente a la acción del ácido en fase estacionaria que en fase exponencial (Rychlick \& Barrow, 2005). Por lo tanto, es importante destacar el marcado efecto bactericida de los sobrenadantes de lactobacilos aislados de kefir sobre este patógeno, aún en fase de crecimiento estacionaria.

Varios trabajos describen el efecto inhibitorio de sobrenadantes de cultivo de distintas bacterias lácticas. En ese sentido el sobrenadante libre de células de L. casei subsp. rhamnosus Lcr35 inhibe el desarrollo de nueve patógenos humanos (Forestier et al. 2001). Fayol-Messaoudi et al. (2005) demostraron que sobrenadantes de L. johnsonii La1, L. rhamnosus GG, L. casei Shirota YIT9029, L. casei DN-114 001 disminuyen la viabilidad de $S$. Typhimurium 4-6 órdenes de magnitud al cabo de 4 horas. De la misma manera, Ogawa et al. (2001) demostraron que los sobrenadantes de dos especies de lactobacilos inhibían el desarrollo de E. coli 0157:H7 (STEC) dependiendo de la concentración de ácido láctico no disociado. Bernet et al. (1997), observaron una disminución de dos órdenes aproximadamente en la viabilidad de S. Tiphimurium cuando fue incubado el patógeno con sobrenadante de L. acidophillus LA1-SCS.

Lin et al. (2008), estudiaron el efecto antagonista de sobrenadante de L. acidophillus (LAP5-SCS) contra dos cepas de S. Choleraesuis encontrando que el efecto bactericida se revertía parcialmente cuando los sobrenadantes fueron sometidos previamente al calor, y completamente cuando los sobrenadantes fueron neutralizados.

Los sobrenadantes de las cepas de Lactobacillus, contienen varios compuestos antimicrobianos (Gopal et al. 2001, Banerjee et al. 2009; Servin 2004), que pueden 
Selección de microorganismos probióticos.

afectar la viabilidad de diversos enteropatógenos (Servin \& Coconnier, 2003). El ácido láctico es el producto principal del metabolismo de azúcares por bacterias lácticas y se sabe que ejerce una acción inhibitoria contra Salmonella por la alta concentración producida (Fayol-Messaoudi et al. 2005; Rishi et al. 2009; Botes et al. 2008) o bien porque actúa permeabilizando la membrana externa de las bacterias Gram (-) permitiendo el ingreso de sustancias antimicrobianas (Alakomi et al. 2000). Nuestros estudios han demostrado que los sobrenadantes de cultivo de lactobacilos aislados de kefir ejercen un efecto antagónico frente a Salmonella. Se podría asociar esta pérdida de viabilidad tanto a ácidos orgánicos como a otras sustancias aún no determinadas en los sobrenadantes diferentes al ácido láctico.

Efecto de los sobrenadantes libres de células de lactobacilos aislados de kefir sobre la asociación e invasión de Salmonella a células Caco-2/TC-7.

A fin de evaluar el efecto de los sobrenadantes de lactobacilos en la asociación e internalización de Salmonella Enteritidis a células epiteliales, este patógeno se resuspendió en los sobrenadantes libres de células de los distintos lactobacilos llevados a pH 4,5 y se determinó su viabilidad después de 1 hora de incubación a $37^{\circ} \mathrm{C}$ (Figura 27).

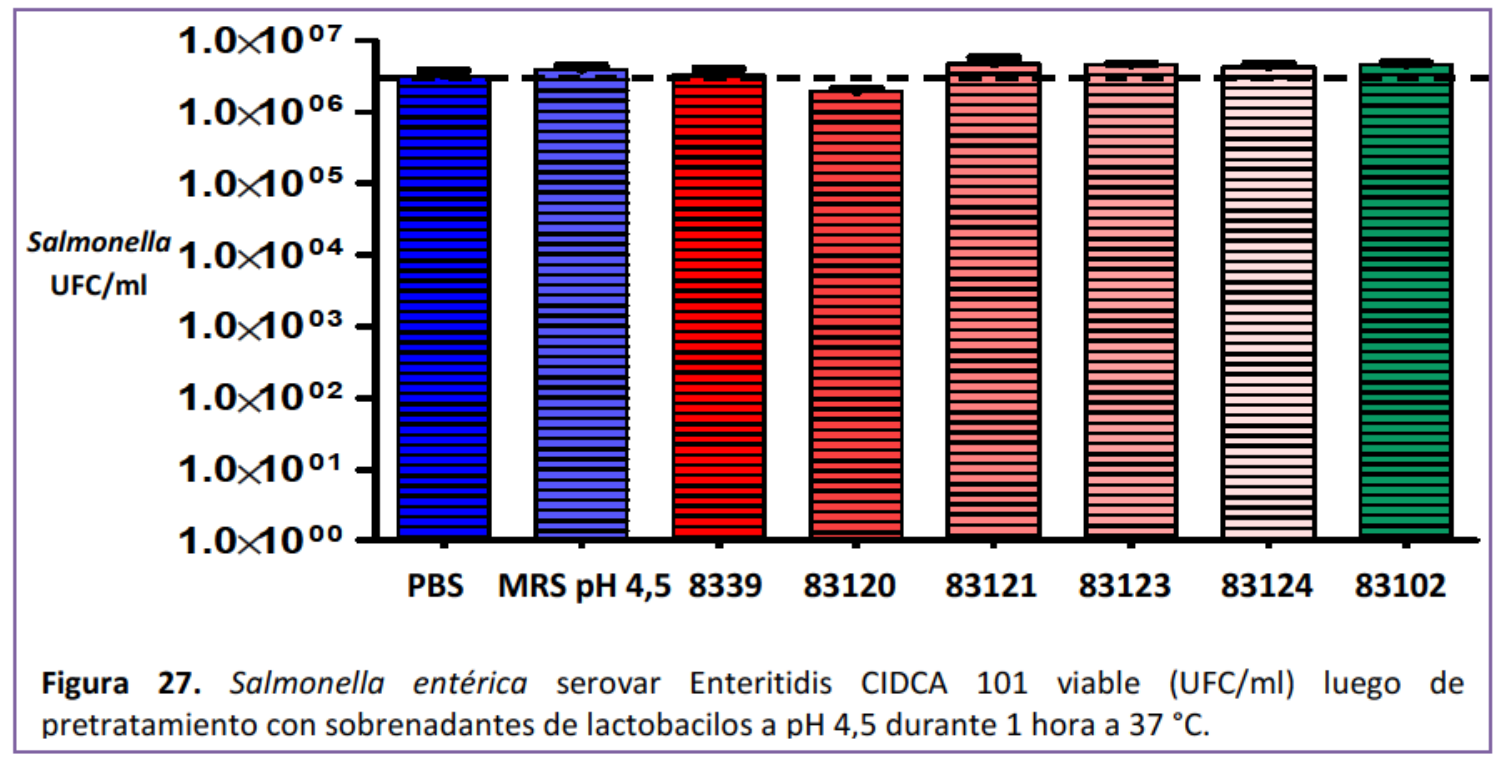

La viabilidad de Salmonella Enteritidis no fue afectada por los componenetes presentes en los sobrenadantes de los distintos lactobacilos estudiados en las condiciones de este ensayo, siendo igual a la viabilidad de Salmonella en PBS. 
Posteriormente, se realizaron los ensayos de asociación e internalización de S. Enteritidis a células Caco-2/TC-7 después del tratamiento durante una hora con los distintos sobrenadantes (Figura 28).

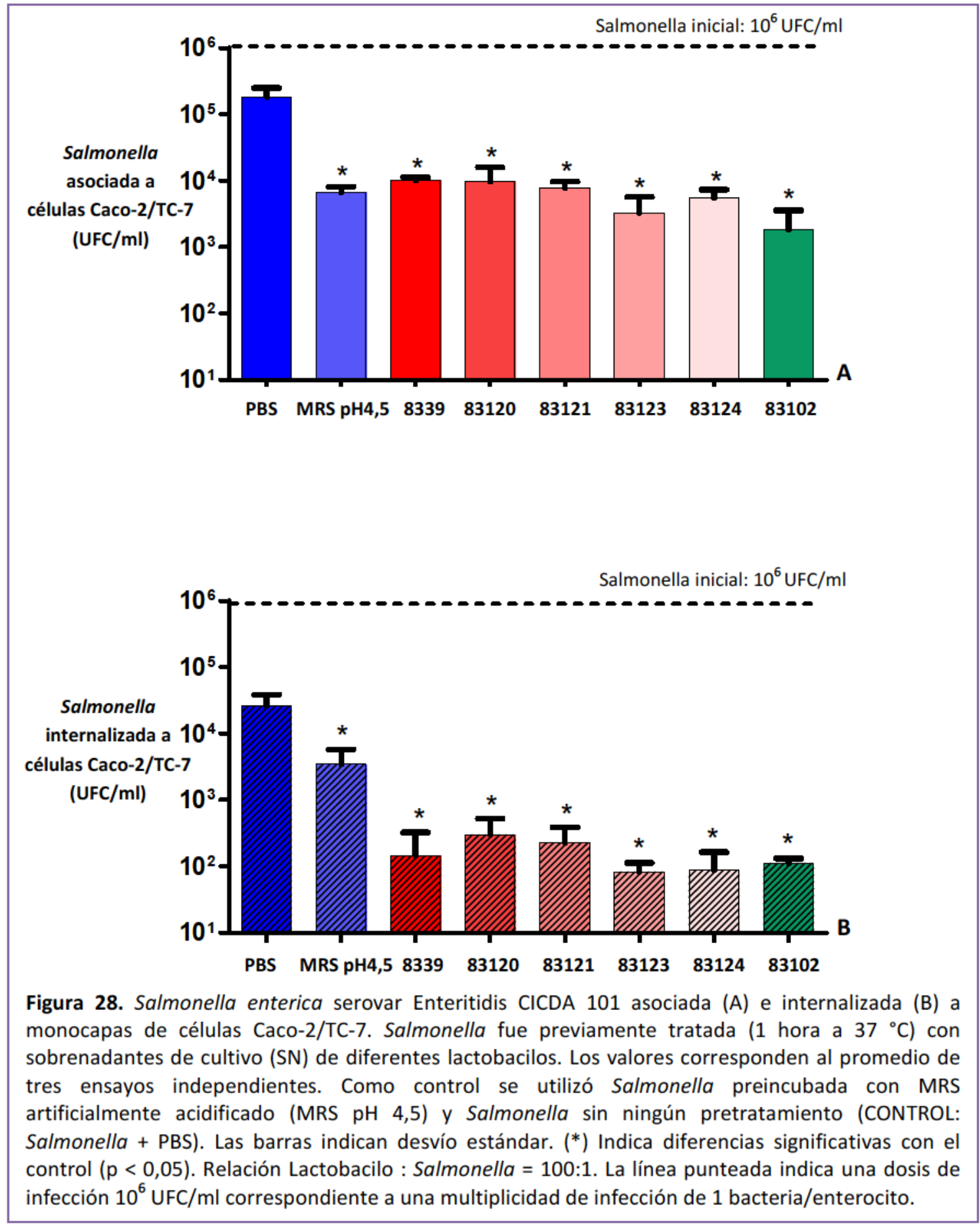

Los ensayos de asociación e internalización de Salmonella después de la incubación con los sobrenadantes de diferentes lactobacilos a pH 4,5 (1 hora a $37^{\circ} \mathrm{C}$ ) demostraron que su capacidad de asociarse a epitelio disminuyó significativamente 
Selección de microorganismos probióticos.

$(p<0,05)$. Asimismo, se observó una fuerte inhibición de la capacidad de Salmonella de internalizarse en la célula epitelial, siendo este efecto menos pronunciado cuando Salmonella se preincubó con MRS artificialmente acidificado al mismo pH de los sobrenadantes estudiados. Debido a que Salmonella depende de sus estructuras superficiales para adherirse e invadir las células intestinales, algún componente del sobrenadante de cultivo podría causar modificaciones en estas estructuras impidiendo la interacción con las células y el posterior daño celular. De manera similar a lo hallado en el presente estudio, Hudault et al. (1997) demostraron que al tratar Salmonella Typhimurium durante 1 hora con el sobrenadante de un cultivo de L. casei GG, la invasión del patógeno a células Caco-2 se reduce. Sin embargo a diferencia de nuestros resultados, no encontraron efecto en la capacidad de asociación. Hay que tener en cuenta que el efecto de cada sobrenadante en la capacidad de invasión de Salmonella a células Caco-2 también depende de la cepa de Salmonella estudiada (Lin et al. 2008).

Al determinar el porcentaje de Salmonella internalizada (Figura 28 B) respecto a Salmonella asociada (Figura $28 \mathrm{~A}$ ) se pudo observar que el tratamiento con todos los sobrenadantes dio un valor entre $0,76 \%$ y $4,13 \%$, mientras que el valor obtenido con el control de MRS fue de 7,90\%. La diferencia entre el control y los sobrenadantes fue significativamente diferente, indicando que los sobrenadantes afectarían tanto la asociación como la capacidad de internalización de Salmonella a células epiteliales.

Como el MRS acidificado a pH 4,5, disminuye la asociación e internalización de Salmonella, se puede concluir que el ácido láctico en el sobrenadante es en parte responsable de la inhibición. Trabajos previos demuestran que los sobrenadantes de cultivo de lactobacilos previenen la adhesión de enteropatógenos a mucus intestinal, epitelio intestinal, e inhiben el desarrollo de patógenos (Ouwehand \& Conway, 1996) y lo relacionan a la presencia de ácidos orgánicos. Los ácidos grasos de cadena corta (AGCC) pueden interferir en la expresión de genes asociados a la invasión de Salmonella, reprimiendo o induciendo el proceso de acuerdo al tipo de ácido y a la concentración en que se produzca (Altier 2005). Lawhon et al. (2002) demostraron que una mezcla de AGCC que simula las condiciones del íleon distal induce la expresión de genes SPI-1, implicados en la invasión, mientras que los mismos ácidos en las proporciones que se encuentran en el colon pueden reprimir los mismos genes. Si bien el efecto sobre la 
invasión de Salmonella de ácidos orgánicos que se encuentran en el tracto gastrointestinal, tales como el acético, el butírico y el propiónico, ha sido bien caracterizado (Durant et al. 1999, 2000; Lawhon et al. 2002; Van Immerseel 2003, 2004, 2006) poco se conoce sobre el efecto del ácido láctico. Hudault et al. (1997) observaron que el efecto protector de la invasión de S. Typhimurium a células Caco-2 por el tratamiento con sobrenadante de un cultivo de L. casei GG se perdía al neutralizar el sobrenadante. En consecuencia, atribuyeron el efecto a algún metabolito producido por el lactobacilo activo a bajo $\mathrm{pH}$ sugiriendo que podría deberse a la presencia de ácido láctico en concentración subletal. Makras et al. (2006) probaron que sobrenadantes de cultivo de 4 cepas pertenecientes al género Lactobacillus sp. y medio de cultivo adicionado con la misma concentración de ácido láctico presente en los sobrenadantes ejercían idéntico efecto reductor de la invasión de S. Typhimurium a células Caco-2/TC7, indicando que el ácido láctico es responsable de la inhibición. Sin embargo, estos mismos autores observaron que la reducción de la invasión mediada por sobrenadantes de L. johnsonii La1 y L. plantarum no podía explicarse sólo por la presencia de este ácido, sugiriendo que habría implicada otra sustancia inhibitoria de naturaleza desconocida.

Los resultados presentados en la Figura 28 indican que los componentes presentes en los sobrenadantes estudiados afectarían a Salmonella inhibiendo su internalización a la célula. Los sobrenadantes de los lactobacilos podrían tener diferentes moléculas que no afectarían la viabilidad del patógeno pero que disminuirían marcadamente su capacidad de invasión a células intestinales. Golowczyc et al. (2007) describieron que el efecto protector de sobrenadantes de 5 cepas de L. kefiri sobre la asociación e invasión de $S$. Enteritidis no podía explicarse sólo por la presencia de ácido láctico. Estos autores hallaron que la proteína de capa-S a la concentración en que se encuentra en sobrenadantes de cultivo de L. kefiri es capaz de asociarse a la superficie de Salmonella e interferir con su capacidad de invasión como también Blomberg et al. (1993) encontraron que el sobrenadante de L. fermentum 104R contiene una proteína que inhibe la interacción de E. coli K88 a mucus porcino. Silva et al. (1987) observaron que $L$. sp. GG, aislada de las heces de humanos, produce una sustancia activa a pH entre 3 y 5 , la cual tiene capacidad inhibitoria contra varias especies bacterianas incluyendo bacterias Gram (+) y Gram (-). Asimismo, Rammelsberg \& Radler (1990) demostraron 
Selección de microorganismos probióticos.

que la bacteriocina de Lactobacillus brevis o L. casei pierde su actividad a valores de $\mathrm{pH}$ neutro. Por otro lado, Bernet et al. (1997), vieron una disminución en la capacidad de adhesión e invasión a células Caco- 2 de $S$. Tiphimurium al concentrar sobrenadante de $L$. acidophillus ya que el mismo secreta una sustancia antimicrobiana (LA1-SCS).

Estos resultados indican la existencia de un mecanismo alternativo, además de la exclusión competitiva del patógeno para reducir la internalización de $S$. Enteritidis en las células epiteliales del colon. Los sobrenadantes afectaron tanto la capacidad de asociación de $S$. Enteritidis como la capacidad de internalizarse en las células. Se podría postular que los sobrenadantes de los lactobacilos estudiados secretan componentes que pueden regular los genes relacionados con la virulencia de $S$. Enteritidis. Esto indicaría que los mecanismos de acción de los sobrenadantes son diferentes al efecto debido a la presencia del microorganismo ya que se ve afectada la asociación como la internalización a las células. Sin embargo, más estudios son necesarios a fin de determinar en qué medida este efecto se debe a la presencia de ácidos orgánicos $u$ otros metabolitos como la capa-S de L. kefiri CIDCA 83102, o debido al exopolisacárido producido por las 5 cepas de L. paracasei. 


\section{CONCLUSIONES PARCIALES}

\section{CAPACIDAD DE ADHESIÓN A EPITELIO Y PASAJE POR EL TRACTO GASTROINTESTINAL}

- El modelo experimental de células epiteliales Caco-2/TC-7 permitió estudiar la capacidad de adhesión de los 13 lactobacilos estudiados. Asimismo, fue un modelo adecuado para evaluar la asociación e internalización de Salmonella enterica serovar Enteritidis CIDCA 101 a células epiteliales.

- En base a su resistencia a la bilis y adhesión a epitelio se seleccionaron las cepas Lactobacillus paracasei CIDCA 8339, CIDCA 83120, CIDCA 83121, CIDCA 83123 y CIDCA 83124 y Lactobacillus kefiri CIDCA 83102 para profundizar los ensayos para determinar su potencialidad probiótica.

- Los lactobacilos seleccionados fueron capaces de adherir a células de epitelio intestinal y a mucina in vitro. Los lactobacilos presentaron valores de adhesión entre $10^{5}$ y $10^{6} \mathrm{UFC} / \mathrm{ml}$ en ambos modelos evaluados.

- Los 6 lactobacilos evaluados presentaron una baja hidrofobicidad superficial. No se observó relación entre la adhesión de lactobacilos a células de epitelio intestinal in vitro y su hidrofobicidad superficial.

- Todos los lactobacilos disminuyeron su viabilidad al ser sometidos al estrés ácido conferido por el jugo gástrico. El tratamiento posterior con sales biliares no modificó el número de células viables en 4 de los lactobacilos estudiados.

- Lactobacillus paracasei CIDCA 83121 y CIDCA 83124 fueron los más afectados por el tratamiento secuencial con ácido y sales biliares, disminuyendo el número de microorganismos viables 4 unidades logarítmicas. Los lactobacilos que mejor se adaptaron a estas condiciones fueron Lactobacillus paracasei CIDCA 8339, CIDCA 
83120 y CIDCA 83123 y Lactobcillus kefiri CIDCA 83102 presentando una caída del número de microorganismos viables inferior a 3 órdenes logarítmicos.

- Las propiedades de adhesión a células epiteliales y mucina aumentaron luego del tratamiento que simula las condiciones gastrointestinales (estrés ácido y sales biliares), respecto a los lactobacilos no tratados. Este efecto dependió de la cepa de lactobacilo estudiado.

- El perfil de proteínas de célula entera de L. paracasei CIDCA 83123 después del estrés ácido y de bilis analizado por electroforesis bidimensional resultó diferente al del control sin tratamiento. Después del pasaje por el tracto gastrointestinal se regularon positivamente 6 péptidos/proteínas, mientras que 5 disminuyeron su intensidad respecto a los lactobacilos control.

- La mayoría de las proteínas que fueron reguladas positivamente corresponden a enzimas de la vía glicolítica, siendo un efecto general del estrés activar la fuente de energía.

- El pasaje por el tracto gastrointestinal in vitro aumentó la expresión de gliceraldehído-3-fosfato deshidrogenasa. Dicha enzima podría estar involucrada en el aumento de la adhesión de L. paracasei 83123 a mucus o células epiteliales después del tratamiento.

\section{ACTIVIDAD ANTAGÓNICA CON SALMONELLA ENTERITIDIS}

- Solamente Lactobacillus paracasei CIDCA 8339 y Lactobacillus kefiri CIDCA 83102 fueron capaces de autoagregar y son los que interaccionan con Salmonella entérica serovar Enteritidis CIDCA 101. Es probable que el mismo factor que produce la autoagregación de las bacterias sea el responsable de la coagregación con el microorganismo patógeno.

- Lactobacillus paracasei CIDCA 8339, CIDCA 83120, CIDCA 83123 y CIDCA 83124 y Lactobacillus kefiri CIDCA 83102 al ser preincubados con Salmonella entérica 
serovar Enteritidis CIDCA 101 redujeron la capacidad del patógeno de internalizarse en las células epiteliales Caco-2/TC-7 respecto al control.

- La preincubación de todos los lactobacilos estudiados con células epiteliales Caco-2/TC-7 redujo el daño producido por Salmonella entérica serovar Enteritidis CIDCA 101 sobre las células epiteliales, evidenciado por una reducción de la capacidad de internalización y mantenimiento de la integridad del citoesqueleto. Este efecto se debe principalmente a una disminución de la capacidad de asociación de Salmonella al epitelio.

- Los sobrenadantes de cultivo de todos los lactobacilos mostraron un marcado efecto bactericida. Este efecto bactericida fue revertido cuando todos los sobrenadantes son llevados a pH 4,5.

- Los sobrenadantes de todos los lactobacilos al ser preincubados con Salmonella entérica serovar Enteritidis CIDCA 101 inhibieron su asociación e internalización a células epiteliales Caco-2/TC-7. La relación entre Salmonella internalizada con respecto a Salmonella asociada a la célula epitelial fue inferior a los controles, indicando que los sobrenadantes de los lactobacilos afectarían la capacidad de Salmonella de asociarse a epitelio así como también la expresión del factor de virulencia disminuyendo la capacidad invasiva.

- En función de esos resultados se seleccionaron Lactobacillus paracasei CIDCA 8339 y Lactobacillus kefiri CIDCA 83102 para evaluar su posible inclusión en geles a base de polisacáridos bacterianos. 
Selección de microorganismos probióticos. 


\section{CAPÍTULO 2}

GELES DE KEFIRAN COMO VEHÍCULO DE MICROORGANISMOS PROBIÓTICOS 


\section{Geles en los alimentos}

Los geles juegan un rol esencial en la textura de los alimentos. Pueden ser empleados para mejorar la calidad, aceptabilidad y seguridad de los alimentos a los cuales se incorporan (Dolz et al. 2006; Laurienzo et al. 2006; Huang et al. 2007). Un gel es un sistema cuya matriz está formada por macromoléculas que se encuentran interconectadas formando una red tridimensional. Estas macromoléculas retienen e inmovilizan una gran cantidad de solvente. Por lo tanto, se trata de un sistema sustancialmente diluido, pero incapaz de fluir (Ferry 1980; Clark 1992). Los geles poseen algunas propiedades que son características del estado sólido pese a ser un sistema en el cual se encuentra presente una gran cantidad de solvente. La red continua de macromoléculas que constituyen el "armazón" que se extiende en el espacio otorga la resistencia que exhiben los geles cuando son sometidos a un esfuerzo y les confiere el carácter elástico. Desde el punto de vista reológico, los geles son materiales viscoelásticos que poseen tanto características de líquidos como de sólidos. Desde un enfoque termodinámico, se encuentran en estado metaestable, y pueden modificarse con el tiempo, ya sea espontáneamente o como consecuencia de la aplicación de fuerzas externas. El carácter dinámico de las uniones que los constituyen puede llevar a cambios graduales en la estructura, que a su vez originan modificaciones en las características reológicas de los geles (Mellema et al. 2002).

Los geles exhiben propiedades microestructurales y mecánicas muy diversas que dificultan su clasificación. Sin embargo, se los denomina "fuertes" o "débiles" según la capacidad para romperse y fluir bajo la aplicación de fuerzas pequeñas (Clark \& Ross-Murphy, 1987).

Las sustancias capaces de formar redes estructurales en los alimentos son principalmente polisacáridos y proteínas (Chen et al. 2006; Cheftel \& Lorient, 1982; 
Geles de kefiran como vehículo de microorganismos probióticos.

Dumay 1988). En muchos casos, las propiedades de los alimentos dependen de dicha gelificación, ya que contribuye a la textura de los productos alimenticios finales.

Geles alimentarios de naturaleza glucídica.

Entre los polisacáridos, el almidón probablemente sea el más utilizado para la obtención de geles debido a su alta disponibilidad y bajo costo. Otros polisacáridos neutros empleados son los galactomananos tales como la goma guar (provenientes de leguminosas), la goma garrofín (proveniente del algarrobo), y los $\beta$-glucanos obtenidos a partir de semillas de cereales. Los polisacáridos cargados que se emplean comúnmente en la formación de geles en alimentos son los xantanos, producidos por Xantomona campestris, los gelanos provenientes de cultivos de Pseudomona elodea, los alginatos y carragenanos, producidos por algas, y las pectinas, polisacáridos estructurales de origen vegetal (Morris 1986; Doublier et al. 2000).

Las bacterias lácticas son generalmente reconocidas como seguras y representan una fuente de polisacáridos natural que se puede utilizar en diversos productos, ya sea incluyendo el microorganismo productor en el fermento o utilizando los exopolisacáridos (EPS) que producen como aditivo (Jolly et al. 2002; Ruas-Madiedo et al. 2005; Piermaría et al. 2008), ofreciendo una amplia alternativa de polisacáridos microbianos para el uso en formulaciones alimentarias (Laws \& Marshall, 2001b). Los exopolisacáridos provenientes de bacterias lácticas difieren en composición de azúcares, tipo de unión glicosídica, presencia de cadenas laterales y/o la presencia de grupos sustituyentes (Laws \& Marshall 2001a). El peso molecular varía desde $1.10^{4}-2.10^{5} \mathrm{Da}$ hasta valores que superan los $10^{6}$ Da (De Vuyst \& F. Vaningelgem 2004). Además, pueden variar en carga, configuración espacial, rigidez y habilidad para interactuar con proteínas (Duboc \& Mollet, 2001).

Estos polisacáridos cobran importancia, pues no sólo contribuyen a la textura de los alimentos mediante la reducción de sinéresis como en yogurth o la mejora en la consistencia como por ejemplo en quesos maduros con bajo contenido de grasa, sino que además confieren efectos benéficos para la salud (Mazeau \& Rinaudo, 2004). Entre los efectos benéficos atribuidos, se puede mencionar la capacidad de reducir el 
colesterol, la capacidad inmunomoduladora, la protección al epitelio intestinal de la acción de microorganismos patógenos o la capacidad de modulación de la microbiota fecal (Nicolic et al. 2012; Ruas-Madiedo et al. 2008; Salazar et al. 2012). Por lo tanto, la utilización de polisacáridos provenientes de bacterias lácticas posibilitaría el desarrollo de alimentos prebióticos o simbióticos, con características funcionales deseables tanto desde el punto de vista tecnológico como desde la óptica del efecto benéfico para la salud que ellos son capaces de ejercer (Ruas-Madiedo et al. 2002a, 2002b).

A pesar de estas propiedades interesantes, el uso de EPS a partir de bacterias lácticas en la industria como aditivos alimentarios es aún limitada debido a los bajos niveles de producción en comparación a la goma xántica producida por microorganismos Gram(-). Una alternativa interesante es el uso de kefiran, el polisacárido producido por las bacterias lácticas de los gránulos de kefir. El kefiran, puede ser aislado con buenos rendimientos y elevado grado de pureza a partir del propio gránulo utilizando metodologías compatibles con la industria alimentaria. El uso de este polisacárido como aditivo alimentario podría presentar una ventaja ya que posee efectos benéficos para la salud, frente al uso de otros polímeros que no poseen dichos beneficios.

Pintado et al. (1996) demostraron que el kefiran forma geles en solución acuosa conteniendo etanol. La fuerza de los geles preparados con $3 \%$ de kefiran en $8 \%$ de etanol son equivalentes a las obtenidas en los geles formados con $3 \%$ de gelatina (Mukai et al. 1990).

Cuando soluciones de kefiran son congeladas, se produce el alineamiento de las moléculas formando un gel. Los geles formados resultan translúcidos con una alta capacidad de retención de agua $(90,43 \% \pm 1,51)$ y suficientemente cohesivos como para soportar su propio peso. Los espectros mecánicos de las muestras congeladas muestran que el módulo elástico (G') es mayor que el módulo viscoso (G") y ambos módulos resultan independientes de la frecuencia, evidenciando un comportamiento tipo gel. El comportamiento de los geles de kefiran a $37^{\circ} \mathrm{C}$ determina su habilidad para fundirse a la temperatura de la boca; esta propiedad resulta relevante para su aplicación en alimentos (Piermaría et al. 2008). 
Geles de kefiran como vehículo de microorganismos probióticos.

Geles de proteínas.

La gelificación de proteínas globulares inducida por tratamiento térmico fue ampliamente estudiada (Clark et al. 2001). Entre los sistemas proteicos más estudiados en lo referente a la capacidad de gelificación se pueden mencionar las proteínas de suero y las proteínas vegetales (soja, amaranto) (Puppo et al. 1995).

Las principales proteínas de suero de leche son la $\beta$-lactoglobulina $(\beta$-Lg) y la $\alpha$-lactoalbúmina ( $\alpha$-La), que presentan una estructura tridimensional compacta, mantenida por muchos enlaces no covalentes débiles y algunos enlaces disulfuro (Steventon et al. 1991). La $\beta$-Lg existe como un dímero de 36,7 kDa en soluciones por encima de su pl de 5,2, pero por debajo de $\mathrm{pH} 3,5$ y por encima de $\mathrm{pH} 7,5$, el dímero se disocia a un monómero expandido, y entre $\mathrm{pH}$ 3,5 y 5,2 el dímero polimeriza a un 147 KDa (Morr \& Ha, 1993; Fox \& McSweeney, 2003). El mecanismo molecular de desnaturalización térmica de $\beta$ - $\mathrm{Lg}$ a $\mathrm{pH}$ neutro incluye la disociación del dímero y la pérdida de la estabilidad de la hélice a unos $77{ }^{\circ} \mathrm{C}$ (Holt 2000). La reactividad de los grupos tiol disminuye significativamente bajo condiciones ácidas y, por lo tanto, principalmente las interacciones no covalentes están involucrados en la estructura de los geles ácidos, mientras que a pH neutro las reacciones de intercambio intermolecular como puentes disulfuro-sulfidrilo libre son favorecidas (Shimada \& Cheftel, 1988). Además, cuando el pH se aproxima al pl, la carga de las proteínas se neutraliza progresivamente, favoreciendo la agregación de proteínas. Así, la estructura de geles depende del pH en el que se preparan (Lupano et al. 1992, 1996).

La segunda proteína del suero de la leche es la $\alpha$-lactoalbúmina ( $\alpha$-La), una proteína globular más pequeña, con 4 puentes disulfuro, que es estructuralmente homóloga a la lisozima y requiere calcio para asumir su pliegue funcional. Es una proteína reguladora de la enzima lactosa sintasa en la glándula mamaria (Fox \& McSweeney, 2003).

La albúmina de suero bovino (BSA) se encuentra tanto en el suero sanguíneo como en la leche. Es una proteína globular más grande, con una estructura principalmente alfa-helicoidal, con 17 puentes disulfuro y un grupo tiol libre. 
La lactoferrina es una glicoproteína monomérica globular, que pertenece a la familia de la transferrina, y presenta actividad anti microbiana (Fox \& McSweeney, 2003, Edwards et al. 2009).

El proceso de gelificación en sistemas alimentarios es normalmente llevado a cabo incluyendo cambios conformacionales de las moléculas de proteínas, su agregación, y la formación de la red tridimensional del gel. La gelificación inducida por el calor en soluciones acuosas de proteína de suero de leche ha sido descrita como un proceso de dos etapas, la desnaturalización de la proteína nativa seguida por la posterior agregación. En la gelificación de las proteínas globulares, la desnaturalización térmica es crítica (Tolstoguzov 1991). La formación de un gel depende de diversos factores tales como la concentración de proteínas, el pH, la fuerza iónica, y la presencia de otros componentes de los alimentos (Gault \& Fauquant, 1992; Tolstoguzov 1993).

Las proteínas de suero son proteínas de alto valor nutricional y debido a sus características estructurales presentan interesantes propiedades funcionales (de Wit 1998; Turgeon \& Beaulieu, 2001; Ha \& Zemel, 2003). En consecuencia, son muy adecuadas para la construcción de vehículos para la entrega de diversos compuestos bioactivos o microorganismos probióticos (Livney 2010) permitiendo su aplicación en la industria alimentaria (Morr 1984, 1992).

Geles mixtos.

En los alimentos, las proteínas y los polisacáridos son los ingredientes más importantes responsables en la formación de la estructura (Tolstoguzov 1991) y su uso en los sistemas mixtos pueden mejorar o modificar su comportamiento funcional (Dickinson \& Galazka, 1991; Dickinson \& Izgi, 1996; Gurov \& Nuss, 1986; Turgeon \& Beaulieu, 2001).

Los sistemas mixtos más estudiados son los geles de gelatina-agar (Boral \& Bohidar, 2010; Singh et al. 2007, 2011). Sin embargo, existen algunos trabajos relacionados a la formación de geles de proteína de suero y polisacáridos tales como pectina o goma xántica. Krzeminski et al. (2014a) estudiaron la formación de complejos de pectina y proteínas de suero en la elaboración del yogurth con bajo contenido en 
Geles de kefiran como vehículo de microorganismos probióticos.

grasa, obteniéndose un producto de igual firmeza y propiedades de flujo similares a las de un yogurth con contenido normal de grasa (Jones et al. 2009). También, los complejos de goma xántica y proteínas de suero han sido usados exitosamente para reemplazar las grasas a pH neutro en tortas heladas (Laneuville et al. 2005) y en queso Petit-Suisse (Ramírez-Santiago et al. 2012).

Además, los complejos de polisacáridos-proteínas son utilizados debido a su capacidad emulsificante, o estabilizante de emulsiones evitando la coalescencia (Dickinson 2008), y a las propiedades texturales que aportan a los productos con bajo contenido en grasa (Jones et al. 2010b).

\section{Inclusión de microorganismos probióticos en los geles}

La amplia variedad de usos de los geles ha llevado a la búsqueda de nuevas alternativas, en cuanto a materiales y metodologías de obtención, capaces de satisfacer los diversos requerimientos planteados. La industria de alimentos está particularmente interesada en encontrar nuevos componentes naturales que aporten a la textura pero que además de satisfacer los requerimientos nutricionales y sensoriales, ofrezcan algunos beneficios adicionales promotores de la salud a quienes los consumen. La revalorización de aquellas moléculas que poseen estas características ha llevado a profundizar las investigaciones en lo referido a la funcionalidad biológica de los componentes alimentarios así como a la capacidad de aportar características reológicas particulares (Laws et al. 2001b; Warrand 2006).

En los recientes años ha crecido el interés por lograr matrices capaces de transportar medicamentos, nutrientes o microorganismos próbióticos y protegerlos durante su pasaje a través del tracto gastrointestinal. Una alternativa es la microencapsulación, definida como la tecnología del empaquetamiento en un material sólido, líquido o gaseoso en cápsulas que liberan sus contenidos a velocidades controladas, durante períodos prolongados de tiempo (Vandamme et al. 2002; Mainville et al. 2005; Crittenden et al. 2006). Estas tecnologías son de gran interés en el sector farmacéutico, pero también tienen relevancia en la industria de alimentos ya que proporcionan protección a los microorganismos al encontrarse dentro de una matriz 
Geles de kefiran como vehículo de microorganismos probióticos.

polimérica de calidad alimentaria (Heidebach et al. 2009), de manera que la selección apropiada de la matriz del alimento es de vital importancia durante el desarrollo de alimentos funcionales probióticos (Doherty et al. 2010).

Las proteínas de suero de leche también se han considerado como una alternativa potencial para incluir bacterias probióticas o sustancias biactivas. Beaulieu et al. (2001) utilizaron un método de gelificación para la formación de perlas de proteína que atrapan el retinol. Ellos encontraron que la proteína de suero de leche formó geles que no eran susceptibles al ataque enzimático durante el pasaje por el tracto gastrointestinal proporcionando una liberación lenta y progresiva del retinol en los sitios de absorción intestinal y la protección contra la oxidación. Hébrard et al. (2006) inmovilizaron Saccharomyces cerevisiae en aislados de proteína de suero mediante la gelificación inducida por frío. La matriz de proteína crea un microambiente que favorece la actividad de las levaduras en las condiciones gástricas severas. Doherty et al. (2010) inmovilizaron Lactobacillus rhamnosus GG en aislado de proteína de suero de leche nativa, desnaturalizada y hidrolizada. Estas bacterias inmovilizadas aumentaron la supervivencia durante 14 días de almacenamiento a $37^{\circ} \mathrm{C}$ en las matrices de proteína de suero de leche (WPI) desnaturalizada y/o hidrolizada, obteniéndose también una protección mayor durante el pasaje por el tracto gastrointestinal in vitro. En este aspecto, la inclusión de microorganismos en matrices alimentarias a base de proteínas de suero seria una alternativa para el desarrollo de nuevos alimentos conteniendo probióticos. 
CAPÍTULO 2

Geles de kefiran como vehículo de microorganismos probióticos. 
Los microorganismos probióticos generalmente son incorporados a productos lácteos o jugo de frutas. Una alternativa para aumentar la eficiencia de estos microorganismos sería utilizar una matriz alimentaria que contenga naturalmente algún ingrediente con propiedades protectoras. Teniendo en cuenta las características fisicoquímicas del kefiran y conociendo su capacidad de formar criogeles, se planteó como objetivo analizar su interacción con otros macrocomponentes y su capacidad para formar geles mixtos a fin de utilizarlos como vehículo de microorganismos probióticos.

Para ello se plantearon los siguientes objetivos específicos:

- Evaluar las condiciones de formación de geles mixtos de kefiran con azúcares tales como sacarosa y fructosa.

- Evaluar las condiciones de formación de geles mixtos de kefiran con proteínas de suero de leche (WPI) y caracterizar los geles mixtos obtenidos.

- Realizar la inclusión de microorganismos potencialmente probióticos en los geles mixtos obtenidos y estudiar la viabilidad de los mismos durante el proceso de elaboración.

- Evaluar la resistencia de los microorganismos incluidos en los geles durante el pasaje por el tracto gastrointestinal y su capacidad de adhesión a epitelio. 
CAPÍTULO 2

Geles de kefiran como vehículo de microorganismos probióticos. 


\section{Obtención de kefiran}

La obtención y purificación de kefiran se realizó según Rimada \& Abraham (2006). Una cantidad pesada de granos de kefir CIDCA AGK1 obtenidos por subcultivos sucesivos en leche descremada fue tratado en agua hirviendo [1:10 ( $p / v)]$ durante 30 minutos con agitación discontinua. La mezcla se centrifugó (Avanti J25 de Beckman Coulter Inc. centrífuga, Palo Alto, CA, EE.UU.) a 10.000 g durante 20 minutos a $20^{\circ} \mathrm{C}$ y el polisacárido en el sobrenadante se precipitó mediante la adición de dos volúmenes de etanol y se dejó reposar a $-20{ }^{\circ} \mathrm{C}$ durante la noche. Posteriormente se centrifugó a 10.000 g durante 20 minutos a $4{ }^{\circ} \mathrm{C}$. El precipitado se disolvió en agua caliente y el proceso de precipitación y centrifugación se repitió dos veces. El precipitado final se disolvió en agua destilada caliente (Rimada \& Abraham, 2001). La concentración de polisacárido se determinó por el método de Antrona, con soluciones de glucosa como estándares. Todas las muestras fueron analizadas para corroborar ausencia de otros azúcares por cromatografía en capa fina cualitativa. La concentración de proteínas en la solución de kefiran se determinó por el método de Bradford (Bradford 1976). La solución de kefiran se liofilizó en un Heto FD4 (Equipo de Laboratorio, Dinamarca) y el polisacárido obtenido se almacenó a $4{ }^{\circ} \mathrm{C}$ en botellas herméticas hasta su uso.

\section{Preparación de geles de kefiran con azúcares y/o proteínas}

Geles mixtos de kefiran y azúcares.

Se prepararon dispersiones en agua destilada conteniendo 2,0 \% (p/p) de kefiran y $0 ; 5,88 ; 10 ; 17,64 ; 30$ y $50 \%(\mathrm{p} / \mathrm{p})$ de fructosa o sacarosa. Las mismas fueron calentadas a $70{ }^{\circ} \mathrm{C}$ con agitación continua hasta completa solubilización. Alícuotas de 
Geles de kefiran como vehículo de microorganismos probióticos.

cada una de las diferentes soluciones fueron colocadas en recipientes plásticos cilíndricos de $35 \mathrm{~mm}$ de diámetro interno y cubiertas con film. Un grupo de estas alícuotas fue colocado inmediatamente en freezer a $-20{ }^{\circ} \mathrm{C}$ por un período de 24 horas. Estas alícuotas fueron luego transferidas a $4{ }^{\circ} \mathrm{C}$ por el mismo tiempo. El otro grupo de alícuotas, empleadas para estudios comparativos, no fueron congeladas y se colocaron directamente durante 48 horas en heladera a $4{ }^{\circ} \mathrm{C}$ antes de su utilización.

\section{Geles de proteínas.}

Se utilizó aislado de proteína de suero de leche (WPI) comercial (Arla Foods Ingredients, Ambh, Dinamarca). Según lo especificado por el fabricante, el aislado contiene un mínimo de $92 \%$ de proteínas, siendo los principales constituyentes proteicos: $\beta$ - lactoglobulina (74 \%), $\alpha$-lactoalbúmina (18 \%) y albúmina de suero bovino (6\%). El aislado contiene lactosa y grasa (cada uno a un contenido máximo de 0,2 \%), y minerales: sodio $(0,5 \%)$, potasio $(1,3 \%)$, y calcio $(0,1 \%)$.

La concentración final de proteína en buffer fosfato $\mathrm{pH} 7$ de las soluciones para formar geles se ajustó a concentraciones que van de 2,0 a 10,0% (p/p) (Puyol et al. 2001). Para la formación de los geles de proteínas, las soluciones fueron calentadas a $90{ }^{\circ} \mathrm{C}$ durante 10 minutos para desnaturalizar las proteínas, e inmediatamente enfriadas en baño de agua fría hasta temperatura ambiente. Se colocaron en heladera a $4^{\circ} \mathrm{C}$ hasta su utilización.

\section{Geles mixtos de kefiran y proteínas.}

La concentración final del aislado de proteína de suero (WPI) en buffer fosfato pH 7 de las muestras se ajustó a concentraciones que van de 3,0 a 8,0 \% (p/p) y la concentración de kefiran utilizada fue de 1,0 \% (p/p). Para la formación de los geles mixtos de kefiran con proteínas, las soluciones fueron calentadas a $90{ }^{\circ} \mathrm{C}$ durante 10 minutos e inmediatamente enfriadas en baño de agua fría hasta temperatura ambiente, proceso que llamamos ETAPA 1. Luego fueron colocadas inmediatamente en freezer a $-20{ }^{\circ} \mathrm{C}$ por un período de 24 horas correspondiente a las condiciones de gelificación del 
kefiran, y luego fueron transferidas a $4{ }^{\circ} \mathrm{C}$ por el mismo tiempo, proceso que llamamos ETAPA 2. Estas muestras fueron almacenadas a $4{ }^{\circ} \mathrm{C}$ al menos 24 horas hasta su utilización.

\section{Caracterización de las soluciones}

Se evaluó el comportamiento de las soluciones utilizando un reómetro ReoStress 600 (Termo Haake, Alemania) en modo rotacional con un sistema sensor plato-plato paralelo, de superficie rugosa y $1 \mathrm{~mm}$ de separación entre platos. Las soluciones se termostatizaron a $20^{\circ} \mathrm{C}$ utilizando un baño de agua (Circulator DC50, Thermo Haake). Se registró el esfuerzo de corte $(\tau)$ en función del gradiente de velocidad $(\dot{\gamma})$. Se utilizó una aceleración de 4,17 $\mathrm{s}^{-2}$ para alcanzar en 2 minutos un gradiente de velocidad de $500 \mathrm{~s}^{-1}$, se mantuvo el mismo durante 1 minuto y luego se procedió al descenso de dicho gradiente hasta $0 \mathrm{~s}^{-1}$ utilizando una aceleración igual a la antes mencionada pero de signo negativo. A partir de las gráficas correspondientes al comportamiento de flujo se obtuvo la viscosidad aparente ( Ostwald de Waele $\left(\tau=\mathrm{K} .\left({ }^{\gamma}\right) \mathrm{n}\right)$ para obtener el índice de consistencia $(\mathrm{K})$ y el índice de comportamiento de flujo (n).

\section{Caracterización de los geles}

\section{Actividad Acuosa.}

La determinación de la actividad acuosa se realizó en el equipo Aqua Lab (Decagon Devices, Inc., Washington). Las muestras fueron colocadas en los recipientes del equipo de acuerdo a las instrucciones del fabricante y se esperó la llegada al equilibrio. El equipo fue calibrado con agua bidestilada y solución de CIK saturada. Las determinaciones se efectuaron por triplicado. 
Geles de kefiran como vehículo de microorganismos probióticos.

Capacidad de retención de agua (WHC).

Se efectuó una centrifugación de los geles a 3.000 g durante 5 minutos a $20^{\circ} \mathrm{C}$. Los sobrenadantes fueron eliminados mediante pipeta e inversión de los eppendorf. Se determinaron los pesos antes y después de la centrifugación. WHC (\%) se calculó como el porcentaje de agua retenido en relación al peso inicial del gel (Wu et al. 2009). Asimismo, se determinó el contenido de azúcares en el exudado durante la centrifugación mediante el método de Antrona. Todas las determinaciones se realizaron por triplicado.

Reometría oscilatoria de baja amplitud de deformación.

Las medidas fueron llevadas a cabo en un reómetro RheoStress 600 (Haake) empleando una geometría de platos paralelos de superficie rugosa de $35 \mathrm{~mm}$ de diámetro y $1 \mathrm{~mm}$ de separación entre los platos. Las muestras fueron cuidadosamente removidas del recipiente y colocadas en el plato inferior del reómetro. La temperatura fue mantenida a $20^{\circ} \mathrm{C}$ mediante un baño de agua circulante (DC50, Haake). La región de viscoelasticidad lineal fue determinada mediante la realización de barridos de esfuerzo de corte a frecuencia fija $(1 \mathrm{~Hz})$ a 5,20 y $40^{\circ} \mathrm{C}$.

Dentro de dicho rango lineal de viscoelasticidad se evaluaron G' (módulo elástico) y G" (módulo viscoso) en función de la frecuencia $(0,1-10 \mathrm{~Hz})$. El módulo elástico (G'), el módulo viscoso (G") y la tangente del ángulo de desfasaje (tan( $(\delta))$ fueron evaluados como función de la frecuencia (entre 0,1 y 10,0 Hz). El módulo elástico (G') describe, como su nombre lo indica, el comportamiento elástico del sistema, se encuentra vinculado a la energía que se almacena en el mismo y que puede ser recuperada cuando el esfuerzo aplicado es removido. Por esta particularidad a G' también se lo denomina módulo de almacenamiento. El módulo viscoso (G") es una medida de la energía perdida en forma de calor, asociada al comportamiento viscoso. El módulo G" es llamado también módulo de pérdida, en contraposición con la denominación módulo de almacenamiento, utilizada para G'.

La tangente del ángulo de desfasaje $\tan (\delta)$ es definida como: 
$\tan (\delta)=G^{\prime \prime} / G^{\prime}$

y está directamente relacionada con la energía perdida con respecto a la energía recuperada en cada ciclo. Puede variar entre 0 e infinito y cuanto menor es su valor indica un mayor carácter elástico.

\section{Calorimetría Diferencial de Barrido (DSC).}

Se colocaron las muestras en cápsulas de aluminio previamente pesadas y selladas. El barrido de temperatura fue de $4-100{ }^{\circ} \mathrm{C}$ y la velocidad de calentamiento fue de $10{ }^{\circ} \mathrm{C} / \mathrm{min}$. Una cápsula vacía fue utilizada como referencia para todas las medidas. Luego del barrido de todas las muestras, las cápsulas fueron perforadas y secadas a peso constante en estufa a $105{ }^{\circ} \mathrm{C}$ para obtención de peso seco. Los termogramas de temperaturas de transición y entalpías de transición $(\Delta \mathrm{H})$ fueron obtenidos mediante el software 2000 de Análisis TA Universal.

\section{Análisis de perfil de textura.}

Los geles fueron evaluados utilizando un texturómetro TA.XT2i Texture Analyser (Stable Micro-Systems Ltd, Inglaterra) en el modo de análisis de perfil de textura, realizando dos ciclos de compresión uniaxiales. Se utilizó una sonda de $75 \mathrm{~mm}$ de diámetro a una velocidad de $0,5 \mathrm{~mm} / \mathrm{s}$ y los geles se comprimieron hasta el $30 \%$ de su altura original. La evaluación se realizó a temperatura ambiente registrándose la fuerza en función del tiempo (Figura 29). 
Geles de kefiran como vehículo de microorganismos probióticos.

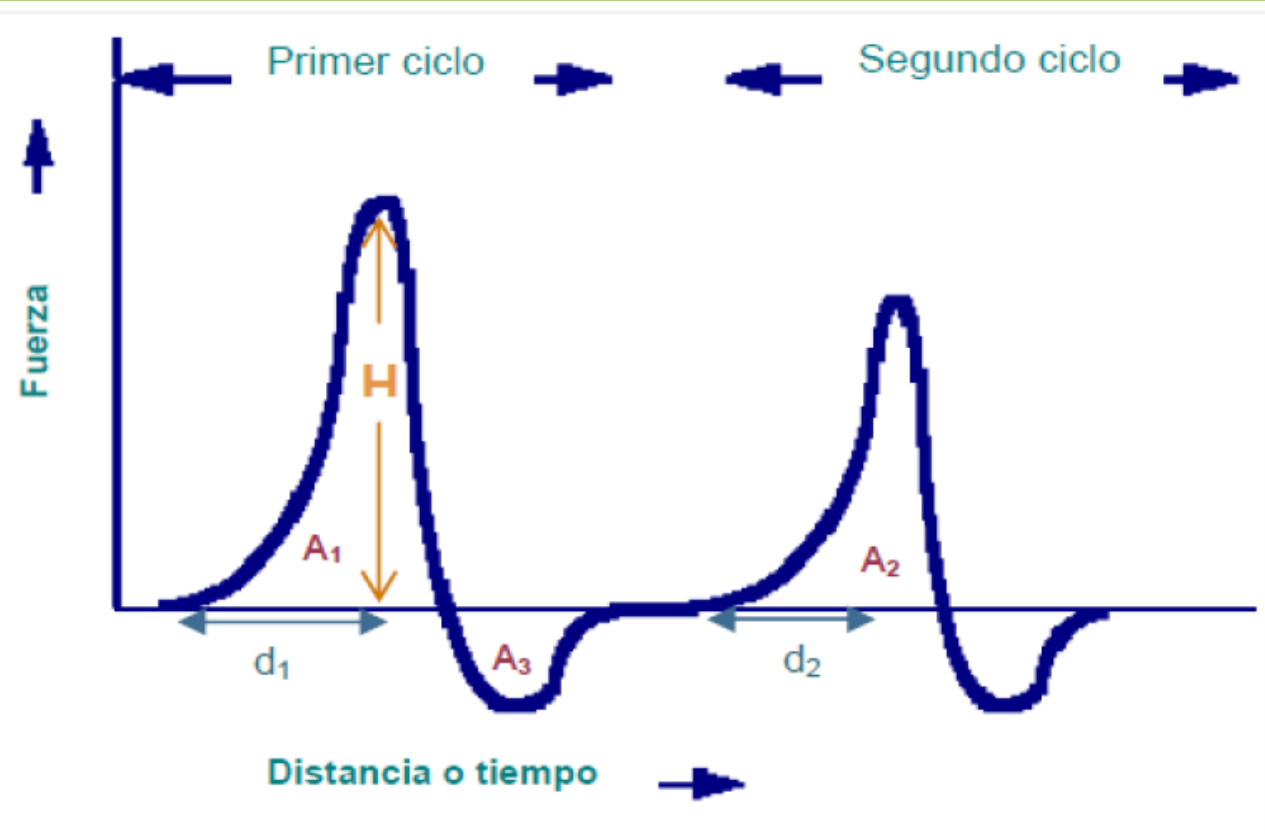

Figura 29. Esquema de un perfil de textura típico (adaptado de Friedman et al. 1963).

A partir del análisis de las curvas fuerza-tiempo (o fuerza-distancia) obtenidas, se determinaron los parámetros como dureza, cohesividad, adhesividad y elasticidad.

La dureza corresponde a la fuerza máxima registrada, altura del primer pico $(\mathrm{H}), \mathrm{y}$ se vincula con la resistencia a la compresión. Es la fuerza necesaria para lograr la deformación predeterminada.

La cohesividad es la relación entre las áreas del segundo y primer pico (A2/A1) del perfil y está vinculada con el trabajo necesario para vencer las uniones internas del material.

La adhesividad es el valor absoluto del área del pico negativo (A3) que aparece después del primer pico, corresponde al trabajo necesario para vencer las fuerzas atractivas entre la superficie del material y otros materiales, en este caso el sensor del texturómetro. Es mayormente una característica de superficie que depende de la combinación de los efectos de las fuerzas adhesivas y cohesivas, así como de la viscoelasticidad del material (Adhikari et al. 2001).

La elasticidad está definida como la relación $(\mathrm{d} 2 / \mathrm{d} 1)$ y se relaciona con la recuperación del material entre el final de la primera compresión y el comienzo de la segunda. La elasticidad es la percepción de la "gomosidad" del gel en la boca, y es una 
medida de la cantidad de estructura del gel que se pierde en la compresión inicial (Sanderson 1990).

Microscopía electrónica (SEM).

Los geles fueron fijados utilizando nitrógeno líquido $\left(-196{ }^{\circ} \mathrm{C}\right)$ e inmediatamente liofilizados en un liofilizador Heto FD4 (Lab Equipment, Dinamarca). Las muestras fueron luego cubiertas con una capa de oro de $20 \mathrm{~nm}$ de espesor utilizando un equipo Balzers SCD 030 (Balzers, Liechtenstein). Finalmente fueron observadas en un microscopio electrónico de barrido Philips 505 (Holanda), el cual fue operado con un voltaje de 20 kV. La microscopía fue realizada en la División de Microscopía de Exploración del Centro de Investigación y Desarrollo en Ciencias Aplicadas (CINDECA - CONICET/UNLP, La Plata, Argentina). El diámetro de poro fue calculado por análisis de las fotografías mediante el programa ImageJ (Schneider et al. 2012).

\section{Inclusión de microorganismos en geles mixtos}

Obtención de Lactobacillus paracasei CIDCA 8339 y Lactobacillus kefiri CIDCA 83102.

Lactobacillus paracasei y Lactobacillus kefiri fueron activados mediante dos repiques consecutivos y cultivados en MRS a $30{ }^{\circ} \mathrm{C}$ durante 48 horas y 72 horas, respectivamente. Luego de la incubación, las células fueron concentradas mediante centrifugación a $5000 \mathrm{~g}$ por 10 minutos y el pellet obtenido fue resuspendido en buffer fosfato $\mathrm{pH} 7$ (ver Apéndice).

Obtención de geles de kefiran, proteínas y fructosa con microorganismos.

Se prepararon dispersiones en buffer fosfato $\mathrm{pH} 7$ conteniendo 1,0 \% (p/p) de kefiran, 3,0 \% (p/p) de proteínas de suero de leche (WPI) y $12,0 \%(p / p)$ de fructosa. Las 
Geles de kefiran como vehículo de microorganismos probióticos.

mismas fueron previamente homogeneizadas y calentadas a $90{ }^{\circ} \mathrm{C}$ durante 10 minutos e inmediatamente enfriadas en baño de agua fría a $4{ }^{\circ} \mathrm{C}$ hasta alcanzar temperatura ambiente. Una vez templada la solución preparada se adicionó L. paracasei 8339 o L. kefiri 83102 a una concentración final de $1.10^{8} \mathrm{UFC} / \mathrm{ml}$. Se agitó suavemente hasta completa homogeneización y se tomaron alícuotas de cada una de las diferentes soluciones para ser colocadas en eppendorf estériles e inmediatamente enfriadas en freezer a $-20{ }^{\circ} \mathrm{C}$ por un período de 24 horas. Estas alícuotas fueron luego transferidas a $4{ }^{\circ} \mathrm{C}$ hasta su utilización.

Se realizaron los siguientes controles:

- Los lactobacilos se resuspendieron en buffer fosfato $\mathrm{pH} 7$ y se mantuvieron a $4{ }^{\circ} \mathrm{C}$ durante 48 horas (Control 0 ).

- L. paracasei CIDCA 8339 y L. kefiri CIDCA 83102 fueron resuspendidos en $1,0 \%(\mathrm{p} / \mathrm{p})$ de kefiran, 3,0 \% (p/p) de proteínas de suero de leche (WPI) y $12,0 \%(\mathrm{p} / \mathrm{p})$ de fructosa $\mathrm{y}$ almacenados en heladera durante 48 horas (Control $)$.

Se cuantificó el número de microorganismos viables incluidos en los geles, así como también en los controles correspondientes, mediante diluciones seriadas en triptona $0,1 \%(p / v)$ y recuento en agar MRS. Las placas fueron incubadas a $30{ }^{\circ} \mathrm{C}$ en aerobiosis durante 48 horas. Los resultados se presentaron como UFC/ml. Los ensayos se realizaron al menos tres veces.

Resistencia al pasaje gastrointestinal in vitro de los microorganismos incluidos en el gel.

Para evaluar la resistencia de L. paracasei CIDCA 8339 y L. kefiri CIDCA 83102 incluidos en los geles los mismos fueron sometidos a las condiciones gastrointestinales simuladas como se describió en el Capítulo I, Materiales y Métodos, basado en el protocolo de Grimoud et al. (2010). 
El mismo ensayo se realizó con los lactobacilos resuspendidos en buffer fosfato pH 7 y en la suspensión de 1,0 \% (p/p) de kefiran, 3,0 \% (p/p) de proteínas de suero de leche (WPI) y $12,0 \%(p / p)$ fructosa, previo a la formación del gel. Los ensayos se realizaron al menos tres veces.

Capacidad de adhesión de los microorganismos incluidos en el gel.

La capacidad de adhesión a células epiteliales (Caco-2/TC-7) de los lactobacilos antes y después del estrés ácido y de bilis, se realizó de acuerdo al protocolo detallado en el Capítulo I, Materiales y Métodos. Para la condición Gel, los geles fueron tratados con solución ácida y de bilis a una temperatura de $37^{\circ} \mathrm{C}$. El mismo ensayo se realizó con los lactobacilos resuspendidos en buffer fosfato $\mathrm{pH} 7$ y en la suspensión conteniendo $1,0 \%(p / p)$ de kefiran, 3,0 \% (p/p) de proteínas de suero de leche (WPI) y $12,0 \%(p / p)$ fructosa, previo a la formación del gel.

\section{Análisis estadístico}

El estudio estadístico se realizó con el programa GRAPHPAD Prism version 5.0 para Windows (San Diego, CA). Se efectuó un análisis de varianza simple (ANOVA) para determinar la diferencia entre medias. Las diferencias significativas entre los valores medios de cada experimento fueron determinadas por el test Tukey (intervalo de confianza del 95 \%). Todos los experimentos fueron realizados al menos por triplicado. 
CAPÍTULO 2

Geles de kefiran como vehículo de microorganismos probióticos. 


\section{Geles de kefiran con azúcares}

Los azúcares de bajo peso molecular son aditivos o ingredientes comunes en una amplia variedad de alimentos procesados. Junto con sus efectos edulcorantes, estos azúcares modifican las propiedades físicas del sistema alimentario. Los edulcorantes más comunes utilizados en los alimentos, sacarosa y fructosa, contribuyen a las características físicas y funcionales de los alimentos y bebidas, tales como la mejora del sabor, color, punto de congelación, estabilidad osmótica, además del propio dulzor (Davis 1995).

Debido a las propiedades saludables del kefiran y la capacidad del polisacárido para formar criogeles, el kefiran se convierte en una matriz prometedora para el desarrollo de alimentos con valor nutricional agregado debido a las propiedades promotoras de la salud asociadas a este polisacárido. La presencia de mono y disacáridos como cosolutos en soluciones gelificantes puede promover la asociación intermolecular de biopolímeros, aunque la inclusión de pequeñas moléculas no siempre conduce a un refuerzo de la red (Evageliou et al. 2000a), por ello se evaluó el efecto de la presencia de edulcorantes como sacarosa y fructosa en la capacidad de formar geles del kefiran.

Comportamiento reológico de soluciones de kefiran con sacarosa y fructosa.

En una primera etapa, se analizó el efecto del agregado de azúcares en el comportamiento de flujo y viscosidad aparente de la soluciones del kefiran ya que las propiedades fisicoquímicas pueden incidir en las interacciones que se forman al someter las soluciones al proceso de congelación-descongelación requerido para la formación de los geles. 
Geles de kefiran como vehículo de microorganismos probióticos.

En la Tabla 8 se presenta el comportamiento de flujo de las soluciones obtenidas de kefiran con fructosa y sacarosa. Las soluciones de kefiran mostraron curvas de flujo que corresponden a un comportamiento pseudoplástico sin área de histéresis. Se ajustó el modelo de Ostwald de Waele a los datos experimentales obtenidos con un coeficiente de correlación de 0,999 en todos los ensayos. Los índices de flujo (n) fueron todos menores a 1. La solución de kefiran sin azúcares presentó un valor de (n) de 0,6818 y este valor disminuyó con el aumento de la concentración de azúcar siendo de 0,4595 y 0,4797 para las soluciones de kefiran con 50,0 \% (p/p) de sacarosa o fructosa, respectivamente. La viscosidad aparente a $300 \mathrm{~s}^{-1}\left(\eta_{\mathrm{ap}} 300 \mathrm{~s}^{-1}\right)$ de la solución de kefiran fue de 46,59 mPa.s y este valor aumentó con el aumento de las concentraciones de azúcares alcanzando un valor de $612,85 \mathrm{mPa}$.s en la solución conteniendo 50 \% de sacarosa y de 249,30 mPa.s en la solución conteniendo la misma concentración de fructosa.

Tabla 8. Viscosidades aparentes a $300 \mathrm{~s}^{-1}\left(\eta_{\text {ap }} 300 \mathrm{~s}^{-1}\right)$, índice de consistencia (K), índice de flujo (n) y coeficiente de correlación $\left(\mathrm{r}^{2}\right)$, obtenidos ajustando los datos experimentales al modelo de Ostwald de Waele, en función de las concentraciones de azúcar (sacarosa o fructosa) en las soluciones de kefirán. Los resultados fueron obtenidos a $20^{\circ} \mathrm{C}$.

\begin{tabular}{|c|c|c|c|c|c|}
\hline Azúcar & $\begin{array}{c}\text { Concentración } \\
\qquad(p / p)\end{array}$ & $\begin{array}{c}\mathrm{K}^{*} \\
(\mathrm{~Pa} . \mathrm{s}-\mathrm{n})\end{array}$ & $n *$ & $r^{2}$ & $\begin{array}{c}\eta_{\text {ap }} 300 \mathrm{~s}^{-1} * \\
(\mathrm{mPa} . \mathrm{s})\end{array}$ \\
\hline & 0 & $0,2845 \pm 0,0221^{\mathrm{a}}$ & $0,6818 \pm 0.0110^{a}$ & 0,9996 & $46,59 \pm 0,62^{a}$ \\
\hline \multirow{5}{*}{ sacarosa } & 5,9 & $0,4745 \pm 0,0351^{\mathrm{a}}$ & $0,6268 \pm 0.0048^{a, b, c}$ & 0,9994 & $56,96 \pm 5,81^{a, b}$ \\
\hline & 10,0 & $0,5711 \pm 0,0171^{\mathrm{a}}$ & $0,6188 \pm 0.0017^{a, b}$ & 0,9995 & $65,40 \pm 1,30^{b, c}$ \\
\hline & 17,6 & $0,7541 \pm 0,1003^{a}$ & $0,5967 \pm 0.0055^{b, c, d}$ & 0,9995 & $75,96 \pm 7,81^{c, d}$ \\
\hline & 30,0 & $1,5615 \pm 0,1874^{a}$ & $0,5439 \pm 0.0018^{\mathrm{d}, \mathrm{e}}$ & 0,9996 & $116,10 \pm 12,87^{\mathrm{e}}$ \\
\hline & 50,0 & $9,0800 \pm 2,9400^{b}$ & $0,4595 \pm 0.1318^{e, f}$ & 0,9993 & $612,85 \pm 38,82^{\mathrm{g}}$ \\
\hline \multirow{5}{*}{ fructosa } & 5,9 & $0,4875 \pm 0,0025^{a}$ & $0,6325 \pm 0,0018^{a, b}$ & 0,9995 & $60,34 \pm 0,27^{a, b, c}$ \\
\hline & 10,0 & $0,5155 \pm 0,0369^{a}$ & $0,6245 \pm 0,0088^{b, c}$ & 0,9995 & $60,91 \pm 1,21^{a, b, c}$ \\
\hline & 17,6 & $0,6882 \pm 0,0195^{a}$ & $0,6134 \pm 0,0049^{b, c}$ & 0,9995 & $76,46 \pm 4,35^{c, d}$ \\
\hline & 30,0 & $1,0260 \pm 0,0198^{a}$ & $0,5741 \pm 0,0088^{c, d}$ & 0,9996 & $90,74 \pm 2,64^{d}$ \\
\hline & 50,0 & $4,9235 \pm 0,9991^{a}$ & $0,4797 \pm 0,0474^{f}$ & 0,9994 & $249,30 \pm 16,97^{f}$ \\
\hline
\end{tabular}


Obtención de los geles y caracterización fisicoquímica.

Estas soluciones fueron sometidas a un ciclo de congelación-descongelación para evaluar si las soluciones eran capaces de formar geles. La inclusión de sacarosa o fructosa en las soluciones de kefiran no impidió la formación de gel, por el contrario, después de un ciclo de congelación-descongelación, se obtuvieron geles translúcidos y autoportantes con todas las soluciones analizadas. La $\mathrm{a}_{\mathrm{w}}$ a $20{ }^{\circ} \mathrm{C}$ de los geles fue cercana a 1 para los geles de kefiran y de 0,9465 $\pm 0,0025$ y 0,9245 $\pm 0,0005$ para las concentraciones más altas utilizadas de sacarosa y fructosa respectivamente, sin observarse diferencias significativas respecto a los geles de kefiran sin azúcares.

Tabla 9. Valores de actividad acuosa obtenidos para los geles mixtos de kefiran a las concentraciones de sacarosa y fructosa estudiadas.

\begin{tabular}{c|c|c}
$\%(\mathrm{p} / \mathrm{p})$ & \multicolumn{1}{c}{ Sacarosa } & Fructosa \\
\hline $0,0 \%$ & $1,0015 \pm 0,0005$ & $1,0015 \pm 0,0005$ \\
$5,9 \%$ & $1,0000 \pm 0,0020$ & $0,9995 \pm 0,0015$ \\
$10,0 \%$ & $0,9965 \pm 0,0005$ & $0,9890 \pm 0,0002$ \\
$17,6 \%$ & $0,9915 \pm 0,0015$ & $0,9800 \pm 0,0030$ \\
$30,0 \%$ & $0,9775 \pm 0,0025$ & $0,9590 \pm 0,0020$ \\
$50,0 \%$ & $0,9465 \pm 0,0025$ & $0,9245 \pm 0,0005$ \\
\hline
\end{tabular}

La microestructura de los geles con sacarosa y fructosa se evaluó mediante microscopía electrónica de barrido con una ampliación de 600 X (Figura 30).

Los geles mostraron una estructura tridimensional altamente porosa excepto aquéllos conteniendo las concentraciones más altas de sacarosa y fructosa, cuya microestructura tenía la apariencia de láminas superpuestas de polisacárido. El tamaño de poro de los geles que contenían bajas concentraciones de azúcar fue mayor que la de los geles de kefiran. Los geles preparados con concentraciones mayores de 30,0 \% (p/p) de sacarosa y mayores de $17,6 \%(p / p)$ de fructosa presentaron tamaños de poro significativamente menores a los encontrados para los geles de kefiran sin azúcares. 


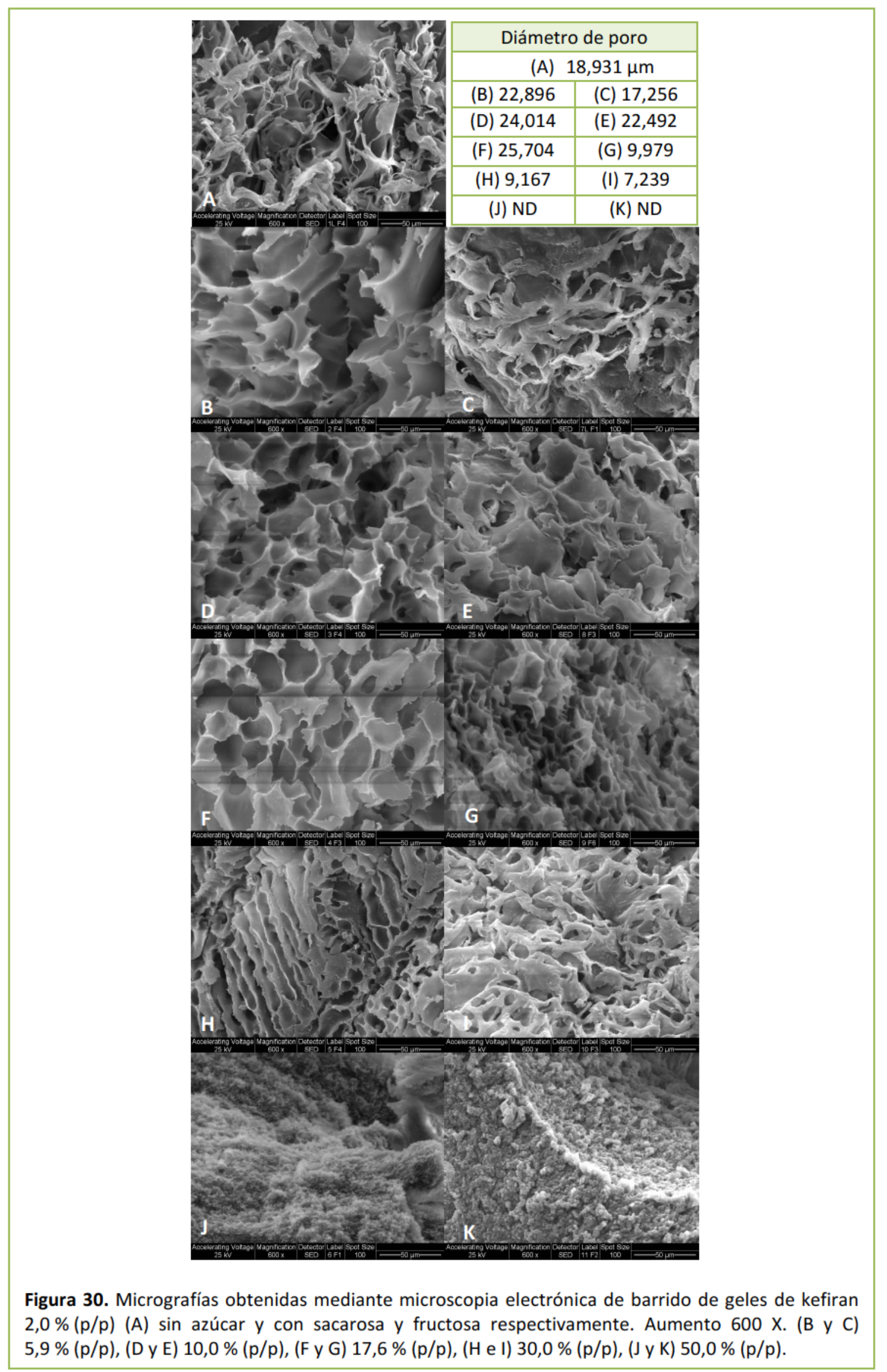


Se determinó la capacidad de retención de agua (WHC) de los geles como fue explicado en Materiales y Métodos página 118. Los resultados se presentan en la Figura 31.

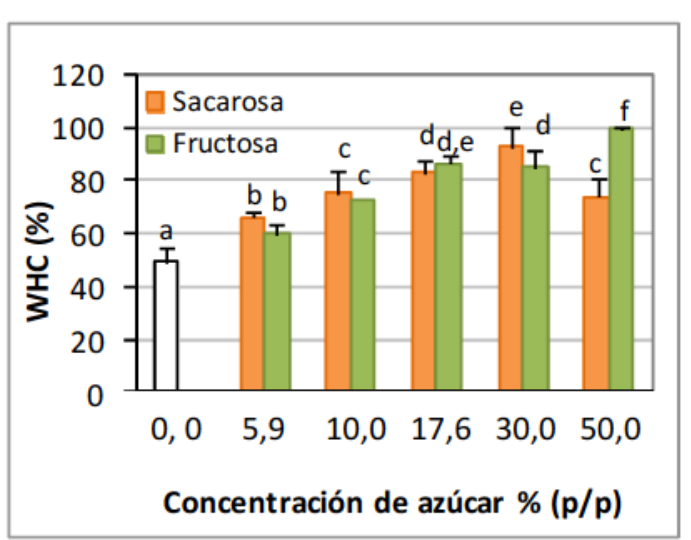

Figura 31. Capacidad de retención de agua (WHC) de geles de kefiran 2,0\% p/p) sin azúcar y con $5,9 \%, 10,0 \%, 17,6 \%, 30,0 \%$ y $50,0 \%(p / p)$ de sacarosa y fructosa. Diferentes letras sobre barras de error indican diferencias significativas $(p \leq 0,05)$.

La capacidad de retención de agua de los geles de kefiran fue mayor a medida que aumentó la concentración de azúcar, alcanzando un valor cercano a 100 \% para los geles de kefiran con 50,0 \% (p/p) de fructosa (Figura 31). Los geles de kefiran con sacarosa aumentaron su WHC con el aumento de la concentración de sacarosa hasta una concentración de 30,0\% (p/p) correspondiendo a un valor de 92,5 \% que luego disminuyó a 73,0 \% al aumentar la concentración de este azúcar hasta 50,0 \% indicando que cada azúcar ejerce un efecto diferente sobre las propiedades del gel.

Se determinó el espectro mecánico de los geles obtenidos mediante reometría oscilatoria de baja amplitud de deformación. El espectro mecánico de un gel/solución proporciona información sobre el comportamiento frente a una deformación sinusoidal de los geles obtenidos dentro de la región de viscoelasticidad lineal. A modo de ejemplo, en la Figura 32 se muestran los espectros mecánicos de los geles de kefiran, y los geles de kefiran con $30 \%$ (p/p) de sacarosa y fructosa. El módulo elástico ( $\left.\mathrm{G}^{\prime}\right)$ de los geles de kefiran con y sin azúcares, fue mayor que el módulo viscoso (G") a todas las frecuencias estudiadas, y ambos módulos fueron prácticamente independientes de la frecuencia indicando un comportamiento de gel (Biliadieris 1992; Peressini et al. 2003; RossMurphy 1995). 
Geles de kefiran como vehículo de microorganismos probióticos.

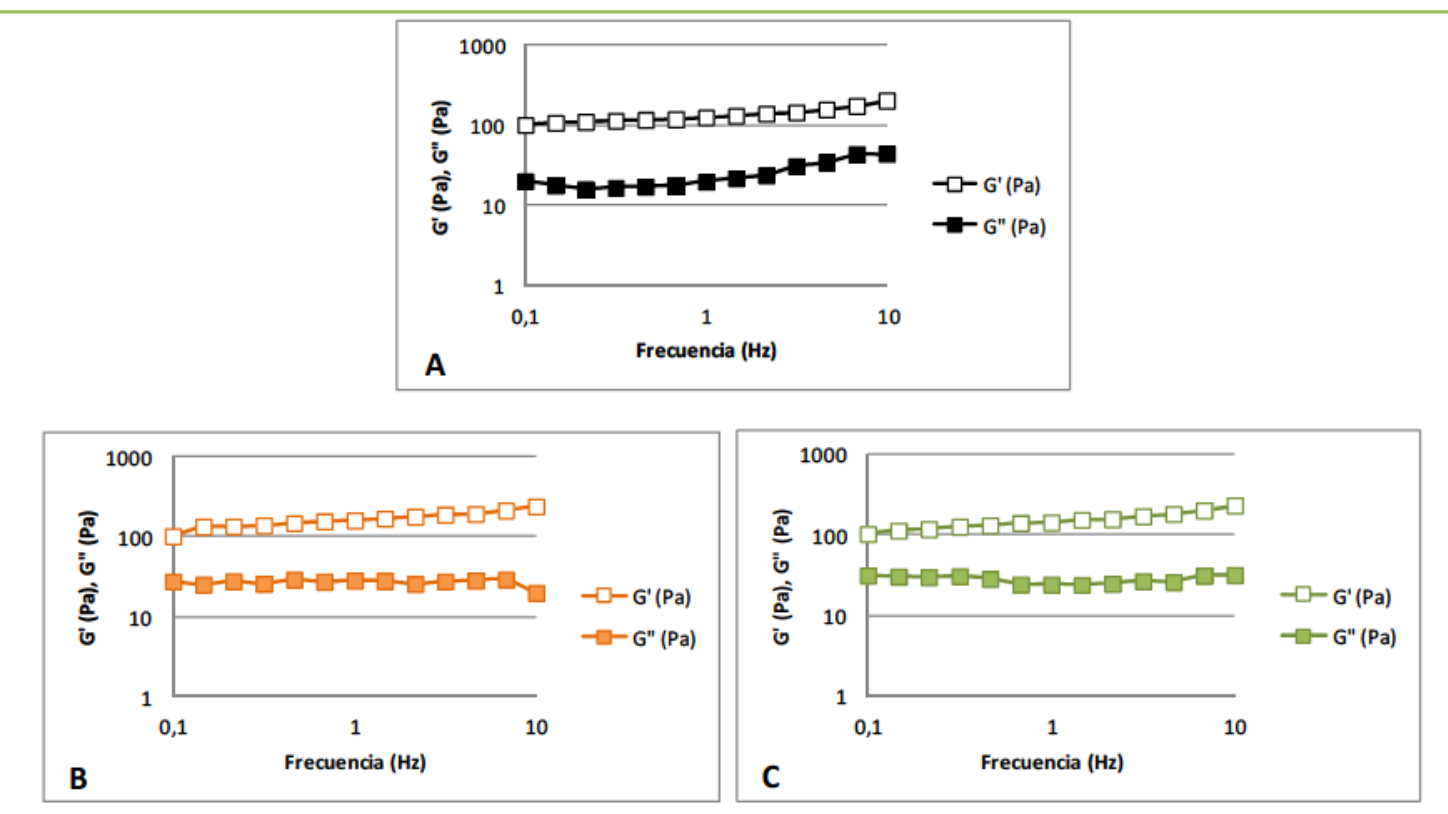

Figura 32. Espectros mecánicos obtenidos a $0,1 \mathrm{~Pa}$ y $20^{\circ} \mathrm{C}$, de los geles obtenidos luego del ciclo de congelación-descongelación de soluciones conteniendo $2,0 \%(\mathrm{p} / \mathrm{p})$ de kefiran sin azúcares $(\mathrm{A})$ y con $30,0 \%(\mathrm{p} / \mathrm{p})$ de sacarosa (B) o fructosa (C).

Para comparar los parámetros viscoelásticos entre los distintos geles, el módulo elástico (G'), el módulo viscoso (G") y la tangente del ángulo de desfasaje ( $\tan (\delta))$ fueron evaluados a la frecuencia de $1 \mathrm{~Hz}$ (Figura 33).

La incorporación de sacarosa en concentraciones de 5,9 \% a 30,0 \% (p/p) a los geles de kefiran, aumentó el módulo elástico y el módulo viscoso. Cuando la concentración de sacarosa fue 50,0 \% (p/p), los valores obtenidos de ambos módulos fueron iguales al del gel de kefiran (Figura $33 \mathrm{~A}$ ).

El agregado de bajas concentraciones de fructosa $(5,9 \%$ y $10,0 \%(p / p))$ disminuyó el módulo elástico de los geles, sin embargo, el agregado de mayores concentraciones de este azúcar dio como resultado geles con mayor carácter elástico. El módulo viscoso G" aumentó con la concentración de fructosa hasta 30,0 \% y luego disminuyó a un valor comparable a la del gel de kefiran con 5,9 \% del mismo azúcar (Figura 33 B).

La Figura $33 \mathrm{C}$ muestra la tangente del ángulo de desfasaje $(\tan (\delta))$ de los geles de kefiran con distintas concentraciones de los azúcares estudiados. La inclusión de hasta $30,0 \%(\mathrm{p} / \mathrm{p})$ de sacarosa y fructosa produjo geles con mayores valores de $\tan (\delta)$. Los geles preparados con 50,0 \% (p/p) de azúcar presentaron el mismo valor de $\tan (\delta)$ que los geles de kefiran. Aunque ambos azúcares tuvieron el mismo efecto cualitativo 
Geles de kefiran como vehículo de microorganismos probióticos.

sobre la $\tan (\delta)$, el grado en que fueron afectadas las propiedades viscoelásticas del gel dependió del tipo de azúcar, ya que los geles de kefiran que contenían fructosa mostraron mayores valores de $\tan (\delta)$ que los suplementados con sacarosa a la misma concentración. Sin embargo, a la concentración de azúcar más alta evaluada, se observó una disminución en $\tan (\delta)$ en los geles de kefiran con fructosa debido a un incremento en el módulo elástico; mientras que la disminución observada en $\tan (\delta)$ para los geles de kefiran con sacarosa se produjo debido a una mayor disminución en el módulo viscoso con respecto a la observada con el módulo elástico.
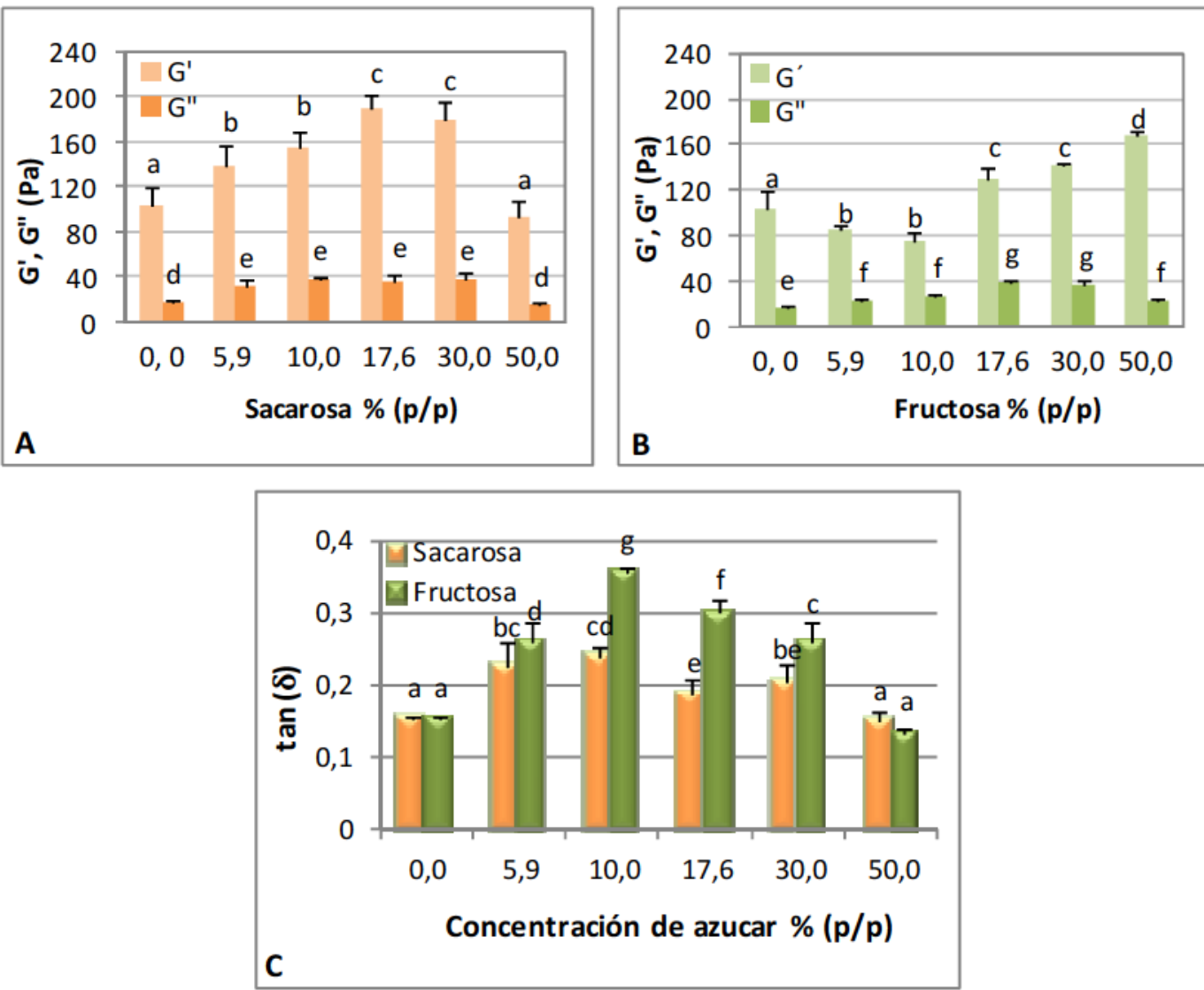

Figura 33. Módulo elástico (G') y viscoso (G") de geles de kefiran $2 \%$ (p/p) con 5,9 \%, 10,0 \%, 17,6 \%, $30,0 \%$ y $50,0 \%(\mathrm{p} / \mathrm{p})$ de sacarosa $(\mathrm{A})$ y fructosa $(\mathrm{B})$, y la tangente del ángulo de desfasaje $(\tan (\delta))$ a las mismas concentraciones de ambos azúcares (C) (todas las medidas fueron evaluadas a $1 \mathrm{~Hz}$ de frecuencia y a $20^{\circ} \mathrm{C}$ ). Dentro del mismo gráfico, las letras sobre las barras de error indican diferencias significativas $(p \leq 0,05)$.

El aumento del módulo elástico con la concentración de azúcar podría explicarse porque los hidratos de carbono de bajo peso molecular podrían interactuar con los hidrocoloides a través de enlaces de hidrógeno, aumentando la rigidez de las cadenas de 
Geles de kefiran como vehículo de microorganismos probióticos.

los polisacáridos. Cadenas más rígidas podrían producir un mayor módulo elástico (G'), ya que se necesitarían fuerzas de flexión adicionales para deformar las redes (Maurer et al. 2012). Además, la introducción de grandes cantidades de monosacáridos o disacáridos en sistemas acuosos competiría con el polímero por su interacción con el agua, con la consiguiente disminución en la eficacia de las interacciones polímerosolvente, favoreciendo una auto-asociación de las cadenas de polímero. Este proceso resulta en un aumento en el modulo G' con el aumento de la concentración de sacarosa. El agregado de 50,0 \% de sacarosa a la solución de kefiran, produjo una disminución pronunciada en el módulo G' resultando en geles de kefiran con menor carácter elástico. Según los resultados presentados, con el aumento de la concentración de sacarosa, las interacciones polímero-polímero se hacen más fuertes, sin embargo, a mayores concentraciones de sacarosa, se produciría una inhibición uniéndose a las cadenas del polímero y bloqueando las interacciones de las cadenas requeridas para formar las uniones de la red del gel. Este mismo efecto se observó para criogeles de sacarosaagarosa (Maurer et al. 2012) y para geles de galactomanano con sacarosa, fructosa y glucosa (Doyle et al. 2006).

La presencia de fructosa o sacarosa afectó de manera diferente las características de los geles de kefiran indicando que diferentes azúcares, pueden promover la asociación de los biopolímeros de manera diferente. Resultados similares fueron descriptos por Evageliou et al. (2000a, 2000b); quienes trabajaron con geles de pectina de alto metoxilo y observaron diferencias sustanciales en la fuerza del gel dependiendo del tipo de azúcar utilizado en concentraciones equivalentes de sacarosa, glucosa o fructosa. La presencia de los azúcares produjo un aumento en la fuerza del gel de pectina, siendo más débiles los geles obtenidos con fructosa. Del mismo modo, Doyle et al. (2006) estudiaron el efecto de la inclusión de diferentes azúcares en la textura de los geles de galactomanano, y encontraron que la fuerza del gel y el módulo de Young dependían del azúcar presente.

La adición de 0 a 30,0 \% de sacarosa en geles de kefiran produjo geles con módulos elásticos más altos que los geles adicionados con fructosa a las mismas concentraciones, y esta diferencia se hizo más pronunciada cuando la adición de sacarosa y fructosa se aproximó al 50,0 \%, ya que en presencia de fructosa se reforzó la 
Geles de kefiran como vehículo de microorganismos probióticos.

estructura aumentándose el valor de G', mientras que la inclusión de sacarosa interfirió en la formación de la red del gel como se evidenció al obtener un módulo elástico similar al del gel de kefiran. Puesto que los grupos hidroxilos primarios pueden formar puentes de hidrógeno fuertes, la inhibición de la asociación intermolecular dependería del número de esos grupos por monosacárido y podría explicar el diferente efecto de cada azúcar estudiado (Doyle et al. 2006).

Las diferencias en las características de los geles obtenidos con altas concentraciones de ambos azúcares podría ser el resultado, entre otros parámetros, de las diferencias en la viscosidad de la solución. Aunque dos azúcares pueden compartir una composición química idéntica, la orientación de los grupos hidroxilo puede influir en la organización de las moléculas de agua en la primera capa de solvatación (Dashnau et al. 2005). Lazaridou et al. (2008) informaron que la adición de azúcares a soluciones de ß-glucano retardó la crioestructuración. Geles de ß-glucano de alto peso molecular exhibieron espectros mecánicos de geles fuertes y elásticos que luego cambiaron a geles débiles con la inclusión de 15 \% de sacarosa en la formulación, o soluciones líquidas con la inclusión de $15 \%$ de fructosa.

La Figura 34 muestra los módulos elásticos G' y viscosos G" y la tangente del ángulo de desfasaje $\tan (\delta)$ como función de la temperatura para los geles de kefirán tanto en ausencia como en presencia de $30,0 \%$ de sacarosa o fructosa, evaluados a $1 \mathrm{~Hz}$. Cuando se evaluaron los parámetros reológicos de los geles durante el calentamiento, en los geles con azúcares se observó una modificación en cuanto a la temperatura y magnitud de los cambios observados, respecto a los geles sin azúcares. 
Geles de kefiran como vehículo de microorganismos probióticos.
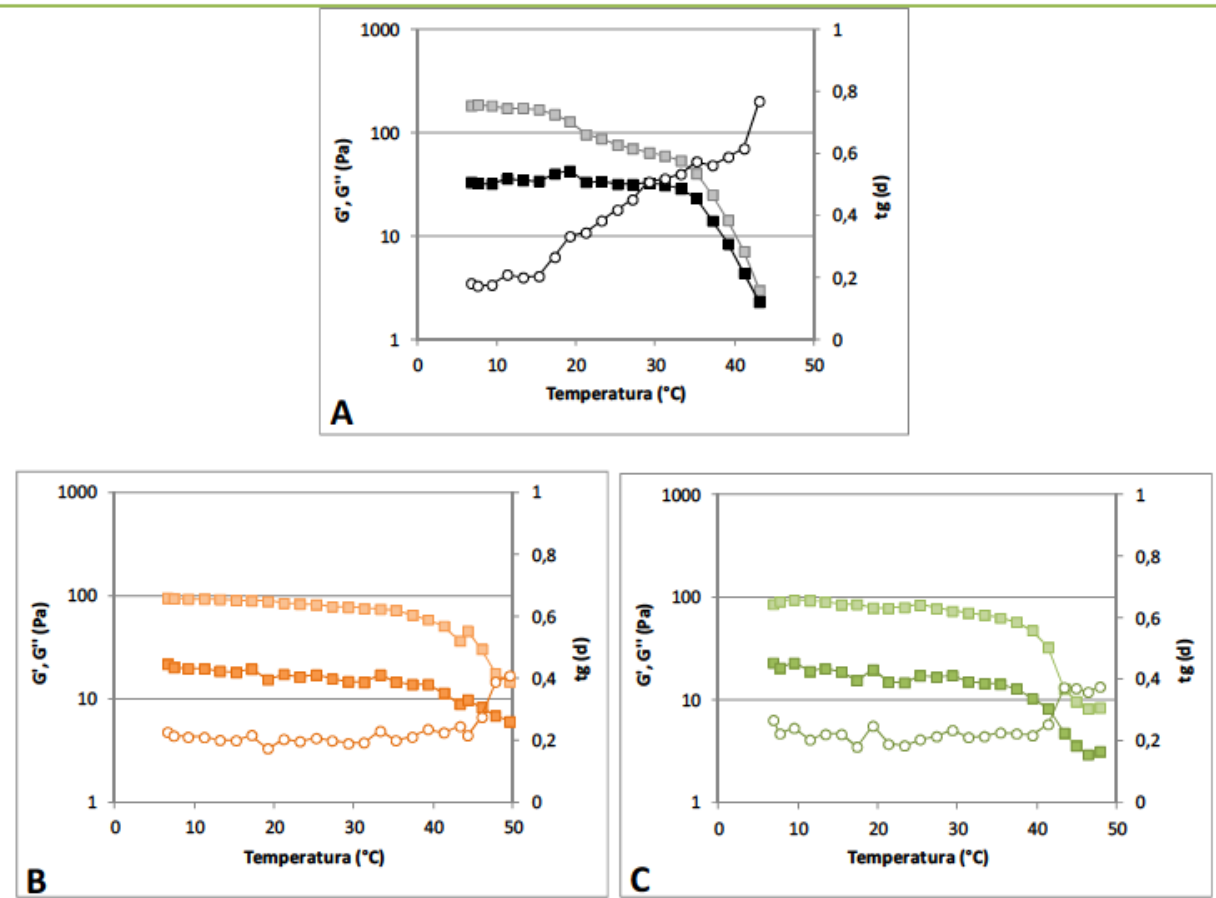

Figura 34. Módulo elástico $\mathrm{G}^{\prime}(\square)$, módulo viscoso $\mathrm{G}^{\prime \prime}(\boldsymbol{\square})$ y tangente del ángulo de desfasaje $\tan (\delta)(O)$ a $1 \mathrm{~Hz}$ y 0,1 Pa como función de la temperatura durante el calentamiento de los geles de kefiran sin azúcar (A), o suplementados con 30,0\% (p/p) de sacarosa (B) o fructosa (C).

En los geles de kefiran (Figura 34 A) se observó que los módulos elástico y viscoso (G' y G"), durante el calentamiento decaen suave y progresivamente con el aumento de la temperatura, pero a una temperatura determinada (umbral), descienden abruptamente. Cuando la sacarosa (Figura 34 B) o fructosa (Figura 34 C) fueron incluidos en los geles de kefiran, la caída fue menos pronunciada que la observada en los geles sin azúcares, y la temperatura a la que comenzó el descenso en G' se desplazó a la derecha indicando que esto ocurría a valores más altos de temperatura. A fin de una comparación, se determinó la temperatura a la que el valor de G' se redujo a $1 / 5$ de su valor a $20^{\circ} \mathrm{C}$ para cada gel. Esta temperatura se desplazó de $38^{\circ} \mathrm{C}$ para el gel de kefiran sin azúcar, a $47{ }^{\circ} \mathrm{C}$ y $42{ }^{\circ} \mathrm{C}$ cuando el gel contenía $30,0 \%$ de sacarosa o fructosa, respectivamente. Los termogramas correspondientes de los geles de kefiran sin azúcar indican una transición endotérmica en $39,7 \pm 6,6^{\circ} \mathrm{C}$. La entalpía de este proceso fue de $32,5 \pm 7,5 \mathrm{~mJ} / \mathrm{mg}$. No se observó transición endotérmica en los termogramas correspondientes a los geles con azúcar. 
Geles de kefiran como vehículo de microorganismos probióticos.

De acuerdo a estos resultados, se puede concluir que luego de un ciclo de congelación-descongelación, las soluciones de kefiran con sacarosa o fructosa forman criogeles. El comportamiento de los geles obtenidos depende del azúcar y concentración utilizada. Las moléculas de sacarosa y fructosa contribuyen a la retención de agua y a un aumento en los módulos de G' y G" a causa de un mayor número de moléculas presentes. Las interacciones entre estos azúcares con el polisacárido podrían interferir/favorecer la formación de puentes de hidrógeno entre las moléculas del polisacárido, modificando así la viscoelasticidad del gel.

Desde el punto de vista sensorial, los geles que contienen fructosa son más dulces que los obtenidos con la misma cantidad de sacarosa. Además, los geles de kefiran con el mismo grado de dulzor como los que contienen $17,6 \%$ de fructosa y $30,0 \%(p / p)$ de sacarosa, presentan diferentes características fisicoquímicas, lo que permite la posibilidad de elegir la formulación adecuada para elaborar criogeles para un propósito comercial en particular. 
Geles de kefiran como vehículo de microorganismos probióticos.

\section{Formación de geles de kefiran y proteínas de suero de leche}

La manipulación inteligente de mezclas de biopolímeros, proteínas y polisacáridos, es una vía promisoria para la generación de nuevas estructuras y texturas en los alimentos así como para la obtención de micro y nanoestructuras con diferentes aplicaciones. Los polisacáridos contribuyen a importantes características estructurales en numerosos sistemas alimentarios (Walter 1998), entre las más importantes se encuentra su capacidad gelificante (Morris \& Rees, 1978; Morris 1998) y su capacidad para estabilizar espumas y emulsiones (Carp et al. 2001; Dickinson 1998). Los sistemas mixtos proteína-polisacárido suelen conceder al alimento propiedades mejoradas respecto a las que proporcionan ambos componentes en forma individual (Dickinson 1993).

La capacidad de las proteínas de suero de leche para formar geles bajo condiciones específicas es una propiedad funcional importante para obtener varios productos alimenticios de textura y características sensoriales deseables (Barbut 1993; Foegeding et al. 2002; Kinsella \& Whitehead, 1989; Langton \& Hermansson, 1992).

En esta parte del capítulo se estudió la formación de geles mixtos de kefiran y proteínas de suero de leche (WPI) con la finalidad de utilizarlos como vehículo de microorganismos probióticos. Para ello, se analizaron previamente las características del aislado de proteínas de suero de leche en lo referente a su capacidad de formar geles.

Geles de aislado de proteína de suero: Selección de las concentraciones de proteína capaces de formar geles.

En una primera etapa se analizó el efecto de la concentración de proteínas en la obtención de geles, y las condiciones de proceso para su obtención. Se realizaron geles de aislado de proteína de suero de leche (WPI) a concentraciones de 2,0 \% a 10,0 \% $(\mathrm{p} / \mathrm{p})$ de WPI en buffer fosfato $\mathrm{pH}$ 7. Las soluciones fueron calentadas durante 10 minutos a $90{ }^{\circ} \mathrm{C}$, para permitir la desnaturalización de las proteínas de suero de leche (Figura 35) y luego enfriadas inmediatamente en baño de agua fría hasta llegar a temperatura ambiente. 


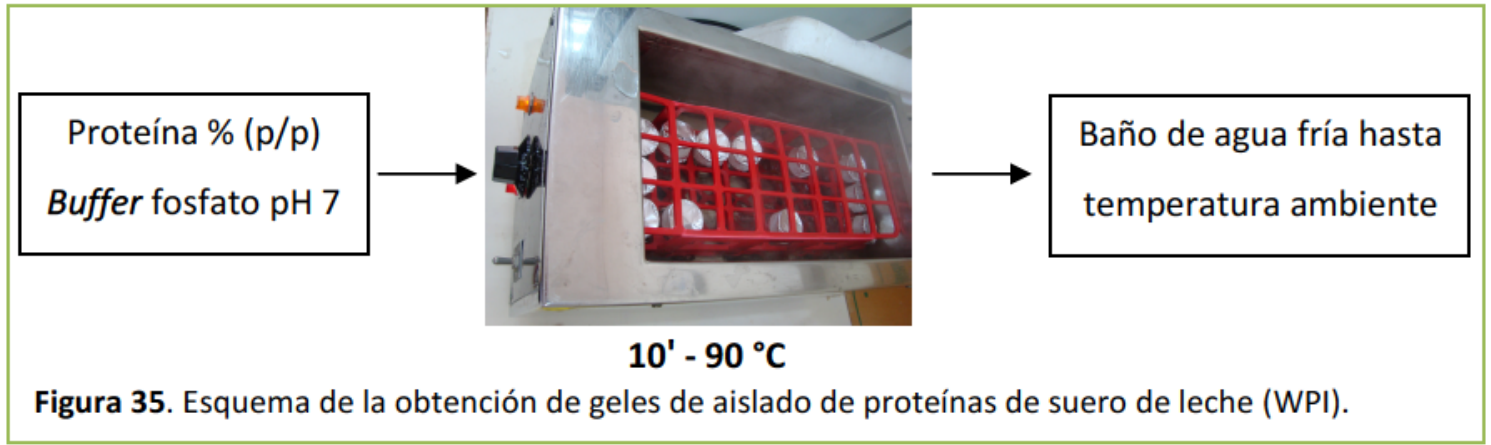

Se evaluaron macroscópicamente los geles obtenidos y se presentan en la Figura 36. Los geles obtenidos a partir de soluciones $8,0 \% ; 9,0 \%$ y $10,0 \%(p / p)$ de WPI resultaron duros y firmes, y se formaron durante el calentamiento, mientras que los geles obtenidos a partir de soluciones 5,0 \%; 6,0 \% y 7,0\% (p/p) de WPI resultaron geles débiles y frágiles. Las concentraciones $2,0 \%$ y 4,0 \% (p/p) de WPI no permitieron la formación de un gel verdadero dando soluciones viscosas.

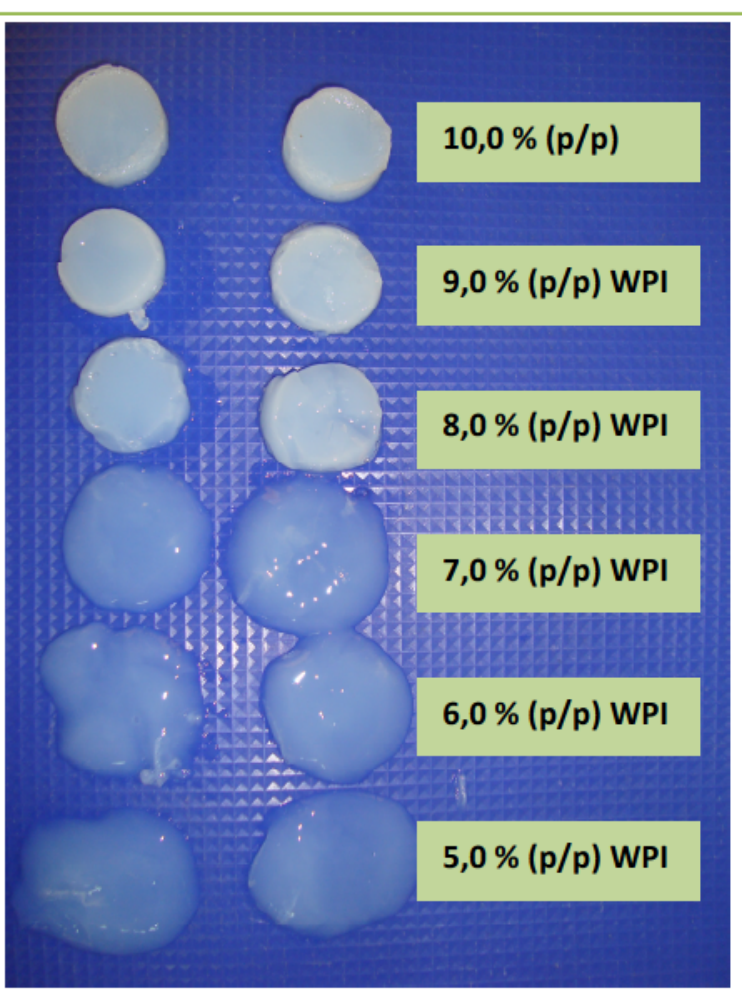

Figura 36. Geles de aislado de proteína de suero de leche obtenidos a partir de soluciones de diferente concentración aislado de proteína de suero (WPI). Los mismos fueron obtenidos mediante calentamiento a $90{ }^{\circ} \mathrm{C}$ durante 10 minutos e inmediatamente enfriados en baño de agua fría hasta 
Geles de kefiran como vehículo de microorganismos probióticos.

La gelificación implica la formación de una estructura tridimensional mediante una agregación progresiva de macromoléculas o partículas a través de uniones químicas o interacciones físicas bajo determinadas condiciones (Clark 1992; Renard \& Lefebvre 1992; Tobitani \& Ross-Murphy, 1977; Verheul \& Roefs, 1998a). Las propiedades fisicoquímicas de los geles de proteína de suero de leche quedan definidas principalmente por las interacciones moleculares que definen la microestructura de los geles, las cuales dependen de la concentración de proteína, $\mathrm{pH}$ y la fuerza iónica de la solución (Barbut 1993; Foegeding et al. 1995; Langton \& Hermansson, 1992; Shimada \& Cheftel, 1988; Verheul \& Roefs, 1998a, 1998b). Los resultados presentados en este trabajo permiten concluir que a partir de $8 \%(\mathrm{p} / \mathrm{p})$ de WPI se formaron geles duros, mientras que a concentraciones menores se obtuvieron soluciones y geles frágiles, indicando que la concentración de proteína juega un papel clave en la formación del gel. Trabajos previos demostraron que geles obtenidos con concentración de proteínas de suero entre $7 \%$ y $20 \%(\mathrm{p} / \mathrm{p})$ presentan diferentes características de textura, mientras que a concentraciones superiores a $20 \%(\mathrm{p} / \mathrm{p})$ es difícil obtener una dispersión homogénea adecuada para la gelificación. Por otro lado, a concentraciones más bajas $<$ 7 \% (p/p)) no se observa la formación de gel (Huffman 1996; Tang et al. 1995), coincidiendo con los resultados presentados en este trabajo.

La gelificación inducida por calor provoca la desnaturalización de las proteínas y la generación de nuevas interacciones hidrofóbicas entre las proteínas desplegadas (Dissanayake et al. 2013). Además, a pH 7, la gelificación se podría reforzar por el intercambio entre enlaces disulfuro-sulfhidrilo que se ven favorecidos a $\mathrm{pH}$ neutro (Lupano et al. 1992; Shimada \& Cheftel, 1988; Yamul \& Lupano, 2003), que pueden ser iniciados por $\beta$-lactoglobulina o $\alpha$-lactoalbúmina, que tienen grupos SH libres (Lupano et al. 1992, 1996; Shimada \& Cheftel, 1988).

Efecto del tratamiento a $-20^{\circ} \mathrm{C}$ en la formación de geles de proteína de suero de leche.

Para evaluar el efecto del proceso de congelación- descongelación utilizado para elaborar los geles de kefiran, en la preparación de los geles de proteínas de suero, se 
procedió a realizar la preparación de los geles mediante la combinación de dos etapas. Una, correspondiente al proceso de desnaturalización y gelificación de las proteínas, que consiste en un calentamiento durante 10 minutos a $90{ }^{\circ} \mathrm{C}$ y luego enfriamiento en baño de agua fría hasta llegar a temperatura ambiente (ETAPA 1). Y otra, en la cual los geles obtenidos en el paso anterior fueron llevados a $-20^{\circ} \mathrm{C}$ durante 24 horas y otras 24 horas a $4{ }^{\circ} \mathrm{C}$, lo que llamamos ETAPA 2. Las concentraciones de WPI utilizadas fueron 3,0; 4,0; 6,$0 ; 7,0$ y $8,0 \%(p / p)$ a fin de ver el efecto de la Etapa 2 en geles débiles, como en geles más duros y consistentes. Los geles obtenidos se presentan en la Figura 37.

Los geles obtenidos en ambas condiciones mostraron diferencias en cuanto a textura y consistencia. El tratamiento de congelación-descongelación (enfriamiento a $-20{ }^{\circ} \mathrm{C}$ durante 24 horas y luego almacenamiento a $4{ }^{\circ} \mathrm{C}$ - Etapa 2) utilizado en la elaboración de los geles, permitió la formación de nuevas interacciones entre los macrocomponentes ya que se observaron geles duros y firmes a partir de soluciones con $6,0 \% ; 7,0 \%$ y $8,0 \%(\mathrm{p} / \mathrm{p})$ de WPI, a diferencia de los obtenidos solamente con la Etapa 1 donde se obtuvieron geles débiles (Figura 37 A). Los geles obtenidos utilizando ambas etapas a partir de soluciones con 3,0 \% y 4,0\% (p/p) de WPI, resultaron ser geles autoportantes pero menos firmes que los obtenidos a concentraciones mayores (Figura 37 B). Sin embargo, a estas concentraciones no se formó gel en ausencia de este tratamiento (Figura $37 \mathrm{~A}$ ). 
Geles de kefiran como vehículo de microorganismos probióticos.

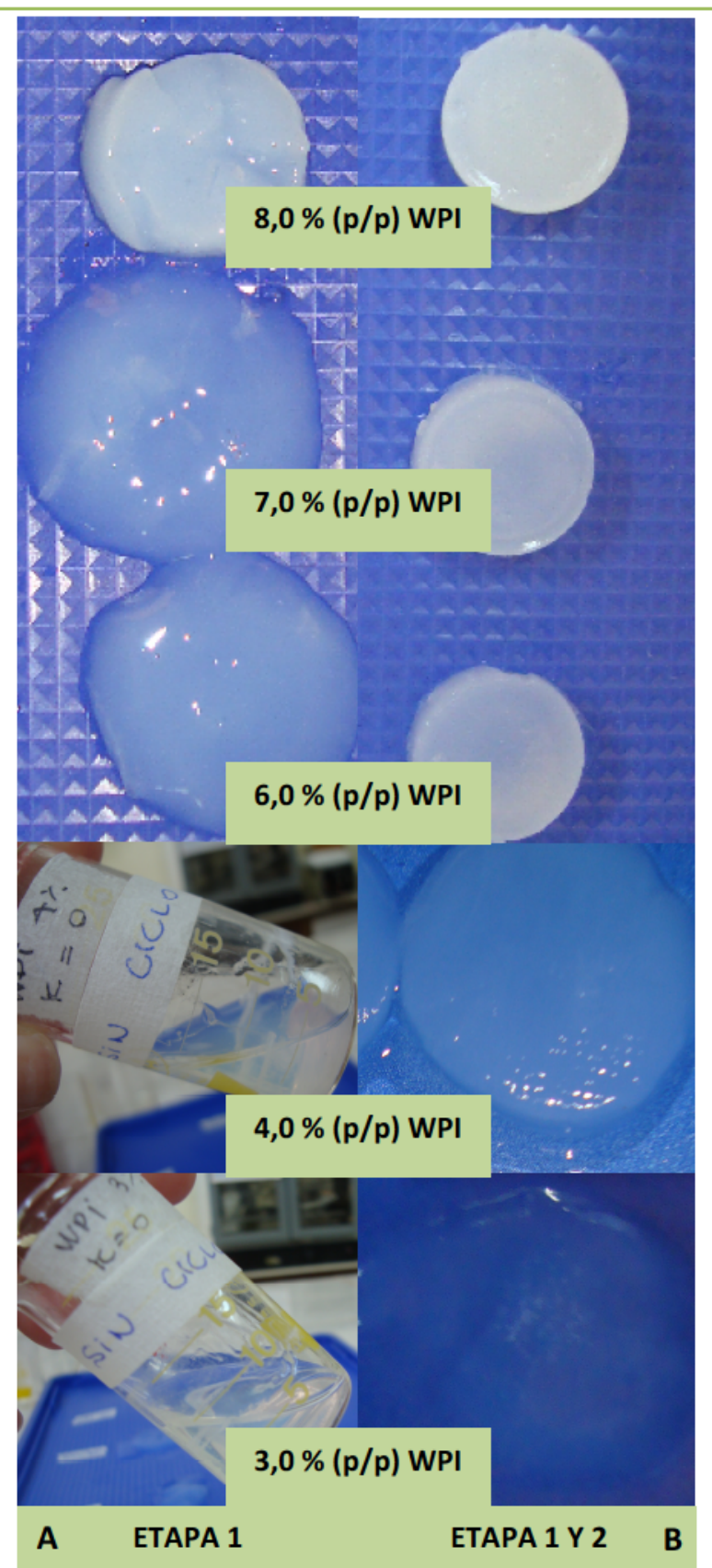

Figura 37. Geles de proteína de suero de leche obtenidos mediante tratamiento a $90{ }^{\circ} \mathrm{C}$ durante 10 minutos y enfriados en baño de agua fría hasta temperatura ambiente (ETAPA 1) (A), y geles obtenidos mediante tratamiento térmico (ETAPA 1) combinado con enfriamiento a $-20{ }^{\circ} \mathrm{C}$ durante 24 horas y luego almacenamiento a $4{ }^{\circ} \mathrm{C}$ (ETAPA 1 y 2) (B). Se utilizaron soluciones de proteína de suero en concentraciones de 3,$0 ; 4,0 ; 6,0 ; 7,0$ y $8,0 \%$ (p/p).

La gelificación en frío de soluciones de proteínas desnaturalizadas por calor ha sido previamente informada para $\beta$-lactoglobulina, concentrados de proteínas de suero de leche, y aislados de suero de leche (Vreeker et al. 1992; Barbut y Foegeding, 1993; Sato et al. 1995; Elofsson et al. 1997; Ju y Kilara, 1998a, b). Al enfriarse una solución de proteína de suero de leche precalentada se produce la desnaturalización térmica de la 
Geles de kefiran como vehículo de microorganismos probióticos.

$\beta$-lactoglobulina que incluye la disociación del dímero, la pérdida de la estabilidad de la hélice a $65{ }^{\circ} \mathrm{C}$ aproximadamente y la formación de enlaces disulfuro (Holt 2000). La formación de estos enlaces disulfuro en geles obtenidos mediante tratamiento térmico a $90{ }^{\circ} \mathrm{C}$ está bien establecida (Hoffmann \& van Mil. 1997). Estas uniones dan fuerza al gel y mejoran la estabilidad del mismo (Alting et al. 2000).

Debido a que la gelificación en frío puede ocurrir después de la adición de dicho componente a una matriz alimentaria, tiene un potencial considerable en la industria para la elaboración de productos congelados con texturas definidas (Bryant \& McClements, 1998).

Se analizó el espectro mecánico de los geles obtenidos a partir de soluciones $3,0 \%$ y $4,0 \%(\mathrm{p} / \mathrm{p})$ de WPI y de las soluciones mediante reometría oscilatoria de baja amplitud de deformación. El espectro mecánico proporciona información sobre el comportamiento de las muestras obtenidas dentro de la región de viscoelasticidad lineal.

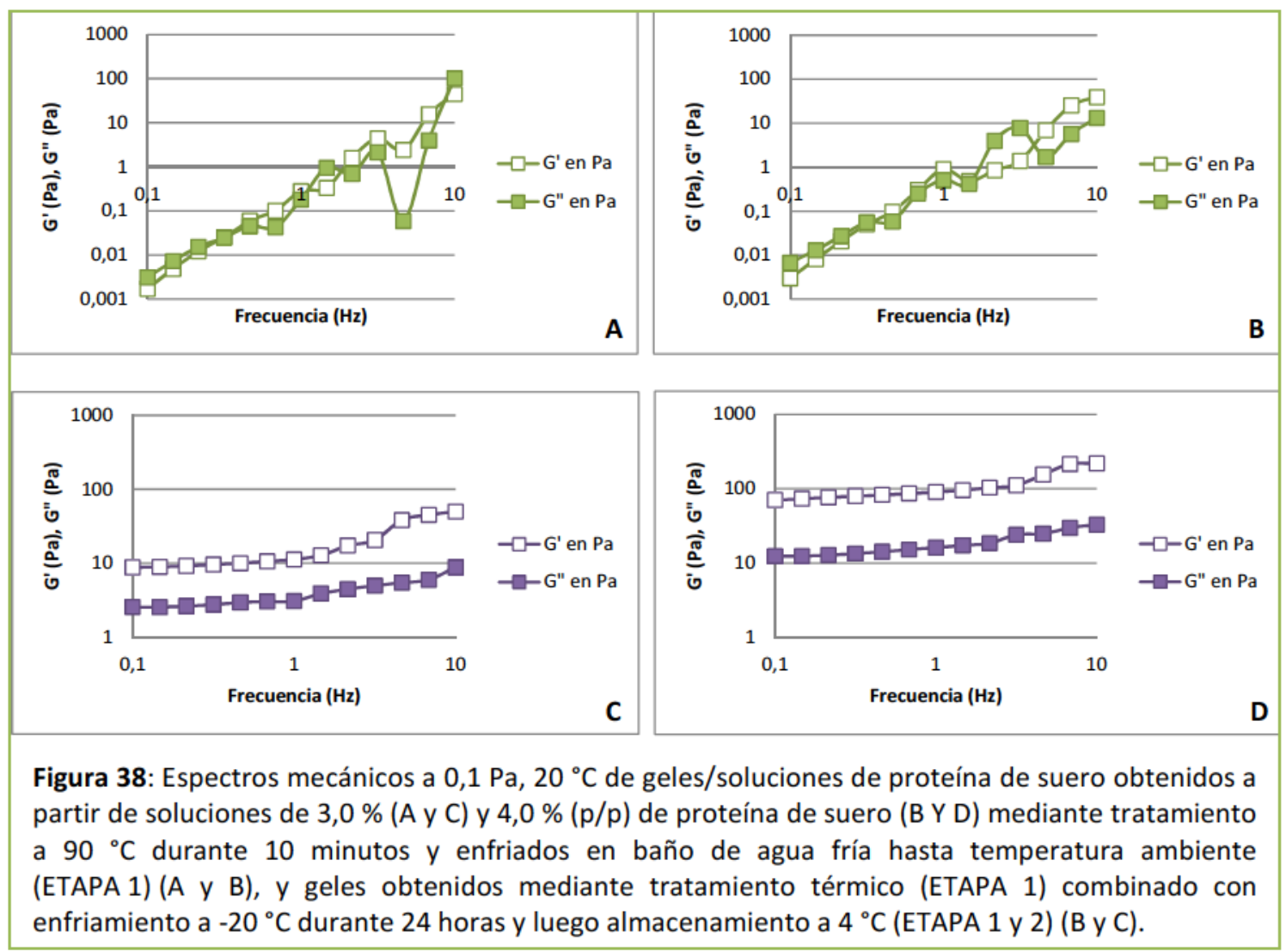

En la Figura 38 A y B se muestran los espectros correspondientes a las soluciones de proteína de suero de leche 3,0 \% y 4,0\% (p/p) obtenidas mediante la Etapa 1 . En 
Geles de kefiran como vehículo de microorganismos probióticos.

estas condiciones no se obtuvieron geles verdaderos sino que el comportamiento reológico fue el de una solución. La Figura 38 C y D muestra los resultados obtenidos cuando a las soluciones de proteína de suero de leche 3,0 \% y 4,0 \% (p/p) se les realizó además el proceso de congelación-descongelación (Etapa 1 y 2).

Se analizó la tangente del ángulo de desfasaje $(\tan (\delta))$ a $1 \mathrm{~Hz}$ de frecuencia. Los valores de $\tan (\delta)$ indicaron que solo estamos en presencia de geles cuando se realizaron ambas etapas para la obtención del gel ya que se obtuvieron valores de 0,27 y 0,18 de $\tan (\delta)$ para $3,0 \%$ y $4,0 \%(p / p)$ de $W P I$, respectivamente, mientras que en ausencia del proceso de congelación-descongelación los valores obtenidos fueron 0,60 y 0,56 respectivamente, indicando ausencia de gel.

En aquellas condiciones donde se obtuvo un comportamiento reológico de gel se evaluó el módulo elástico (G') y el módulo viscoso (G") a $1 \mathrm{~Hz}$ de frecuencia (Figura 39). Se observó que ambos módulos aumentan con la concentración de proteína siendo el valor de G' de 10,47 Pa y 86,51 Pa y el de G" de 2,81 Pa y 15,71 Pa para los geles preparados con $3,0 \%$ y $4,0 \%(\mathrm{p} / \mathrm{p})$ de $\mathrm{WPI}$, respectivamente.

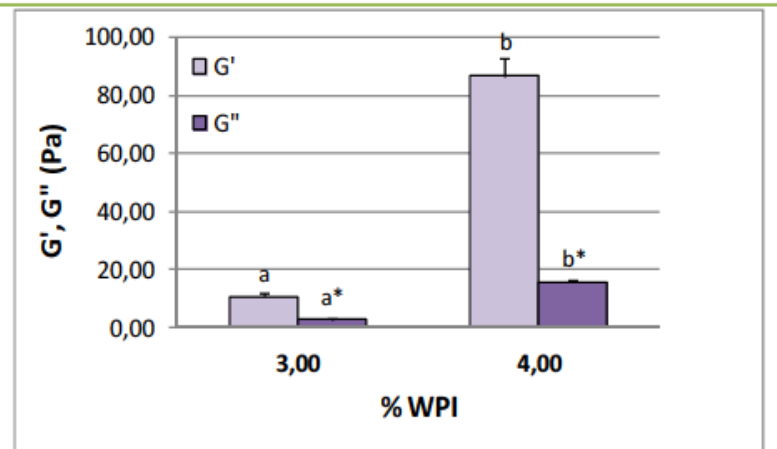

Figura 39. Módulo elástico (G') y viscoso (G") de geles obtenidos a partir de soluciones de 3,0 \% y $4,0 \%(p / p)$ de proteína de suero mediante tratamiento a $90{ }^{\circ} \mathrm{C}$ durante 10 minutos y enfriados en baño de agua fría hasta temperatura ambiente combinado con enfriamiento a $-20{ }^{\circ} \mathrm{C}$ durante 24 horas y luego almacenamiento a $4{ }^{\circ} \mathrm{C}$ (ETAPA 1 y 2 ).

Diferentes tipos de interacciones intervienen en la formación del gel proteico, tales como interacciones de van der Waals, puentes de hidrógeno, interacciones hidrofóbicas, interacciones electrostáticas y enlaces covalentes (por ejemplo, puentes disulfuro) (Kinsella \& Whitehead, 1989; Ziegler \& Foegeding, 1990). La gelificación inducida por calor de $\beta$-Lactogloblulina $(\beta-\mathrm{Lg})$ ha sido estudiada a diferentes $\mathrm{pH}$ (Clark et al. 2001; Langton \& Hermansson, 1992; Relkin 1996; Stading \& Hermansson, 1991, 
Geles de kefiran como vehículo de microorganismos probióticos.

1992). A pH neutro, la $\beta$-Lg tiene una carga negativa muy alta, la cual resulta en interacciones repulsivas y buena interacción con el solvente facilitando su desnaturalización. Durante la transición conformacional de $\beta$-Lg en el rango de pH 6 - 9 ocurre un aumento de la actividad del grupo tiol, debido a que el pK de este grupo es $\sim 8$ (Dunnill \& Green, 1966); por lo tanto, las reacciones de intercambio tiol-disulfuro son más probables en este rango de $\mathrm{pH}$. A valores de $\mathrm{pH}$ mayores a 6 , la molécula de $\beta$ - $\mathrm{Lg}$ nativa se desnaturaliza por calor y luego la molécula desnaturalizada se agrega por medio de uniones disulfuro. Si la concentración es suficientemente alta estos agregados interaccionan formando la estructura del gel. Es factible pensar que en los geles obtenidos en este trabajo elaborados a $\mathrm{pH} 7$, exista un importante intercambio entre grupos tiol-disulfuro que contribuyan a la estructura del gel.

Geles mixtos de proteína de suero de leche y kefiran.

Tal como se dijo anteriormente, las proteínas de suero de leche se utilizan cada vez más para la formación de geles en diversos alimentos, incluyendo productos lácteos y postres, bebidas, productos de confitería y productos cárnicos (de Wit 1998). Por otra parte, en presencia de polisacáridos, forman una amplia gama de geles con diferentes propiedades físicas (Tolstoguzov 1986). Geles mixtos de proteína de suero de leche y polisacárido se utilizan para elaborar alimentos tanto naturales como industriales. La presencia de diversos polisacáridos modifica la microestructura y las propiedades mecánicas de los geles mixtos.

Se evaluó el agregado de 1,0 \% (p/p) de kefiran sobre geles obtenidos a partir de soluciones de 3,0; 4,0; 6,0; 7,0 y 8,0 \% (p/p) de WPI. Al desconocer la interacción de las proteínas de suero de leche con el kefiran, se estudió el agregado del mismo en geles proteicos débiles $(3,0 \%$ y $4,0 \%)$, como en geles proteicos firmes $(6,0 \% ; 7,0 \%$ y $8,0 \%)$ para indagar el efecto del kefiran sobre los mismos, a fin de obtener geles autoportantes capaces de funcionar como vehículo de microorganismos probióticos.

Como la elaboración de los geles conlleva una etapa de calentamiento, los microorganismos deben ser adicionados luego de ésta, a fin de conservar su viabilidad, Es por ello que en esta etapa (Etapa 1) se necesita obtener una solución que luego de 
Geles de kefiran como vehículo de microorganismos probióticos.

someterla al proceso de congelación-descongelación (Etapa 2) dará lugar a la formación del gel. A modo de ejemplo, en la Figura 40 se muestra el aspecto de las soluciones de WPI luego del calentamiento a $90^{\circ} \mathrm{C}$ durante 10 minutos y enfriados inmediatamente en baño de agua fría hasta alcanzar temperatura ambiente (Etapa 1).

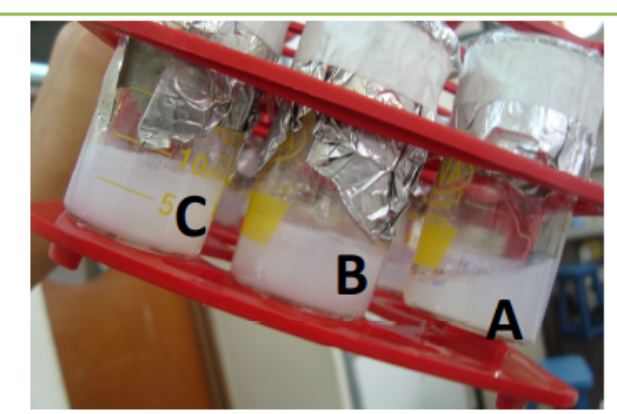

Figura 40. Aspecto de las soluciones/geles de proteínas de suero de leche (WPI) y kefiran 1,0 \% (p/p) después del calentamiento en baño de agua a $90{ }^{\circ} \mathrm{C}$ durante 10 minutos e inmedatamente enfriados en baño de agua fría hasta temperatura ambiente (Etapa 1). A - 4,0\% (p/p); B - 6,0\% (p/p); C - 7,0\% (p/p) de aislado de proteína de suero de leche.

Cuando las soluciones de kefiran y WPI fueron calentadas durante 10 minutos a $90^{\circ} \mathrm{C}$, y luego enfriadas inmediatamente en baño de agua fría hasta llegar a temperatura ambiente (Etapa 1), sólo las muestras correspondientes a una concentración de WPI $3,0 \%$ y $4,0 \%(p / p)$ se mantuvieron líquidas al alcanzar temperatura ambiente, tal como se observa en la Figura $40 \mathrm{~A}$. Mientras que soluciones con concentraciones mayores a éstas $(6,0 \% ; 7,0 \%$ y $8,0 \%)$, gelificaron durante el calentamiento a $90{ }^{\circ} \mathrm{C}$ y enfriamiento en baño de agua fría (Figura 40 B y C).

Para continuar con el análisis, se seleccionaron los geles mixtos obtenidos a partir de soluciones $3,0 \%$ y 4,0 \% (p/p) de WPI y $1,0 \%(p / p)$ de kefiran utilizando para su elaboración el proceso completo combinando ambas etapas. Estas condiciones de elaboración de los geles son compatibles para su uso como vehículos de microorganismos. Llamaremos 3WPI-K a los geles mixtos obtenidos a partir de $3,0 \%(\mathrm{p} / \mathrm{p})$ de WPI y $1,0 \%(\mathrm{p} / \mathrm{p})$ de kefiran, y $\mathbf{4 W P I - K}$ a los geles obtenidos a partir de $4,0 \%(p / p)$ de WPI y $1,0 \%(p / p)$ de kefiran, obtenidos mediante ambas etapas. En concentraciones superiores de WPI en presencia del polisacárido la gelificación ocurrió durante la Etapa 1, descartando esta condición ya que no era apta para la inclusión de microorganismos. En la Figura 41 se muestran los geles de kefiran y WPI obtenidos. 
Geles de kefiran como vehículo de microorganismos probióticos.
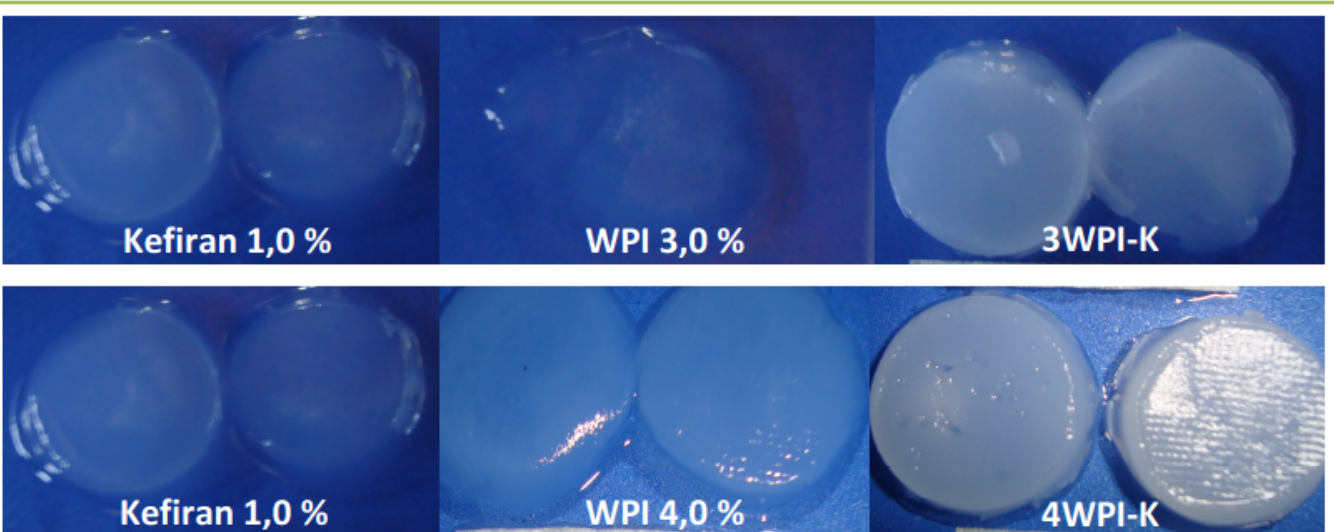

Figura 41. Geles de aislado de proteina de suero al 3,0 \% y 4,0 \% (p/p) y kefiran $1,0 \%$ (p/p) solos y mixtos (3WPI-K y $4 \mathrm{WPI}-\mathrm{K}$ ), obtenidos mediante tratamiento a $90{ }^{\circ} \mathrm{C}$ durante 10 minutos y enfriados en baño de agua fría hasta temperatura ambiente combinado con enfriamiento a $-20^{\circ} \mathrm{C}$ durante 24 horas y luego almacenamiento a $4{ }^{\circ} \mathrm{C}$ (ETAPA 1 y 2 ).

Analizando el aspecto macroscópico de los geles mixtos se pudo conlcuir que el kefiran tuvo un efecto positivo reforzando la estructura de los geles de proteína de suero de leche (WPI) respecto a los geles elaborados en ausencia del polisacárido. El mismo resultado fue descripto previamente por Spotti et al. (2014) para geles de WPI donde la adición de dextrano produjo un aumento en la rigidez del gel y una mejora del carácter elástico.

Desde el punto de vista de los consumidores, la firmeza y la cremosidad son las principales características sensoriales más importantes en quesos untables y postres lácteos. Estas características son muy complejas y no pueden definirse con una sola propiedad física medida. Varias metodologías fisicoquímicas pueden predecir la formación de las estructuras de los geles en soluciones de más de un componente. En lo que respecta a las propiedades reológicas, dos características son importantes, la viscosidad y la elasticidad que se reflejan en la calidad organoléptica del producto y su apariencia. La viscosidad es la propiedad de un material para resistir a la deformación y se relaciona directamente con la fluidez, mientras que la elasticidad representa la propiedad de un material para recuperarse después de una deformación (Renard et al. 2006).

Para caracterizar los geles mixtos obtenidos con 1,0\% (p/p) de kefiran y 3,0 \% y $4 \%(p / p)$ de WPI (3WPI-K y 4WPI-K) se utilizó reometría oscilatoria de baja amplitud de deformación. Se analizó el espectro mecánico de los geles (esfuerzo 0,1 Pa) dentro del 
CAPÍTULO 2

Geles de kefiran como vehículo de microorganismos probióticos.

rango de viscoelasticidad lineal. El módulo elástico $\left(G^{\prime}\right)$ de los geles de kefiran con proteínas fue mayor que el módulo viscoso (G") a todas las frecuencias estudiadas y ambos módulos fueron prácticamente independientes de la frecuencia lo que indica un comportamiento de gel (Figura 42) (Picout \& Ross-Murphy, 2001).

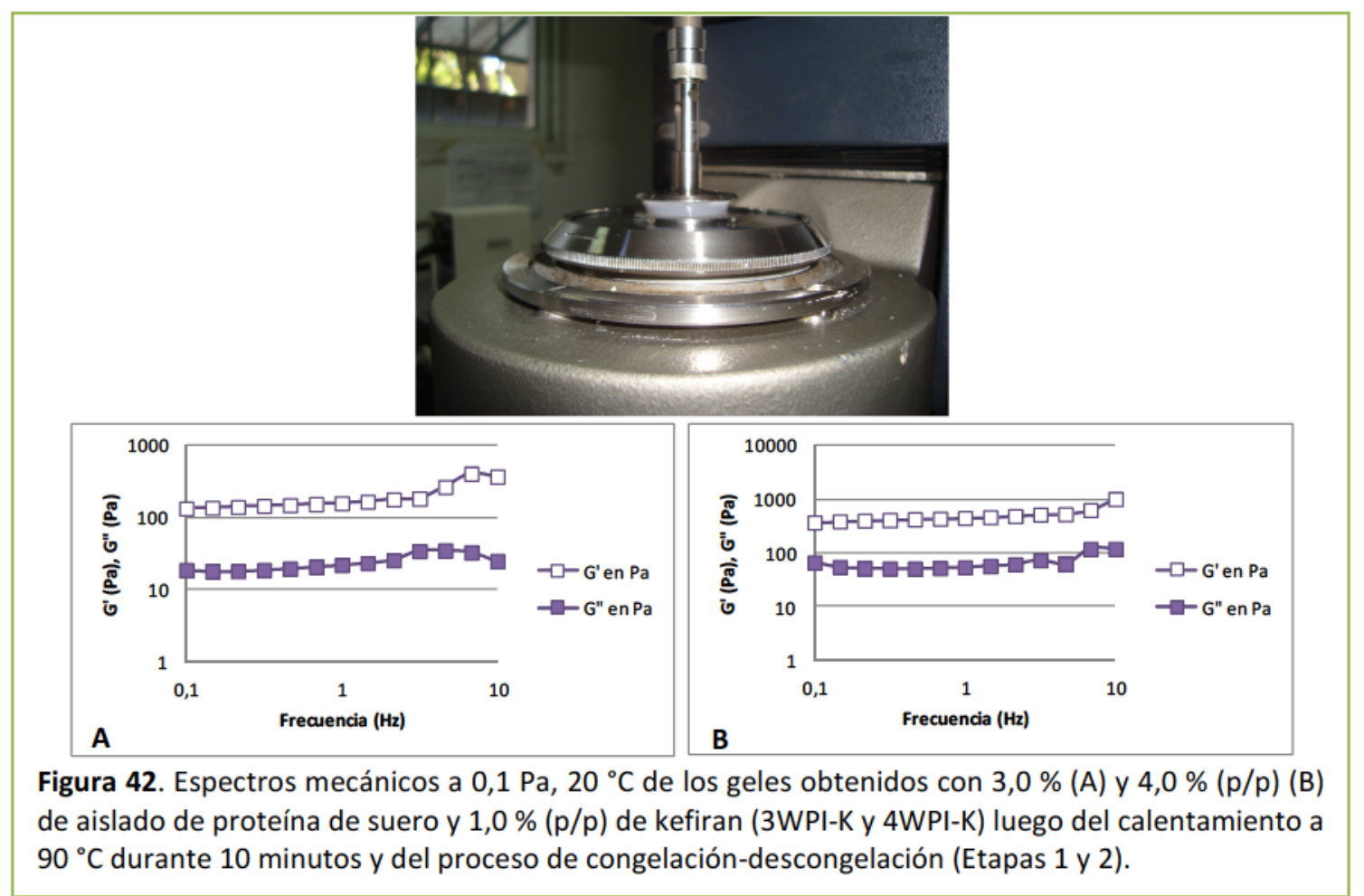

El módulo elástico (G'), el módulo viscoso (G") y la tangente del ángulo de desfasaje $\tan (\delta)$ fueron evaluados a $1 \mathrm{~Hz}$ de frecuencia (Figura 43).
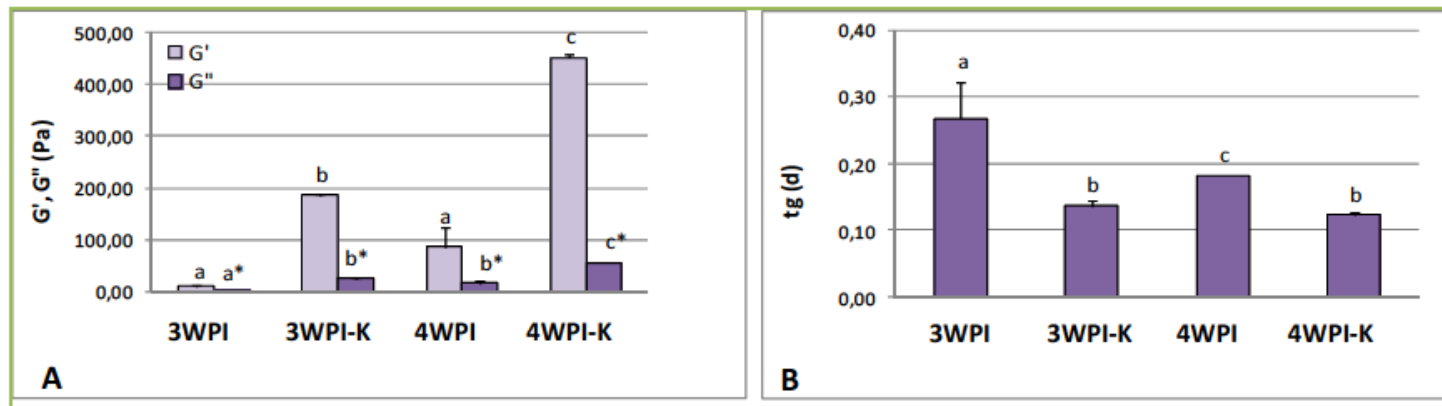

Figura 43. Módulo elástico (G') y viscoso (G") (A) y tangente del ángulo de desfasaje $(\tan (\delta))(B)$ de de los geles obtenidos a partir de soluciones con 3,0\% (A) y 4,0\% (p/p) (B) de aislado de proteína de suero y $1,0 \%(\mathrm{p} / \mathrm{p})$ de kefiran ( $3 \mathrm{WPI}-\mathrm{K}$ y $4 \mathrm{WPI}-\mathrm{K}$ ) mediante tratamiento a $90^{\circ} \mathrm{C}$ durante 10 minutos y enfriados en baño de agua fría hasta temperatura ambiente combinado con enfriamiento a $-20^{\circ} \mathrm{C}$ durante 24 horas y luego almacenamiento a $4{ }^{\circ} \mathrm{C}$ (ETAPA 1 y 2 ). Las letras sobre las barras de error indican diferencias significativas $(p \leq 0,05)$. 
Al incorporar kefiran a las soluciones de WPI, aumentó el módulo elástico (G') y el módulo viscoso (G") de los geles obtenidos, y disminuyó la tangente del ángulo de desfasaje $\tan (\delta)$ a ambas concentraciones de proteínas estudiadas. El efecto del kefiran fue más pronunciado en los geles preparados con mayor concentración de proteína hecho que puede observarse en un mayor incremento porcentual en ambos módulos. Estos resultados indicarían que el kefiran influye en la estructura del gel favoreciendo uniones que refuerzan la estructura.

Comparando los geles mixtos de proteína de suero y kefiran (3WPI-K y 4WPI-K), se pudo observar que tanto el módulo elástico como el módulo viscoso fueron significativamente mayores al aumentar la concentración de proteína. Sin embargo, no se observaron diferencias significativas en los valores de la $\tan (\delta)$ de ambos geles mixtos.

Fitzsimons et al. (2008) estudiaron el comportamiento de sistemas mixtos de WPI y goma guar con concentraciones de proteína del $3 \%(p / p)$ y encontraron que el agregado de bajas concentraciones de goma guar aumentaba el valor del módulo elástico del gel, sin embargo concentraciones mayores provocaban una disminución de este valor, lo que fue atribuido a una excesiva agregación de la proteína, con una precipitación incipiente, con lo cual el gel finalmente colapsaba. Estos resultados difieren de los encontrados en el presente trabajo, indicando que cada sistema polisacárido-proteína es específico.

Durante la masticación el alimento experimenta cambios debido a que se modifica la temperatura, la humedad y se somete a esfuerzos y deformaciones que son percibidos antes de tragar (van Vliet 2002). El análisis de perfil de textura es una evaluación que en cierto modo imita el proceso de masticación (Szczesniak 2002).

Cuando los geles de kefiran fueron evaluados mediante análisis de perfil de textura se obtuvieron curvas de fuerza-tiempo. A modo de ejemplo, en la Figura 44 se presentan los perfiles correspondientes a dos de los geles analizados, geles de WPI al $4,0 \%(p / p)(\mathbf{W P I})$ y geles mixtos de WPI 4,0 \% (p/p) y kefiran $1,0 \%(p / p)(\mathbf{W P I}-\mathbf{K})$. 
Geles de kefiran como vehículo de microorganismos probióticos.

En los perfiles de textura de los geles, pudieron observarse claramente los picos correspondientes a cada uno de los ciclos de compresión efectuados y la aparición del pico negativo que representa la adhesividad.

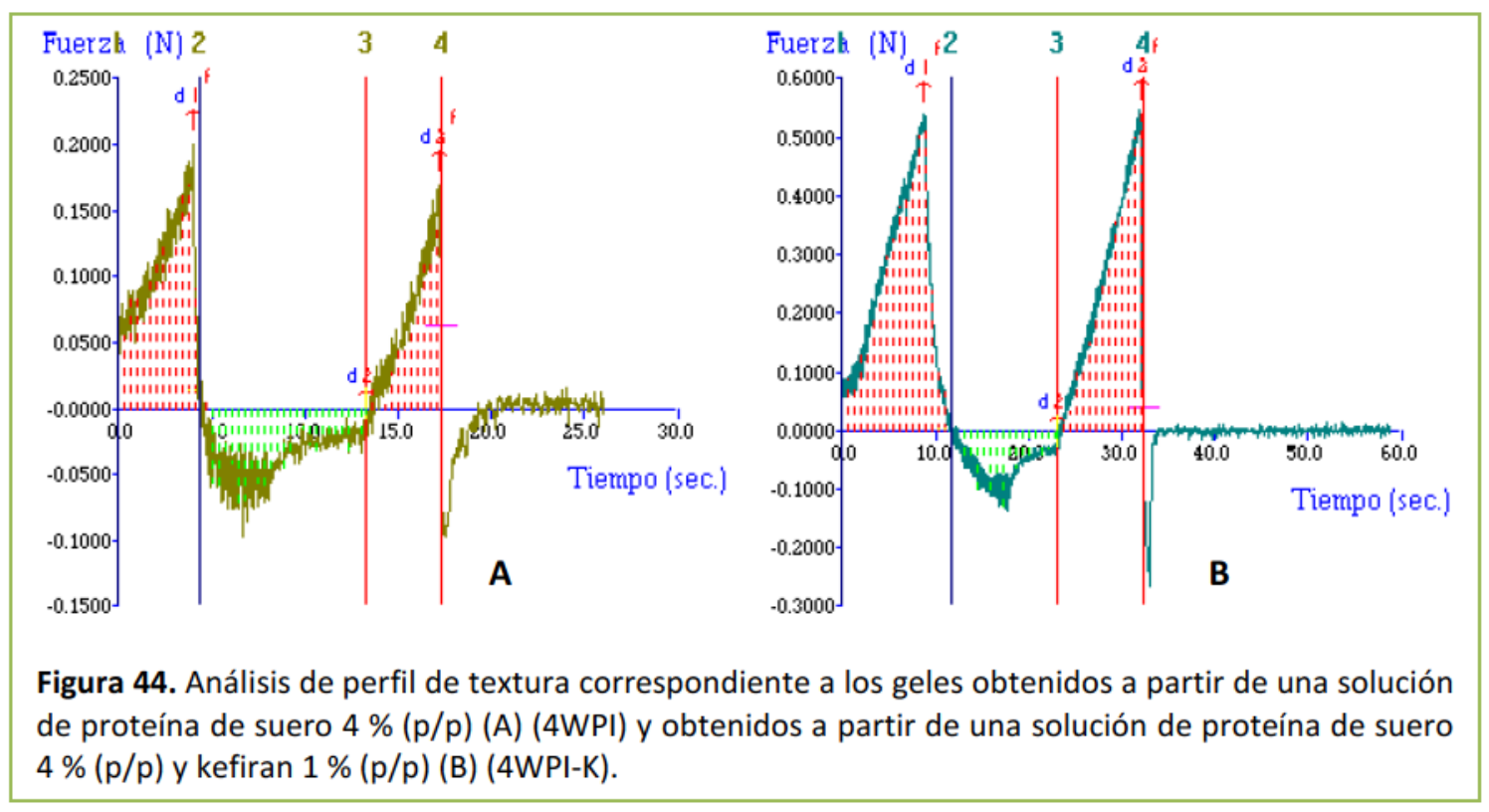

A partir de los gráficos de perfil de textura se calculó la dureza $\left(F_{\text {máx }}\right)$ de los geles, la cohesividad $\left(A_{2} / A_{1}\right)$, la adhesividad $\left(\left|A_{3}\right|\right)$, y el parámetro elasticidad $\left(d_{2} / d_{1}\right)$ (Tabla 10).

Tabla 10. Valores de dureza $\left(F_{\text {max }}\right)$, cohesividad $\left(A_{2} / A_{1}\right)$, adhesividad $\left(\left|A_{3}\right|\right)$, y elasticidad $\left(d_{2} / d_{1}\right)$ de los geles proteicos y mixtos obtenidos. Las letras presentan diferencias significativas para cada parámetro

\begin{tabular}{|c|c|c|c|c|}
\hline \multirow{2}{*}{} & \multicolumn{2}{|c|}{ WPI } & \multicolumn{2}{c|}{ WPI-K } \\
\cline { 2 - 5 } & $\mathbf{3 , 0} \%$ & $\mathbf{4 , 0} \%$ & $\mathbf{3 , 0} \%$ & $\mathbf{4 , 0} \%$ \\
\hline Dureza (N) & $0,140 \pm 0,007^{\mathrm{a}}$ & $0,211 \pm 0,004^{\mathrm{ab}}$ & $0,231 \pm 0,050^{\mathrm{b}}$ & $0,574 \pm 0,031^{\mathrm{c}}$ \\
\hline Cohesividad (\%) & ND & $48,42 \pm 9,39^{\mathrm{a}}$ & $64,82 \pm 3,86^{\mathrm{a}}$ & $74,44 \pm 3,86^{\mathrm{a}}$ \\
\hline Adhesividad (N.s) & $1,54 \pm 0,14^{\mathrm{a}}$ & $0,37 \pm 0,08^{\mathrm{bc}}$ & $0,18 \pm 0,08^{\mathrm{b}}$ & $0,67 \pm 0,02^{\mathrm{c}}$ \\
\hline Elasticidad (\%) $\mathbf{d}_{\mathbf{3}} / \mathbf{d}_{\mathbf{1}}$ & ND & $99,63 \pm 11,43^{\mathrm{a}}$ & $102,57 \pm 3,20^{\mathrm{a}}$ & $101,03 \pm 0,91^{{ }^{\mathrm{a}}}$ \\
\hline
\end{tabular}

Los geles preparados con $3,0 \%(p / p)$ de WPI resultaron ser débiles y en consecuencia no pudo determinarse la cohesividad ni la elasticidad en las condiciones del ensayo. Sin embargo, el agregado de kefiran aumentó la dureza y permitió la determinación de estos parámetros. 
Geles de kefiran como vehículo de microorganismos probióticos.

El agregado de kefiran a los geles elaborados con 4,0 \% (p/p) de WPI aumentó la dureza y no se obtuvieron diferencias significativas en los otros parámetros.

Al comparar los parámetros obtenidos en los geles mixtos, al aumentar la concentración de WPI se observó un aumento de la dureza y la adhesividad, no encontrándose diferencias significativas en los otros parámetros. Los geles con WPI $4,0 \%(p / p)$ y kefiran presentaron el mayor valor de dureza de 0,574 $\pm 0,003 \mathrm{~N}$. Este valor fue similar al valor de dureza encontrado por Salvador \& Fiszman (1998) al caracterizar geles obtenidos a partir de leche acidificada con $\delta$-gluconolactona adicionada de gelatina al $3 \%$. Estos autores, trabajando con el mismo equipo utilizado en este trabajo $\mathrm{y}$ en similares condiciones de ensayo, encontraron valores de dureza entre 0,57 $\mathrm{N}$ y 0,94 N. Yamul \& Lupano (2005) estudiaron geles mixtos de proteínas de suero de leche con harina de trigo y observaron un aumento en la firmeza, elasticidad y adhesividad de los geles mixtos respecto a los geles de proteína de suero. El agregado de kefiran, al igual que el agregado de la harina de trigo, produjo un aumento en la firmeza de los geles. Las modificaciones inducidas por el kefiran en los otros parámetros dependieron de la concentración de proteína de suero estudiada.

Por último, se procedió a la determinación de la capacidad de retención de agua (WHC). Para ello los geles fueron sometidos a una fuerza centrífuga, como se indicó en Materiales y Métodos y los resultados obtenidos se presentan en la Figura 45.

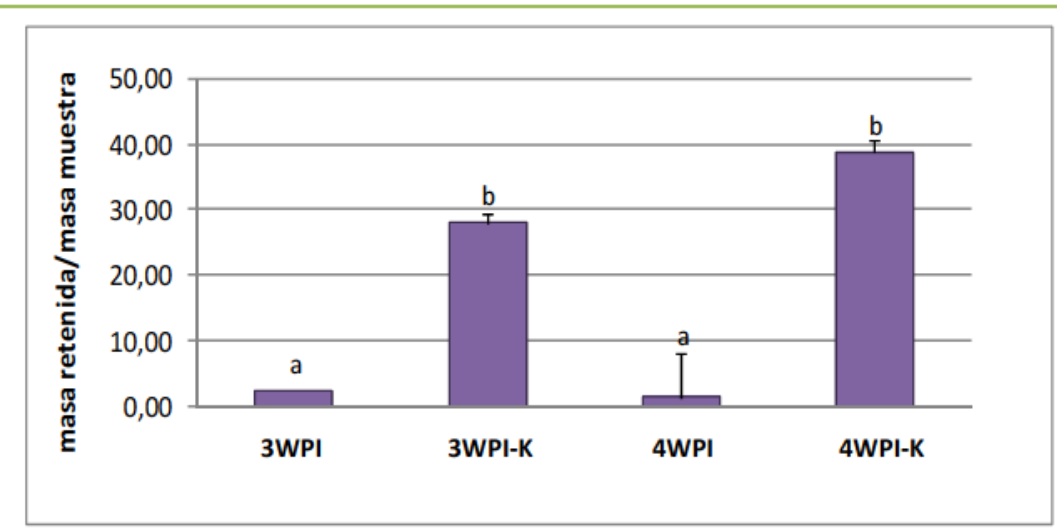

Figura 45. Capacidad de retención de agua (\% WHC) de geles mixtos de WPI y kefiran conteniendo $1,0 \%(p / p)$ kefiran y $3,0 \%$ y $4,0 \%(p / p)$ de WPI (3WPI-K y 4WPI-K), elaborados mediante ambas etapas ( 24 horas a $-20^{\circ} \mathrm{C}$ y 24 horas a $4{ }^{\circ} \mathrm{C}$ ). Diferentes letras sobre barras de error indican diferencias significativas ( $p \leq 0,05)$. 
Geles de kefiran como vehículo de microorganismos probióticos.

Los valores de WHC de los geles obtenidos a ambas concentraciones de WPI no mostraron diferencias significativas entre ellos, tanto en los geles proteicos, como en los geles mixtos $(p>0,05)$. Sin embargo, se observó un aumento significativo en la capacidad de retención de agua de los geles mixtos respecto a los geles proteicos, posiblemente debido a que el kefiran posee una alta capacidad de interactuar con las moléculas de agua por su naturaleza glucídica. La capacidad de retención de agua de los geles mixtos de proteína y kefiran fue menor a la de los geles de kefiran con azúcares analizados previamente, demostrando la importancia de las moléculas glucídicas en este parámetro.

Muchas mezclas de agentes gelificantes son utilizadas en alimentos procesados y productos alimenticios destinados a la confitería y productos de panadería (Tolstoguzov 1995). En la industria alimentaria, se han utilizado geles de gelatina adicionados con diferentes polisacáridos para el desarrollo de un caviar analógico (Tolstoguzov 1978, 1979, 1995; Braudo et al. 1986; Tolstogusov et al. 1973). Además, geles de alginato de calcio con almidón y proteínas también fueron descriptos previamente para el uso de productos en la elaboración de pasta no tradicional (Tolstoguzov et al. 1975, 1976, 1978; Tolstoguzov 1979). Otra aplicación que está cobrando interés es la utilización de componentes capaces de formar geles como sustitutos de grasa para la producción de alimentos con bajo contenido graso (Zasypkin et al. 1997).

Las interacciones entre proteínas y polisacáridos se pueden dividir en dos grupos: interacciones atractivas o interacciones repulsivas, y pueden estar dadas por diferentes tipos de fuerzas (Figura 46). 
Geles de kefiran como vehículo de microorganismos probióticos.

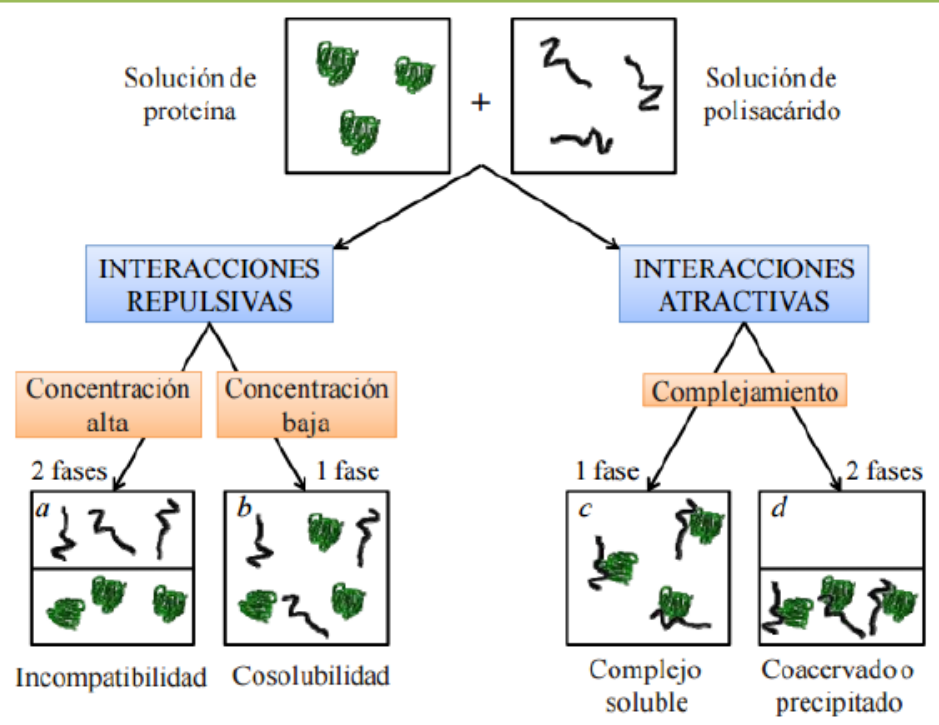

Figura 46. Representación esquemática de los cuatro posibles sistemas obtenidos por mezclar soluciones de una proteína y un polisacárido. Adaptado de de Kruif \& Tuinier (2001) y McClements (2006).

La interacción de los dos biopolímeros puede ser segregativa (los biopolímeros se repelen unos a otros y entonces se definen como incompatibles) o asociativa (los biopolímeros se atraen unos a otros) (de Kruif \& Tuinier, 2001; McClements 2006; Tolstoguzov 1986; Tolstoguzov 2003).

Cuando predominan las fuerzas de repulsión entre los biopolímeros (por ejemplo si ambos poseen la misma carga neta), puede obtenerse un sistema de dos fases donde cada componente se encuentra en fases diferentes (a). En soluciones diluidas la mezcla es estable debido al efecto predominante de la entropía de mezclado y la proteína y el polisacárido son cosolubles: sistema (b).

En condiciones en las que existe atracción entre las moléculas de los distintos biopolímeros (los biopolímeros poseen carga neta opuesta) puede producirse la formación de complejos no solubles que precipitan, obteniéndose dos fases separadas: una fase "coacervada" que contiene a los complejos y otra fase diluida, con baja concentración de ambos biopolímeros ("coacervación compleja": sistema (d)). En ciertos casos las atracciones electrostáticas pueden llevar a la formación de complejos solubles, obteniéndose un sistema de una sola fase. En este caso estamos en presencia del efecto de solubilidad por complejamiento: sistema (c) (Tolstoguzov 1986, 1990, 1991; Tolstoguzov et al. 1985). Teniendo en cuenta los resultados presentados, el kefiran y las proteínas de suero podrían interaccionar mediante la formación de complejos solubles, 
Geles de kefiran como vehículo de microorganismos probióticos.

ya que el kefiran neutro podría interactuar con las proteínas de suero a partir de interacciones no iónicas o bien que no interaccionen pero permanezcan ambos solubles (cosolubilidad).

En la Tabla 11 se presenta a modo de resumen el efecto ejercido por el kefiran a los geles de proteína de suero. El agregado de kefiran a los geles de proteína de suero aumentó la opacidad de los geles, a su vez, se observó una disminución de la tangente del ángulo de desfasaje $(\tan (\delta))$ debido a que el aumento del módulo elástico (G') fue mayor al aumento del módulo viscoso (G"), hecho que indica un aumento del carácter sólido de los geles. Asimismo, la capacidad de retención de agua (WHC) de los geles aumentó en presencia del kefiran respecto a los geles proteicos debido a la capacidad del polisacárido de interactuar con las moléculas de agua. Se observó también un aumento en la dureza de los geles mixtos respecto de los geles proteicos, sin observarse diferencias en la cohesividad y elasticidad con el agregado de kefiran.

Tabla 11. Efecto del agregado de kefiran en el aspecto macroscópico y caracterización fisicoquímica de geles de aislado de proteína de suero de leche.

\begin{tabular}{|c|c|}
\multicolumn{2}{|c|}{ Efecto kefiran } \\
\hline Opalescencia & $\uparrow$ \\
\hline G' $^{\prime}$ & $\uparrow$ \\
\hline G" & $\uparrow$ \\
\hline $\tan (\delta)$ & $\downarrow$ \\
\hline WHC & $\uparrow$ \\
\hline Dureza & $\uparrow$ \\
\hline Cohesividad & $=$ \\
\hline Elasticidad & $=$ \\
\hline
\end{tabular}

Fitzsimons et al. (2008) encontraron que las interacciones segregativas en sistemas mixtos de WPI y goma guar (una fase única) promovieron la agregación de las proteínas del suero desnaturalizadas y que la velocidad y la agregación aumentó con el aumento de la concentración de goma guar. Después del calentamiento de sistemas mixtos de pectina y proteínas del suero también se observaron diferentes distribuciones de peso molecular y un aumento en el tamaño promedio de los agregados (Beaulieu et al. 2005).

La incompatibilidad de los polisacáridos con las proteínas (interacción segregativa) disminuye en el siguiente orden: polisacáridos con grupos carboxilo > 
Geles de kefiran como vehículo de microorganismos probióticos.

polisacáridos neutros > polisacáridos con grupos sulfato; además, los polisacáridos lineales son más incompatibles con proteínas que los polisacáridos ramificados (Grinberg \& Tolstoguzov, 1997). Capron et al. (1999) investigaron la agregación térmica de $\beta$-Lg en presencia de $\mathrm{k}$-carragenano (polisacárido con grupos sulfato). La agregación térmica de $\beta$-Lg a pH 7 sigue un mecanismo de dos etapas: primero la formación de agregados globulares pequeños y segundo la asociación de estos pequeños glóbulos en agregados más grandes. Aymard et al. (1996), demostraron que el polisacárido acelera la agregación (segunda etapa) y al formar los geles mixtos observaron una separación de microfases entre los grandes agregados de $\beta$-Lg y $\mathrm{k}$-carragenano, lo que aumenta la concentración local de la proteína y por lo tanto su cinética de agregación. Sugirieron que probablemente otros polisacáridos podrían provocar el mismo efecto.

Los resultados de este trabajo mostraron que la asociación entre WPI y kefiran en solución acuosa tiene un fuerte impacto sobre las propiedades funcionales. El hecho de que el aislado proteico gelifique en presencia de kefiran, en concentraciones donde observamos que la proteína sola no gelificaba, demuestra que existe un efecto sinérgico en estos sistemas mixtos. Este efecto sinérgico se puede atribuir principalmente al fenómeno de "volúmenes de exclusión". El kefiran es un polisacárido neutro y podría capturar moléculas de agua promoviendo las interacciones proteína-proteína que aumentarían la dureza del gel (Tabla 10). Sin embargo, no se puede descartar que el kefiran interaccione con las proteínas y forme parte de la matriz gel (efecto asociativo).

Estos dos efectos pueden resultar en cambios específicos sobre las propiedades funcionales (Carp et al. 2001; Tolstoguzov 1997b) y en la posibilidad de controlar y mejorar las propiedades de los geles, pudiendo ser explotado para el diseño de alimentos con una textura deseada conteniendo kefiran como un ingrediente bioactivo.

De esta manera, el conocimiento y la caracterización de las interacciones entre proteínas y polisacáridos permitirán la manipulación de propiedades macroscópicas de productos alimenticios, controlando las interacciones de un modo deseable, y logrando así la optimización en el uso de los ingredientes alimentarios.

Teniendo en cuenta los resultados presentados se seleccionaron los geles obtenidos a partir de kefiran $1,0 \%(\mathrm{p} / \mathrm{p})$ y $3,0 \%(\mathrm{p} / \mathrm{p})$ de proteína de suero (WPI) como vehículo para los microorganismos probióticos, condición donde después del 
CAPÍTULO 2

Geles de kefiran como vehículo de microorganismos probióticos.

calentamiento y enfriamiento hasta temperatura ambiente se mantienen los componentes en solución y después del ciclo de congelación - descongelación se forman geles autoportantes. La Figura 47 muestra el aspecto de los geles obtenidos en dicha condición.

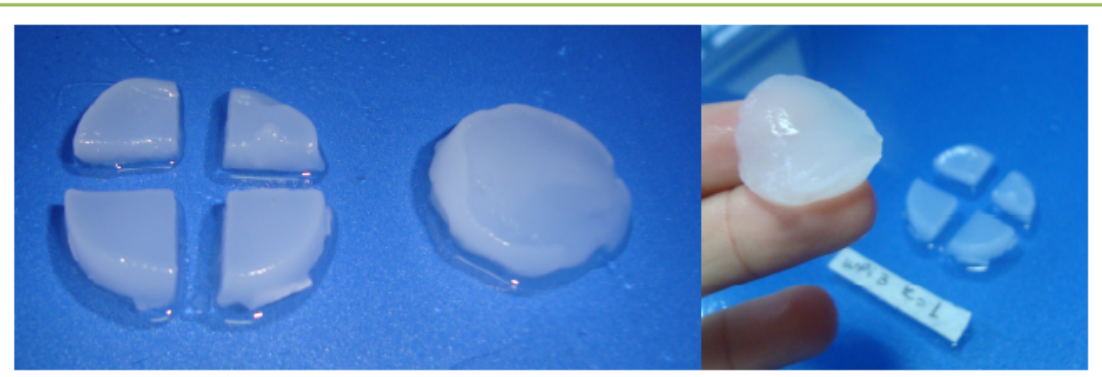

Figura 47. Aspecto de los geles obtenidos a partir de suspensiones de 3,0\% (p/p) de aislado de proteína de suero (WPI) y $1,0 \%(\mathrm{p} / \mathrm{p})$ de kefiran, elaborados mediante tratamiento a $90{ }^{\circ} \mathrm{C}$ durante 10 minutos, enfriados en baño de agua hasta temperatura ambiente, congelados a $-20^{\circ} \mathrm{C}$ durante 24 horas y almacenados a $4^{\circ} \mathrm{C}$ (Etapas 1 y 2 ).

\section{Inclusión de microorganismos en geles}

En base a los resultados obtenidos en el Capítulo I se seleccionaron L. kefiri CIDCA 83102 y L. paracasei CIDCA 8339 para su inclusión en los geles combinados de kefiran y WPI. Estos lactobacilos resistieron las condiciones simuladas del tracto gastrointestinal, aumentaron significativamente la adhesión a epitelio luego de someterse al estrés ácido y de bilis, y presentaron actividad antagónica frente a Salmonella Enteritidis.

En función de los resultados obtenidos se seleccionó como vehículo de los microorganismos los geles obtenidos a partir de soluciones de kefiran 1,0 \% (p/p) y proteínas de suero de leche (WPI) 3,0 \% (p/p). A los mismos se les adicionó fructosa $12,0 \%(\mathrm{p} / \mathrm{p})$ como responsable del dulzor. La concentración de fructosa fue estimada a partir de la concentración de sacarosa presente en gelatina comercial en base a su poder edulcorante equivalente.

Los geles combinados de kefiran, WPI y fructosa utilizados como vehículos de microorganismos se muestran en la Figura 48. 


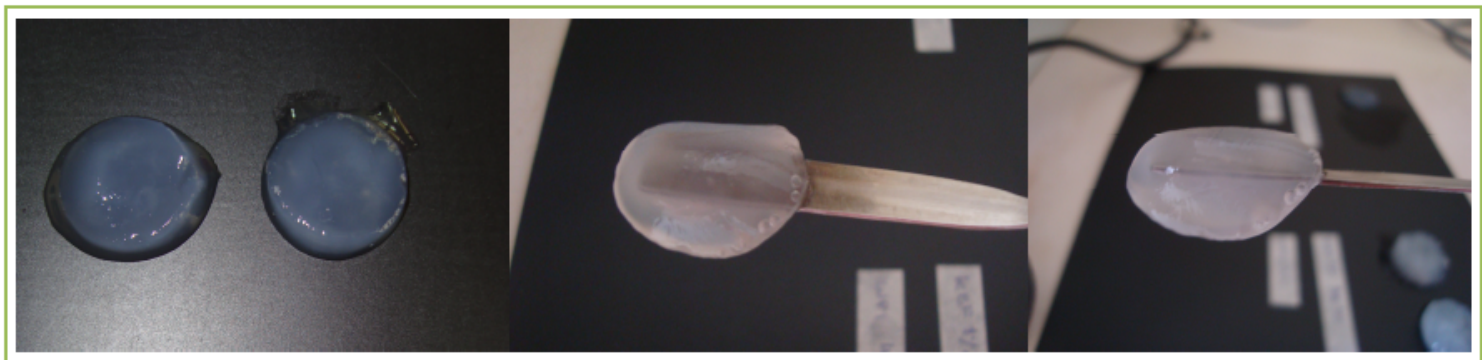

Figura 48. Aspecto de los geles autoportantes seleccionados de kefiran 1,0\% (p/p), proteína de suero de leche (WPI) 3,0\% (p/p) y fructosa $12,0 \%(p / p)$.

Resistencia de L. paracasei 8339 y L. kefiri 83102 al proceso de formación del gel.

Para la elaboración de los geles mixtos con microorganismos (condición Gel) los mismos fueron adicionados a la solución de kefiran $(1,0 \%(\mathrm{p} / \mathrm{p}))$, proteínas de suero de leche (WPI 3,0\% (p/p)) y fructosa $(12,0 \%(\mathrm{p} / \mathrm{p}))$ luego del tratamiento térmico a $90{ }^{\circ} \mathrm{C} y$ enfriamiento a temperatura ambiente (Etapa 1) en una condición donde todavía los componentes de la matriz se encuentran en solución para lograr una adecuada distribución de los microorganismos. Posteriormente se realizó el ciclo de congelación-descongelación correspondiente a la última etapa de formación del gel (Etapa 2). Se analizó la supervivencia de los microorganismos al proceso de elaboración de los geles.

Se realizaron dos controles:

Control cepa (Controlo): donde los microorganismos $\left(10^{8} \mathrm{UFC} / \mathrm{g}\right)$ se resuspendieron en buffer fosfato $\mathrm{pH} 7$.

Control Solución (Controls): donde los microorganismos $\left(10^{8} \mathrm{UFC} / \mathrm{g}\right)$ se incluyeron en una solución de kefiran 1,0 \% (p/p), proteínas de suero de leche (WPI) 3,0 \% (p/p) y fructosa $12,0 \%(p / p)$.

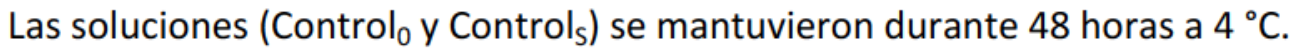

En la Figura 49 se muestra el esquema experimental indicando el agregado de los microorganismos y las etapas en las que se realizaron los recuentos. 
CAPÍTULO 2

Geles de kefiran como vehículo de microorganismos probióticos.

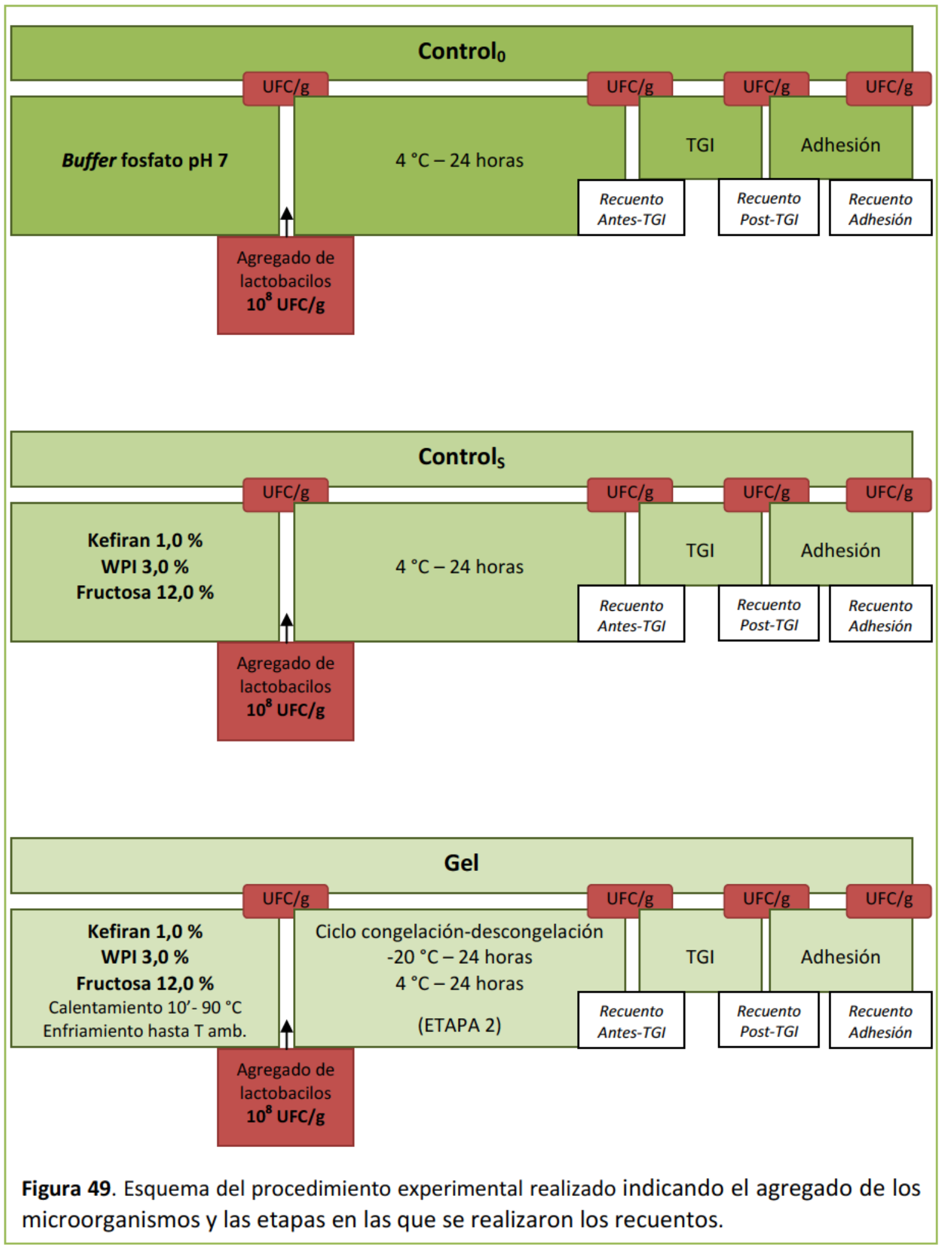

Estos ensayos se realizaron incorporando en los geles L. paracasei CIDCA 8339 y L. kefiri CIDCA 83102. Los resultados obtenidos en cada condición se muestran en la Figura 50. 
Geles de kefiran como vehículo de microorganismos probióticos.
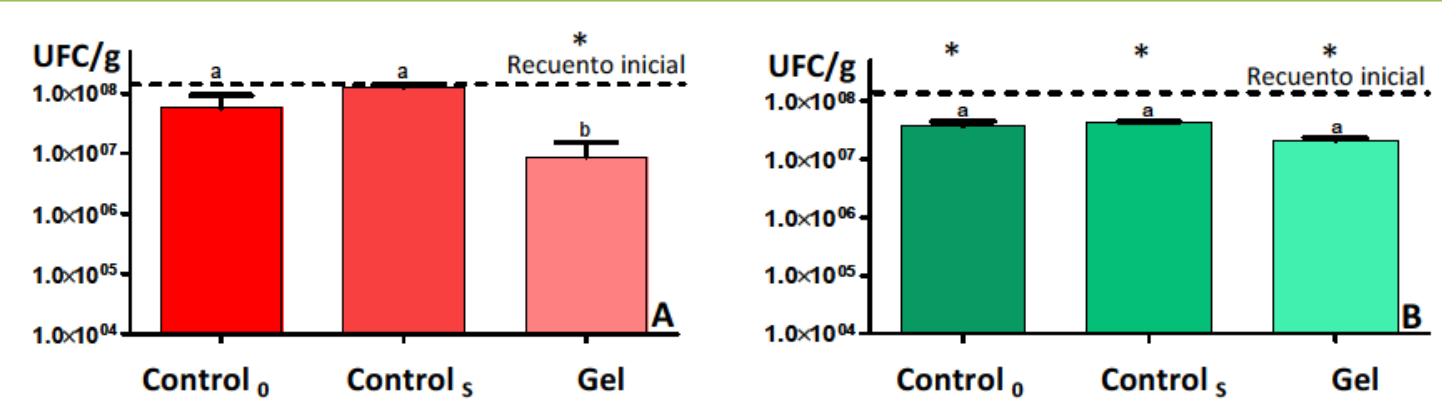

Figura 50. Viabilidad (UFC/g) de Lactobacillus paracasei CIDCA 8339 (A) y Lactobacillus kefiri CIDCA

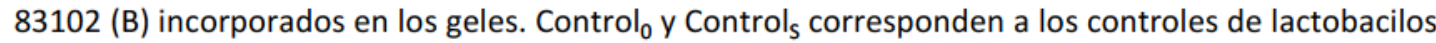
en buffer fosfato $\mathrm{pH} 7$ y al control de lactobacilos en solución de los componentes de la matriz del gel, respectivamente. Recuento inicial $1.10^{8} \mathrm{UFC} / \mathrm{g}$. Las letras presentan diferencias significativas entre el gel y los controles. $\left({ }^{*}\right)$ indica diferencias significativas respecto al recuento inicial correspondiente $\left(1.10^{8} \mathrm{UFC} / \mathrm{g}\right)$.

En la Figura 50 A se muestran los resultados obtenidos cuando se incorporó al gel L. paracasei CIDCA 8339. Se puede observar que el proceso de congelacióndescongelación correspondiente a la formación del gel afectó significativamente la viabilidad de L. paracasei CIDCA 8339, respecto a los controles que no fueron sometidos a la congelación-descongelación. Esto podría indicar que la congelación afecta la viabilidad de este microorganismo o bien, parte de los mismos quedarían adheridos a la matriz del gel dificultando el recuento posterior.

Sin embargo, al analizar los resultados obtenidos al incorporar L. kefiri CIDCA 83102 , todos los recuentos fueron significativamente diferentes respecto al recuento inicial $\left(1.10^{8} \mathrm{UFC} / \mathrm{g}\right)$. Esto indicaría que tanto el almacenamiento a $4{ }^{\circ} \mathrm{C}$ durante 48 horas como el proceso de congelación-descongelación, afectaron la viabilidad de este lactobacilo, que disminuyó su viabilidad en medio ciclo logarítmico, no encontrándose diferencias significativas en la viabilidad de los lactobacilos incluidos en los geles con respecto a los controles (Figura $50 \mathrm{~B}$ ).

Se han desarrollado posibles vehículos para microorganismos probióticos con incorporación de ingredientes prebióticos, como un queso crema con incorporación de Bifidobacterium animalis Bb-12 y Lactobacillus acidophilus con inulina como agente prebiótico (Alves et al. 2013), o una mousse de chocolate con L. paracasei LBC 82 e inulina (Aragon-Alegro et al. 2007). En ambos trabajos describen que los 
Geles de kefiran como vehículo de microorganismos probióticos.

microorganismos se mantienen viables en el producto luego de un mes de almacenamiento.

Boylston et al. (2004) recomiendan el nivel de $10^{6} \mathrm{UFC} / \mathrm{g}$ al momento de consumir un alimento con Lactobacillus acidophilus, bifidobacterias y otros microorganismos probióticos. En nuestro producto se cumpliría tal condición ya que el número de lactobacilos viables luego del proceso de elaboración del gel fue de $10^{7} \mathrm{UFC} / \mathrm{g}$.

Resistencia al pasaje por el tracto gastrointestinal in vitro de Lactobacillus paracasei 8339 y Lactobacillus kefiri 83102 incluidos en los geles mixtos.

Si bien la tolerancia al ácido y a la bilis y la capacidad de adhesión de los microorganismos son esenciales en la evaluación de un microorganismo probiótico, generalmente son estudiadas antes de la incorporación en los alimentos portadores (Schillinger et al. 2005). Sin embargo, es conocido que Streptococcus thermophilus y Lactobacillus delbrueckii subsp. bulgaricus presentan una pobre capacidad de supervivencia cuando se someten a la acidez gástrica in vitro, y se ha demostrado que la misma es protegida cuando se utiliza yogurth como portador de estos microorganismos (Lick et al. 2001). En consecuencia, es de importancia evaluar la tolerancia gastrointestinal de microorganismos probióticos en la matriz del alimento (Schillinger et al. 2005). Las propiedades funcionales de los probióticos pueden variar debido a diversos factores asociados con los alimentos portadores, incluyendo los ingredientes utilizados, el procedimiento de fabricación, las propiedades físicoquímicas del producto y las condiciones de almacenamiento.

Por lo tanto, se evaluó la resistencia al pasaje por el tracto gastrointestinal in vitro de L. paracasei CIDCA 8339 y L. kefiri CIDCA 83102 incluidos en el gel y los respectivos controles. Los resultados se muestran en la Figura 51 y fueron expresados como lactobacilos que permanecieron viables cada $10^{8} \mathrm{UFC} / \mathrm{g}$ de lactobacilos iniciales. 
Geles de kefiran como vehículo de microorganismos probióticos.
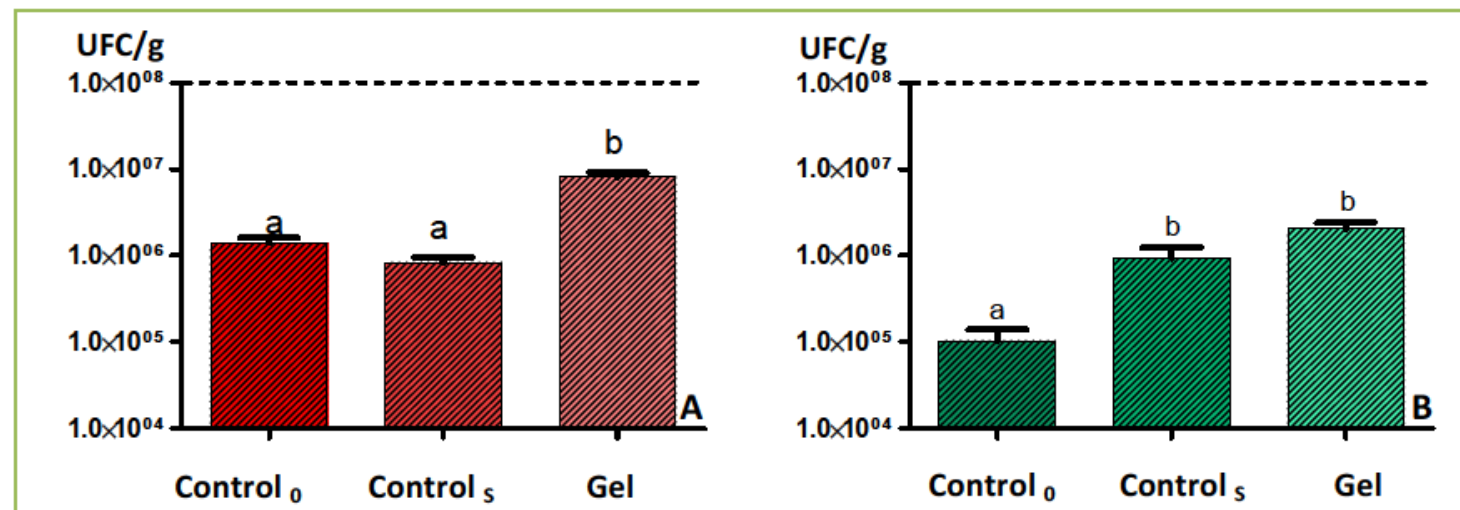

Figura 51. Viabilidad (UFC/g) de Lactobacillus paracasei CIDCA 8339 (A) y Lactobacillus kefiri CIDCA 83102 (B) incorporados en los geles sometidos al pasaje del tracto gastrointestinal. Control 0 y Controls corresponden a los controles de lactobacilos en buffer fosfato $\mathrm{pH} 7 \mathrm{y}$ al control del lactobacilo en solución de los componentes de la matriz del gel, respectivamente. Recuento previo al tratamiento $1.10^{8} \mathrm{UFC} / \mathrm{g}$. Las letras presentan diferencias significativas entre los microorganismos

Analizando la Figura $51 \mathrm{~A}$, donde se presentan los resultados obtenidos con L. paracasei CIDCA 8339, se pudo observar que este lactobacilo en buffer fosfato como en la solución conteniendo los componentes de la matriz del gel se ve afectado por el estrés ácido y de bilis, disminuyendo el número de microorganismos viables en dos ciclos logarítmicos. Sin embargo, se observó protección cuando los lactobacilos se encontraban incluidos en la matriz del gel ya que el número de microorganismos viables disminuyó sólo un ciclo logarítmico. Esto indicaría que el efecto protector del gel se debe a la propia estructura del gel más que a la presencia de los componentes que lo integran.

Cuando L. kefiri CIDCA 83102 fue sometido a las mismas condiciones, los lactobacilos incluidos en el gel fueron protegidos del estrés ácido y de bilis en comparación con la resistencia de los microorganismos en buffer fosfato, sin embargo, no se observaron diferencias significativas respecto a la resistencia de los microorganismos en la solución con los componentes que forman el gel (Controls). Esto indicaría que los propios componentes de la matriz estarían ejerciendo el efecto protector. 
Geles de kefiran como vehículo de microorganismos probióticos.

Adhesión a células Caco-2/TC-7 de Lactobacillus paracasei CIDCA 8339 y Lactobacillus kefiri CIDCA 83102 incluidos en la matriz alimentaria (gel).

Por último, se evaluó la adhesión de los lactobacilos incluidos en la matriz del gel a células de epitelio intestinal Caco-2/TC-7 luego del paso por el tracto gastrointestinal in vitro. En la Figura 52 se muestra el número de microorganismos viables incluidos en la matriz del gel que fueron capaces de adherirse a las células epiteliales previo al estrés ácido y de bilis. Además, se muestra la adhesión de los microorganismos después de la simulación por el tracto gastrointestinal en buffer fosfato $\mathrm{pH} 7$ y en la solución con los componentes de la matriz del gel. Los resultados fueron expresados como lactobacilos adheridos cada $10^{8} \mathrm{UFC} / \mathrm{g}$ de lactobacilos que resistieron el proceso del tracto gastrointestinal in vitro.
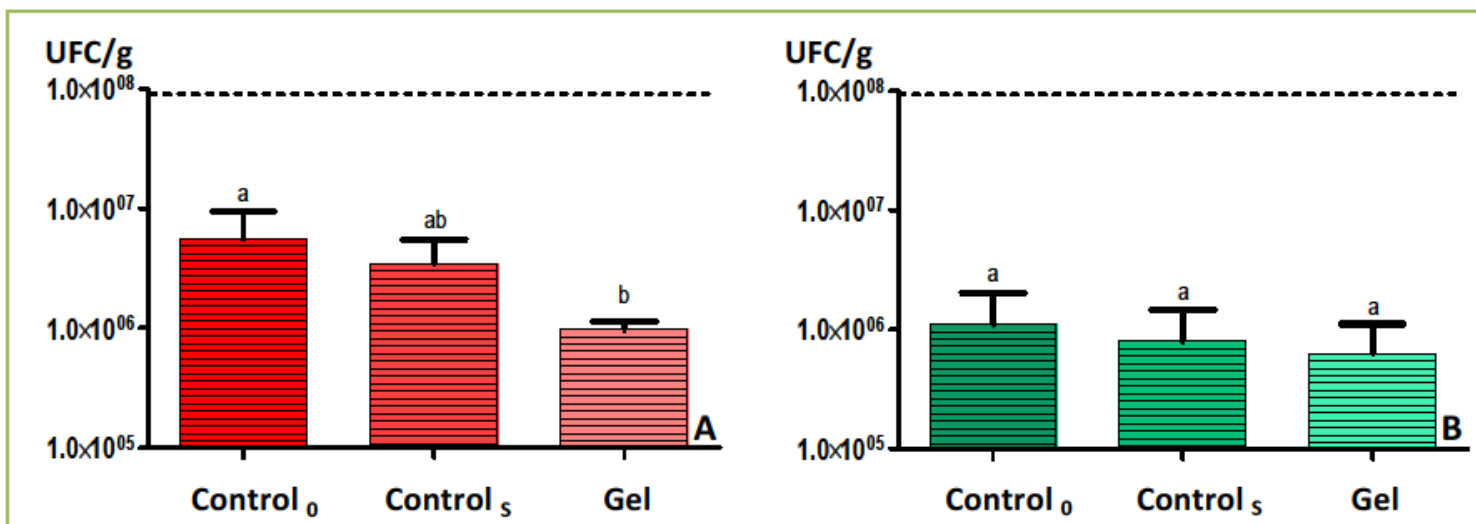

Figura 52. Lactobacillus paracasei CIDCA 8339 (A) y Lactobacillus kefiri CIDCA 83102 (B) adheridos a células de epitelio intestinal Caco-2/TC-7 (UFC/g) incorporados en los geles. Control o y Controls corresponden a los controles de lactobacilos en buffer fosfato $\mathrm{pH} 7 \mathrm{y}$ al control del lactobacilo en solución de los componentes de la matriz del gel, respectivamente. Los valores de adhesión fueron referidos a un recuento previo de $1.10^{8} \mathrm{UFC} / \mathrm{g}$. Las letras presentan diferencias significativas entre los microorganismos incluidos en el gel y en los controles.

La Figura 52 A muestra la adhesión de L. paracasei 8339 a células de epitelio intestinal luego del estrés ácido y de bilis. Se observó una mayor capacidad de adhesión de L. paracasei CIDCA 8339 cuando se encontraba en buffer fosfato pH 7 respecto a los lactobacilos incluidos en el gel. De todas formas, esta diferencia no superó el orden logarítmico, adhiriéndose $1,2.10^{6}$ UFC de lactobacilos a células epiteliales encontrándose incluidos en el Gel, respecto a $8,5.10^{6}$ UFC de lactobacilos adheridos a células encontrándose en la solución control (Controlo). Esto podría deberse a una pobre 
Geles de kefiran como vehículo de microorganismos probióticos.

liberación del lactobacilo del gel, por lo que sería conveniente profundizar estos estudios mediante ensayos in vivo. Sin embargo, la presencia de los componentes de la matriz del gel en estado solución no afectaron la capacidad de adhesión de L. paracasei CIDCA 8339 ya que no fue significativamente diferente del control en buffer fosfato (Controls: $3,5.10^{6}$ UFC) (Figura 52 A). La disminución en la capacidad de adhesión de este lactobacilo cuando está incluido en el gel podría deberse a que estos lactobacilos producen exopolisacáridos que estarían interactuando con la matriz del gel dificultando su liberación y posterior contacto con la célula epitelial.

La Figura 52 B muestra la capacidad de L. kefiri CIDCA 83102 incluidos en el gel de adherirse a células de epitelio intestinal. Para este lactobacilo, no se observaron diferencias significativas en la capacidad de adhesión a las células de epitelio intestinal respecto a los lactobacilos libres, indicando que ni la matriz del gel ni los componentes en solución ejercerían algún tipo de impedimento que dificulte la interacción del lactobacilo con las células, adhiriéndose del orden de $10^{6} \mathrm{UFC} / \mathrm{g}$ lactobacilos.

Hasta el momento, se analizó el efecto de la matriz alimentaria elegida sobre los lactobacilos durante la formación del gel, la resistencia al pasaje por el tracto gastrointestinal y la capacidad de adherirse a epitelio, en comparación con los controles.

Teniendo en cuenta lo que ocurre al ingerir un alimento, es de interés analizar la sobrevida de los microorganismos desde la ingesta del alimento con los lactobacilos incorporados en la matriz del gel hasta que los mismos se adhieren a las células de epitelio. En la Figura 53 se presentan los resultados obtenidos de un alimento a base de un gel de kefiran, proteínas de suero y fructosa, con una carga microbiana inicial de $1.10^{8} \mathrm{UFC} / \mathrm{g}$. 
Geles de kefiran como vehículo de microorganismos probióticos.

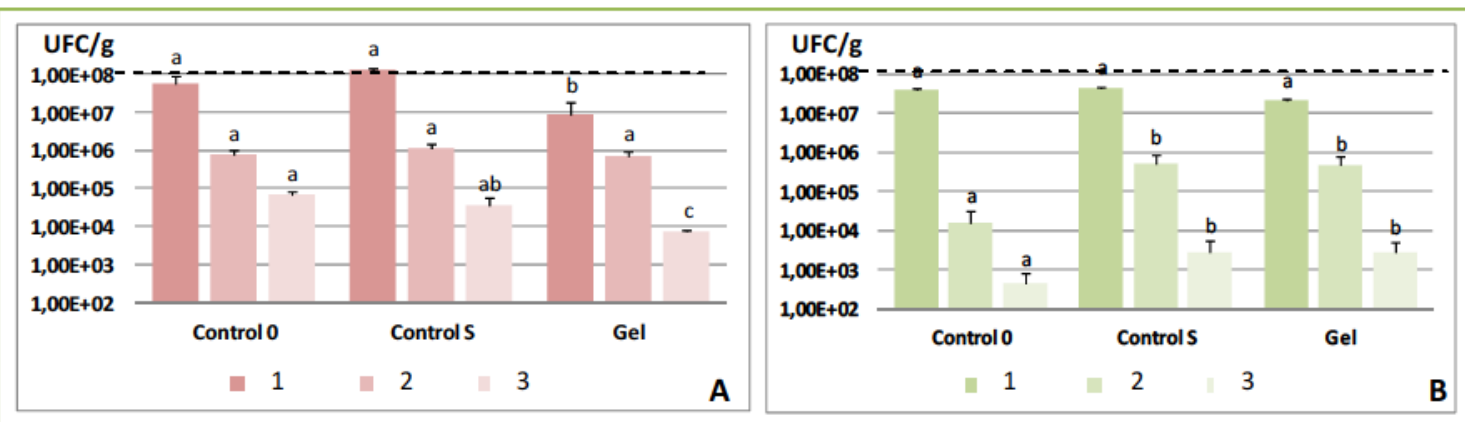

Figura 53. Viabilidad y capacidad de adhesión de Lactobacillus paracasei CIDCA 8339 (A) y Lactobacillus kefiri CIDCA 83102 (B) (UFC/g) incorporados en los geles. Número de microorganismos viables que resisten el proceso de elaboración de los geles (1), el pasaje por el tracto gastrointestinal (2) y se adhieren a células de epitelio in vitro (3). Control y Controls corresponden a los controles de lactobacilos en buffer fosfato $\mathrm{pH} 7$ y al control del lactobacilo en solución de los componentes de la matriz del gel, respectivamente. Las letras presentan diferencias significativas entre los microorganismos incluidos en el gel y en los controles.

Al analizar la capacidad de adhesión a células de epitelio intestinal de L. paracasei CIDCA 8339 incluidos en el gel respecto a los controles (Figura 53 A) se observó que luego del proceso de formación del gel el número de células viables disminuyó en un ciclo logarítmico y después de las condiciones de estrés ácido y de bilis el número de lactobacilos viables resultó igual que en los controles. En esta condición, la pérdida de viabilidad en la formación del gel se vio contrarrestada por la protección otorgada por la matriz del gel frente a las condiciones gastrointestinales. Finalmente lograron adherirse alrededor de $10^{4} \mathrm{UFC} / \mathrm{g}$ de $L$. paracasei a células de epitelio intestinal Caco-2/TC-7.

Como la etapa crítica de L. paracasei en solución tanto en buffer fosfato como en la solución con los componentes de la matriz del gel fue el estrés ácido y de bilis, es clave destacar la protección otorgada dada por el gel en esta etapa. Estos resultados son prometedores ya que desde la ingesta del alimento con lactobacilos hasta la llegada al intestino se observó una pérdida de viabilidad de 2 órdenes logarítmicos, con lo cual, podrían obtenerse mejores resultados al aumentar el número inicial de lactobacilos incluidos en el gel, ya conociendo el comportamiento de los mismos en la matriz del alimento en cada etapa.

Por otro lado, L. kefiri CIDCA 83102 (Figura 53 B) en todas las etapas se vio beneficiado al estar incluido en la matriz del gel o en solución con los componentes de la matriz, tanto en la protección frente al estrés ácido y de bilis, como en la adhesión al epitelio intestinal ya que la capacidad de adhesión de los lactobacilos incluidos en el gel 
luego del estrés ácido y de bilis fue significativamente superior al control en buffer fosfato.

Hasta la fecha son muy pocos los trabajos sobre el efecto de las diferentes matrices alimentarias portadoras de probióticos en la tolerancia a la digestión y a la capacidad de adhesión de bacterias probióticas. Bove et al. (2013) estudiaron la supervivencia de Lactobacillus plantarum WCFS1, en un sistema humano oro-gástricointestinal (OGI) in vitro. Utilizaron diferentes matrices como leche reconstituida al $10 \%$, caldo SRA, solución salina $(0,85 \% \mathrm{CINa})$, y pasta enriquecida con $\beta$-glucano para comparar las propiedades de protección y almacenamiento, observando la mayor supervivencia en las matrices complejas y ricas en nutrientes. Saxelin et al. (2010) realizaron estudios in vivo donde evaluaron la recuperación fecal después de la administración de cápsulas de celulosa, yogurth o queso conteniendo una combinación de Lactobacillus rhamnosus GG y LC705, Propionibacterium freudenreichii subsp. shermanii JS, y Bifidobacterium animalis subsp. lactis Bb12. Los participantes consumieron $10^{10} \mathrm{UFC} /$ día de la combinación de probióticos. Al final de la intervención, observaron una alta recuperación de L. rhamnosus GG y LC705 en todos los grupos sin observar efecto de la matriz utilizada. Sin embargo, $P$. freudenreichii subsp. shermanii JS y $B$. animalis subsp. lactis $\mathrm{Bb} 12$, se recuperaron mejor al ser administrados en el yogurth.

En conclusión, L. paracasei CIDCA 8339 se vio afectado por el proceso de congelación-descongelación y su inclusión en el gel protegió a esta cepa del estrés ácido y de bilis. No obstante, el número de lactobacilos que se adhiere a las células epiteliales respecto a los ingeridos fue menor en comparación a los lactobacilos libres, indicando que podría dificultarse la liberación de este microorganismo del gel. L. kefiri CIDCA 83102 se vio protegido por los componentes de la matriz del gel más que por la propia estructura del gel durante el paso por las condiciones gastrointestinales, y el número de microorganismos adheridos a células epiteliales respecto a los ingeridos fue mayor que cuando se encontraban en buffer fosfato.

Estos resultados, sugieren que el estudio de cada cepa probiótica debe ser probado adecuadamente en los alimentos portadores, y que la simple extrapolación de productos o variedades similares no necesariamente debe ser aceptada. 
CAPÍTULO 2

Geles de kefiran como vehículo de microorganismos probióticos. 


\section{CONCLUSIONES PARCIALES}

\section{GELES DE KEFIRAN CON AZÚCARES}

- Las soluciones de sacarosa-kefiran o fructosa-kefiran fueron capaces de formar geles después de un ciclo de congelación-descongelación.

- El agregado de sacarosa o fructosa a las soluciones de kefiran aumentó la viscosidad aparente y modificó el comportamiento de flujo. Los cambios en las soluciones se evidenciaron en propiedades fisicoquímicas diferentes en los geles obtenidos.

- Las moléculas de sacarosa y fructosa contribuyeron al aumento de la capacidad de retención de agua.

- Todos los geles mostraron estructura tridimensional altamente porosa excepto los que contenían alta concentración de sacarosa y fructosa.

- El agregado de sacarosa y fructosa a los geles de kefiran aumentó el módulo viscoso y el módulo elástico (G' y G"). El aumento del módulo elástico podría deberse a que el azúcar en sistemas acuosos competiría con el polímero por su interacción con el agua, esto favorecería la auto-asociación de las cadenas de kefiran.

- La adición de 0 a 30,0 \% (p/p) de sacarosa a geles de kefiran produjo módulos elásticos más altos que los adicionados con fructosa a las mismas concentraciones.

- A temperaturas superiores a $37{ }^{\circ} \mathrm{C}$ se produjo un descenso abrupto del módulo viscoso y el módulo elástico de los geles de kefiran. El agregado de azúcares desplazó esta temperatura a valores mayores. 
Geles de kefiran como vehículo de microorganismos probióticos.

- Geles de kefiran con el mismo grado de dulzor, tales como los que contienen $17,6 \%(p / p)$ de fructosa y $30,0 \%(p / p)$ de sacarosa, presentaron diferentes características físicoquímicas, permitiendo así la posibilidad de elegir la formulación adecuada para la producción de un criogel con las características deseadas.

\section{FORMACIÓN DE GELES DE KEFIRAN Y PROTEÍNAS DE SUERO DE LECHE}

- La elaboración de los geles combinados requirió un proceso en dos etapas. Una etapa de calentamiento durante 10 minutos a $90{ }^{\circ} \mathrm{C}$ (ETAPA 1$)$, y otra etapa que consistió en un ciclo de congelación-descongelación a $-20{ }^{\circ} \mathrm{C}$ y almacenamiento a $4{ }^{\circ} \mathrm{C}$ (ETAPA 2).

- El ciclo de congelación-descongelación reforzó la estructura de los geles proteicos, en comparación a los geles sin dicho ciclo.

- El agregado de kefiran a soluciones de proteína de suero de leche permitió la formación de geles mixtos autoportantes a concentraciones de proteína más bajas.

- Los geles mixtos obtenidos a partir de proteína de suero de leche 3,0 \% y $4,0 \%(p / p)$ y kefiran $1,0 \%(p / p)$ resultaron más opacos que los geles proteicos.

- La capacidad de retención de agua de los geles mixtos fue mayor a la de los geles proteicos debido a la capacidad del polisacárido de interactuar con las moléculas de agua.

- La inclusión de kefiran en la formulación de los geles disminuyó la tangente del ángulo de desfasaje tan( $\delta$ ) debido a que el aumento del módulo elástico (G') fue mayor al aumento del módulo viscoso (G"), indicando que el kefiran favorece uniones que refuerzan la estructura del gel. 
- En el análisis de perfil de textura se observó un aumento en la dureza de los geles mixtos respecto de los geles proteicos, sin observarse diferencias en la cohesividad y elasticidad.

- La mínima concentración de proteínas de suero que gelificó en presencia de kefiran $1,0 \%(p / p)$ fue $3,0 \%(p / p)$. Por ello fue la combinación seleccionada como matriz alimentaria para incluir los microorganismos probióticos.

\section{INCLUSIÓN DE MICROORGANISMOS EN GELES}

- El proceso de elaboración de los geles como matriz alimentaria portadora de microorganismos afectó la viabilidad de Lactobacillus paracasei CIDCA 8339 en comparación con los lactobacilos libres. Lactobacillus kefiri CIDCA 83102 se vio afectado por el proceso de congelación-descongelación de igual manera que el almacenamiento a $4{ }^{\circ} \mathrm{C}$ durante 48 horas.

- El gel de kefiran, proteína de suero y fructosa protegió a Lactobacillus paracasei CIDCA 8339 y Lactobacillus kefiri CIDCA 83102 frente a las condiciones gastrointestinales in vitro respecto a los microorganismos libres.

- La capacidad de adhesión de Lactobcillus paracasei CIDCA 8339 se vio afectada al estar incluido en el gel, mientras que no se observó lo mismo para Lactobacillus kefiri CIDCA 83102.

- La resistencia al pasaje gastrointestinal simulado y la capacidad de adhesión a células epiteliales in vitro dependió de la cepa y la matriz utilizada.

- El gel seleccionado resultó ser una matriz adecuada para ser utilizada como vehículo de microorganismos probióticos ya que su proceso de elaboración fue sencillo y aplicable a gran escala. 
CAPÍTULO 2

Geles de kefiran como vehículo de microorganismos probióticos. 


\section{CONCLUSIONES}

\section{GENERALES}


Atendiendo a la inquietud de desarrollar nuevos alimentos funcionales que contribuyan de manera natural al buen estado de salud y/o eviten contraer enfermedades, se planteó en el presente trabajo la elaboración de geles de kefiran como vehículo de microorganismos probióticos aislados de kefir. Este producto no sólo tendría las propiedades otorgadas por los microorganismos sino también las propiedades promotoras de salud asociadas al kefiran, otorgándole mayor valor agregado a los productos en los que se utilice.

El kefiran, polisacárido obtenido mediante una metodología simple a partir de los gránulos de kefir de leche, tiene la ventaja de ser producido por microorganismos con status GRAS (generalmente reconocidos como seguros). Tiene efectos promotores de la salud como propiedades antiinflamatorias, antitumoral, inmunomoduladora e hipocolesterolémica, hecho que lo hace un ingrediente o aditivo de interés para su uso en la industria de alimentos. En este trabajo, se demostró que este polisacárido es capaz de formar geles en presencia de azúcares que se utilizan como endulzantes (sacarosa y fructosa) mediante un proceso de congelación-descongelación, por ello, se los llama criogeles. Los geles de kefiran y azúcares fueron translúcidos, presentaron una elevada capacidad de retención de agua y habilidad de fundirse a la temperatura de la boca, características que los hacen interesantes para ser aplicados en la industria de alimentos.

El agregado de kefiran reforzó la estructura de los geles de proteínas de suero de leche. La incorporación de este polisacárido ejerció un sinergismo con las proteínas de suero ya que se obtuvieron geles con buenas propiedades reológicas, a muy bajas concentraciones de proteína, que en ausencia del polisacárido no gelifican. Estos geles además resultaron ser autoportantes.

En virtud de los resultados obtenidos se seleccionó una concentración de proteínas de $3,0 \%(\mathrm{p} / \mathrm{p})$ y de kefiran de $1,0 \%(\mathrm{p} / \mathrm{p})$ para la elaboración de los geles a fin 
de contener los microorganismos probióticos y se les adicionó fructosa para contribuir al dulzor.

Se optimizó el procedimiento de elaboración de los geles de kefiran y proteínas de suero. El proceso de elaboración involucró una etapa de calentamiento durante 10 minutos a $90{ }^{\circ} \mathrm{C}$, correspondiente al proceso de desnaturalización de las proteínas, y otra, en lo cual los geles obtenidos en el paso anterior fueron llevados a $-20{ }^{\circ} \mathrm{C}$ durante 24 horas y otras 24 horas a $4{ }^{\circ} \mathrm{C}$, correspondiente al ciclo de congelación-descongelación necesario para la gelificación del kefiran. Ciertos geles de proteína de suero gelifican en caliente, en la primer etapa, dependiendo de la concentración de proteína utilizada, imposibilitando la adición de microorganizmos probióticos. En este caso, fue primordial optimizar el proceso de elaboración del gel para permitir la incorporación de los microorganismos en la solución con los componentes que darán lugar a la formación del gel, posterior a la etapa de calentamiento, a fin de conservar su viabilidad. Por ello, luego del calentamiento, las muestras fueron enfriadas en baño de agua fría hasta temperatura ambiente para la incorporación de los microorganismos. De esta manera, al ser llevados a $-20^{\circ} \mathrm{C}$, la solución gelifica atrapando los microorganismos en ella.

A fin de seleccionar los microorganismos a incluir en los geles y dado que en el CIDCA se contaba con 20 nuevos aislados cuya potencialidad probiótica se desconocía, se analizaron los mismos en lo referente a su capacidad de resistir el pasaje por el tracto gastrointestinal, su capacidad de adhesión a epitelio y su capacidad de inhibir in vitro a Salmonella entérica serovar Enteritidis CIDCA 101, dada la relevancia de este patógeno como causante de enfermedades de transmisión alimentaria.

Utilizando el modelo de epitelio intestinal Caco-2/TC-7, se demostró que Lactobacillus paracasei CIDCA 8339, CIDCA 83120, CIDCA 83121, CIDCA 83123, CIDCA 83124 y Lactobacillus kefiri CIDCA 83102 fueron capaces de adherirse a las células de epitelio intestinal in vitro, y aumentar dicha capacidad luego de ser tratadas con soluciones que simulan el pasaje por el tracto gastrointestinal. Esto indica que estos lactobacilos una vez ingeridos son capaces de aumentar su tiempo de residencia en el intestino. Los lactobacilos presentaron valores de adhesión entre $10^{5}$ y $10^{6} \mathrm{UFC} / \mathrm{ml}$ que aumentaron luego del tratamiento que simula las condiciones gastrointestinales (estrés ácido y de bilis). El estrés ácido y de bilis indujo en L. paracasei CIDCA 8339 la regulación positiva de proteínas de la vía glicolítica, siendo un efecto general del estrés activar la 
fuente de energía, o de proteínas de superficie que pudieran estar asociadas a la adhesión a mucus o a células de epitelio intestinal después del tratamiento.

Además, la preincubación de todos los lactobacilos estudiados con células epiteliales Caco-2/TC-7 redujo el daño producido por Salmonella entérica serovar Enteritidis CIDCA 101 sobre las células epiteliales. Por un lado, la preincubación de cada lactobacilo con Salmonella, como el efecto barrera otorgado por los lactobacilos sobre las células, redujo la capacidad del patógeno de internalizarse en las células epiteliales Caco-2/TC-7 respecto al control. Por otro lado, se observó un efecto bactericida de todos los sobrenadantes estudiados, siendo el mismo revertido a pH 4,5. La preincubación de Salmonella con estos sobrenadantes parcialmente neutralizados inhibieron su asociación e internalización a células epiteliales Caco-2/TC-7.

En virtud de los resultados obtenidos se seleccionaron Lactobacillus kefiri CIDCA 83102 y Lactobacillus paracasei CIDCA 8339 para su inclusión en los geles.

El proceso de elaboración de los geles afectó la viabilidad de Lactobacillus paracasei CIDCA 8339 en comparación con los lactobacilos libres. Lactobacillus kefiri CIDCA 83102 se vio afectado por el proceso de congelación-descongelación de igual manera que el almacenamiento a $4{ }^{\circ} \mathrm{C}$ durante 48 horas. A su vez, el gel protegió a ambos lactobacilos frente al estrés ácido y de bilis respecto a los microorganismos libres. La capacidad de adhesión a células epiteliales se vio afectada al estar incluido Lactobcillus paracasei CIDCA 8339 en el gel, mientras que no se observó lo mismo para Lactobacillus kefiri CIDCA 83102. Estos resultados resaltan la importancia del estudio de los microorganismos dentro de las matrices correspondientes, ya que no pueden predecirse comportamientos a partir de los resultados de los microorganismos en solución.

Se pudo concluir que el producto obtenido a base de geles de kefiran 1,0 \% (p/p) y proteínas de suero $3,0 \%(\mathrm{p} / \mathrm{p})$ con adición de fructosa $12,0 \%(\mathrm{p} / \mathrm{p})$ resultaron adecuados para la inclusión de Lactobacillus paracasei CIDCA 8339 y Lactobacillus kefiri CIDCA 83102, con un proceso de elaboración sencillo, aplicable a gran escala y manteniendo las condiciones de viabilidad de los lactobacilos durante el proceso de elaboración. Asimismo, los microorganismos incluidos en el gel también resistieron el pasaje por tracto gastrointestinal y son capaces de adherirse al epitelio intestinal. 
De este modo, los resultados aquí presentados son los primeros donde se evalúa la posibilidad de utilizar los geles de kefiran como vehículo de microorganismos probióticos y el estudio de los mismos durante el proceso digestivo, desde su consumo, hasta su adhesión a epitelio, dentro de la matriz del alimento.

Estos resultados son prometedores ya que las cepas seleccionadas son de interés para el desarrollo de nuevos alimentos con probióticos. Sin embargo, se necesitan estudios in vivo para la aplicación de estas cepas para la formulación de los alimentos funcionales a base de geles de kefiran conteniendo probióticos. 
APÉNDICE

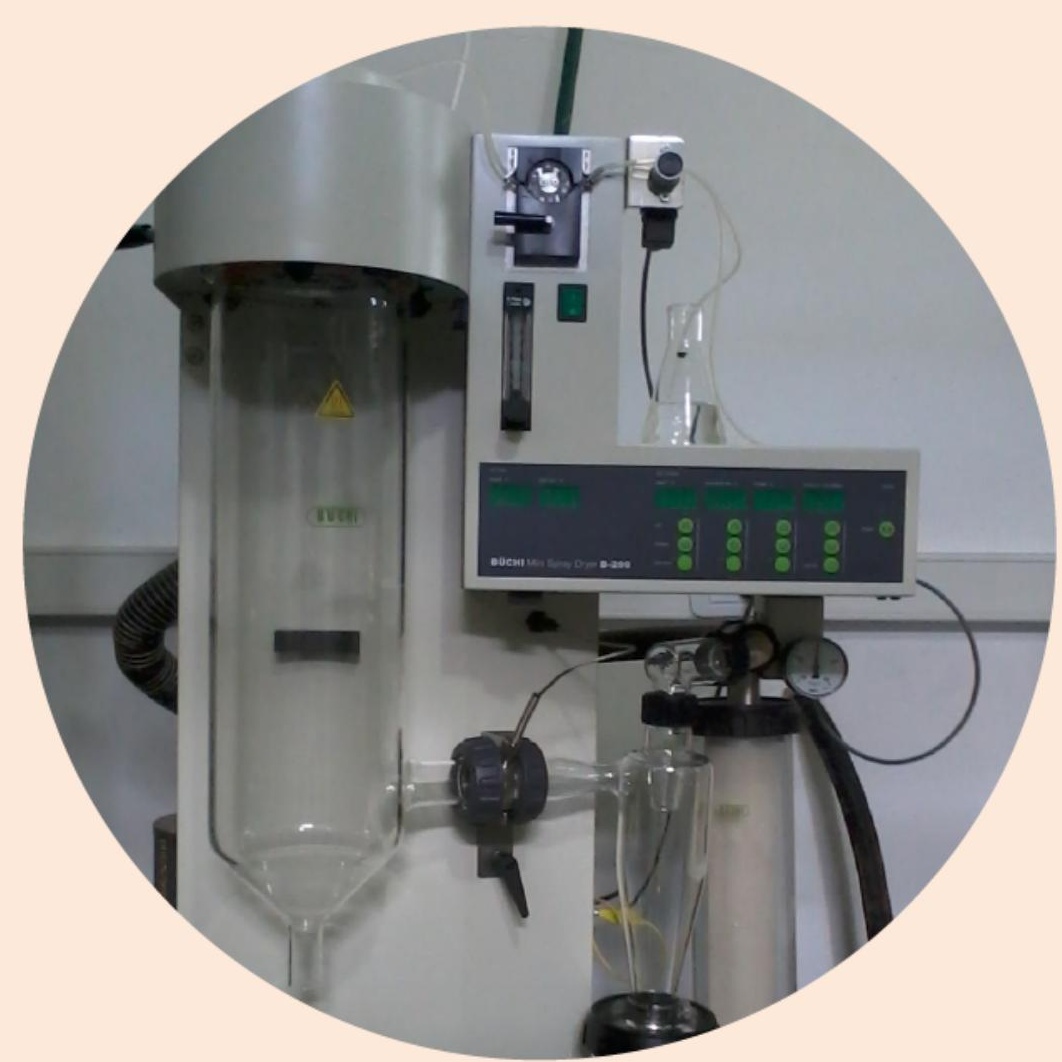




\section{Medios de cultivos}

- Caldo MRS (De Man, Rogosa, Sharpe) (De Man, Rogosa, Sharpe , 1960), Difco, Detroit, USA.

$\begin{array}{ll}\text { Peptona universal } & 10 \mathrm{~g} / \mathrm{l} \\ \text { Extracto de carne } & 10 \mathrm{~g} / \mathrm{l} \\ \text { Extracto de levadura } & 5 \mathrm{~g} / \mathrm{l} \\ \mathrm{D}(+) \text { glucosa } & 20 \mathrm{~g} / \mathrm{l} \\ \mathrm{K}_{2} \mathrm{HPO}_{4} & 2 \mathrm{~g} / \mathrm{l} \\ \text { Tween } 80 & 1 \mathrm{~g} / \mathrm{l} \\ \text { Citrato ácido de amonio } & 2 \mathrm{~g} / \mathrm{l} \\ \text { Acetato de sodio } & 5 \mathrm{~g} / \mathrm{l} \\ \mathrm{MgSO}_{4} & 0,1 \mathrm{~g} / \mathrm{l} \\ \mathrm{MnSO}_{4} & 0,05 \mathrm{~g} / \mathrm{l} \\ \mathrm{pH}=6,5 \pm 0,2 & \end{array}$

- Agar MRS

Caldo MRS adicionado con agar en concentración 1,5 g/l.

- Caldo nutritivo

$\begin{array}{ll}\text { Extracto de carne } & 3 \mathrm{~g} / \mathrm{l} \\ \text { Peptona de carne } & 5 \mathrm{~g} / \mathrm{l} \\ \mathrm{pH}=7 \pm 0,2 & \end{array}$


- Agar Nutritivo (Parafarm, Argentina)

$\begin{array}{ll}\text { Peptona de carne } & 5 \mathrm{~g} / \mathrm{l} \\ \text { Extracto de carne } & 3 \mathrm{~g} / \mathrm{l} \\ \text { Agar - agar } & 12 \mathrm{~g} / \mathrm{l} \\ \text { Agua bidestilada c.s.p. } & 1 \mathrm{I}\end{array}$

Peptona y extracto de carne: BIOKAR, Francia

- Triptona

Triptona

$1 \mathrm{~g} / \mathrm{l}$

- Buffer Fosfato Salino (PBS)

$\begin{array}{ll}\mathrm{NaCl} & 9 \mathrm{~g} / \mathrm{l} \\ \mathrm{Na}_{2} \mathrm{HPO}_{4} & 0,795 \mathrm{~g} / \mathrm{L} \\ \mathrm{KH}_{2} \mathrm{PO}_{4} & 0,144 \mathrm{~g} / \mathrm{l} \\ \text { Agua bidestilada c.s.p. } & 1 \mathrm{I} \\ \mathrm{pH}=7-7,4 & \end{array}$

Los medios de cultivos y buffers listados anteriormente, fueron preparados con agua bidestilada. La esterilización se realizó por autoclave a $121^{\circ} \mathrm{C}$ durante $15-20 \mathrm{~min}$.

- Buffer Fosfato

$\begin{array}{ll}\mathrm{OHNa}(0,1 \mathrm{M}) & 29,1 \mathrm{ml} \\ \mathrm{KH}_{2} \mathrm{PO}_{4}(0,1 \mathrm{M}) & 50 \mathrm{ml} \\ \text { Volúmen final } & 100 \mathrm{ml} \\ \mathrm{pH}=7 \pm 0,2 & \end{array}$




\section{Coloraciones}

- Tinción de Gram

Cristal violeta

Safranina (solución madre)

Safranina (solución de trabajo)

Lugol

Decolorante
$10 \mathrm{~g} / \mathrm{l}$ en agua destilada

$25 \mathrm{~g} / \mathrm{l}$ en etanol

solución madre diluida $1 / 10$

$10 \mathrm{~g} \mathrm{I}+20 \mathrm{~g} \mathrm{KI}$ en 1 litro de agua destilada

etanol-acetona 4:1

Las soluciones se filtran antes de utilizarlas.

\begin{tabular}{|cc|}
\hline Protocolo & Tiempo de exposición (seg) \\
\hline Cristal violeta & 120 \\
Lugol & 30 \\
Lugol & 30 \\
\hline Lavar con agua & 10 \\
Decolorante & \\
Lavar con agua & 120 \\
Safranina & \\
\hline
\end{tabular}

Medios de cultivo para células eucariotas

- DMEM (Dulbecco Modified Eagle's Medium), (GIBCO, EEUU)

DMEM Completo

$\begin{array}{ll}\text { DMEM } & 1 \text { sobre/l } \\ \text { Penicilina/estreptomicina (1000 IU, } 1000 \mu \mathrm{g} / \mathrm{ml} \text { ) } & 13 \mathrm{ml} / \mathrm{l} \\ \text { Suero Fetal Bovino (inactivado } 30 \mathrm{~min} \text { a } 58^{\circ} \mathrm{C} \text { ) } & 180 \mathrm{ml} / \mathrm{l}\end{array}$


Aminoácidos no esenciales 100X

Gentamicina (50 mg/ml)

$\mathrm{NaHCO}_{3}$

Agua de irrigación quirúrgica

$\mathrm{pH}=7,00 \pm 0,2$

DMEM adhesión (DMEM sin suplementar)

DMEM

$\mathrm{NaHCO}_{3}$

Agua de irrigación quirúrgica

$\mathrm{pH}=7,00 \pm 0,2$
1 sobre/l

$2 \mathrm{~g} / \mathrm{l}$

11

Los medios para las células eucariotas, se prepararon utilizando agua de irrigación quirúrgica (Droguería Lino, Argentina). Los medios de esterilizaron por membrana de filtración estéril de 0,22 $\mu \mathrm{m}$.

Los aminoácidos no esenciales 100X, fueron provistos por GIBCO-Invitrogen Corporation.

\section{Cultivo de células intestinales y preparación de placas}

Se utilizaron células de la línea Caco-2/TC-7. Las células se mantienen congeladas en nitrógeno líquido en viales de $1 \mathrm{ml}$ de medio DMEM completo con $5 \%$ de dimetilsulfóxido (Riedel-de Haën AG, D-3016 Seelze, Alemania) como crioprotector. Para reactivarlas se descongeló un vial a $37^{\circ} \mathrm{C}$, se centrifugó a $1000 \mathrm{rpm}$ durante 10 minutos para retirar el crioprotector, se resuspendieron las células en $1 \mathrm{ml}$ de medio de cultivo fresco, y se cultivaron en una botella de $25 \mathrm{~cm}^{2}$ (Corning Costar Co., Cambridge, MA, USA) con $4 \mathrm{ml}$ de medio DMEN completo. El cultivo se mantuvo a $37^{\circ} \mathrm{C}$ en estufa con atmósfera controlada (5\% $\mathrm{CO}_{2}-95 \%$ aire) cambiando el medio cada 2 días. A los 5-7 días se obtuvo una monocapa confluente y se repicó a una botella de $75 \mathrm{~cm}^{2}$. En cada repique la monocapa se observó en un microscopio invertido para verificar la 
uniformidad y continuidad de la monocapa. Los repiques se realizaron de la siguiente manera: se descartó el medio ya agotado y se lavó la monocapa tres veces con PBS estéril, luego se colocó $10 \mathrm{ml}$ de solución de tripsina (Tripsina 0,75 g/l; EDTA 0,2 g/l) y se llevó a la estufa a $37{ }^{\circ} \mathrm{C}$ durante 5 minutos. Cuando se observaron los primeros indicios de desprendimiento celular, se levantó la monocapa y se diluyó en $10 \mathrm{ml}$ de DMEM para inactivar la enzima. Se centrifugó a baja velocidad durante 5 minutos, se descartó el medio y se reemplazó por medio DMEM fresco. Se tomaron $50 \mu \mathrm{l}$ de la suspensión de células y se mezclaron con igual volumen de una solución de azul tripán (al $10 \%$ en PBS). Se realizó el recuento de células en una cámara de Neubauer contando sólo aquellas células que se veían brillantes (es decir, que estaban viables). Se realizó la dilución apropiada para cada línea celular y se procedió a preparar las placas para los ensayos. Para las células Caco-2/TC-7 se agregaron $2,5.10^{5}$ células/fosa.

Para los ensayos, las células fueron sembradas en placas de 24 fosas (Corning Costar Co., Cambridge, MA, USA). A cada fosa se le agregó $0,5 \mathrm{ml}$ de la suspensión de células correspondiente para cada línea. Las placas con células Caco-2/TC-7 se incubaron 7 días (células en confluencia) a $37^{\circ} \mathrm{C}$ en una estufa de atmósfera controlada ( $5 \% \mathrm{CO}_{2}-95 \%$ aire) cambiando el medio cada 2 días. Para los ensayos en donde se realizó una observación microscópica, las células se crecieron sobre un vidrio de $12 \mathrm{~mm}$ de diámetro colocado dentro de la fosa. Estos vidrios fueron previamente lavados con agua y detergente no iónico (Extran MAO2 neutro, Merck, Darmstadt, Alemania) y luego de un enjuague exhaustivo con agua destilada, se colocaron en cajas de Petri y se esterilizaron en autoclave. 


\section{BIBLIOGRAFÍA}

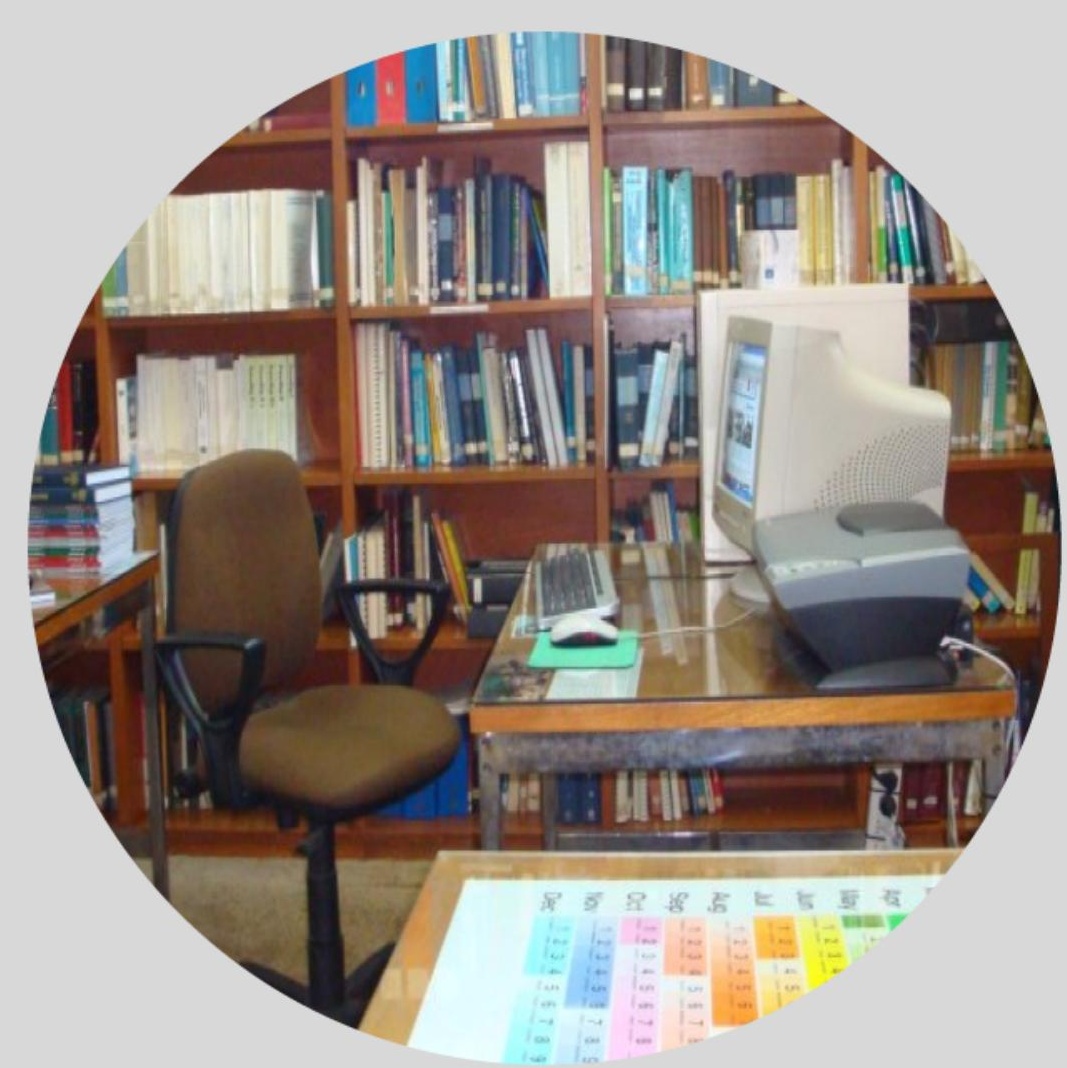




\section{BIBLIOGRAFÍA}

Abraham, A.G. \& De Antoni, G.L. (1999). Characterization of kefir grains grown in cows' milk and in soya milk. The Journal of dairy research. $66,327-333$.

Abrams, S.A., Griffin, I.J., Hawthorne, K.M., Liang, L., Gunn, S.K., Darlington, G., Ellis, K.J. (2005). A combination of prebiotic short- and long- chain inulin-type fructans enhances calcium absorption and bone mineralization in young adolescents. American Journal of Clinical Nutrition. 82, 471-476.

Adhikari, B., Howes, T., Bhandari, B.R. \& Truong, V. (2001). Stickiness in foods: mechanisms and test methods- a review. International Journal of Food Properties. 4, 1-33.

Adlerberth, I., Ahrne, S., Johansson, M.L., Molin, G., Hanson, L.A. \& Wold, A.E. (1996). A mannose-specific adherence mechanism in Lactobacillus plantarum conferring binding to the human colonic cell line HT-29. Applied Environmental Microbiology. 62, 2244-2251.

Agarwal, K.N. \& Bhasin, S.K. (2002). Feasibility studies to control diarrhea in children by feeding fermented milk preparations Actimel and Indian Dahi. Europe Journal Clinical Nutrition. 56, 56-59.

Agarwal, K.N., Bhasin, S.K., Faridi, M.M.A., Mathur, M. \& Gupta, S. (2001). Lactobacillus casei in the control of acute diarrhea. A pilot study. Indian Pediatrics. 38, 905-910.

Alakomi, H.L., Skytta, E., Saarela, M., Mattila-Sandholm, T., Latva-Kala, K. \& Helander, I.M. (2000). Lactic acid permeabilizes gram-negative bacteria by disrupting the outer membrane. Applied and Environmental Microbiology. 66, 2001-2005.

Alander, M., Satokari, R., Korpela, R., Saxelin, M., Vilpponen-Salmela, T., MattilaSandholm. T. \& von Wright, A. (1999). Persistence of colonization of human colonic mucosa by a probiotic strain, Lactobacillus rhamnosus GG, after oral consumption. Applied and Environmental Microbiology. 65, 351-354.

Altier, C. (2005). Genetic and environmental control of Salmonella invasion. Journal of Microbiology. 43, 85-92.

Alting, A.C., Hamer, R.J., de Kruif, C.G. \& Visschers, R.W. (2000). Formation of disulfide bonds in acid-induced gels of preheated whey protein isolate. Journal of Agricultural Food Chemistry. 48, 5001-5007.

Alves, L.L., Richards N.S.P.S., Mattanna, P., Andrade, D.F., Rezer, A.P.S., Milani, L.I.G., Cruz, A.G. \& Faria, J.A.F. (2013). Cream cheese as a symbiotic food carrier using 
Bifidobacterium animalis Bb-12 and Lactobacillus acidophilus La-5 and inulin. International Journal of Dairy Technology. 66, 63-69.

Anal, A.K. \& Singh, H. (2007). Recent advances in microencapsulation of probiotics for industrial applications and targeted delivery. Trends in Food Science \& Technology. 18, 240-251.

Angulo, L., Lopez, E. \& Lema, C. (1993). Microflora present in kefir grains of the Galician Region (north-west of spain). Journal of Dairy Research. 60, 263-267.

Antonie, J.M., Meance, S., Cayuela, C., Turchet, P., Raimondi, A., Lucas, C. (2000). Effect of a specific probiotic (Bifidobacterium sp. DN 173010) on gut transit time in elderly. Federation of American Societies for Experimental Biology Journal. 14, 160-11.

Apostolou, E., Kirjavainen, P.V., Saxelin, M., Rautelin, H., Valtonen, V., Salminen, S.J. \& Ouwehand, A.C. (2001). Good adhesion properties of probiotics: A potential risk for bacteremia? FEMS Immunology and Medical Microbiology. 31, 35-39.

Aragon-Alegro, L.C., Alarcon, J.H., Cardarellib, H.R., Chih Chiu,M. \& Isay Saad, S.M. (2007). Potentially probiotic and synbiotic chocolate mousse. Food Science and Technology. 40, 669-675.

Arai, S. (1996). Studies of functional foods in Japan - State of the art. Bioscience Biotechnology Biochemistry. 60, 9-15.

Araújo, E. A., de Carvalhoa, A.F., Leandro, E.S., Furtado, M.M., de Moraes, C.A. (2010). Development of a symbiotic cottage cheese added with Lactobacillus delbrueckii UFV $\mathrm{H} 2 \mathrm{~b} 20$ and inulin. Journal of Functional Foods. 2, 85-89.

Aymard, P., Gimel, J. C., Nicolai, T. \& Durand, D. (1996). Experimental evidence for a twostep process in the aggregation of $\beta$-lactoglobulin at $\mathrm{pH}$ 7. Journal de Chimie Physique et de Physico-Chimie Biologique. 93, 987-997.

Banerjee, P., Merkel, G.J. \& Bhunia, A.K. (2009). Lactobacillus delbrueckii ssp. bulgaricus B-30892 can inhibit cytotoxic effects and adhesion of pathogenic Clostridium difficile to Caco-2 cells. Gut Pathogens. 1, 8.

Barbut, S. \& Foegeding, E. A. (1993). $\mathrm{Ca}^{+2}$ induced gelation of preheated whey protein isolate. Journal of Food Science. 58, 867-871.

Barthel, M., Hapfelmeier, S., Quintanilla-Martinez, L., Kremer, M., Rohde, M., Hogardt, M., Pfeffer, K., Russmann, H., Hardt, W-D. (2003). Pretreatment of mice with streptomycin provides a Salmonella enterica serovar Typhimurium colitis model that allows analysis of both pathogen and host. Infection and Immunity. 71, 2839-58.

Beaulieu, M., Corredig, M., Turgeon, S. L., Wicker, L. \& Doublier, J.L. (2005). The formation of heat-induced protein aggregates in whey protein/pectin mixtures studied by size exclusion chromatography coupled with multi-angle laser light scattering detection. Food Hydrocolloids. 19, 803-812. 
Beaulieu, M., Turgeon, S.L. \& Doublier, J.L. (2001). Rheology, texture and microstructure of whey proteins/low methoxyl pectins mixed gels with added calcium. International Dairy Journal. 11, 961-967.

Beebe, J.A. \& Frey, P.A. (1998). Galactose mutarotase: purification, characterization, and investigations of two important histidine residues. Biochemistry. 37,14989-14997.

Bernet, M.F., Brassart, D., Neeser, J.R. \& Servin, A.L. (1994). Lactobacillus acidophilus LA 1 binds to cultured human intestinal cell lines and inhibits cell attachment and cell invasion by enterovirulent bacteria. Gut. 35, 483-489.

Bernet-Camard, M.F., Lievin, V., Brassart, D., Neeser, J.R., Servin, A.L. \& Hudault, S. (1997). The human Lactobacillus acidophilus strain LA1 secretes a nonbacteriocin antibacterial substance(s) active in vitro and in vivo. Applied and Enviromental Microbiology. 63, 2747-2753.

Biliadieris, C.G. (1992). Structures and phase transitions of starch in food systems. Food Technology. 46, 98-109.

Blomberg, L., Henriksson, A. \& Conway, P.L. (1993). Inhibition of adhesion of Escherichia coli $\mathrm{K} 88$ to piglet ileal mucus by Lactobacillus spp. Applied and Environmental Microbiology. 59, 34-39.

Blum, S., Reniero, R., Schifrin, E.J., Crittenden, R., Mattila-Sandholm, T., Ouwehand, A.C., Salminen, S., Von Wright, A., Saarela, M., Saxelin, M., Collins, K. \& Morelli, L. (1999). Adhesion studies for probiotics: need for validation and refinement. Trends in Food Science \& Technology. 10, 405-410.

Bolla, P.A., Carasi, P., Bolla, Mde los A., De Antoni G. L., Serradel, M. de los A. (2013). Protective effect of a mixture of kefir-isolated lactic acid bacteria and yeasts in a hamster model of Clostridium difficile infection. Anaerobe. 21, 28-33.

Boris, S., Suarez, J.E., Vazquez, F. \& Barbes, C. (1998). Adherence of human vaginal lactobacilli to vaginal epithelial cells and interaction with uropathogens. Infection and Immunity. 66, 1985-1989.

Botes, M., Loos, B., van Reenen, C.A., Dicks, L.M. (2008). Adhesion of the probiotic strains Enterococcus mundtii ST4SA and Lactobacillus plantarum 423 to Caco-2 cells under conditions simulating the intestinal tract, and in the presence of antibiotics and anti-inflammatory medicaments. Archives of Microbiology. 190, 573-584.

Bottazzi, V., Zacconi, C., Sarra, P. G., Dallavalle, P. \& Parisi, M. G. (1994). Kefir: Microbiologia, Chimica e Tecnologia. Industria del Latte. 30, 41-62.

Bove, P., Russo, P., Capozzi, V., Gallone, A. \& Spanob, G.D. (2013). Lactobacillus plantarum passage through an oro-gastro-intestinal tract simulator: Carrier matrix effect and transcriptional analysis of genes associated to stress and probiosis. Microbiological Research. 168, 351-9. 
Boylston, T.D., Vinderola, C.G., Ghoddusi, H.B. \& Reinheimer, J.A. (2004). Incorporation of bifidobacteria into cheeses: challenges and rewards. International Dairy Journal. 14, 375-387.

Bradford, M. (1976). A rapid and sensitive method for quantization of microgram quantities of protein utilising the principle of protein-dye binding. Analytical Biochemistry. 72, 248-254.

Brialy, C., Rivalland, P., Coiffard, L. \& De Roeck Holtzhauer, Y. (1995). Microbiological study of lyophilized dairy kefir. Folia Microbiologica. 40, 198-200.

Bron, P.A., Grangette, C., Mercenier, A., de Vos, W.M. \& Kleerebezem, M. (2004). Identification of Lactobacillus plantarum genes that are induced in the gastrointestinal tract of mice. Journal of bacteriology. 186, 5721-5729.

Bryant, C. M.; McClements, D. J. Molecular basis of protein functionality with special consideration of cold-set gels derived from heat-denatured whey. Trends Food Sci. Technol.1998, 9, 143-151.

Capron, I., Nicolai, T. \& Durand, D. (1999). Heat induced aggregation and gelation of $\beta$ lactoglobulin in the presence of K-carrageenan. Food Hydrocolloids. 13, 1-5.

Carasi, P., Ambrosis, N., De Antoni, G. L., Bressollier, P., Urdaci, M. C. \& Serradell, M.D.L.A. (2013). Adhesion properties of potentially probiotic Lactobacillus kefiri to gastrointestinal mucus. Journal of Dairy Research. 81, 16-23.

Carp, D.J., Barholomai, G.B., Relkin, P. \& Pilosof, A.M.R. (2001). Effects of denaturation on soy protein-xanthan interactions: comparison of a whipping-rheological and a bubbling method. Colloids and Surfaces B: Biointerfaces. 21, 163-171.

Casey, P.G., Casey, G.D., Gardiner, G.E., Tangney, M., Stanton, C., Ross, R.P., Hill C. \& Fitzgerald, G.F. (2004). Isolation and characterization of anti -Salmonella lactic acid bacteria from the porcine gastrointestinal tract. Letter and Applied Microbiology. 39, 431-438.

Castro, L.A. \& De Robetto, C. 2006. Probióticos: utilidad clínica. Colombia médica. 37, 308-314.

Cats, A., Kuipers, E., Bosschaert, M., Post, R., Vanderbroucke-Grauils, C. \& Kusters, J. (2003). Effect of frequent consumption of a Lactobacillus casei-containing milk drink in Helicobacter pylori colonized subjects. Alimentary Pharmacology and Therapeutics. 17, 429.

Cebrián, R., Baños, A., Valdivia, E., Pérez-Pulido, R., Martínez-Bueno, M. \& Maqueda, M. (2012). Characterization of functional, safety, and probiotic properties of Enterococcus faecalis UGRA10, a new AS-48-producer strain. Food Microbiology. 30, 59-67.

Cevikbas, A., Yemni, E., Ezzedenn, F.W., Yardimici, T., Cevikbas, U. \& Stohs, S.J. (1994). Antitumoural antibacterial and antifungal activities of kefir and kefir grain. Phytotherapy Research. 8, 78-82. 
Chaila, Z., Ortiz Zavalla, J., Alarcón, O., Gusils, C., Gauffin Cano, P., Moreno, R., Oliver, G. \& Gonzalez, S. (2005). Relation between probiotic milk administration and some bone turnover markers. Journal Food Technology. 3, 135-142.

Chateau, N., Castellanos, I. \& Deschamps, A. (1993). Distribution of pathogen inhibition in the Lactobacillus isolates of a commercial probiotic consortium. Journal Applied Bacteriology. 74, 36-40.

Cheftel, J. C. \& Lorient, D. (1982). Les proprié tés fonctionnelles des protéines laityeres et leur amélioration. Lait. 62, 436-483.

Chen, H., Wang, S. \& Chen, M. (2008). Microbiological study of lactic acid bacteria in kefir grains by culture-dependent and culture-independent methods. Food Microbiology. 25, 492-501.

Chen, H.H., Xu, S.Y., Wang, Z. (2006). Gelation properties of flaxseed gum. Journal of Food Engineering. 77, 295-303.

Chimalizeni, Y., Kawaza, K. \& Molyneux, E. (2010). The epidemiology and management of non typhoidal salmonella infections. Advances in Experimental Medicine and Biology. 659, 33-46.

Clark, A. H. (1992). Gels and gelling. En: H. G. Schwartzberg, \& R. W. Hartel, Physical chemistry of foods (pp. 263-305). New York: Marcel Dekker.

Clark, A. H., Kavanagh, G. M. \& Ross-Murphy, S. B. (2001). Globular protein gelation theory and experiment. Food Hydrocolloids. 15, 383-400.

Clark, A.H. \& Ross-Murphy, S.B. (1987). Structural and mechanical properties of biopolymer gels. Advances in Polymer Science. 83, 57-192.

Cobo Sanz, J.M., Mateos, J.A. \& Muñoz Conejo, A. (2006). Effect of Lactobacillus casei on the incidence of infectious conditions in children. Nutrition Hospital. 21, 547-51.

Cóccaro, G.C. (2010). Desarrollo de nuevos productos. Alimentos funcionales y novel food. Alternativas para el diseño de alimentos y su marco legal.

Coconnier, M.H., Bernet M.F., Kerneis S., Chauviere, G., Fourniat J. \& Servin, A.L. (1993a). Inhibition of adhesion of enteroinvasive pathogens to human intestinal Caco-2 cells by Lactobacillus acidophilus LB strain decreases bacterial invasion. FEMS Microbiology. 110, 299-306.

Coconnier, M.H., Bernet, M.F., Chauviere, G., Servin, A.L. (1993b). Adhering heat-killed human Lactobacillus acidophilus, strain LB, inhibits the process of pathogenicity of diarrhoeagenic bacteria in cultured human intestinal cells. Journal of Diarrhoeal Disease Research. 11, 235-242.

Coconnier, M.H., Lievin, V., Bernet-Camard, M.F., Hudault, S. \& Servin, A.L. (1997). Antibacterial effect of the adhering human Lactobacillus acidophilus strain LB. Antimicrobiology Agents and Chemotherapy. 41, 1046-1052. 
Coconnier, M.H., Lievin, V., Lorrot, M. \& Servin, A.L. (1999). Antagonistic Activity of Lactobacillus acidophilus LB against Intracellular Salmonella enterica Serovar Typhimurium Infecting Human Enterocyte-Like Caco-2/TC-7 Cells. Applied and environmental microbiology. 66, 1152-1157.

Código Alimentario Argentino. Capítulo VIII. Alimentos Lácteos, Art 576.

Código Alimentario Argentino. Capítulo VXII. Alimentos de Régimen o Dietéticos, Artículo 1389 (Resolución Conjunta SPRel N²61/2011 y SAGyP N²2/2011).

Código Alimentario Argentino. Capítulo VXII. Alimentos de Régimen o Dietéticos, Artículo 1390 (Resolución Conjunta SPRel N²29/2011 y SAGyP N 731/2011)

Collado, M.C., Gueimonde, M., Hernandez, M., Sanz, Y. \& Salminen, S. (2005). Adhesion of Selected Bifidobacterium Strains to Human Intestinal Mucus and the Role of Adhesion in Enteropathogen Exclusion. Journal of Food Protection. 68, 2672-2678.

Collado, M.C., Meriluoto, J. \& Salminen, S. (2007). Role of commercial probiotic strains against human pathogen adhesion to intestinal mucus. Letters in Applied Microbiology. 45, 454-460.

Coudray, C., Bellanger, J. \& Catilglia-Delavaud, C. (1997). Effect of soluble and partly soluble dietary fibres supplementation on absorption and balance of calcium, magnesium, iron and zinc in healthy young men. European Journal of Clinical Nutrition. $51,375-80$.

Crittenden, R., Weerakkody, R., Sanguansri, L. \& Augustin, M.A. (2006). Synbiotic microcapsules that enhance microbial viability during nonrefrigerated storage and gastrointestinal transit. Applied and Environmental Microbiology. 72, 2280-2282.

Darwin, K.H. \& Miller, V.L. (1999) Molecular Basis of the Interaction of Salmonella with the Intestinal Mucosa. Clinical Microbiology Reviews. 12, 405-428.

Das, J.K., Mishra, D., Ray, P., Tripathy, P., Beuria, T.K., Singh, N. \& Suar, M. (2013). In vitro evaluation of anti-infective activity of a Lactobacillus plantarum strain against Salmonella enterica serovar Enteritidis. Gut Pathogens. 5, artículo 11.

Dashnau, J.L., Sharp, K.A., \& Vanderkooi, J.M. (2005). Carbohydrate intramolecular hydrogen bonding cooperativity and its effect on water structure Journal of Physical. Chemistry. 109, 24152-24159.

Davidson, M.H., Maki, K.C. \& Synecki, C. (1998). Evaluation of the influence of dietary inulin on serum lipids in adults with hypercholesterolemia. Journal of Nutrition. 18, 50317.

Davis, E.A. (1995). Functionality of sugars: physicochemical interactions in foods. The American Journal of Clinical Nutrition. 62, 170-177.

De Kruif, C.G. \& Tuinier, R. (2001). Polysaccharide protein interactions. Food Hydrocolloids. 15, 555-563. 
De Leeuw, E., Li, X.Q., Lu \& W.Y. (2006). Binding characteristics of the Lactobacillus brevis ATCC 8287 surface layer to extracellular matrix proteins. FEMS Microbiol Letters. 260, 210-215.

De Moreno de LeBlanc, A., Matar C., Farnworth, E., Perdigon, G. (2007). Study of immune cells involved in the antitumor effect of kefir in a murine breast cancer model. Journal Dairy Science. 90, 1920-1928.

De Simone, C. (2005). Impact of prebiotics and probiotics on enteric flora. Journal of Pediatric Gastroenterology and Nutrition. 40, 1-40.

De Vrese, M., Keller, B., Barth, C.A. (1992). Enhancement of intestinal hydrolysis of lactose by microbial $\beta$-galactosidase (EC 3.2.1.23) of kefir. British Journal of Nutrition. 67, 67-75.

De Vuyst, L. \& F. Vaningelgem. (2004). Developing new polysaccharides from lactic acid bacteria. 275-320. In B. M. McKenna (ed.), Texture in food, vol. 2. Semi-solid foods. Woodhead Publishing Ltd., Cambridge, United Kingdom.

De Wit, J. N. (1998). Nutritional and functional characteristics of whey proteins in food products. Journal of Dairy Science. 81, 597-608.

Deepika, G. \& Charalampopoulos, D. (2010). Surface and adhesion properties of lactobacilli. Advances in Applied Microbiology. 70, 127-152.

Deepika, G., Green, R.J., Frazier, R.A., Charalampopoulos, D. (2009). Effect of growth time on the surface and adhesion properties of Lactobacillus rhamnosus GG. Journal of Applied Microbiology. 107, 1230-1240.

Del Re, B., Sgorbati, B., Miglioli, M. \& Palenzona, D. (2000). Adhesion, autoaggregation and hydrophobicity of 13 strains of Bifidobacterium longum. Letters in Applied Microbiology. 31, 438-442.

Delzenne, N.M., Neyrinck, A.M. \& Cani, P.D. (2011). Modulation of the gut microbiota by nutrients with prebiotic properties: consequences for host health in the context of obesity and metabolic síndrome. Microbial Cell Factories. 10, 1-10.

Dickinson, E. \& Galazka, Y. B. (1991). Emulsion stabilization by ionic and cova-lent complexes of beta-lactoglobulin with polysaccharides. Food Hydrocolloids. 5, 281-296.

Dickinson, E. \& Izgi, E. (1996). Foam stabilization by protein-polysaccharide complexes. Colloids and Surfaces. Physicochemical and Engineering Aspects. 113,191-201.

Dickinson, E. (1993). Protein-polysaccharide interactions in food colloids. En: E. Dickinson, \& P. Walstra, Food Colloids and polymers: stability and mechanical properties (77- 93). Cambridge, UK: The Royal Society of Chemistry.

Dickinson, E. (1998). Stability and rheological implications of electrostatic milk proteinpolysaccharide interactions. Trend in Food Science and Technology. 9, 347-354. 
Diplock, A.T., Aggett, P.J., Ashwell, M., Bornet, F., Fern, E.B., Roberfroid, M. (1996). Scientific concepts of functional foods in Europe: consensus document. British Journal of Nutrition. 81, 1- 27.

Dissanayake, M., Ramchandran, L., Piyadasa, C. \& Vasiljevic, T. (2013). Influence of heat and $\mathrm{pH}$ on structure and conformation of whey proteins. International Dairy Journal 28 , 56-61.

Dobson A., O'Sullivan O., Cotter P.D., Ross P. \& Hill C. (2011). High throughput sequence based analysis of the bacterial composition of kefir and an associated kefir grain. FEMS Microbiology Letters. 320, 56-62.

Doherty, S.B., Gee, V.L., Ross, R.P., Stanton, C., Fitzgerald, G.F. \& Brodkorb, A. (2011). Development and characterisation of whey protein micro-beads as potential matrices for probiotic protection. Food Hydrocolloids. 25, 1604-1617.

Doherty, S.B., Gee, V.L., Ross, R.P., Stanton, C., Fitzgerald, G.F. \& Brodkorb, A. (2010). Efficacy of whey protein gel networks as potential viability-enhancing scaffolds for cell immobilization of Lactobacillus rhamnosus GG. Journal of Microbiological. 80, 231-241.

Dolz, M., Hernandez, M. J. \& Delegido, J. (2006). Oscillatory Measurements for Salad Dressings Stabilized with Modified Starch, Xanthan Gum and Locust Bean Gum. Journal of Applied Polymer Science. 102, 897-903.

Doublier, J.L., Garnier, C., Renard, D. \& Sanchez, C. (2000). Protein-polysaccharide interactions. Current Opinion in Colloid and Interface Science. 5, 184-196.

Dousset, X. \& Caillet, F. (1993). Aspects microbiologiques et biochimiques de la fermentation du kefir. Microbiologie Aliments Nutrition. 11, 463-470.

Doyle, J.P., Giannouli, P., Martin, E.J., Brooks, M. \& Morris, E.R. (2006). Effect of sugars, galactose content and chainlengthon freeze-thaw gelation of galactomannans. Carbohydrate Polymers. 64, 391-401.

Doyle, R.J. \& Rosenberg, M. (1990). Microbial cell surface hidrophobicity. American Society for Microbiology, American Society of Microbiology, Washington. D.C. 1-38.

Duboc, P. \& Mollet, B. (2001). Applications of exopolysaccharides in the dairy industry. International Dairy Journal. 11, 759-768.

Dumay, E. (1988). Dénaturation thermique de la b-lactoglobuline et proprietes gelifiantes des concentrés protéiques de lactosérum. In D. Lorient, B. Colas, \& M. Le Meste (Eds.), Proprietes fonctionnelles des macromolecules alimentaires (pp. 67-87). Paris: Technique et Documentation.

Dunne, C., O'Mahony, L., Murphy, L., Thornton, G., Morrissey, D., O'Halloran, S., Feeney, M., Flynn, S., Fitzgerald, G., Daly, C., Kiely, B., O'Sullivan, G.C., Shanahan, F. \& Collins, J.K. (2001). In vitro selection criteria for probiotic bacteria of human origin: correlation with in vivo findings. The American Journal of Clinical Nutrition. 73, 386-392. 
Dunnill, P. \& Green, D.W. (1966). Sulphydryl groups and the $N \leftrightarrow R$ conformational change in $\beta$-lactoglobulin. Journal of Molecular Biology. 15, 147-151.

Durant, J.A., Corrier, D.E., Byrd, J.A., Stanker, L.H. \& Ricke, S.C. (1999). Feed deprivation affects crop environment and modulates Salmonella enteritidis colonization and invasion of leghorn hens. Applied and Environmental Microbiology. 65, 1919-1923.

Durant, J.A., Lowry, V.K., Nisbet, D.J., Stanker, L.H., Corrier, D. E. \& Ricke, S. C. (2000). Late logarithmic Salmonella typhimurium HEp-2 cell association and invasion response to short-chain fatty acid addition. Journal of Food Safety. 20, 1-11.

Edwards, P.B., Creamer, L.K. \& Jameson, G.B. Structure and stability of whey proteins. (2009) In Milk Proteins, from Expression to Food, 1 edn. Edited by Thompson A, Boland, M.J., Singh, H., Amsterdam: Elsevier, Academic Press. 161-203. Taylor SL (Series Editor): Food Science and Technology, International Series.

Ehrmann M.A., Kurzak P., Bauer J. \& Vogel R.F. (2002). Characterization of lactobacilli towards their use as probiotic adjuncts in poultry. Journal of Applied Microbiology. 92, 966-975.

Elofsson, C., Dejmek, P., Paulsson, M. \& Burling, H. (1997)Characterization of a coldgelling whey protein concentrate. International Dairy Journal. 7, 601-608.

Evageliou, V., Richardson, R. K. \& Morris, E.R. (2000b). Effect of pH, sugar type and thermal annealing on high-methoxy pectin gels. Carbohydrates Polymers, 42, 245-259.

Evageliou, V., Richardson, R.K, \& Morris, E.R. (2000a). Effect of sucrose, glucose and fructose on gelation of oxidised starch. Carbohydrate Polymers, 42, 261-272.

Fábrega, A. \& Vila, J. (2013). Salmonella enterica serovar Typhimurium skills to succeed in the host: Virulence and regulation. Clinical Microbiology Reviews. 26, 308-341.

FAO/WHO (2002). Joint FAO/WHO (Food and Agriculture Organization/World Health Organization) working group report on drafting guidelines for the evaluation of probiotics in food. London, Ontario, Canada. Guidelines for the evaluation of probiotics in food. Joint working group report on drafting. London, Ontario, 2002: 1-11.

Farnworth, E.R. (2005). Kefir: a complex probiotic. Food Science and Technology Bulletin: Functional Foods. 2, 1-17.

Fayol-Messaoudi, D., Berger, C., Coconnier-Polter, M-H., Lievin-Le Moal, V. \& Servin, A. (2005). pH, lactic acid, and non lactic acid dependent activities of probiotic lactobacilli against Salmonella enterica serovar Typhimurium. Applied and Environmental Microbiology. 71, 6008-6013.

Fernandez, M., Boris, S. \& Barbes, C. (2003). Probiotic properties of human lactobacilli strains to be used in the gastrointestinal tract. Journal of Applied Microbiology. 94, 449-455.

Ferry, J. D. (1980). Viscoelstic properties of polymers. 486-544, John Wilet \& sons, New York. 
Finlay, B. B., Ruschkowski, S. \& Dedhar, S. (1991). Cytoskeletal rearrangements accompanying Salmonella entry into epithelial cells. Journal of Cell Science. 99, 283-296.

Fitzsimons, S.M., Mulvihill, D.M. \& Morris, E.R. (2008). Large enhancements in thermogelation of whey protein isolate by incorporation of very low concentrations of guar gum. Food Hydrocolloids. 22, 576-586.

Foegeding, E.A., Bowland, E.L. \& Hardin, C.C. (1995). Factors that determine the fracture properties and microstructure of globular protein gels. Food Hydrocolloids. 9, 237-249.

Foegeding, E.A., Davis, J.P., Doucet, D. \& McGuffey, M. K. (2002). Advances in modifying and understanding whey protein functionality. Trends in Food Science \& Technology. 13, 151-159.

Fontenla de Petrino, S., Bibas Bonet, M.E., Mesón, O. \& Perdigón, G. (2002). The effect of Lactobacillus casei on an experimental model of atopy. Food and Agricultural Immunology. 14, 181-189.

Fooks, L.J. \& Gibson, G.R. (2002a). In vitro investigations of the effect of probiotics and prebiotics on selected human intestinal pathogens. FEMS Microbiology Ecology. 39, 67-75.

Fooks, L.J. \& Gibson, G.R. (2002b). Probiotics as modulators of the gut flora. British Journal of Nutrition. 88, 39-49.

Forestier, C., De Champs, C., Vatoux, C. \& Joly, B. (2001). Probiotic activities of Lactobacillus casei rhamnosus: in vitro adherence to intestinal cells and antimicrobial properties. Research in Microbiology. 152, 167-173.

Forrest, S.A., Yada, R.Y. \& Rousseau, D. (2005). Interactions of vitamin D3 with bovine $\beta$ lactoglobulin and casein. Journal of Agricultural Food Chemistry. 53, 8003-9.

Fox, P.F. \& McSweeney, P.L.H. (2003). Advanced Dairy Chemistry, Proteins Part A, vol. 1, 3 edn. New York: Kluwer Academic/Plenum Publishers.

Friedman, H.H., Whitney, J.E. \& Szczesniak, A.S. (1963) The Texturometer-A New Instrument for Objective Texture Measurement. Journal of Food Science. 28, 390-396.

Fuente: Sistema de Información Regional para la Vigilancia Epidemiológica de las Enfermedades Transmitidas por Alimentos [SIRVETA].

Fujisawa, T., Adachi, S., Toba, T., Arihara, K. \& Mitsuoka, T. (1988). Lactobacillus kefiranofaciens sp. nov. isolated from kefir grains. International Journal of Systematic Bacteriology. 38, 12-14.

Fuller, R. (1997). Introduction. In: Probiotics 2, Applications and practical aspects, Chapman and Hall. London. New York, 1-9.

Funmilola, A.A., Sánchez, B., Adeniyi, B.A., de los Reyes-Gavilán C.G., Margolles, A. \& Ruas-Madiedo, P. (2011). Evaluation of the functional potential of Weissella and Lactobacillus isolates obtained from Nigerian traditional fermented foods and cow's intestine. International Journal of Food Microbiology. 147, 97-104. 
Furtado Martins, E.M., Mota Ramos, A., Lago Vanzela, E.S., Stringheta, P.C., de Oliveira Pinto, C.L. \& Martins, J.M. (2013). Review -Products of vegetable origin: A new alternative for the consumption of probiotic bacteria. Food Research International. 51. 764-770.

Furukawa, N., liyama, R., Takahashi, T. \& Yamanaka, Y. (1992). Effect of oral administration of water soluble fraction from kefir grain on antibody production in mice. Animal Science Technology. 63, 428-436.

Gaon, D., Doweck, Y., Zavaglia, A., Holgado, A. \& Oliver, G. (1995). Lactose digestion by milk fermented with human strains of Lactobacillus acidophilus and Lactobacillus casei. Medicina. 55, 237-242.

Gaon, D., Garcia, H., Winter, L., Rodriguez, N., Quintas, R., Gonzalez, S.N. \& Oliver, G. (2003). Effect of Lactobacillus strains and Saccharomyces boulardii on persistent diarrhea in children. Medicina; 63:293-298. Trabajo de actualización diaeta. (B.Aires). 25, 121.

Gaon, D., Garmendia, C., Murrielo, N.O., de Cucco Games, A., Cerchio, A., Quintas, R., Gonzalez, S.N. \& Oliver, G. (2002). Effect of Lactobacillus strains (L. casei and L. acidophilus Cerela) on bacterial overgrowth-related chronic diarrhea. Medicina. 62, 159163.

Garbers, I., Britz, T.J., Witthuhn, R. C. (2004). PCR-based denaturing gradient gel electrophoretictypification and identification of the microbial consortium present in kefir grains. World Journal of Microbiology and Biotechnology. 20, 687-693.

Gardiner, G.E., Casey, P.G., Casey, G., Lynch, B., Lawlor, P.G., Hill, C., Fitzgerald, G.F., Stanton, C., Ross, R.P. (2004). Relative ability of orally administ ered Lactobacillus murinus to predominate and persist in the porcine gastrointestinal tract. Applied and Environmental Microbiology. 70, 1895-1906.

Garrote G.L., Abraham A.G., De Antoni G.L. (2010). Microbial Interactions in Kefir: A Natural Probiotic Drink. In Biotechnology of Lactic Acid Bacteria: Novel Applications. 18, 327-340.

Garrote, G.L., Abraham, A.G. \& De Antoni G.L. (2001). Chemical and microbiological characterisation of kefir grains. Journal of Dairy Research. 68, 639-652.

Garrote, G.L., Abraham, A.G. \& De Antoni, G.L. (1997). Preservation of kefir grain, a comparative study. Lebensmittel, Wissenchaft u Technologie. 30, 77-84.

Garrote, G.L., Abraham, A.G. \& De Antoni, G.L. (2000). Inhibitory power of kefir: The role of organic acids. Journal of Food Protection. 63, 364-369.

Garrote, G.L., Abraham, A.G., \& De Antoni, G.L. (1998). Characteristics of kefir prepared with different grain: milk ratios. Journal of Dairy Research. 65, 149-154.

Gault, P. \& Fauquant, J. (1992). Heat-induced gelation of $\beta$-lactoglobulin-Influence of $\mathrm{pH}$, ionic-strength and presence of other whey proteins. Dairy Science Technology. 72, 491-510. 
Gawkowski, D. \& Chikindas, M.L. (2013). Non-dairy probiotic beverages: the next step into human health. Beneficial Microbes. 4: 127-42.

Gibson, G.R., Beatty, E.B., Wang, X. \& Cummings, J.H. (1995). Selective stimulation of bifidobateria in human colon by oligofructose and inulin. Gastroenterology. 108, 975-82.

Gill, H. S. \& Rutherfurd, K. J. (2001). Immune enhancement conferred by oral delivery of Lactobacillus rhamnosus HNOO1 in different milk-based substrates. Journal of Dairy Research. 68, 611-616.

Global Industry Analysts, Inc., 2012

Golowczyc, M.A. (2008). Tesis doctoral: Caracterización taxonómica, probiótica y tecnológica de lactobacilos aislados de kefir. Facultad de Ciencias Exactas, Universidad Nacional de La Plata.

Golowczyc, M.A., Gugliada, M.J., Hollmann, A., Delfederico, L, Garrote, G.L., Abraham, A.G., Semorile, L., De Antoni, G.L. (2008). Characterization of homofermentative lactobacilli isolated from kefir grains: potential use as probiotic. Journal Dairy Reserch. 75, 211-217.

Golowczyc, M.A., Mobili, P., Garrote, G.L., Abraham, A.G., De Antoni, G.L. (2007). Protective action of Lactobacillus kefir carrying S-layer protein against Salmonella enterica serovar Enteritidis. Internationaal Journal Food Microbiology. 118, 264-273.

Golowczyc, M.A., Mobili, P., Garrote, G.L., De Los Angeles Serradell, M., Abraham, A.G., De Antoni, G.L. (2009). Interaction between Lactobacillus kefir and Saccharomyces lipolytica isolated from kefir grains: Evidence for lectin-like activity of bacterial surface proteins. Journal of Dairy Research. 76, 111-116.

Gonzalez, S., Albarracin, G., Locascio de Ruiz Pesce, M., Male, M., Apella, M.C., Pesce de Ruiz Holgado, A. \& Oliver, G. (1990). Prevention of infantile diarrhea by fermented milk. Microbiologie-Aliments Nutrition. 8, 349-354.

González-Rodríguez, I., Sánchez, B., Ruiz, L., Turroni, F., Ventura, M, Ruas-Madiedo, P., Gueimonde, M. \& Margolles, A. (2012). Role of extracellular transaldolase from Bifidobacterium bifidum in mucin adhesion and aggregation. Applied and Environmental Microbiology. 78, 3992-3998.

Gopal, P.K., Prasad, J., Smart, J. \& Gill, H.S. (2001). In vitro adherence properties of Lactobacillus rhamnosus DR20 and Bifidobacterium lactis DR10 strains and their antagonistic activity against an enterotoxigenic Escherichia coli. International Journal Food Microbiology. 67, 207-216.

Grimoud, J., Durand, H., Courtin, C., Monsan, P., Ouarné, F., Theodorou, V., Roques, C. (2010). In vitro screening of probiotic lactic acid bacteria and prebiotic glucooligosaccharides to select effective synbiotics. Anaerobe. 16, 493-500.

Grinberg, V.Y. \& Tolstoguzov, V.B. (1997). Thermodynamic incompatibility of proteins and polysaccharides in solutions. Food Hydrocolloids. 11, 145-158. 
Grupo de trabajo Alimentos Funcionales INAL - ANMAT. Los alimentos y las enfermedades, Boletín para consumidores $\mathrm{N}^{\circ} 18$ y 19, mayo 2003.

Guarner, F., Perdigon, G., Corthier, G., Salminen, S., Koletzko, B. \& Morelli L. (2005). Should yoghurt cultures be considered probiotic? British Journal of Nutrition. 93, 783-786.

Guerin-Danan, C., Chabanet, C., Pedone, C., Popot, F., Vaissade, P., Bouley, C., Szylit, O. \& Andrieux, C. (1998). Milk fermented with yogurt and Lactobacillus casei compared with yogurt and gelled milk: influence on intestinal microflora in healthy infants. American Journal of Clinical Nutrition. 67, 111-117.

Gulmez, M. \& Guven, A. (2003). Survival of Escherichia coli 0157:H7, Listeria monocytogenes $4 \mathrm{~b}$ and Yersinia enterocolitica $\mathrm{O} 3$ in different yogur and kefir combinations as prefermentation contaminant. Journal of Applied Microbiology. 95, 631-636.

Gurov, A.N., \& Nuss, P.V. (1986). Protein-polysaccharide complexes as surfactants. Nahrung Food. 30, 349-353.

Ha, E. \& Zemel, M. B. (2003). Functional properties of whey, whey components, and essential amino acids: mechanisms underlying health benefits for active people (review). The Journal of Nutritional Biochemistry. 14, 251-258.

Haeri, A., Khodaii, Z., Ghaderian, S.M.H., Panah, A.S.T. \& Najar, R.A. (2012). Comparison of adherence patterns of a selection of probiotic bacteria to Caco-2, HEp-2, and T84 cell lines. Annals of Microbiology. 62, 339-344.

Halle, C., Leroi, F., Dousset, X., Pidoux, M. (1994). Les kefirs. Des associations bacteries lactique-levures. In: Bacteries lactiques: aspects fondamentaux et technologiques. 2, 169-182. Eds.: de Roissart, H. \& Luquet, F. M.

Hamet, M. F., Londero, A., Medrano, M., Vercammen, E., Van Hoorde, K., Garrote, G. L., Geert Huys, Vandammec, P. \& Abraham, A. G. (2013). Application of culture-dependent and culture-independent methods for the identification of Lactobacillus kefiranofaciens in microbial consortia present in kefir grains. Food Microbiology. 36, 327-334.

Hébrard, G., Blanquet, S., Beyssac, E., Remondetto, G., Subirade, M. \& Alric, M. (2006). Use of whey protein beads as a new carrier system for recombinant yeasts in human digestive tract. Journal of Biotechnology. 15, 151-60.

Heenan, C.N., Adams, M.C., Hosken, R.W. \& Fleet, G.H. (2004). Survival and sensory acceptability of probiotic microorganisms in a non-fermented frozen vegetarian dessert. Lebensmittel Wissenschaft Und Technologie. 37, 461-466.

Heidebach, T., Först, P., Kulozik, U. (2009). Microencapsulation of probiotic cells by means of rennet-gelation of milk proteins. Food Hydrocolloids. 23, 1670-1677.

Hertzler, S.R. \& Clancy S.M. (2003). Kefir improves lactose digestion and tolerance in adults with lactose maldigestion. Journal of the American Dietetic Association. 103, 582-587. 
Higashi, S. \& Micato-Ku. (2006). Lactobacilos casei Shirota y Virus de la Influenza, Boletín Probiótico $N^{\circ} 11$ Yakult, Argentina. 14, 37-0300.

Hoffmann, M.A.M. \& Van Mil, P.J.J.M. (1997). Heat-induced aggregation of $\hat{a}-$ lactoglobulin: role of the free thiol group and disulphide bonds. Journal of Agricultural Food Chemistry. 45, 2942-2948.

Hoffmann, M.A.M., Roefs, S.P.F.M., Verheul, M., van Mil, P.J.J.M. \& de Kruif, K.G. (1996). Aggregation of $\beta$-lactoglobulin studied by in situ light scattering. Journal of Dairy Research. 63, 423-440.

Holt, C. (2000). Molecular basis of whey protein food functionalities. Australian Journal of Food Science and Technology. 55, 53-55.

Huang, Y., Wang, X., Wang, J., Wu, F., Sui, Y., Yang, L., Wang, Z. (2013a). Lactobacillus plantarum strains as potential probiotic cultures with cholesterol-lowering activity. Journal of Dairy Science. 96, 2746-2753.

Huang, Y., Wu, F., Wang, X., Sui, Y., Yang, L., Wang, J. (2013b). Characterization of Lactobacillus plantarum Lp27 isolated from Tibetan kefir grains: A potential probiotic bacterium with cholesterol-lowering effects. Journal of Dairy Science. 96, 2816-2825.

Huang, Y.B., Wang, R.J., Chang, J.S., Tsai, Y.H. \& Wu, P.C. (2007). Evaluation of ketoprofen formulations via penetration rate and irritation in vivo study. International Journal of Pharmaceutics. 339, 47-51.

Hudault, S., Lievin, V., Bernet-Camard, M.F. \& Servin, A.L. (1997). Antagonistic activity exerted in vitro and in vivo by Lactobacillus casei (strain GG) against Salmonella typhimurium C5 infection. Applied and Environmental Microbiology. 63, 513-518.

Huffman, L.M. (1996). Processing whey protein for use as food ingredient. Food Technology. 51, 89-93.

Hugo, A., Kakisu, E., De Antoni, G. \& Pérez, P.F. (2008). Lactobacilli antagonize biological effects of enterohaemorragic Escherichia coli in vitro. Letter in Applied Microbiology. 46, 613-619.

Ismaiel, A.A., Ghaly, M.F. \& El-Naggar, A.K. (2011). Milk kefir: Ultrastructure, antimicrobial activity and efficacy on aflatoxin b1 production by Aspergillus flavus. Current Microbiology. 62, 1602-1609.

Isolauri, E., Salminen, S. \& Ouwehand, A.C. (2004). Probiotic. Best Practice \& Research Clinical Gastroenterology. 18, 299-313.

Isoulari, E., Juntunen, M. \& Rautanen, T. (1991). A human Lactobacillus strain (Lactobacillus casei GG) promotes recovery from acute diarrhea in children. Pediatrics. 88, 90-7.

Jacobsen, C.N., Nielsen, V.R., Hayford, A.E., Moller, P.L., Michaelsen, K.F., Paerregaard, A., Sandstrom, B., Tvede, M. \& Jakobsen, M. (1999). Screening of probiotic activities of forty-seven strains of Lactobacillus spp. by in vitro techniques and evaluation of the 
colonization ability of five selected strains in humans. Applied and Environmental Microbiology. 65, 4949-4956.

Jacson, T.G., Taylor, G.R.J. \& Clohessy, A.M. (1999). The effects of the daily intake of inulin on fasting lipid, insulin and glucose concentration in middle-aged men and women. British Journal of Nutrition. 89, 23-30.

Jianzhong, Z., Xiaoli, L. B., Hanhu, J. \& Mingsheng, D. (2009). Analysis of the microflora in Tibetan kefir grains using denaturing gradient gel electrophoresis. Food Microbiology. 26, 770-775.

Jin, L.Z., Ho, Y.W., Ali, M.A., Abdullah, N., Jalaludin S. (1996). Effect of adherent Lactobacillus spp. on in vitro adherence of Salmonella to the intestinal epithelial cells of chicken. Journal of Applied Bacteriology. 81, 201-206.

Jolly, L., Vincent, S., Duboc, P. \& Neeser, J. R. (2002). Exploiting exopolysaccharides from lactic acid bacteria. Antonie van Leeuwenhoek. 82,367-374.

Jones, O.G., Decker, E.A. \& McClements, D.J. (2009). Formation of biopolymer particles by thermal treatment of b-lactoglobulin-pectin complexes. Food Hydrocolloids. 23, 1312-1321.

Jones, O.G., Lesmes, U., Dubin, P. \& McClements, D.J. (2010). Effect of polysaccharide charge on formation and properties of biopolymer nanoparticles created by heat treatment of $\beta$-lactoglobulin-pectin complexes. Food Hydrocolloids. 24, 374-383.

Ju, Z. Y. \& Kilara, A. (1998). Effects of preheating on properties of aggregates and of coldset gels of whey protein isolate. Journal of Agricultural Food Chemistry. 46, 3604-3608.

Kakisu, E.J., Abraham, A.G., Pérez, P.F. \& De Antoni, G.L. (2007). Inhibition of Bacillus cereus in milk fermented with kefir grains. Journal of Food Protection. 70, 2613-2616.

Kalliomaki M., Salminen S. \& Isolauri E. (2008). Positive interactions with the microbiota: probiotics. Advances in Experimental Medicine and Biology. 635, 57-66.

Kandler, O. \& Kunath, P. (1983). Lactobacillus kefir sp. nov., a component of the microflora of kefir. Systematic and Applied Microbiology. 4, 286-294.

Kinsella, J.E., \& Whitehead, D.M. (1989). Proteins in whey: chemical, physical, and functional properties. In E. K. John (Ed.), Advances in food and nutrition research. 33, 343-438. Academic Press.

Kociubinski, G., Pérez, P. \& De Antoni, G.L. (1999). Screening of bile resistance and bile precipitation in lactic acid bacteria and bifidobacteria. Journal of Food Protection. 62, 905-912.

Kolenbrander, P. E. (1991). Microbial Cell-Cell interactions, Dworkin M. (ed.), American Society for Microbiology, Washington D. C., 303.

Kooiman P. (1968). The chemical structure of kefiran, the water-soluble polysaccharide of kefir grain. Carbohydrate Research. 7, 200-211. 
Koroleva N. S. (1988). Starters for fermented milks, section 4: kefir and kumys starters. Bulletin of the International Dairy Federation. 227, 35-40.

Koroleva, N.S. (1991). Products prepared with lactic acid bacteria and yeasts. Elsevier Applied Sciences Publishers. 159-179.

Krzeminski, A., Prell, K.A., Busch-Stockfisch, M., Weiss, J., Hinrichs, J. (2014). Whey protein-pectin complexes as new texturising elements in fat-reduced yogurth systems. International Dairy Journal. 36, 118-127.

Kurmann, J.A. \& Rasic, J.L. (1991). The health potential of products containing bifidobacteria. In: Robinson, R.K. (Ed.), Therapeutic properties of fermented milks. Elsevier. 117-158.

La Riviére J.W.M., Kooiman P. \& Schmidt K. (1967). Kefiran, a novel polysaccharide produced in the Kefir grain by Lactobacillus brevis. Archiv für Mikrobiologe. 59, 269-278.

Laemmli, U. K. (1970). Cleavage of Structural Proteins during the Assembly of the Head of Bacteriophage T4. Nature 227, 680-685.

Laiho, K., Ouwehand, A., Salminen, S. \& Isolauri, E. (2002). Inventing probiotic functional foods for patients with allergic disease. Ann Allergy Asthma Immunology. 89, 75-82.

Lajolo, F. M. (2002). Functional foods: Latin American perspectives. British Journal of Nutrition. 88 145-150.

Laneuville, S.I., Paquin, P. \& Turgeon, S.L. (2005). Formula optimization of a low-fat food system containing whey protein isolate-xanthan gum complexes as fat replacer. Journal of Food Science. 70, 513-519.

Langton, M. \& Hermansson, A.M. (1992). Fine-stranded and particulate gels of $\beta$-lactoglobulin and whey protein at varying pH. Food Hydrocolloids. 5, 523-539.

Latorre García, L., Del Castillo-Agudo, L. \& Polaina, J. (2007). Taxonomical classification of yeasts isolated from kefir based on the sequence of their ribosomal RNA genes. World Journal of Microbiology and Biotechnology. 23, 785-791.

Laurienzo, P., Malinconico, M., Pizzano, R., Manzo, C., Piciocchi, N., Sorrentino, A. \& Volpe, M.G. (2006). Natural polysaccharide-based gels for dairy food preservation. Journal Dairy Science. 89, 2856-64.

Lawhon, S.D., Maurer, R., Suyemoto, M. \& Altier, C. (2002). Intestinal short-chain fatty acids alter Salmonella typhimurium invasion gene expression and virulence through BarA/SirA. Molecular Microbiology. 46, 1451-1464.

Laws, A. \& Marshall, V. (2001b). The relevance of exopolysaccharides to the rheological properties in milk fermented with ropy strains of lactic acid bacteria. International Dairy Journal. 11, 709-721.

Laws, A., Gu, Y. \& Marshall, V. (2001a) Biosynthesis, characterization, and design of bacterial exopolysaccharides from lactic acid bacteria. Biotechnology Advances. 19, 597-625. 
Lazaridou, A., Vaikousi, H. \& Biliaderis, C.G. (2008). Effects of polyols on cryostructurization of barley $\beta$-glucans. Food Hydrocolloids. 22, 263-277.

Lee M.Y., Ahn K.S., Kwon O.K., Kim M.J., Kim M.K., Lee I.Y., Oh S.R., Lee H.K. (2007). Antiinflammatory and anti-allergic effects of kefir in a mouse asthma model. Immunobiology. 212, 647-654.

Lee, Y.K. \& Puong, K.Y. (2002). Competition for adhesion between probiotics and human gastrointestinal pathogens in the presence of carbohydrate. British Journal of Nutrition. 88, 101-108.

Lee, Y.K., Lim, C.Y., Teng, W.L., Ouwehand, A.C., Tuomola, E.M. \& Salminen, S. (2000). Quantitative approach in the study of adhesion of lactic acid bacteria to intestinal cells and their competition with enterobacteria. Applied and Environmental Microbiology. 66, 3692-3697.

Lee, Y.K., Puong, K.Y., Ouwehand, A.C. \& Salminen, S. (2003). Displacement of bacterial pathogens from mucus and Caco-2 cell surface by lactobacilli. Journal of Medical Microbiology. 52, 925-930.

Lick, S., Drescher, K. \& Heller, K.J. (2001). Survival of Lactobacillus delbrueckii subsp. bulgaricus and Streptococcus thermophilus in the terminal ileum of fistulated Gottingen minipigs. Applied and Environmental Microbiology. 67, 4137-4143.

Lin, C.-K., Tsai, H.-C., Lin, P.-P., Tsen, H.-Y. \& Tsai, C.-C. (2008). Lactobacillus acidophilus LAP5 able to inhibit the Salmonella choleraesuis invasion to the human Caco-2 epithelial cell. Anaerobe. 14, 251-255.

Liong, M.T., Shah, N.P. (2005). Acid and bile tolerance and cholesterol removal ability of lactobacilli strains. Journal of Dairy Science. 88, 55-66.

Liu, J.R., Wang, S.Y., Lin, Y.Y. \& Lin, C.W. (2002). Antitumor activity of milk kefir and soy milk kefir in tumor-bearing mice. Nutrition and Cancer. 44, 182-187.

Liu, J-R., Wang, S-Y., Chen, M., Chen, H., Yueh, P., Lin, C-W. (2006). Hypocholesterolaemic effects of milk-kefir and soyamilk-kefir in cholesterol-fed hamsters. British Journal of Nutrition. 95, 939-946.

Livney, Y.D. (2010). Milk Proteins as vehicles for bioactives. Current Opinion in Colloids and Surface Science. 15, 73-83.

Lombardi, A.M., Bevilaqua, A.E. \& Califano, A.N. (1994). Variation in organic acids content during ripeninig of Reggianito cheese in air-tight sealed bags. Food Chemistry. 51, 221-226.

Londero, A. (2012). Tesis doctoral: Alimentos funcionales: Obtención de un producto probiótico para aves a partir de suero de quesería fermentado con microorganismos de kefir. Facultad de Ciencias Exactas, Universidad Nacional de La Plata. 
Londero, A., Hamet, M.F., De Antoni, G.L., Garrote, G.L., Abraham, A.G. (2012). Kefir grains as starter for whey fermentation at different temperatures: chemical and microbiological characterization. Journal of Dairy Research. 79, 262-271.

Londero, A., León Peláez, M.A., Diosma, G., De Antoni, G.L., Abraham, A.G. \& Garrote, G.L. (2014). Fermented whey as poultry feed additive to prevent fungal contamination. Journal of the Science of Food and Agriculture. 94, 3189-3194

Lopitz-Otsoa, F., Rementeria, A., Elguezabal, N., Garaizar, J. (2006). Kefir: A symbiotic yeasts-bacteria community with alleged healthy capabilities. Revista Iberoamericana de Micología. 23, 67-74.

Lorca, G., Torino, M.I., Font de Valdez, G. \& Ljungh, A.A. 2002. Lactobacilli express cell surface proteins which mediate binding of immobilized collagen and fibronectin. FEMS Microbiology Letters. 206, 31-37.

Lozinsky, V., Galaev, I.Y., Plieva, F.M., Savina, I.M., Jungvid, H., \& Mattiasson, B. (2003). Polymeric cryogels as promising materials of biotechnological interest. Trends in Biotechnology. 21, 445-451.

Lupano, C.E., Dumay, E. \& Cheftel, J.C. (1992). Gelling properties of whey protein isolate: influence of calcium removal by dialysis or diafiltration at acid or neutral $\mathrm{pH}$. International Journal of Food Science and Technology. 27, 615-628.

Lupano, C.E., Renzi, L.A. \& Romera, V. (1996). Gelation of whey protein concentrate in acidic conditions: effect of $\mathrm{pH}$. Journal of Agricultural and Food Chemistry. 44, 3010-3014.

Macfarlane, G. \& Cummings, J. (1999). Probiotics and prebiotics: can regulating the activities of intestinal bacteria benefit health? British Medical Journal. 318, 999-1003.

Maciel, B.M., Sriranganathan, N., Romano, C.C., dos Santos, T.F., Dias, J.C.T., Gross, E. \& Rezende, R.P. (2012). Infection cycle of Salmonella enterica serovar Enteritidis in latent carrier mice. Canadian Journal of Microbiology. 58, 1389-1395.

Maeda, H., Zhu, X., Omura, K., Suzuki, S. \& Kitamura, S. (2004a). Structural characterization and biological activities of an exopolysaccharide kefiran produced by Lactobacillus kefiranofaciens WT-2B(T). Journal of Agricultural and Food Chemistry. 52, 5533-5538.

Maeda, H., Zhu, X., Omura, K., Suzuki, S., Kitamura, S. (2004b). Effects of an exopolysaccharide (kefiran) on lipids, blood pressure, blood glucose, and constipation. BioFactors (Oxford, England). 22, 197-200.

Magalhães, K.T., Pereira, M.A., Nicolau, A., Dragone, G., Domingues, L. \& Teixeira, J.A. (2010). Production of fermented cheese whey-based beverage using kefir grains as starter culture: Evaluation of morphological and microbial variations. Bioresource Technology. 101, 8843-8850. 
Magra, T.I., Antoniou, K.D. \& Psomas, E.I. (2012). Effect of milk fat, kefir grain inoculum and storage time on the flow properties and microbiological characteristics of kefir. Journal of Texture Studies. 43, 299-308.

Mainville, I., Arcand, Y. \& Farnworth, E. R. (2005) A dynamic model that simulates the human upper gastrointestinal tract for the study of probiotics. International Journal of Food Microbiology, 99, 287-296.

Makras, L., Triantafyllou, V., Fayol-Messaoudi, D., Adriany, T., Zoumpopoulou, G. \& Tsakalidou, E. (2006). Kinetic analysis of the antibacterial activity of probiotic lactobacilli towards Salmonella enterica serovar Typhimurium reveals a role for lactic acid and other inhibitory compounds. Research in Microbiology. 157, 241-247.

Maldonado Galdeano, C. \& Perdigón, G. (2004). Role of viability of probiotics strains in their persistente in the gut and in mucosal immune stimulation. Journal Applied Microbiology. 97,673-681.

Maragkoudakis, P.A., Zoumpopoulou G., Miaris C., Kalantzopoulos G., Pot B. \& Tsakalidou E. (2006). Probiotic potential of Lactobacillus strains isolated from dairy products. International Dairy Journal. 16, 189-199.

Marco Trade News, 2012

Marcos, A., Wärnberg, J., Nova, E., Gómez, S., Alvarez, A., Alvarez, R., Mateos, J.A., Cobo, J.M. (2004). The effect of milk fermented by yogurt cultures plus Lactobacillus casei DN114001 on the immune response of subjetcs under academic examination stress. Europe Journal of Nutrition. 6, 381-389.

Margulis, L. (1996). From kefir to death. In: How things are. 69-78. William Morrow and Co. New York, USA.

Marquina, D., Santos, A., Corpas, I., Munoz, J., Zazo, J. \& Pienado, J.M. (2002). Dietary influence of kefir on microbial activities in the mouse bowel. Letters in Applied Microbiology. 35, 136-140.

Marteau, P., Cuillerier, E., Meance, S., Gerhardt, M.F., Myara, A., Bouvier, M., Bouley, C., Tondu, F., Bommelaer, G. \& Grimaud, J.C. (2002). Bifidobacterium animalis strain DN173-010 shortens the colonic transit time in healthy women: a double-blind, randomized, controlled study. Alimentary Pharmacology and Therapeutics. 16, 587-593.

Marteau, P., Pochart, P., Bouhnik, Y. \& Ramband, J.C. (1993). The fate and effects of transiting nonpathogenic microrganisms in the human intestine. World Review Nutrition and Dietetics. 74, 1-21.

Marteau, P., Vesa, T. \& Rambaud, J.C. (1997). Lactose malabsorption. In: Fuller R, ed. Probiotics 2: applications and practical aspects. London: Chapman \& Hall. 65-88.

Martins, F.S., Dalmasso, G., Arantes, R.M.E., Doye, A., Lemichez, E., Lagadec, P., Imbert, V., Peyron, J.F., Rampal, P., Nicoli, J.R. \& Czerucka, D. (2010). Interaction of Saccharomyces boulardii with Salmonella enterica serovar Typhimurium protects mice and modifies T84 cell response to the infection. PLOS ONE, 5 art. $\mathrm{N}^{\circ}$. e8925 5, 1-12. 
Matsumoto, M., Tani, H., Ono, H., Ohishi, H. \& Benno, Y. (2002). Adhesive property of Bifidobacterium lactis LKM512 and predominant bacteria of intestinal microflora to human intestinal mucin. Current Microbiology. 44, 212-215.

Maurer, S., Junghans, A. \& Vilgis, T.A. (2012). Impact of xanthan gum, sucrose and fructose on the viscoelastic properties of agarose hydrogels. Food Hydrocolloids. 29, 298-307.

Mazeau, K. \& Rinaudo, M. (2004). The prediction of the characteristics of some polysaccharides from molecular modelling. Comparison with effective behaviour. Food Hydrocolloids. 18, 885-898.

McClements, D.J. (2006). Non-covalent interactions between proteins and polysaccharides. Biotechnology Advances. 24, 621-625.

Meance, S., Cayuela, C., Raimondi, A., Turchet, P., Lucas, C. \& Antoine, J.M. (2003). Recent advances in the use of Functional Foods: effects of the commercial fermented milk with Bifidobacterium animalis strain DN-173 010 and yoghurt strains on gut transit time in the elderly. Microbial Ecology in Health and Disease. 15, 15-22.

Meance, S., Cayuela, C., Turchet, P., Raimondi, A., Lucas, C. \& Antoine, J.M. (2001). A fermented milk with a Bifidobacterium Probiotic Strain DN- 173010 shortened oro-fecal gut transit time in elderly. Microbial Ecology in Health and Disease. 13, 217-222.

Medici, M., Vinderola, C.G. \& Perdigón, G. (2004). Gut mucosal immunostimulation by probiotic fresh cheese. International Dairy Journal. 14, 611-618.

Medrano, M., Hamet, M.F., Abraham, A.G. \& Pérez, P.F. (2009). Kefiran protects Caco-2 cells from cytopathic effects induced by Bacillus cereus infection. Journal Antonie van Leeuwenhoek. 96, 505-505.

Medrano, M., Pérez, P.F. \& Abraham, A.G. (2008). Kefiran antagonizes cytopathic effects of Bacillus cereus extracellular factors. International Journal of Food Microbiology. 122, 1-7.

Medrano, M., Racedo, S.M., Rolny, I.S., Abraham, A.G. \& Pérez, P.F. (2011). Oral administration of kefiran induces changes in the balance of immune cells in a murine model. Journal of Agricultural and Food Chemistry. 59, 5299-5304.

Mellema, M., van Opheusden, J.H.J. \& van Vliet, T. (2002).Categorization of rheological scaling models for particle gels applied to casein gels. Journal of Rheology. 46, 11.

Michelli, L., Uccelletti, D., Palleschi, C. \& Crescenzi, V. (1999). Isolation and characterisation of a ropy Lactobacillus strain producing the exopolysaccharide kefiran. Applied Microbiology and Biotechnology. 53, 69-74.

Minelli, E.B., Benini A., Marzotto, M., Sbarbati, A., Ruzzenente, O., Ferrario, R., Hendriks, H. \& Dellaglio, F. (2004). Assessment of novel probiotic Lactobacillus casei strains for the production of functional dairy foods. International Dairy Journal. 14, 723-736. 
Mobili, P., Londero, A., Maria, T.M.R., Eusébio, M.E.S., De Antoni, G.L., Fausto, R. \& Gómez-Zavaglia, A. (2009). Characterization of S-layer proteins of Lactobacillus by FTIR spectroscopy and differential scanning calorimetry. Vibrational Spectroscopy. 50, 68-77.

Molska, I., Moniuszco, I., Komorows, K.A.M. \& Merilanen, V. (1983). Characteristics of bacilli of Lactobacillus casei species appearing in kefir grains. Acta Alimentaria PoloUnica. 9, 80-88.

Morr, C.V. \& Ha, E.Y.W. (1993). Whey protein concentrates and isolates: processing and functional properties. Critical Review in Food Science and Nutrition. 33, 431-436.

Morr, C.V. (1984). Production and use of milk proteins in foods. Food Technology. 38, 3948.

Morr, C.V. (1992). Improving the texture and functionality of whey protein concentrate. Food Technology. 1, 110-113.

Morris V. (1986). Multicomponent gels. In: Gums and Stabilizers for Food Industry (eds), Philips, G.O., Wedlock, D.J. \& Williams, P.A., 3rd ed., Elsevier, London. 87-99.

Morris, E.R. \& Rees, D.A. (1978). Principles of biopolymer gelation: possible models for mucus gel structure. British Medical Bulletin. 34, 49-53.

Morris, V.J. (1998). Gelation of polysaccharides. Functional properties of food macromolecules. 143-226.

Mukai, T., Toba, T. \& Adachi, S. (1990) Structural investigation of the capsular polysaccharide from Lactobacillus kefiranofaciens K1. Carbohydrate Research. 204, 227-232.

Mukai, T., Toba, T., Itoh, T. \& Adachi, S. (1988). Structural Microheterogeneity of Kefiran from Kefir Grais. Japanise Journal of Zootechnical Sciience, 59,167-176.

Murofushi, M., Shiomi, M. \& Aibara K. (1983). Effect of orally administered polysaccharide from kefir grain on delayed-type hypersensitivity and tumor growth in mice. Japanese Journal of Medical Science and Biology. 36, 49-53.

Mynott, T.L., Crossett, B. \& Prathalingam, S.R. (2002). Proteolytic inhibition of Salmonella enterica serovar typhimurium-induced activation of the mitogen-activated protein kinases ERK and JNK in cultured human intestinal cells. Infection and Immunity. 70, 86-95.

Nikolíc D., Mureşan, R.C., Feng, W. \& Singer, W. (2012). Scaled correlation analysis: A better way to compute a cross-correlogram. European Journal of Neuroscience. 35, 74262.

Ofek, I. \& Doyle, R.J. (1994). Bacterial adhesion to cells and tissues. Chapman \& Hall (Eds.), New York, London.

Ogawa, M., Shimizu, K., Nomoto, K., Tanak, R., Hamabata, T., Yamasaki, S. \& Takeda, Y. (2001). Inhibition of in vitro growth of Shiga toxin producing Escherichia coli O157:H7 by 
probiotic Lactobacillus strains due to production of lactic acid. International Journal of Food Microbiology. 68, 135-140.

Ojeda, J.J., Romero-Gonzalez, M.E., Bachmann, R.T., Edyvean, R.G.J. \& Banwart, S.A. (2008). Characterization of the cell surface and cell wall chemistry of drinking water bacteria by combining XPS, FTIR spectroscopy, modeling, and potentiometric titrations. Langmuir. 24, 4032-4040.

Olagnero, G., Genevois, C., Irei, V., Marcenado, J. \& Bendersky, S. (2007). Functional foods: Concepts, Definitions and Global Legal Frame. DIAETA. 25, 31-39.

OMS/FAO. Probiotics in foods. (2006). Health and Nutritional Properties and Guidelines for Evaluation, FAO Food and Nutrition Paper. 92-5-105513-0, 85.

Ottogalli, G., Galli, A., Resmini, P. \& Volonterio, G. (1973). Composizione microbiologique, chimica ed ultraestructtura dei granuli di kefir. Annali di Microbiologia ed Enzimologia. 23, 109-121.

Ouwehand, A.C. \& Conway, P.L. (1996). Specificity of spent culture fluids of Lactobacillus spp. to inhibit adhesion of enteropathogenic fimbriated Escherichia coli cells. Microbial Ecology in Health and Disease. 9, 239-246.

Ouwehand, A.C., Kirjavainen, P.V., Gronlund, M.M., Isolauri, E. \& Salminen, S.J. (1999a). Adhesion of probiotic micro-organisms to intestinal mucus. International Dairy Journal. 9, 623-630.

Ouwehand, A.C., Niemi, P. \& Salminen, S.J. (1999b). The normal faecal microbiota does not affect the adhesion of probiotic bacteria in vitro. FEMS Microbiol Letters. 177, 35-38.

Palou, A., Serra, F. \& Pico, C. (2003). General aspects on the assessment of functional foods in the European Union. European Journal of Clinical Nutrition. 57, 12-17.

Parra M.D., Martinez de Moretín, B.E., Cobo, J.M., Mateos, J.A. \& Martínez, J.A. (2004a). Monocyte function in healthy middle aged people receiving fermented milk containing Lactobacillus casei. Journal of Nutrition Health and Ageing. 8, 208-211.

Parra, M.D., Martinez de Moretín, B.E., Cobo, J.M., Mateos, J.A. \& Martínez, J.A. (2004b). Daily ingestion of fermented milk containing Lactobacillus casei DN114001 improves innate defense capacity in healthy middle aged people. Journal of Physiology and Biochemistry. 60, 85-92.

Patrick, M.E., Adcock, P.M., Gomez, T.M., Altekruse, S.F., Holland, B.H., Tauxe, R.V. \& Swerdlow, D.L, (2004). Salmonella Enteritidis Infections, United States, 1985-1999. Emerging Infectious Diseases. 10, 1-7.

Pedone, C.A., Arnaud, C.C., Postaire, E.R., Bouley, C.F. \& Reinert, P. (2000). Multicentric study of the effect of milk fermented by Lactobacillus casei on the incidence of diarrhoea. International Journal of Clinicial Practice. 54, 568-571.

Pedone, C.A., Bernabeu, A.O., Postaire, E.R., Bouley, C.F. \& Reinert, P. (1999). The effect of supplementation with milk fermented by Lactobacillus casei (strain DN-114 001) on 
acute diarrhoea in children attending day care centers. International Journal of Clinical Practice. 53, 179-184.

Perdigon, G., Fuller, R. \& Raya, R. (2001). Lactic acid bacteria and their effect on the immune system. Current Issues in Intestinal Microbiology. 2, 27-42.

Perdigon, G., Maldonado Galdeano, C., Valdez, J.C., Medici, M. (2002). Interaction of lactic acid bacteria with the gut immune system. European Journal of Clinical Nutrition. 56, 21-26.

Pereg, D., Kimhi, O., Tirosh, A., Orr, N., Kayouf, R. \& Lishner, M. (2005). The effect of fermented yogurt on prevention of diarrhea in a healthy adult population. American Journal Infect Control. 33, 2, 122-5.

Peressini, D., Bravin, B., Lapasin, R., Rizzotti, C. \& Sensidoni, A. (2003). Starchmethylcellulose based edible film: rheological properties of film-forming dispersions. Journal of Food Engineering. 59, 25-32.

Perez, P.F., Minnaard, Y., Disalvo, E.A., De Antoni, G.L. (1998). Surface properties of bifidobacterial strains of human origin. Applied and Environmental Microbiology. 64, 21-26.

Piątek, J., Gibas-Dorna, M., Olejnik, A., Krauss, H., Wierzbicki, K., Żukiewicz-Sobczak, W. \& Głowacki, M. (2012). The viability and intestinal epithelial cell adhesion of probiotic strain combination--in vitro study. Annals of Agricultural and Environmental Medicine. 19, 99-102.

Picout, D.R. \& Ross-Murphy, S.B. (2001). Thermoreversible and irreversible physical gels from biopolymers. In Polymer Gels and Networks. Osada, Y. \& Khokhlov, A.R., Eds. Marcel Dekker, New York. pp. 27-46.

Piermaria, J., Bosch, A., Pinotti, A., Garcia, M.A. \& Abraham, A.G. (2009). Films based on kefiran, an exopolysaccharide obtained from kefir grain: development and characterization. Food Hydrocolloids. 23, 684-690.

Piermaria, J., Bosch, A., Pinotti, A., Yantorno, O., Garcia, M.A. \& Abraham, A.G. (2011). Kefiran films plasticized with sugars and polyols: water vapor barrier and mechanical properties in relation to their microstructure analyzed by ATR/FT-IR spectroscopy. Food Hydrocolloids. 25, 1261-1269.

Piermaria, J., de la Canal, M. \& Abraham, A.G. (2008). Gelling properties of kefiran, a food grade polysaccharide obtained from kefir grain. Food Hydrocolloids. 22, 1520-1527.

Pintado, M.E., Lopes Da Silva, J.A., Fernandes, P.B., Xavier Malcata, F. \& Hogg, T.A. (1996). Microbiological and rheological studies on portuguese kefir grains. International Journal of Food Science and Technology. 31, 15-26.

Pinto, M., Robine-Leon, S., Appay, D., Kedinger, M., Triadou, N., Dussaulx, E., Lacroix, B., Simon-Assmann, P., Haffen, K., Fogh, J., Zweibaum, A. (1983). Enterocyte -like differentiation and polarization of the human colon carcinoma cell line Caco-2 in culture. Biological Chemistry. 47, 323-330. 
Possemiers, S., Marzorati, M., Verstraete, W., Van de Wiele, T. (2010). Bacteria and chocolate: A successful combination for probiotic delivery. International Journal of Food Microbiology. 141, 97-103.

Powell, J.E., Witthuhn, R.C., Todorov, S.D. \& Dicks, L.M.T. (2007). Characterization of bacteriocin ST8KF produced by a kefir isolate Lactobacillus plantarum ST8KF. International Dairy Journal. 17, 190-198.

Pujol, P., Huguet, J., Drobnic, F., Banquells, M., Ruiz, O., Galilea, P., Segarra, N., Aguilera, S., Burnat, A., Mateos, J.A. \& Postaire, E. (2000). The effect of fermented milk containing Lactobacillus casei on the immune response to exercise. Sports Medicine, Training and Rehabilitation. 9, 209-223.

Puppo, M.C., Lupano, C.E., Añon, M.C. (1995). Gelation of soybean protein isolates in acidic conditions. Effect of $\mathrm{pH}$ and protein concentration. Journal of Agricultural and Food Chemistry. 43, 2356-2361.

Puyol, P., Pérez, M.D. \& Horne, D.S. (2001). Heat-induced gelation of whey protein isolates (WPI): effect of $\mathrm{NaCl}$ and protein concentration. Food Hydrocolloids. 15, 233-237.

Quirós, A., Hernández-Ledesma, B., Ramos, M., Amigo, L. \& Recio, I. (2005). Angiotensinconverting enzyme inhibitory activity of peptides derived from caprine kefir. Journal of Dairy Science. 88, 3480-3487.

Ramírez-Santiago, C., Lobato-Calleros, C., Espinosa-Andrews, H. \& Vernon-Carter, E. (2012). Viscoelastic properties and overall sensory acceptability of reduced-fat PetitSuisse cheese made by replacing milk fat with complex coacervate. Dairy Science and Technology. 92, 383-398.

Rammelsberg, M. \& Radler, F. (1990). Antibacterial polypeptides of Lactobacillus species. Journal Applied Bacteriology. 69, 177-184.

Reddy, B.S. (1999). Possible mechanisms by which pro- and prebiotics influence colon carcinogenesis and tumor growth. Journal of Nutrition. 129, 1478-1482.

Reid, G. \& Burton, J. (2002). Use of Lactobacillus to prevent infection by pathogenic bacteria. Microbiology Infection. 4, 319-324.

Reid, G., McGroarty, J.A., Angotti, R. \& Cook, R. L. (1988). Lacobacillus inhibitor production against Escherichia Coli and coaggregation ability with uropathogens. Canadian Journal of Microbiology. 34, 344-351.

Relkin, P. (1996). Thermal unfolding of $\beta$-lactoglobulin, $\alpha$-lactalbumin, and bovine serum albumin. A thermodynamic approach. Critical Reviews in Food Science and Nutrition. 36, 565-601.

Renard, D. \& Lefebre, J. (1992). Gelation of globular proteins: Effect of $\mathrm{pH}$ and ionic strenght on the critical concentration for gel formation. A simple model and its application to $\beta$-lactoglobulin heat-induced gelation. International Journal of Biological macromolecules. 14, 287-291. 
Renard, D., van de Velde, F. \& Visschers, R.W. (2006). The gap between food gel structure, texture and perception. Food Hydrocolloids. 20, 423-431.

Rimada P.S. \& Abraham A.G. (2003). Comparative study of different methodologies to determine the exopolysaccharide produced by kefir grains in milk and whey. Le lait. 83, 79-88.

Rimada, P.S. \& Abraham, A.G. (2001). Polysaccharide production by kefir grains during whey fermentation. Journal of Dairy Research. 68, 653-661.

Rimada, P.S. \& Abraham, A.G. (2006). Kefiran improves rheological properties of glucono-delta-lactone induced skim milk gels. International Dairy Journal. 16, 33-39.

Rinkinen, M., Jalava, K., Westermarck, E., Salminen, S. \& Ouwehand, A.C. (2003). Interaction between probiotic lactic acid bacteria and canine enteric pathogens: A risk factor for intestinal Enterococcus faecium colonization? Veterinary Microbiology. 92, 111-119.

Río, M.E., Zago, L.B., García, H. \& Winter, L. (2002). El estado nutricional modifica la efectividad de un suplemento dietario de bacterias lácticas sobre la aparición de patologías de vías respiratorias en niños. Archivos Latinoamericanos de Nutrición. 52, 29-35.

Río, M.E., Zago, L.B., García, H. \& Winter, L. (2004). El estado nutricional modifica la efectividad de un suplemento dietario de bacterias lácticas sobre la aparición, prevención y cura de diarrea infantiles. Archivos Latinoamericanos de Nutrición. 54, 287-294.

Rishi, P., Mavi, S.K., Bharrhan, S., Shukla, G., Tewari, R. (2009). Protective efficacy of probiotic alone or in conjunction with a prebiotic in Salmonella-induced liver damage. FEMS Microbiol Ecology. 69, 222-230.

Roberfroid, M.B. (2000). Prebiotics and probiotics: are they functional foods?. American Journal of Clinical Nutrition. 71, 1682-1687.

Roberfroid, M.B. (2002). Global view on functional foods: European perspectives. British Journal of Nutrition. 88, 133-138.

Rodrígues, K.L., Gaudino Caputo, L.R., Tavares Carvalho, J.C., Evangelista, J. \& Schneedorf, J.M. (2005). Antimicrobial and healing activity of kefir and kefiran extract. International Journal of Antimicrobial Agents. 25, 404-408.

Roos, S., Aleljung, P., Normand, R., Lee, B., Wadström, T., Lindberg, M. \& Jonsson, H. (1996). A collagen binding protein from Lactobacillus reuteri is part of an $A B C$ transporter? FEMS Microbiology Letters. 144, 33-38.

Rosi, J. \& Rossi, J. (1978). I microorganismi del kefir: I fermenti lattici. Sienza e Tecnica Lattiero-Casearia. 29, 291-305. 
Ross-Murphy, S.B. (1995). Rheology of Biopolymer Solutions and gels. En New PhysicoChemical Techniques for the Characterization of Complex Food Systems. Ed.: Dickinson. E. Blackie Academic \& Professional, Glasgow. 130-156.

Ruas-Madiedo P., Abraham A.G., Mozzi F. \& de los Reyes-Gavilán C.G. (2008). Functionality of exopolysaccharides produced by lactic acid bacteria. In Molecular aspects of lactic acid bacteria for traditional and new applications. pp. 137-166. Eds.: Mayo B., López P. \& Pérez-Martínez G. Kerala: Research Signpost.

Ruas-Madiedo, P. \& de los Reyes-Gavilán, C.G. (2005). Invited review: Methods for the screening, isolation, and characterization of exopolysaccharides produced by lactic acid bacteria. Journal of Dairy Science. 88, 843-856.

Ruas-Madiedo, P., Gueimonde, M., Arigoni, F., de los Reyes-Gavilán, C.G. \& Margolles, A. (2009). Bile affects the synthesis of exopolysaccharides by Bifidobacterium animalis. Applied and environmental microbiology. 75, 1204-1207.

Ruas-Madiedo, P., Gueimonde, M., Margolles, A., de los Reyes-Gavilán, C.G. \& Salminen, S. (2006). Exopolysaccharides produced by probiotic strains modify the adhesion of probiotics and enteropathogens to human intestinal mucus. Journal of Food Protection. 69, 2011-2019.

Ruas-Madiedo, P., Hugenholtz, J. \& Zoon, P. (2002a). An overview of the functionality of exopolysaccharides produced by lactic acid bacteria. International Dairy Journal. 12, 163-171.

Ruas-Madiedo, P., Tuinier, R., Kanning, M. \& Zoon, P. (2002b). Role of exopolysaccharides produced by Lactococcus lactis subsp. cremoris on the viscosity of fermented milks. International Dairy Journal. 12, 689-695.

Ruiz, L., Margolles, A. \& Sánchez, B. (2013). Bile resistance mechanismsin Lactobacillus and Bifidobacterium. Frontiers in microbiology. 4, 1-8.

Ryan, M.P., Rea, M.C., Hill, C., Ross, P. (1996). An application in Cheddar cheese manufacture for a strain of Lactococcus lactis producing a novel broad-spectrum bacteriocin, lacticin 3147. Applied and Environmental Microbiology. 62, 612-619.

Rychlick, I. \& Barrow, P.A. (2005). Salmonella stress management and its relevance to behavior during intestinal colonization and infection. FEMS Microbiology Reviews. 29, 1021-1040.

Turgeon, S.L. \& Beaulieu, M. (2001). Improvement and modification of whey protein gel texture using polysaccharides. Food Hydrocolloids. 15, 583-591.

Saarela, M., Mogensen, G., Fondén, R., Matto, J. \& Mattila-Sandholm, T. (2000). Probiotic bacteria: safety, functional and technology properties. Journal Biotechnology. 84, 197-215.

Saavedra, J.M., Bauman, N.A. \& Oung, I. (1994), Feeding Bifidobaterium bifidum and Streptococcus thermophilus to infant in hospital for prevention of diarrhoea and shedding of rotavirus. Lancet. 344, 1046-1049. 
Sabir, F., Beyatli, Y., Cokmus, C., Onal-Darilmaz, D. (2010). Assessment of Potential Probiotic Properties of Lactobacillus spp., Lactococcus spp., and Pediococcus spp. Strains Isolated from Kefir. Journal of Food Science. 75, 568-573.

Salazar, N., Ruas-Madiedo, P., Prieto, A., Calle, L.P. \& de los Reyes-Gavilan, C.G. (2012). Characterization of exopolysaccharides produced by Bifidobacterium longum NB667 and Its cholate-resistant derivative strain IPLA B667dCo. Journal of Agriculture and Food Chemistry. 60, 1028-1035.

Salvador, A. \& Fiszman, S.M. (1998). Textural Characteristics and Dynamic Oscillatory Rheology of Maturation of Milk Gelatin Gels with Low Acidity. Journal of Dairy Science. 81, 1525-1531.

Salyers, A. \& Whit, D. (2002) Salmonella species. En: Bacterial Pathogenesis. A Molecular Approach. Second edition. Ed. ASM Press, Washington DC, USA.

Sambrook, J. \& D. W. Russell. (2001). Molecular Cloning: A Laboratory Manual, Third ed. Cold Spring Harbor Laboratory Press, Cold Spring Harbor, NY.

Sánchez, B., Ruiz, L., de los Reyes-Gavilán, C.G., Margolles, A. (2008). Proteomics of stress response in Bifidobacterium. Frontiers in Bioscience. 13, 6905-6919.

Sanderson, G.R. (1990). Gellan gum. En Food gels. Ed.: P. Harris, Elsevier Science Publishing Co. Inc., New York. 201-232.

Santos, A., San Mauro, M., Sanchez, A., Torres, J.M. \& Marquina, D. (2003). The antimicrobial properties of different strains of Lactobacillus spp. isolated from kefir. Systematic and Applied Microbiology. 26, 434-437.

Sato, K., Nakamura, M., Nishiya, T., Kawanari, M. \& Nakajima, I. (1995). Preparation of a gel of partially heat-denatured whey protein by proteolytic digestion. Milchwissenschaft. 50, 389-392.

Saxelin, M., Lassig, A., Karjalainen, H., Tynkkynen, S., Surakka, A., Vapaatalo, H., et al. (2010). Persistence of probiotic strains in the gastrointestinal tract when administered as capsules, yoghurt, or cheese. International Journal of Food Microbiology. 144, 293-300.

Schar-Zammaretti, P., Dillmann, M.L., D'Amico, N., Affolter, M. \& Ubbink, J. (2005). Influence of fermentation medium composition on physicochemical surface properties of Lactobacillus acidophilus. Applied and Environmental Microbiology. 71, 8165-8173.

Schillinger, U., Guigas, C. \& Heinrich Holzapfel, W. (2005). In vitro adherence and other properties of lactobacilli used in probiotic yoghurt-like products. International Dairy Journal. 15, 1289-1297.

Schneider, C.A., Rasband, W.S. \& Eliceiri, K.W. (2012). NIH Image to ImageJ: 25 years of image analysis. Nature Methods. 9, 671-675.

Servin, A.L \& Coconnier, M.H. (2003). Adhesion of probiotic strains to the intestinal mucosa and the interaction with pathogens. Best practice \& Research Clinical Gastroenterology. 17, 741-754. 
Servin, A.L. (2004). Antagonistic activities of lactobacilli and bifidobacteria against microbial pathogens. FEMS Microbiology Reviews. 28, 405-440.

Shah, D. H., Zhou, X., Addwebi, T., Davis, M. A., Orfe, L. \& Call, D. R. (2011). Cell invasion of poultry-associated salmonella enterica serovar enteritidis isolates is associated with pathogenicity, motility and proteins secreted by the type III secretion system. Microbiology. 157, 1428-1445.

Shimada, K. \& Cheftel, J.C. (1988). Texture characteristics, protein solubility, and sulfhydryl group/disulfide bond contents of heat-induced gels of whey protein isolate. Journal of Agricultural and Food Chemistry. 36, 1018-1025.

Shimizu, M. (2014). History and Current Status of Functional Food Regulations in Japan. Nutraceutical and Functional Food Regulations in the United States and Around the World: Second Edition. 257-263.

Shiomi, M., Sasaki, K., Murofushi, M. \& Aibara, K. (1982). Antitumor activity in mice of orally administered polysaccharide from kefir grain. Japanese Journal of Medical Science and Biology. 35, 75-80.

Sillanpaa, J., Martinez, B., Antikainen, J., Toba, T., Kalkkinen, N., Tankka, S., Lounatmaa, K. \& Keranen, J. (2000). Characterization of the collagen-binding S-layer protein CbsA of Lactobacillus crispatus. Journal Bacteriology. 182, 6440-6450.

Silva, K.R., Rodrigues, S.A., Filho, L X. \& Lima, A.S. (2009). Antimicrobial Activity of Broth Fermented with Kefir Grains. Applied Biochemistry and Biotechnology. 152, 316-325.

Silva, M., Jacobus, N. V., Deneke, C. \& Gorbach, S. L. (1987). Antimicrobial substance from a human Lactobacillus strain. Antimicrobiology Agents Chemother. 31, 1231-1233.

Simova, E., Beshkova, D., Angelov, A., Hristozova, T., Frengova, G. \& Spasov, Z. (2002). Lactic acid bacteria and yeasts in kefir grains and kefir made from them. Journal of Industrial Microbiology and Biotechnology. 28, 1-6.

Siró, I., Kápolna, E., Kápolna, B. \& Lugasi, A. Functional food. (2008). Product development, marketing and consumer acceptance. A review. Appetite. 51, 456-467.

Sloan, E. (1999). The new market: foods for the not-so-healthy. Food Technology. 53, 5460.

Spotti, M.J., Martinez, M.J., Pilosof, A.M.R., Candioti, M., Rubiolo, A.C. \& Carrara, C.R. (2014). Rheological properties of whey protein and dextran conjugates at different reaction times. Food Hydrocolloids. 38, 76-84.

Stading, M. \& Hermansson, A.M. (1991). Large deformation properties of $\beta$-lactoglobulin gel structures. Food Hydrocolloids. 5, 339-352.

Stading, M. \& Hermansson, A.M. (1992). Inhomogeneous fine-stranded $\beta$-lactoglobulin gels. Food Hydrocolloids. 5, 455-470. 
Steventon, A.J., Gladden, L.F. \& Fryer, P.J. (1991). A percolation analysis of the concentration dependence of the gelation of whey protein concentrates. Journal of Texture Studies. 22, 201-218.

St-Onge, M.P., Farnworth, E.R., Savard, T., Chabot, D., Mafu, A. \& Jones, P.J.H. (2002). Kefir consumption does not alter plasma lipid levels or cholesterol fractional synthesis rates relative to milk in hyperlipidemic men: A randomized controlled trial. $B M C$ Complementary and Alternative Medicine, art. $\mathrm{N}^{\circ} 1$.

Suzuki, T. \& Hara, H. (2004). Various nondisgestible saccharides open a paracellular calcium transport pathway with the induction of intracellular calcium in human intestinal Caco-2 Cells. Journal of Nutrition. 134, 1935-1941.

Szczesniak, A.S. (2002). Texture is a sensory property. Food Quality and Preference. 13, 215-225.

Takase, S., Goda, T. \& Watanabe, M. (1994). Monostearylglycerol-starch complex: its digestability and effects on glycemic and lipogenic responses. Journal of Nutrition. 40, 23-36.

Takizawa, S., Kojima, S., Tamura, S., Fujinaga, S., Benno, Y. \& Nakase, T. (1994). Lactobacillus kefirgranum sp. nov. and lactobacillus parakefir sp. nov., two new species from kefir grains. International Journal of Systematic Bacteriology. 44, 435-439.

Tallon, R., Arias, S., Bressollier, P. \& Urdaci, M.C. (2007). Strain- and matrix-dependent adhesion of Lactobacillus plantarum is mediated by proteinaceous bacterial compounds. Journal of applied microbiology. 102, 442-51.

Tanaka, R. (1997). Lactobacillus, bifidobacterium and intestinal infections diarrhea. Japan: Special Anniversary Edition of Healthist, Gra-met. 121-28.

Tang, Q., McCarthy, O. \& Munro, P. (1995). Oscillatory rheological study of the gelation mechanism of whey protein concentrate solutions: effect of physicochemical variables on gel formation. Journal of Dairy Research 60, 543-555.

Thompson J.K., Johnston D.E., Murphy R.J. \& Collins M.A. (1990). Characteristics of a milk fermentation from rural Northern Ireland which resembles kefir. Irish Journal of Food Science Technology. 14, 35-49.

Thoreux, K. \& Schmucker, D.L. (2001). Kefir milk enhances intestinal immunity in young but not old rats. Journal of Nutrition. 131, 807-812.

Tobitani, A. \& Ross-Murphy, S.B. (1997). Heat-induced gelation of globular proteins. 1. Model for the effects of time and temperature on the gelation time of bsa gels. Macromolecules. 30, 4845-4854.

Tolstoguzov, V.B., Tschimirow, Y.I., Suchanow, B.P., Braudo, E.E. \& Kosmina, E.P. (1976). Nahrung. 20, 329-338. 
Tolstoguzov, V. (1986). Functional properties of protein-polysaccharide mixtures. En: J. R. Mitchell, \& D. A. Ledward, Functinal properties of food macromolecules (385-411). London: Elsevier Applied Science Publishers.

Tolstoguzov, V. (1990). Interactions of gelatin with polysaccharides. En: G. O. Phillips, P. A. Williams, \& D. J. Wedlock, Gums and stabilisers for the food industry (pp. 157-175). Oxford: IRL Press.

Tolstoguzov, V. (1991). Functional properties of food proteins and role of proteinpolysaccharide interaction. Food Hydrocolloids. 4, 429-468.

Tolstoguzov, V. (1997). Protein-polysaccharide interactions. En: S. Damodaran \& A. Paraf. Food proteins and their applications (171-198). New York: Marcel Dekker.

Tolstoguzov, V. (2003). Some thermodynamic considerations in food formulation. Food hydrocolloids. 17, 1-23.

Tolstoguzov, V., Grinberg, V., \& Gulov, A. (1985). Some physicochemical approaches to the problem of protein texturisation. Journal of Agricultural and Food Chemistry, 33, 151- 159.

Tolstoguzov, V.B. (1993). Functional properties of food proteins. Role of interactions in protein systems. In K.D. Schwenke \& R. Mothes (Eds.), Food proteins. Structure and functionality (pp. 203-209). Weinheim: VHC.

Tolstoguzov, V.B., Ershova, E.A. \& Braudo, E.E. (1973) Zh. Prikl. Khim. 46, 25-34 (in Russian).

Tolstoguzov, V.B., Tschimirow, Y.I., Braudo, E.E., Wainerman, E.S. \& Kosmina, E.P. (1975). Nahrung. 19, 33-43.

Tolstoguzov, V.B. (1979) Nahrung. 23, 649-654.

Tolstoguzov,V.B. (1978). Artificial Foodstuffs. Nauka, Moscow (in Russian).

Tolstoguzov,V.B. (1995). Some physico-chemical aspects of protein processing in foods. Multicomponent gels. Food Hydrocolloids. 9, 317-332.

Tuomola, E.M. \& Salminen S.J. (1998). Adhesion of some probiotic and dairy Lactobacillus strains to Caco-2 cell cultures. International Journal of Food Microbiology. 41, 45-51.

Tuomola, E.M., Ouwehand, A.C. \& Salminen, S.J. (1999). Human ileostomy glycoproteins as a model for small intestinal mucus to investigate adhesion of probiotics. Letter in Applied Microbiology. 28, 159-163.

Tuomola, E.M., Ouwehand, A.C. and Salminen, S.J. (2000). Chemical, physical and enzymatic pre-treatments of probiotic lactobacilli alter their adhesion to human intestinal mucus glycoproteins. International Journal of Food Microbiology. 60, 75-81. 
Turchet, P., Laurenzano, M., Auboiron, S. \& Antoine, J.M. (2003). Effect of fermented milk containing the probiotic Lactobacillus casei DN-114 001 on winter infections in freeliving elderly subjects: a randomised, controlled pilot study. Journal of Nutrition Health and Ageing. 7, 75-77.

Urdaneta, E., Barrenetxe, J., Aranguren, P., Irigoyen, A., Marzo, F. \& Ibáñez, F.C. (2007). Intestinal beneficial effects of kefir-supplemented diet in rats. Nutrition Research. 27, 653-658.

Valeur, N., Engel, P., Carbajal, N., Connolly, E., Ladefoged, K. (2004). Colonization and Immunomodulation by Lactobacillus reuteri ATCC 55730 in the Human Gastrointestinal Tract. Applied and Environmental Microbiology. 70, 1176-1181.

Van Der Mei, H.C., Van de Belt Gritter, B., Pouwels, P.H., Martinez, B. \& Busscher, H. J. (2003). Cell surface hidrophobicity is conveyed by S-layer proteins - a study in recombinant lactobacilli. Colloids and Surfaces B: Biointerfaces. 28, 127-134.

Van Immerseel, F., De Buck, J., Pasmans, F., Velge, P., Bottreau, E., Fievez, V., et al. (2003). Invasion of Salmonella Enteritidis in avian intestinal epithelial cells in vitro is influenced by short-chain fatty acids. International Journal of Food Microbiology. 85, 237-248.

Van Immerseel, F., Fievez, V., De Buck, J., Pasmans, F., Martel, A. \& Haesebrouck, F. (2004). Microencapsulated short-chain fatty acids in feed modify colonization and invasion early after infection with Salmonella Enteritidis in young chickens. Poultry Science. 83, 69-74.

Van Immerseel, F., Russell, J. B., Flythe, M. D., Gantois, I., Timbermont, L. \& Pasmans, F. (2006). The use of organic acids to combat Salmonella in poultry: A mechanistic explanation of the efficacy. Avian Pathology. 35, 182-188.

Van Loo, J., Cummings, J. \& Delzene, N. (1999). Functional Food properties of nondigestible oligosaccharides: a consensus report from the ENDO projects (DGXII IRII-CT941095). British Journal Nutrition. 81, 121-32.

Van Vliet, T. (2002). On the relation between texture perception and fundamental mechanical parameters for liquids and time dependent solids. Food Quality Preferences. 13, 227-236.

Vancanneyt, M., Mengaud, J., Cleenwerck, I., Vanhonacker, K., Hoste, B., Dawyndt, P., Degivry, M. C., Ringuet, D., Janssens, D. \& Swings, J. (2004). Reclassification of Lactobacillus kefirgranum Takizawa et al. 1994 as Lactobacillus kefiranofaciens subsp. kefirgranum subsp. nov. and emended description of L. kefiranofaciens Fujisawa et al. 1988. International Journal of Systematic and Evolutionary Microbiology. 54, 551-556.

Vandamme, T.F., Lenourry, A., Charreau, C. \& Chaumeil, J. C. (2002) The use of polysaccharides to target drugs to the colon. Carbohydrate Polymers, 48, 219-231.

Vaquero, A.O, Fernández, A.R. \& Dünner, A.P. (2011). Salmonella Enteritidis. Departamento de Epidemiología, Ministerio de Salud. 
Vedamuthu, E.R. (1982). Fermented milks. In Economic Microbiology. 7, 199-226.

Velge, P., Cloeckaert, A. \& Barrow, P. (2005). Emergence of Salmonella epidemics: The problems related to Salmonella enterica serotype Enteritidis and multiple antibiotic resistances in other major serotypes. Veterinary Research. 36, 267-288.

Verheul, M. \& Roefs, S.P.F.M. (1998a). Structure of particulate whey protein gels: effect of $\mathrm{NaCl}$ concentration, $\mathrm{pH}$, heating temperature, and protein composition. Journal of Agricultural and Food Chemistry. 46, 4909-4916.

Verheul, M. \& Roefs, S.P.F.M. (1998b). Structure of whey protein gels, studied by permeability, scanning electron microscopy and rheology. Food Hydrocolloids. 12, 17-24.

Vinderola ,C.G., Medici, M. \& Perdigon G. (2004). Relationship between interaction sites in the gut, hydrophobicity, mucosal immunomodulating capacities and cell wall protein profiles in indigenous and exogenous bacteria. Journal of Applied Microbiology. 96, 230243.

Vinderola, C., Perdigón, G., Reinheimer, J., Medici, M., Prosello, W. \& Ghiberto, D. (2003). Bioqueso llolay Vita: un nuevo queso probiótico con alta respuesta sobre el sistema inmune. Industria Láctea Española. 34-48.

Vinderola, G., Perdigon, G., Duarte, J., Farnworth, E. \& Matar, C. (2006). Effects of the oral administration of the exopolysaccharide produced by Lactobacillus kefiranofaciens on the gut mucosal immunity. Cytokine. 36, 254-260.

Vitiñi, E., Alvarez, S., Medina, M., Medici, M., de Buduguer, M.V. \& Perdigón, G. (2000). Gut mucosal immunostimulation by lactic acid bacteria. Biocell 24, 223-232.

Vreeker, R., Hoekstra, L.L., den Boer, D.C. \& Agterof, W.G.M. (1992). Fractal aggregation of whey proteins. Food Hydrocolloids. 5, 423-435.

Vujicic, I.F., Vulic, M., Konyves, T. (1992). Assimilation of cholesterol in milk by kefir cultures. Biotechnology Letters. 14, 847-850.

Wadstrom, T., Andersson, K., Sydow, M., Axelsson, L., Lindgren, S. \& Gullmar, B. (1987). Surface properties of lactobacilli from the small intestine of pigs. Journal of Applied Bacteriology. 62, 513-520.

Walter, R.H. (1998). Origin and characteristics of polysaccharides. Polysaccharide Dispersions. 1-28. San Diego: Academic Press.

Wang, H.F., Tseng, C.Y., Chang, M.H., Lin, J.A., Tsai, F.J., Tsai, C.H., Lu, Y.C., Lai, C.H., Huang, C.Y., Tsai, C.C. (2012a). Anti-inflammatory effects of probiotic Lactobacillus paracasei on ventricles of BALB/C mice treated with ovalbumin. The Chinese journal of physiology. 55, 37-46.

Wang, S.Y., Chen, K.N., Lo, Y.M., Chiang, M.L., Chen, H.C., Liu, J.R. \& Chen, M.J. (2012b). Investigation of microorganisms involved in biosynthesis of the kefir grain. Food Microbiology. 32, 274-285. 
Warrand, J. (2006). Healthy Polysaccharides. The Next Chapter in Food Products. Food Technology and Biotechnology. 44, 355-370.

Watson, R.D. Sleator, C. Hill, C.G.M. Gahan. (2008). Enhancing bile tolerance improves survival and persistence of Bifidobacterium and actococcus in the murine gastrointestinal tract. BMC Microbiology. Article number 176.

Witthuhn, R.C., Schoeman, T. \& Britz, T.J. (2005). Characterisation of the microbial population at different stages of kefir production and kefir grain mass cultivation. International Dairy Journal. 15, 383-389.

Wu, C., He, G. \& Zhang, J. (2014). Physiological and proteomic analysis of Lactobacillus casei in response to acid adaptation. Journal of Industrial Microbiology and Biotechnology. 41, 1533-1540.

Wu, M., Xiong, Y. L., Chen, J, Tang, X. \& Zhou, G. (2009). Rheological and Microstructural Properties of Porcine Myofibrillar Protein-Lipid Emulsion Composite Gels. Journal of Food Science. 74, 207-217.

www.efsa.europa.eu/en/topics/topic/article13.htm

Yamul, D.K. \& Lupano C.E. (2005). Whey protein concentrate gels with honey and wheat flour. Food Research International. 38, 511-522.

Yamul, D.K. \& Lupano, C.E. (2003). Properties of gels from whey protein concentrate and honey at different pHs. Food Research International. 36, 25-33.

Yokoi, H., Watanabe, T. \& Fuji, Y. (1990). Isolation and Characterization of Polysaccharide-Producing Bacteria from Kefir Grains. Journal of Dairy Science, 73, 1684-1689.

Yoon, Y.H., Cho, J.K., Baek, Y.J. \& Huh, C.S. (1999). Antimutagenic activity of Lactobacillus spp. isolated from kefir and yoghurt and non-starter strains. Korean Journal of Animal Science. 41, 39-44.

Yoshida, T. \& Toyoshima, K. (1994). Lactic acid bacteria and yeast from kefir. Japan Society of Nutrition and Food Science. 47, 55-59.

Yoshida, Y., Yokoi, W., Ohishi, K., Ito, M., Naito, E. \& Sawada, H. (2005). Effects of the cell wall of kluyveromyces marxianus YIT 8292 on the plasma cholesterol and fecal sterol excretion in rats fed on a high-cholesterol diet. Bioscience, Biotechnology and Biochemistry. 69, 714-723.

Yüksekdag, Z.N., Beyatli, Y. \& Aslim, B. (2004). Determination of some characteristics coccoid forms of lactic acid bacteria isolated from turkish kefirs with natural probiotic. Food Science and Technology. 37, 663-667.

Zacconi, C., Scolari, G., Vescovo, M. \& Sarra, P.G. (2003). Competitive exclusion of Campylobacter jejuni by kefir fermented milk. Annals of Microbiology. 53, 179-187.

Zasypkin, D.Y., Braudo, E.E. \& Iolstoguzev, Y.B. (1997). Multicomponent biopolymer gels. Food Hydrocolloids. 11, 159-170. 
Ziegler, G.R. \& Foegeding, E.A. (1990). The gelation of proteins. Advances in Food and Nutrition Research. 34, 203-298.

Zihler, A., Gagnon, M., Chassard, C. \& Lacroix C. (2011). Protective effect of probiotics on Salmonella infectivity assessed with combined in vitro gut fermentation-cellular models. BMC Microbiology. 11, 264.

Zimet, P. \& Livney, Y.D. (2009). Beta-lactoglobulin and its nanocomplexes with pectin as vehicles for omega-3 polyunsaturated fatty acids. Food Hydrocolloids. 23, 1120-6.

Zoetendal, E.G., Akkermans, A.D.L. \& De Vos, W. (1998). Temperature gradient gel electrophoresis analysis of 16S rRNA from human fecal samples reveals stable and host specific communities of active bacteria. Applied and Environmental Microbiology. 64, 3854-3859.

Zourari, A. \& Anifantakis, E.M. (1988). Le kefir caracteres physico-chimiques, microbiologiques et nutritionnels. Technologie de Production. 68, 373-392. 